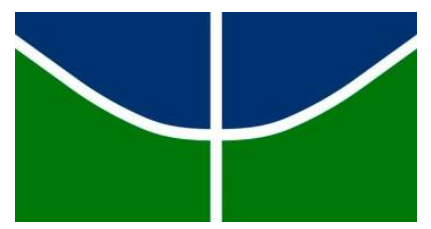

Universidade de Brasília

Instituto de Química

Programa de Pós-Graduação em Química

George Arthur Alves Rabelo

HIBRIDIZAÇÃO MOLECULAR DE NÚCLEOS

NAFTOQUINÔNICOS, CHALCÔNICOS E TRIAZÓLICOS

ATRAVÉS DE REAÇÕES CLICK.

Dissertação de Mestrado

Orientador: Carlos Kleber Zago de Andrade

Brasília-DF

Julho/2016 
George Arthur Alves Rabelo

\section{HIBRIDIZAÇÃo MOLECULAR DE NÚCLEOS NAFTOQUINÔNICOS, CHALCÔNICOS E TRIAZÓLICOS ATRAVÉS DE REAÇÕES CLICK.}

Dissertação apresentada á Banca examinadora do Instituto de Química da Universidade de Brasília como requisito parcial para obtenção do título de Mestre em Química

Orientador:

Prof. Dr. Carlos Kleber Zago de Andrade

Área de Concetração:

Química Orgânica

Brasília-DF

Julho/2016 


\section{FOLHA DE APROVAÇÃO}

Comunicamos a aprovação da Defesa de Dissertação de Mestrado do (a) aluno (a) George Arthur Alves Rabelo, matrícula no 14/0106154, intitulada "Hibridização Molecular de núcleos Naftoquinônicos, Chalcônicos e Triazólicos através de reações click", apresentada no (a) Auditório Azul do Instituto de Química (IQ) da Universidade de Brasília (UnB) em 7 de julho de 2016.

Prof. Dr. Carlos Kleber Zago de Andrade

Presidente de Banca (IQ/UnB)

Prof. Dr. Peter Bakuzis

Membro Titular (IQ/UnB)

Prof. Dr. Wender Alves da Silva

Membro Titular (IQ/UnB)

Prof. Dr. Angelo Henrique de Lira Machado

Membro Suplente (IQ/UnB)

Em 7 de julho de 2016. 


\section{Agradecimentos}

A cada etapa vencida, a responsabilidade em estar mais esclarecido intelectualmente e moralmente toma conta do espírito, mas isso não o amedronta. Isso fornece, sim, combustível a ser queimado no longo caminhar da vida humana. São momentos assim que nos reconecta à importância do caminhar junto, da solidariedade ao próximo e ao mundo. A vitória, quando compartilhada, torna-se glória. Portanto, subir um degrau a mais nessa escadaria infinita da vida não é celebração pessoal, é celebração fraternal com meus entes queridos mais próximos. Alegria, gratidão, esperança e amor, esses sentimentos foram os principais produtos sintetizados na mistura reacional dos meus pensamentos e desejos.

Inicialmente, é absolutamente necessário agradecer aos meus queridos pais. A minha mãe Margareth Alves da Silva, aquela que lutou bravamente contra as intempéries da vida e soube dar amor, educação, valores e muitas memórias maravilhosas aos seus três filhos, grupo no qual orgulhosamente me incluo. Agradeçote, mãe, por todo seu amor e dedicação nessa fase em que precisamos ser instruídos e guiados por alguém que nos ame de verdade, que só queira nosso bem, você fez isso por mim e não há o que eu possa dizer ou expressar que vá demonstrar minha gratidão. Minha vitória é sua também, assim como todos os momentos da minha vida. Hoje somos mais do que mãe e filho, somos grandes amigos que caminham juntos nessa longa jornada. É um prazer ter você ao meu lado. Obrigado.

A meu pai, o agradecimento é proporcional. Os pais têm importância incomensurável, pois são nosso primeiro contato com a realidade humana tão complexa, logo podemos entender o porquê de sua tamanha importância. No fim das contas, eles definem muito mais do que se imagina na sociedade. Voltando ao caro Geraldo Rabelo, mineiro intelectual que esteve presente sempre como um grande apoio nos desafios da vida e em meu desenvolvimento humano. Tenho gratidão enorme por ti, pai, por ter me permitido adentrar a este mundo em um ambiente tão favorável ao desenvolvimento de minhas habilidades e sonhos. Sabemos bem que um apoio, mesmo que singelo, de um pai em nossas decisões nos impulsiona para frente sem termos tempo nem de olharmos para trás. Obrigado, pai. 
A minha família, essa que foi escolhida a dedo. Agradeço a meus irmãos Augusto/Nathalia, André e Marianne, com os quais cresci, me desenvolvi e aprendi importantes lições humanas. Agradeço a meus Avós Amaury, Romualdo e Maria. Em especial, agradeço a minha querida e amada avó, a esotérica Lindauria Freitas, aquela que é matriarca, que é um pilar e que, aos trancos e barrancos, vem cumprindo seus objetivos, ensinando e auxiliando seus mais próximos. Agradeço a minhas incontáveis tias: Kenya, Cibele, Thelma, Fabiola e Grace, as quais, dadas as proporções impostas pela vida, tem importâncias variadas em minha vida, porém são todas muito amadas e queridas. E tem o poderoso tio Sérgio, aquele que deve ser chamado quando tudo der errado, ele vai e resolve, sempre podemos contar com ele e eu não fujo a esta regra, quantas vezes você já não me salvou e me ajudou. Por toda sua solidariedade, amor e compreensão, eu te agradeço muito. Aos inúmero primos e primas, um agradecimento infinito. Em especial, a minhas primas Gabrielle e Isabelle, lindas garotas que tenho a missão de servir como exemplo e de ser o suporte necessário, vocês são minhas irmãzinhas queridas, obrigado pelo amor de vocês. Por fim, o mestre: Henrique. Messiânico de prática e de coração, você já me ensinou tanto e me auxiliou enormemente em fases complicadas na minha vida. A você e sua família, demonstro minha enorme gratidão.

E as amizades? Ah, essas não podem faltar. Quem não tem amigos, não tem nada, já disse um velho sábio por aí. E esses, felizmente, não me faltam, tenho amigos maravilhosos que estão sempre presentes, de uma forma ou de outra, e que são tão importantes que tentar descrever em vocábulos do latim vulgar seria um sacrilégio, mas lá vai.

Aos amigos da irmandade dos sete raios: Anna Novais (swalá), Pedro Torres (pedrita), Hugo Paixão (Obama), Arthur Pieri (arteta), Gabriel Goes (pioruuu), Levi Francisco (Veli), Abilio Oliveira (necrosator), Carlos Ênos (ehnois), Márcio Rodrigues (Reaggae Shark), Murilho Homem (murilete), Felipe Gimenes (Gimenal, pai de todos), Raphael Steigleder (Stei), João Paulo (bigass), Ariel Pirangy (Skol Beats Senses), Laura Xavier (Nuggets), Vitor Araújo (viton), dentre outros. Dedico este trabalho a todos vocês e os agradeço muito pela amizade. 
Aos amigos químicos: Mariane Henz; Fernando dos Santos (Fernandão), aquele que detém a força de Goku e Senna com superação infinita; Agnes (Acnes); Marcos Paulo (Marcusão); Júlia Galvez; Yashmin Blazzio e Luiz Torres (Baiano).

Aos amigos e companheiros LaQMOS/LaPSCA: Jean, Thaissa, Angélica (muito obrigado pelos espectros!!!), Gisele, Carlos Eduardo, Najla, João Victor, Lennine, Ubiratã (Bira), Saulo (Sheila), Giovanni, Lucília e Flávia. A vocês, meus profundos agradecimentos por todo o suporte, auxílio, conhecimentos adquiridos e amizade, todos vocês foram essenciais nessa etapa. Obrigado!

Um agradecimento especial ao colega Mestre Alex Antonio de Oliveira, cujo trabalho e conselhos foram fundamentais para a finalização deste projeto.

Aos colegas professores: Yvone, Arion, Vera, Vilma, Alamara, Lecilda, Danielle, Mara e Mônica.

Agradeço aos professores que tanto me auxiliaram com suas aulas, conhecimentos e suporte científico: Wender Alves da Silva, Peter Bakuzis e Ângelo Machado.

Em especial, agradeço ao meu orientador Carlos Kleber Zago de Andrade, que tem me suportado nesses 4 anos e meio de orientação, estudo, aprendizado e parceria. Sua orientação e a experiência da pesquisa ampliaram meus horizontes e me proporcionaram amadurecimento intelectual e humano que dificilmente teria em outro lugar. Muito obrigado, professor.

Agradeço às pessoas, pois o mundo, os órgãos, os governos, as instituições, todas elas são feitas de, por e para pessoas. Não há necessidade de agradecer às instituições, pois elas já são gratas. 


\section{Resumo}

No presente trabalho, a hibridização molecular é empregada no intuito de desenvolver moléculas híbridas com grande potencial farmacológico. Especificamente, o trabalho é baseado na conjugação de núcleos naftoquinônicos, triazólicos e chalcônicos em uma mesma molécula. Existem inúmeros trabalhos na literatura que citam as diversas atividades biológicas (antibacteriana, antiviral, antiprotozoária, anticâncer, antifúngica, dentre outras) dos três núcleos. Não existem trabalhos na literatura, no momento, que apresentem moléculas formadas pelos três núcleos em questão. $\mathrm{O}$ procedimento experimental se baseou em conjugar os grupos gradativamente. Dois procedimentos gerais foram propostos. $\mathrm{O}$ primeiro se fundamenta na síntese de uma azido-naftoquinona e de diferentes propargiloxi-chalconas, as quais são conjugadas em uma mesma molécula por meio da reação click (CuAAC) através da formação do anel triazólico. O segundo se fundamenta na síntese de uma propargiloxinaftoquinona e de diferentes azido-chalconas, as quais também são conjugadas em uma mesma molécula, por meio da reação click (CuAAC), formando-se, assim, o anel triazólico. As moléculas propostas foram sintetizadas e caracterizadas com sucesso. Estudos de suas atividades biológicas serão um próximo passo da concretização do trabalho como um todo. 
In this study, molecular hybridization is employed in order to develop hybrid molecules with great pharmacological potential. Specifically, the work is based on the combination of naphthoquinone, triazoles and chalcones cores in the same molecule. There are several studies in the literature mentioning the various biological activities (antibacterial, antiviral, anti-protozoan, anti-cancer, anti-fungal, among others) of the three cores. There are no studies in the literature, at this time, reporting molecules formed by all of the three cores. The experimental procedure was based on combining the groups gradually. Two general procedures were explored. The first is based on the synthesis of an azido-naphthoquinone and several propargyloxy-chalcones which are combined in the same molecule by the click reaction (CuAAC) through formation of the triazole ring. The second is based on the synthesis of a propargyloxy-naphthoquinone and several azido-chalcones which are also combined in the same molecule by the click reaction (CuAAC), thus forming the triazole ring. The proposed molecules were successfully synthesized and characterized. Studies of their biological activities will be the next step of the present work. 


\section{Lista de Abreviatura e Acrônimos}

\begin{tabular}{|c|c|}
\hline AIDS & Acquired Immunodeficiency Syndrome \\
\hline ADP & Adenosina difosfato \\
\hline ATP & Adenosina trifosfato \\
\hline $\mathrm{AZT}$ & Azidotimidina \\
\hline CAN & Nitrato de cério (IV) amoniacal \\
\hline CLAE & Cromatografia líquida de Alta Eficiência \\
\hline $\mathrm{CuAAC}$ & Copper(I)-catalyzed azide-alkyne cycloaddition \\
\hline (-)-DIP-Cl® & [(-)-B-clorodiisopinocanfenilborano] \\
\hline DMF & Dimetilformamida \\
\hline DMSO & Dimetilsulfóxido \\
\hline DNA & Deoxyribonucleic acid \\
\hline EM & Espectrometria de massa \\
\hline $\mathrm{FADH}_{2}$ & Dinucleotídeo de flavina e adenina \\
\hline HETCOR & Heteronuclear Correlation \\
\hline HMQC & Heteronuclear Multiple Quantum Correlation \\
\hline HSQC & Heteronuclear Sinlge Quantum Correlation \\
\hline IUPAC & International Union of Pure and Applied Chemistry \\
\hline$J$ & Constante de Acoplamento \\
\hline MO & Micro-ondas \\
\hline NADH & Dinucleotídeo de adenina nicotinamida \\
\hline NBS & N-bromosuccinimida \\
\hline OPP & Pirofosfato \\
\hline PCC & Cloro cromato de piridínio \\
\hline ppm & Parte por milhão \\
\hline Q & Ubiquinona \\
\hline
\end{tabular}




$\begin{array}{ll}\text { RMN } & \text { Ressonância Magnética Nuclear } \\ \text { RMN }{ }^{13} \mathrm{C} & \text { Ressonância Magnética Nuclear de carbono 13 } \\ \text { RMN }{ }^{1} \mathrm{H} & \text { Ressonância Magnética Nuclear de hidrogênio } \\ \text { NHC } & \text { Carbenos N-Hterocíclicos } \\ \text { NMO } & \text { N-metilmorfolina } \\ \text { P } & \text { Coeficiente de partição } \\ \text { Sudam III } & \text { Corante azóico lisocrômico } \\ \text { t.a. } & \text { Temperatura ambiente } \\ \text { TBAI } & \text { Iodeto de tetrabutilamônio } \\ \text { TES } & \text { Trietilsilano } \\ \text { TFA } & \text { Ácido trifluoroacético } \\ \text { THF } & \text { Tetraidrofurano } \\ \text { TMS } & \text { Tetrametilsilano } \\ \text { TPP } & \text { Tiamina pirofosfato } \\ \text { UV-vis } & \text { Ultravioleta e visível } \\ \delta & \text { Deslocamento químico } \\ \end{array}$




\section{Lista de Figuras}

Figura 1 - Estruturas moleculares de algumas quinonas. .......................................... 1

Figura 2 - Estruturas moleculares da ubiquinona, plastoquinona e menaquinona.......... 5

Figura 3 - Estruturas moleculares da arbutina, hidrobenzoquinona e benzoquinona...... 9

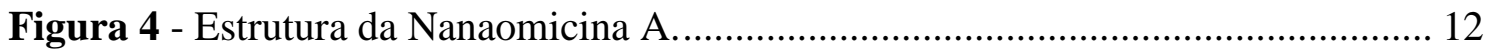

Figura 5 - Estrutura molecular geral de uma chalcona................................................ 14

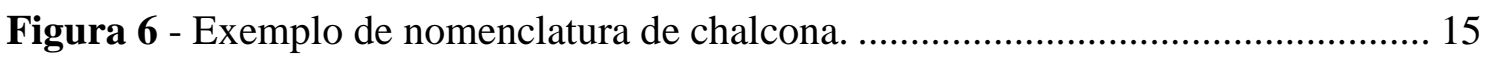

Figura 7 - Estruturas moleculares das chalconas e dibenzalacetonas com atividade

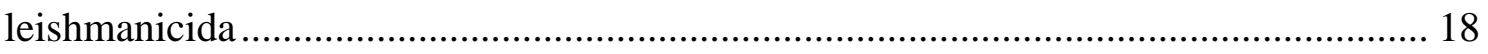

Figura 8 - Estruturas moleculares dos fármacos Anfotericina B, Pentamidina, Paramomicina e Miltefosina.

Figura 9 - Moléculas naturais extraídas das raízes da Crotalaria medicagenina com atividades antimaláricas.

Figura 10 - Grupos de chalconas sintetizadas: chalconas preniladas (43), cromanochalconas (44), cromenochalconas (45) e dihidrocromenochalconas (46)...... 21

Figura 11 - Estruturas moleculares da tazobactama sódica e da rufinamida................. 28

Figura 12 - Estruturas moleculares da podofilotoxina e etoposida. ............................. 29

Figura 13 - Estruturas moleculares dos fármacos Cicloserina, Pirimetamina e

Etambutol. 32

Figura 14 - Moléculas contendo os núcleos naftoquinônico, chalcônico e triazólico... 35

Figura 15 - Espectro de $\mathrm{RMN}{ }^{1} \mathrm{H}\left(600 \mathrm{MHz}, \mathrm{CDCl}_{3}\right)$ do composto 71........................ 39

Figura 16 - Espectro de $\mathrm{RMN}{ }^{13} \mathrm{C}\left(150 \mathrm{MHz}, \mathrm{CDCl}_{3}\right)$ do composto 71...................... 40

Figura 17- Espectro de $\mathrm{RMN}{ }^{1} \mathrm{H}\left(600 \mathrm{MHz}, \mathrm{CDCl}_{3}\right)$ do composto 73 ........................ 42

Figura 18- Espectro de $\mathrm{RMN}{ }^{13} \mathrm{C}\left(150 \mathrm{MHz}, \mathrm{CDCl}_{3}\right)$ do composto 73 ....................... 43

Figura 19 - Espectro de RMN ${ }^{1} \mathrm{H}\left(600 \mathrm{MHz}, \mathrm{DMSO}-d_{6}\right)$ do composto 75c................. 45

Figura 20 - Espectro de RMN ${ }^{13} \mathrm{C}\left(150 \mathrm{MHz}\right.$, DMSO- $\left.d_{6}\right)$ do composto 75c................ 46

Figura 21 - Espectro de $\mathrm{RMN}{ }^{1} \mathrm{H}\left(600 \mathrm{MHz}, \mathrm{CDCl}_{3}\right)$ do composto 75e..................... 47

Figura 22 - Espectro de $\mathrm{RMN}{ }^{13} \mathrm{C}\left(150 \mathrm{MHz}, \mathrm{CDCl}_{3}\right)$ do composto 75e. .................... 48

Figura 23 - Espectro de $\mathrm{RMN}^{1} \mathrm{H}\left(600 \mathrm{MHz}, \mathrm{CDCl}_{3}\right)$ do composto 76a..................... 51

Figura 24 - Espectro de $\mathrm{RMN}^{13} \mathrm{C}\left(150 \mathrm{MHz}, \mathrm{CDCl}_{3}\right)$ do composto 76a.................... 54

Figura 25 - Espectro de $\mathrm{RMN}{ }^{1} \mathrm{H}\left(600 \mathrm{MHz}, \mathrm{CDCl}_{3}\right)$ do composto $76 \mathbf{f}$........................ 56

Figura 26- Espectro de $\mathrm{RMN}{ }^{13} \mathrm{C}\left(150 \mathrm{MHz}, \mathrm{CDCl}_{3}\right)$ do composto 76f...................... 57 
Figura 27 - Espectro de RMN ${ }^{1} \mathrm{H}\left(300 \mathrm{MHz}, \mathrm{DMSO}-d_{6}\right)$ do composto 83 59

Figura 28 - Espectro de RMN ${ }^{13} \mathrm{C}$ (75 MHz, DMSO- $d_{6}$ ) do composto 83. 60

Figura 29 - Espectro de $\mathrm{RMN}{ }^{1} \mathrm{H}\left(600 \mathrm{MHz}, \mathrm{CDCl}_{3}\right)$ do composto $75 f .$. 61

Figura 30 - Espectro de $\mathrm{RMN}{ }^{13} \mathrm{C}\left(150 \mathrm{MHz}, \mathrm{CDCl}_{3}\right)$ do composto $75 f$. 62

Figura 31 - Espectro de $\mathrm{RMN}{ }^{1} \mathrm{H}\left(600 \mathrm{MHz}, \mathrm{CDCl}_{3}\right)$ do composto 77. 64

Figura 32 - Espectro de $\mathrm{RMN}{ }^{13} \mathrm{C}\left(150 \mathrm{MHz}, \mathrm{CDCl}_{3}\right)$ do composto 77. 65

Figura 33 - Espectro de $\mathrm{RMN}{ }^{1} \mathrm{H}\left(600 \mathrm{MHz}, \mathrm{CDCl}_{3}\right)$ do composto 79. 67

Figura 34 - Espectro de $\mathrm{RMN}{ }^{13} \mathrm{C}\left(150 \mathrm{MHz}, \mathrm{CDCl}_{3}\right)$ do composto 79. 68

Figura 35- Espectro de $\mathrm{RMN}{ }^{1} \mathrm{H}\left(600 \mathrm{MHz}, \mathrm{CDCl}_{3}\right)$ do composto 80a....................... 70

Figura 36 - Espectro de $\mathrm{RMN}{ }^{13} \mathrm{C}\left(150 \mathrm{MHz}, \mathrm{CDCl}_{3}\right)$ do composto 80a..................... 71

Figura 37 - Espectro de $\mathrm{RMN}^{1} \mathrm{H}\left(600 \mathrm{MHz}, \mathrm{CDCl}_{3}\right)$ do composto 80e. ..................... 72

Figura 38 - Espectro de $\mathrm{RMN}{ }^{13} \mathrm{C}\left(150 \mathrm{MHz}, \mathrm{CDCl}_{3}\right)$ do composto 80e. .................... 73

Figura 39 - Espectro de RMN ${ }^{1} \mathrm{H}\left(600 \mathrm{MHz}, \mathrm{DMSO}-d_{6}\right)$ do composto 81b. ................ 75

Figura 40 - Espectro de RMN ${ }^{13} \mathrm{C}$ (150 MHz, DMSO-d $d_{6}$ do composto 81b. 76 


\section{Lista de Esquemas}

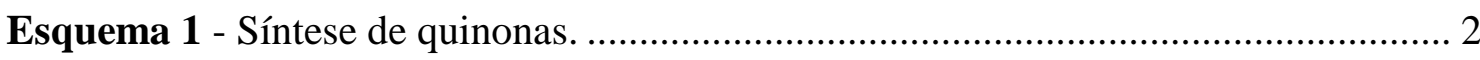

Esquema 2 - Diagrama cíclico representando a relação dos potenciais de redução de derivados benzoquinônicos e seus comportamentos ácido-base ...................................... 3

Esquema 3 - Representação da Cadeia respiratória.......................................................... 5

Esquema 4 - Intermediários principais na biossíntese do ácido 1,4-dihidroxinaftanóico.

Esquema 5 - Etapas finais principais da biossíntese da Vitamina K2 e de outras

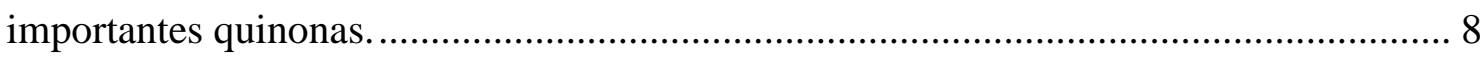

Esquema 6 - Síntese de hidroquinonas e quinonas com cloro na posição 3.................. 10

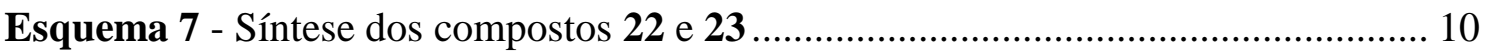

Esquema 8 - Primeiras etapas na síntese enantiosseletiva de uma molécula análoga à Nanaomicina A

Esquema 9 - Etapas finais na síntese enantiosseletiva de uma molécula análoga à

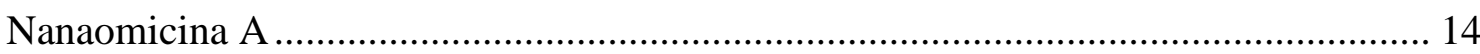

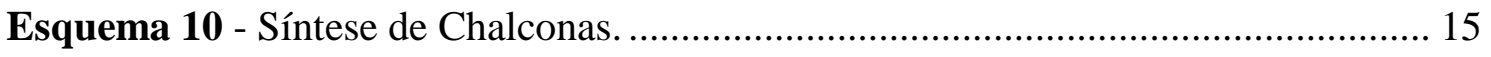

Esquema 11 - Mecanismo de formação da chalcona..................................................... 16

Esquema 12 - Reação de isomerização da chalcona $E$ para a $Z$. ................................... 17

Esquema 13 - Síntese da chalcona prenilada 49 ....................................................... 22

Esquema 14 - Síntese da cromanochalcona 51 ...................................................... 22

Esquema 15 - Primeira reação de 1,3-cicloadição envolvendo azida e alcino ............... 24

Esquema 16 - Representação geral da cicloadição de Huisgen.................................... 24

Esquema 17 - Reação CuAAC utilizando isótopos de cobre-63 ................................. 25

Esquema 18 - Ausência de enriquecimento isotópico nas moléculas 56 e 57 ............. 26

Esquema 19 - Proposta mecanística para as reações CuAAC ...................................... 27

Esquema 20 - Reações click na síntese de podofilotoxinas 1,2,3-triazólicas................ 29

Esquema 21 - Síntese de uma molécula contendo os grupos AZT, chalcona e 1,2,3triazol com potente atividade anticâncer

Esquema 22 - Síntese de uma molécula com núcleos naftoquinônico e 1,2,3-triazólico

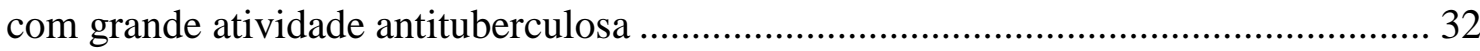

Esquema 23 - Etapas envolvidas na síntese dos compostos híbridos 70 .................... 33

Esquema 24 - Rota sintética para a primeira metodologia geral................................ 36 
Esquema 25 - Rota sintética para a segunda metodologia geral. 37

Esquema 26 - Formação da 2-azido-1,4-naftoquinona.................................................. 38

Esquema 27- Síntese da 4-propargiloxi-acetofenona................................................ 41

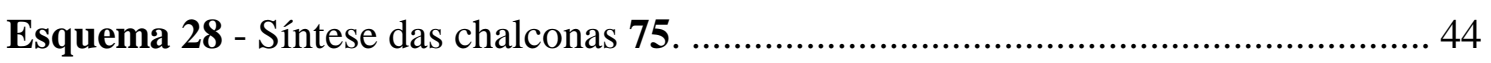

Esquema 29 - Tentativa de reação click entre os compostos 71 e 75a......................... 49

Esquema 30 - Reação click entre os compostos 42 e 46a usando a metodologia III.... 50

Esquema 31 - Reação click entre os compostos 71 e 75a usando a metodologia IV.... 53

Esquema 32 - Reação click entre os compostos 71 e 75a-e usando a metodologia V.. 55

Esquema 33 - Reação click entre os compostos 71 e $75 f$ usando a metodologia V...... 55

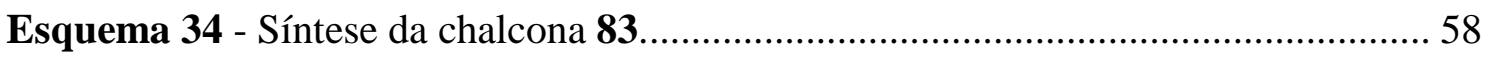

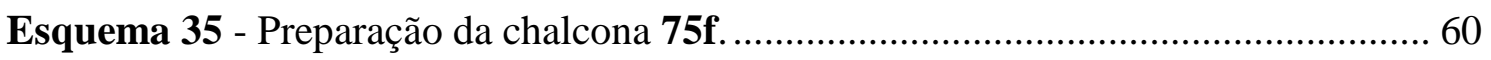

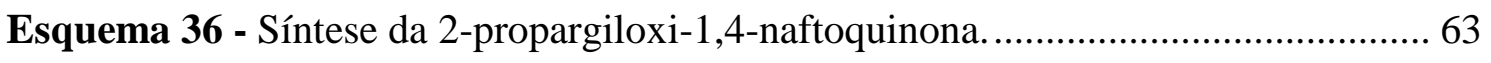

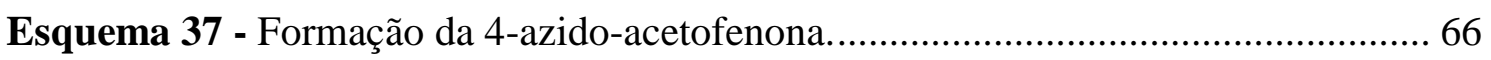

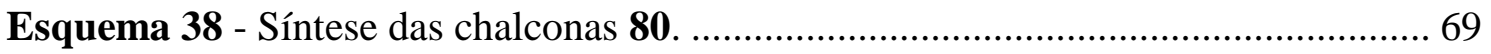

Esquema 39 - Reação click (CuAAC) entre os compostos 77 e 80a-e usando a

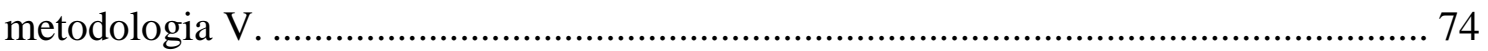

Esquema 40 - Estruturas moleculares dos compostos híbridos 76, 76f e 81............... 77

Esquema 41 - Estruturas moleculares dos compostos 77, 75e e 80e...................................... 77 


\section{Lista de Tabelas}

Tabela 1 - Parâmetros de concentração inibitória, citotoxicidade e lipofilicidade de alguns compostos sintetizados em comparação com o fármaco Miltefosina

Tabela 2 - Dados de concentração inibitória dos compostos sintetizados em comparação com o fármaco Anfotericina B 19

Tabela 3 - Dados de $\mathrm{RMN}{ }^{1} \mathrm{H}\left(600 \mathrm{MHz}, \mathrm{CDCl}_{3}\right)$ do composto 71............................ 39

Tabela 4 - Dados de $\mathrm{RMN}^{13} \mathrm{C}\left(600 \mathrm{MHz}, \mathrm{CDCl}_{3}\right)$ do composto 71 ........................... 40

Tabela 5- Dados de $\mathrm{RMN}^{1} \mathrm{H}\left(600 \mathrm{MHz}, \mathrm{CDCl}_{3}\right)$ do composto 73.............................. 42

Tabela 6- Dados de $\mathrm{RMN}^{13} \mathrm{C}\left(150 \mathrm{MHz}, \mathrm{CDCl}_{3}\right)$ do composto 73 ............................ 43

Tabela 7 - Dados de RMN ${ }^{1} \mathrm{H}\left(600 \mathrm{MHz}, \mathrm{DMSO}-d_{6}\right)$ do composto 75c. ...................... 46

Tabela 8 - Dados de $\mathrm{RMN}^{1} \mathrm{H}\left(600 \mathrm{MHz}, \mathrm{CDCl}_{3}\right)$ do composto 75e ........................... 48

Tabela 9 - Dados de $\mathrm{RMN}{ }^{1} \mathrm{H}\left(600 \mathrm{MHz}, \mathrm{CDCl}_{3}\right)$ do composto 76a............................ 52

Tabela 10 - Dados de $\mathrm{RMN}{ }^{1} \mathrm{H}\left(600 \mathrm{MHz}, \mathrm{CDCl}_{3}\right)$ do composto 76f. ......................... 57

Tabela 11 - Dados de RMN ${ }^{1} \mathrm{H}\left(300 \mathrm{MHz}, \mathrm{DMSO}-d_{6}\right)$ do composto 83 ....................... 59

Tabela 12 - Dados de $\mathrm{RMN}{ }^{1} \mathrm{H}\left(600 \mathrm{MHz}, \mathrm{CDCl}_{3}\right)$ do composto 75f. ........................... 61

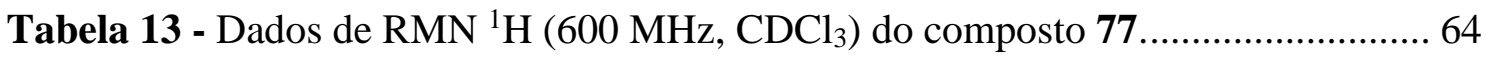

Tabela 14 - Dados de $\mathrm{RMN}{ }^{13} \mathrm{C}\left(150 \mathrm{MHz}, \mathrm{CDCl}_{3}\right)$ do composto 77........................... 65

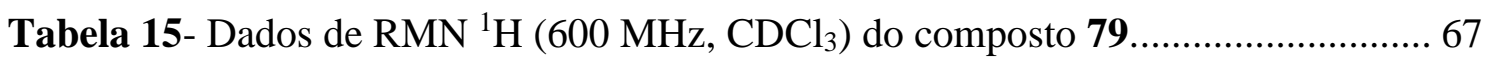

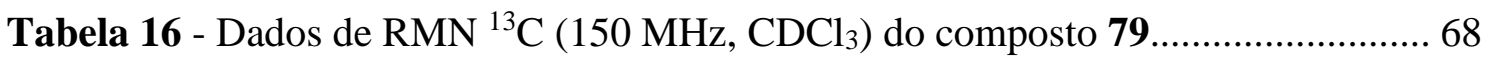

Tabela 17 - Dados de $\mathrm{RMN}{ }^{1} \mathrm{H}\left(600 \mathrm{MHz}, \mathrm{CDCl}_{3}\right)$ do composto 80a.......................... 70

Tabela 18 - Dados de $\mathrm{RMN}{ }^{13} \mathrm{C}\left(150 \mathrm{MHz}, \mathrm{CDCl}_{3}\right)$ do composto 80a......................... 71

Tabela 19 - Dados de $\mathrm{RMN}^{1} \mathrm{H}\left(600 \mathrm{MHz}, \mathrm{CDCl}_{3}\right)$ do composto 80e.......................... 73

Tabela 20 - Dados de RMN ${ }^{1} \mathrm{H}(600 \mathrm{MHz}$, DMSO-d $)$ do composto 81b.................... 75 


\section{Sumário}

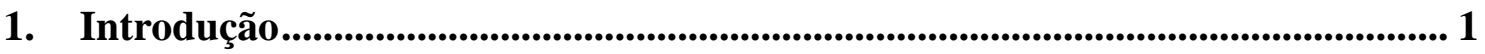

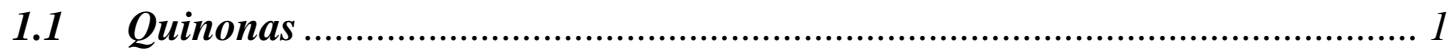

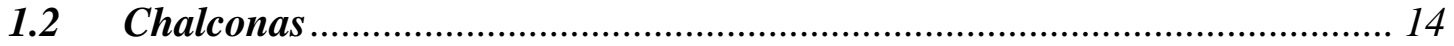

1.3 Reaçães Click e compostos 1,2,3-Triazólicos.............................................. 23

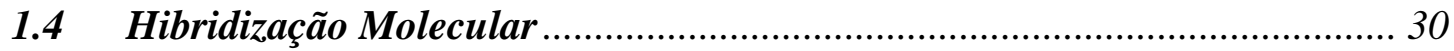

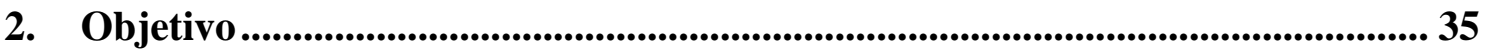

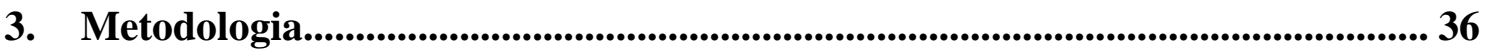

4. Resultados e Discussão................................................................................................. 38

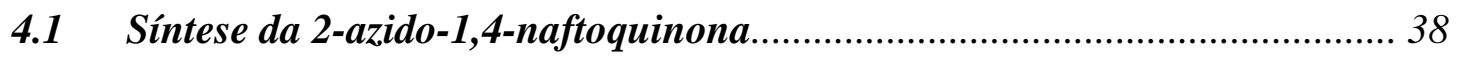

4.2 Sintese da 4-propargiloxi-acetofenona ....................................................... 41

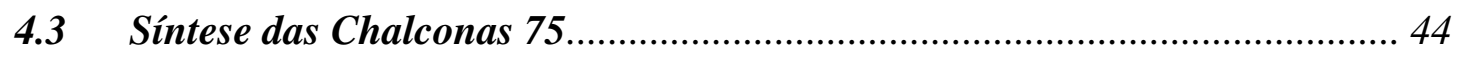

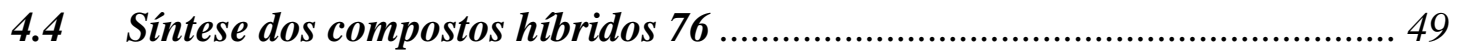

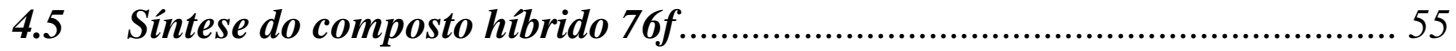

4.6 Síntese da 2-propargiloxi-1,4-naftoquinona ................................................. 63

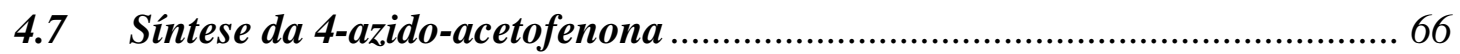

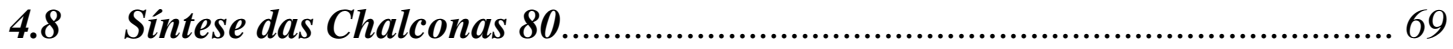

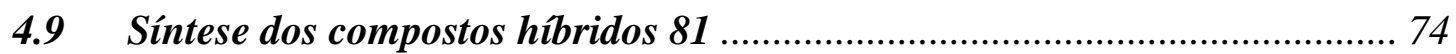

5. Conclusão e Perspectivas ................................................................................... 77

6. Parte Experimental ..................................................................................................... 79

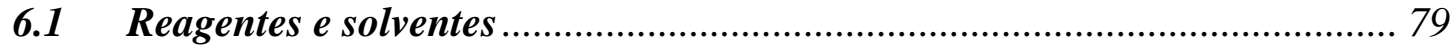

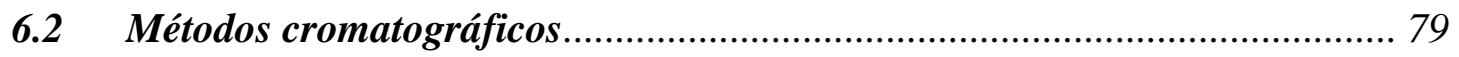

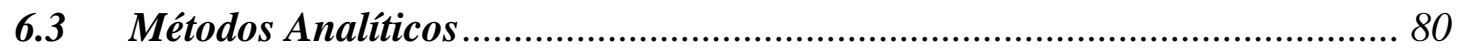

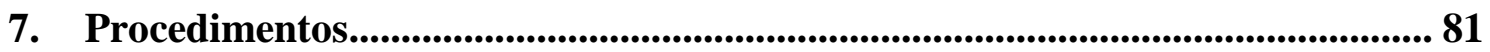

7.1 Procedimento para a síntese da 2-azido-1,4-naftoquinona 71 .................... 81

7.2 Procedimento para a síntese da 4-propargiloxi-acetofenona 73.................. 81

7.3 Procedimento para a síntese da 2-propargiloxi-1,4-naftoquinona 77 ......... 82

7.4 Procedimento para a síntese da 4-azido-acetofenona 79 ........................... 83

7.5 Procedimento geral para síntese de chalconas: ......................................... 84 
7.6 Procedimento para a síntese da (E)-3-(fenil)-1-(4-propargiloxifenil)prop-2en-1-ona 75a.

7.7 Procedimento para a síntese da (E)-3-(fluorofenil)-1-(4-

propargiloxifenil)prop-2-en-1-ona $75 b$

7.8 Procedimento para a síntese da (E)-3-(4-nitrofenil)-1-(4-

propargiloxifenil)prop-2-en-1-ona $75 \mathrm{c}$

7.9 Procedimento para a síntese da (E)-3-(4-dimetilaminofenil)-1-(4-

propargiloxifenil)prop-2-en-1-ona $75 d$.

7.10 Procedimento para a síntese da (E)-3-(3,4-metilenodioxifenil)-1-(4propargiloxifenil)prop-2-en-1-ona 75 e

7.11 Procedimento para a síntese da (E)-3-fenil-1-(3-hidróxifenil)prop-2-en-1ona 83

7.12 Procedimento para a síntese da (E)-3-fenil-1-(3-propargiloxifenil)prop-2-en1-ona $75 f$. 88

7.13 Procedimento para a síntese da (E)-1-(4-azidofenil)-3-fenil-prop-2-en-1-ona $80 a \quad 89$

7.14 Procedimento para a síntese da (E)-1-(4-azidofenil)-3-(4-fluorofenil)prop-2en-1-ona $80 b$.

7.15 Procedimento para a síntese da (E)-1-(4-azidofenil)-3-(4-nitrofenil)prop-2en-1-ona $80 c$.

7.16 Procedimento para a síntese da (E)-1-(4-azidofenil)-3-(4-

dimetilaminofenil)prop-2-en-1-ona 80d

7.17 Procedimento para a síntese da (E)-1-(4-azidofenil)-3-(3,4metilenodioxifenil)prop-2-en-1-ona $80 e$

7.18 Procedimento geral para a síntese de compostos híbridos através de reações click. 92

7.19 Procedimento para a síntese do composto híbrido 76 a 93

7.20 Procedimento para a síntese do composto híbrido $76 b$ 93

7.21 Procedimento para a síntese do composto híbrido $76 c$ 94

7.22 Procedimento para a síntese do composto híbrido $76 d$ 95

7.23 Procedimento para a síntese do composto híbrido 76 e 95

7.24 Procedimento para a síntese do composto híbrido $76 f$. 96

7.25 Procedimento para a síntese do composto híbrido 81 a 97

7.26 Procedimento para a síntese do composto híbrido $81 b$ 98

7.27 Procedimento para a síntese do composto híbrido 81c 98 
7.28 Procedimento para a síntese do composto híbrido 81d

7.29 Procedimento para a síntese do composto híbrido 81e. 100

8. Referências Bibliográficas ........................................................................ 101

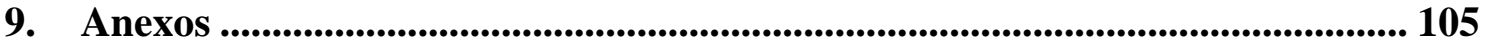




\section{Introdução}

\subsection{Quinonas}

As quinonas são um grupo de moléculas caracterizadas por conter duas carbonilas cetônicas em uma estrutura cíclica hexagonal, conjugadas com ligações duplas. Especificamente, elas podem ser entendidas como 1,2 ou 1,4 ciclohexadienodionas. Suas ligações duplas conjugadas proporcionam um leve caráter aromático. ${ }^{1}$ A Figura 1 apresenta alguns exemplos de quinonas.

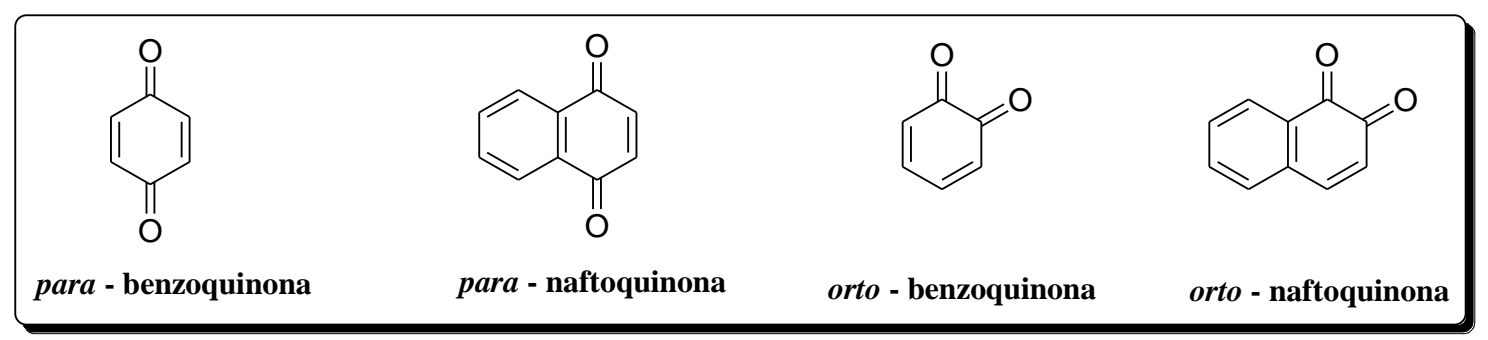

Figura 1 - Estruturas moleculares de algumas quinonas.

Como observado na Figura 1, a nomenclatura desse grupo de moléculas está relacionada com o respectivo sistema aromático. Quinonas com sistemas benzênicos são denominadas benzoquinonas, sistemas naftalênicos são denominados naftoquinonas, assim como sistemas antracênicos, que são denominados antraquinonas. A orientação das carbonilas dos sistemas quinoídicos também caracteriza esse grupo, exemplos são as orientações 1,2 ou orto e as orientações 1,4 ou para. $^{2}$

Quinonas podem ser sintetizadas a partir de grupos aromáticos e agentes oxidantes (Esquema 1). Alguns desses agentes oxidantes usados são: CAN (nitrato de cério (IV) amoniacal), ${ }^{3} \mathrm{PCC}$ (cloro cromato de piridínio), ${ }^{4} \mathrm{NBS}(\mathrm{N} \text {-bromosuccinimida })^{5}$ e $\mathrm{MnO}_{2}$ (dióxido de manganês (II)). ${ }^{6}$

${ }^{1}$ Lumb, J. P. G. Progress in the Chemistry of Quinoidal Natural Products. ProQuest; 2008, p. 1-12.

${ }^{2}$ Gleicher, G. J.; Church, D. F.; Arnold, J. C. J. Amer. Chem. Soc. 1974, 96, 2403.

${ }^{3}$ a) Hannan, R. L.; Barber, R. B.; Rapoport, H. J. Org. Chem. 1979, 44, 2153; b) Jacob III, P.; Callery, P. S.; Shulgin, A. T.; Castagnoli Jr, N. J. Org. Chem. 1976, 41, 3627; c) Nair, V.; Deepthi, A. Chem. Rev. 2007, 107, 1862.

${ }^{4}$ Willis, J. P; Gogins, K. A. Z.; Miller, L. J. Org. Chem. 1981, 46, 3215.

${ }^{5}$ a) Heinzman, S. W.; Grunwell, J. R. Tetrahedron Lett. 1980, 21, 4305; b) Brimble, M. A.; Bachu, P.; Sperry, J. Synthesis, 2007, 2887.

${ }^{6}$ Errazuriz, B.; Tapia, R.; Valderrama, J. A. Tetrahedron Lett. 1985, 26, 819. 


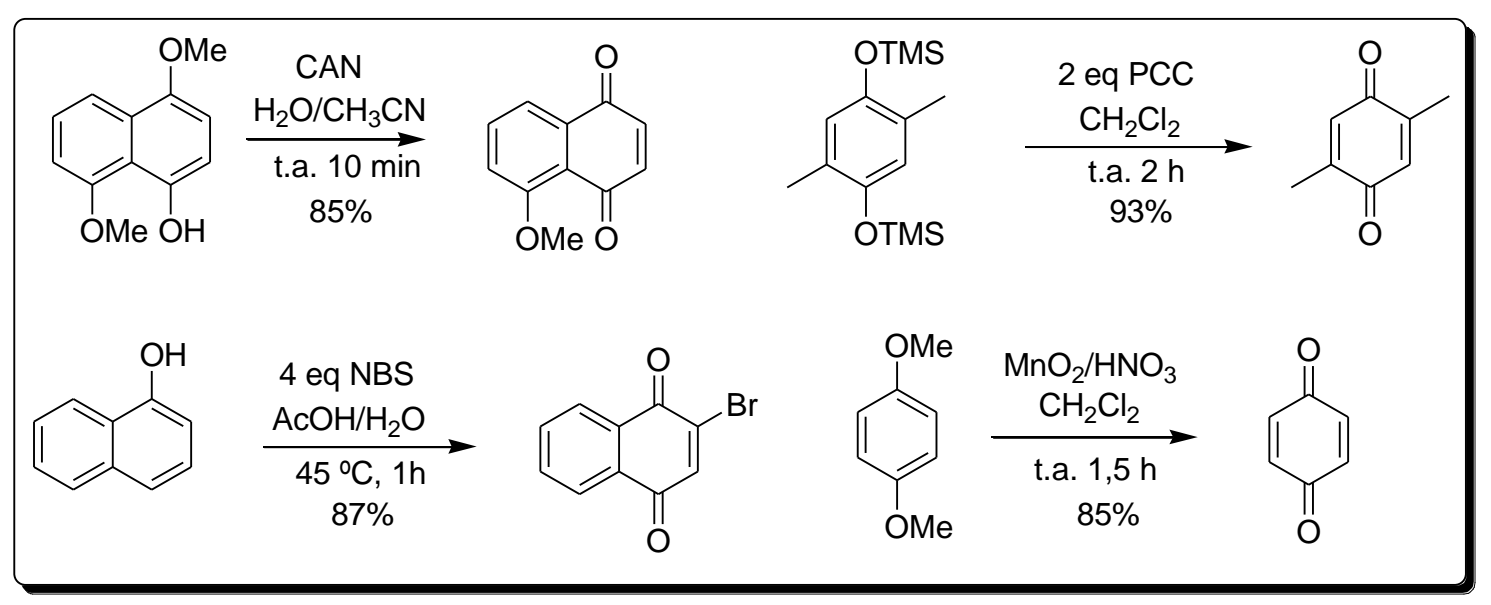

Esquema 1 - Síntese de quinonas.

No que diz respeito à interação das quinonas com células vivas e suas atividades biológicas, três características dessas moléculas se destacam: a capacidade oxidante, a eletrofilicidade e a absorção UV-vis (são coloridas). ${ }^{7}$

O papel oxidante das quinonas envolve a formação de hidroquinonas e semiquinonas. Para a formação de hidroquinonas são necessários dois prótons e dois elétrons. As semiquinonas são a forma reduzida das quinonas com ganho de apenas um elétron e são mais comumente presentes em meios biológicos na forma de ânion radicalar. ${ }^{7}$ O Esquema 2 mostra como os potenciais de redução de quinonas, semiquinonas e hidroquinonas estão correlacionados com a questão ácido-base.7

${ }^{7}$ Monks, T. J.; Hanzlik, R. P.; Cohen, G. M.; Ross, D.; Graham, D. G. Toxicol. Appl. Pharmacol. 1992, 112,2 . 


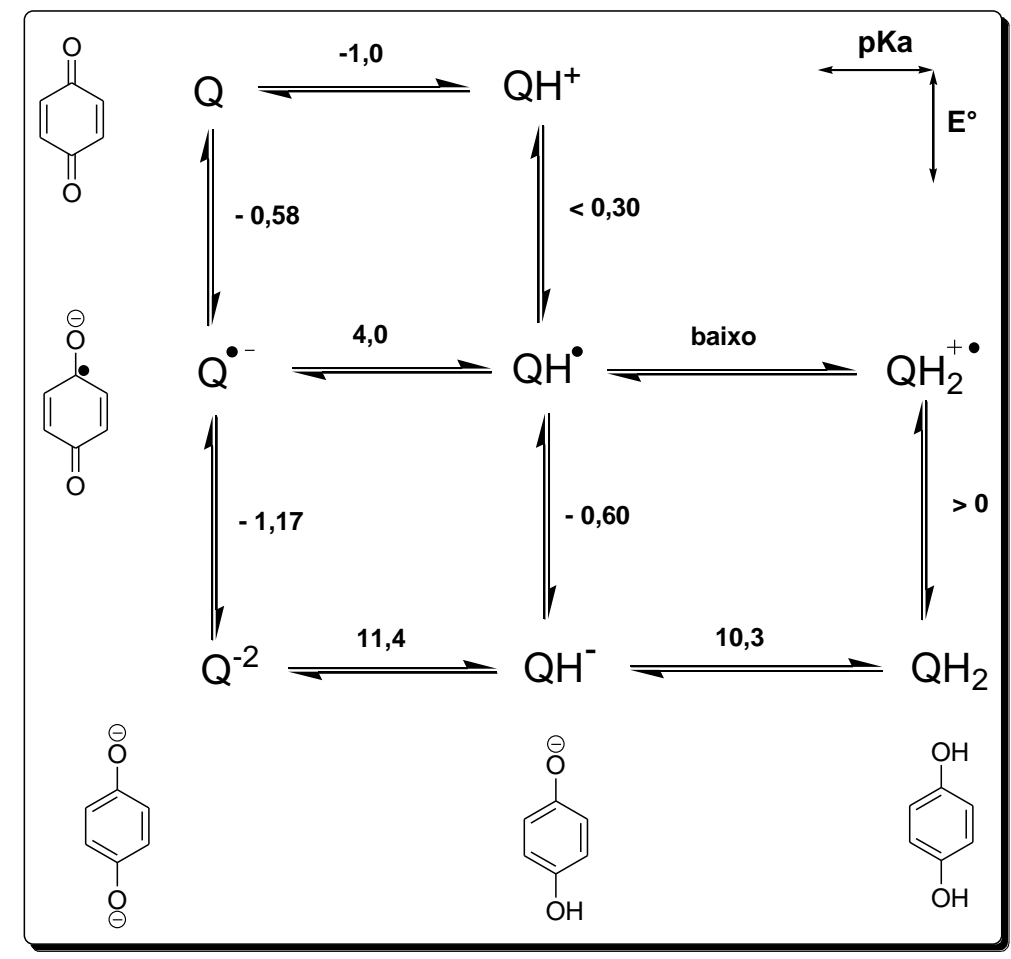

Esquema 2 - Diagrama cíclico representando a relação dos potenciais de redução de derivados benzoquinônicos e seus comportamentos ácido-base. ${ }^{7}$

O efeito de substituintes nas quinonas tem grande influência no seu potencial de redução. Grupos retiradores de elétrons tendem a aumentar o caráter oxidante das quinonas, assim como tornar as respectivas hidroquinonas menos oxidáveis. Do mesmo modo, grupos doadores de elétrons tendem a diminuir o caráter oxidante das quinonas, tornando suas hidroquinonas mais propícias à oxidação. ${ }^{7}$

Em relação à eletrofilicidade, as quinonas são também aceptores de Michael e, portanto, podem sofrer ataques nucleofílicos, levando a reações de adição conjugada. Tióis são nucleófilos que, frequentemente, participam desse processo. Um exemplo deste processo no organismo humano é a metabolização do benzeno. O benzeno, uma vez no organismo, é convertido em hidroquinonas pelo citocromo hepático P450. São, então, subsequentemente oxidados na medula óssea pela enzima peroxidase às quinonas: $p$-benzoquinona e $o$-benzoquinona, as quais são tóxicas. Isso seria um dos fatores que explicaria o porquê da incidência de leucemia em pessoas que tiveram altas exposições ao benzeno. ${ }^{8}$

\footnotetext{
${ }^{8}$ Wellington, K. W. RSC Adv. 2015, 5, 20309.
} 
Fatores estruturais como a simetria e polaridade das moléculas podem influenciar suas propriedades eletrofílicas. Por exemplo, de modo geral, orto-quinonas são mais reativas que para-quinonas. Isso é devido aos momentos dipolares das carbonilas, que no caso das para-quinonas são opostas e reduzem, assim, a eletrofilicidade das moléculas se comparado com suas respectivas orto-quinonas, as quais são mais polarizadas.7

Essas propriedades oxidantes das quinonas têm grande importância nas suas atividades biológicas. Elas são potentes inibidoras de transporte de elétrons, agem como agentes intercalantes no DNA, agentes alquilantes biorredutores, assim também como produzem radicais oxigenados altamente reativos através do ciclo redox sob condições aeróbicas. $^{8}$

Outra importância na biorredução das quinonas é sua presença em vias metabólicas importantes nos processos de respiração celular e fotossíntese. ${ }^{9}$ Uma dessas vias é a fosforilação oxidativa, o processo pelo qual se forma ATP quando há transferência de elétrons do $\mathrm{NADH}$ ou $\mathrm{FADH}_{2}$ para a redução de oxigênio em água através de complexos proteicos por uma série de transportadores de elétrons. ${ }^{9}$ Todo esse processo representa uma etapa da respiração celular conhecida como cadeia respiratória (Esquema 3). Em células eucarióticas, a cadeia respiratória passa por quatro complexos (I, II, III e IV) que contêm transportadores de elétrons que culminam na redução de oxigênio e formação de moléculas de ATP A ubiquinona, também conhecida como coenzima $\mathrm{Q}_{10}$, é uma benzoquinona lipossolúvel com um longo grupo isoprenóide e participa desse processo, no qual recebe elétrons de transportadores dos complexos I e II e os transfere do complexo III para o citocromo c, outro transportador de elétrons. O complexo IV completa a cadeia respiratória transferindo os elétrons ao oxigênio, formando água. ${ }^{10}$

\footnotetext{
${ }^{9}$ Nelson, D. L.; Lehninger, A. L.; Cox, M. M. Lehninger. Principles of Biochemistry. W. H. Freeman; $5^{\text {a }}$ Ed, 2008, p. 719.

${ }^{10}$ Stryer, L. Biochemistry. $4{ }^{\text {a }}$ Ed., Standford University, New York, 1995, p. 501.
} 


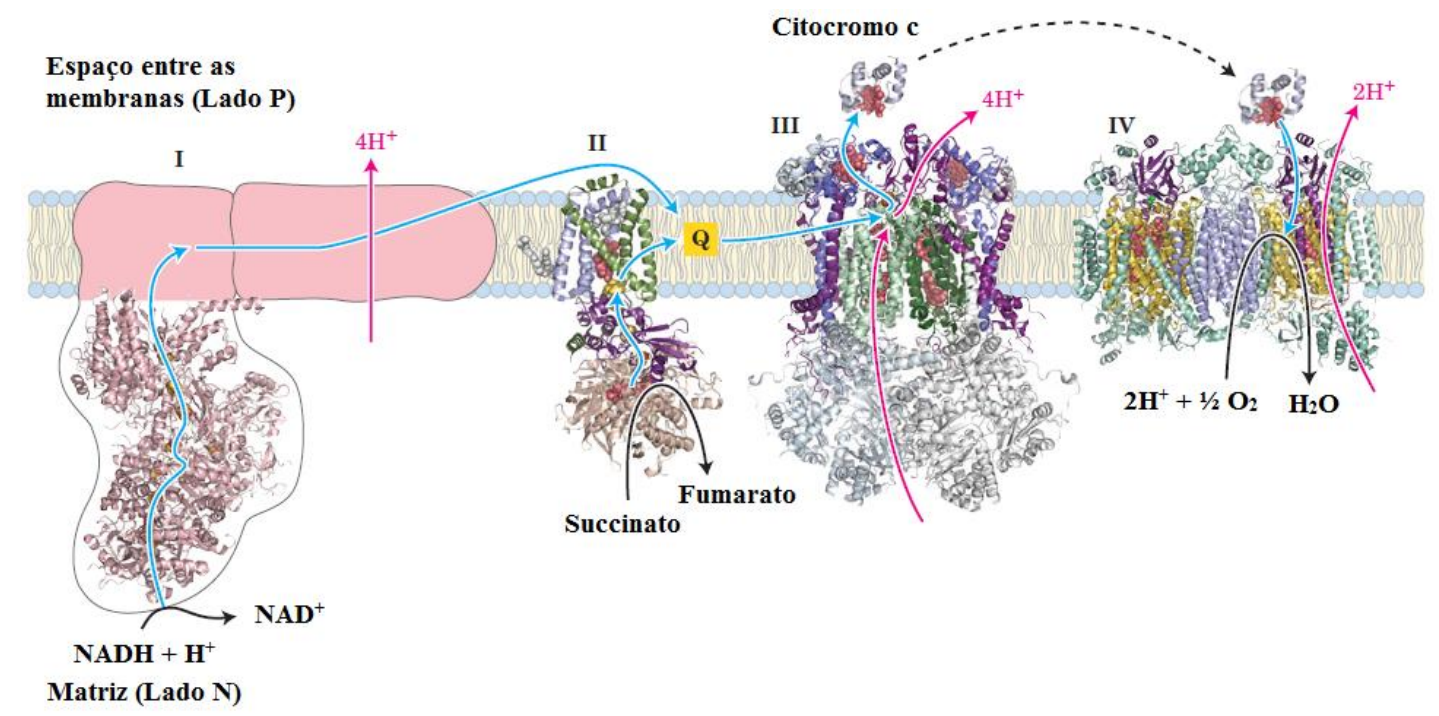

Esquema 3 - Representação da Cadeia respiratória. ${ }^{9}$

Em células procarióticas, a quinona associada com a fosforilação oxidativa é a menaquinona e na fotofosforilação, etapa da fotossíntese, a quinona envolvida é a plastoquinona (Figura 3). ${ }^{10}$

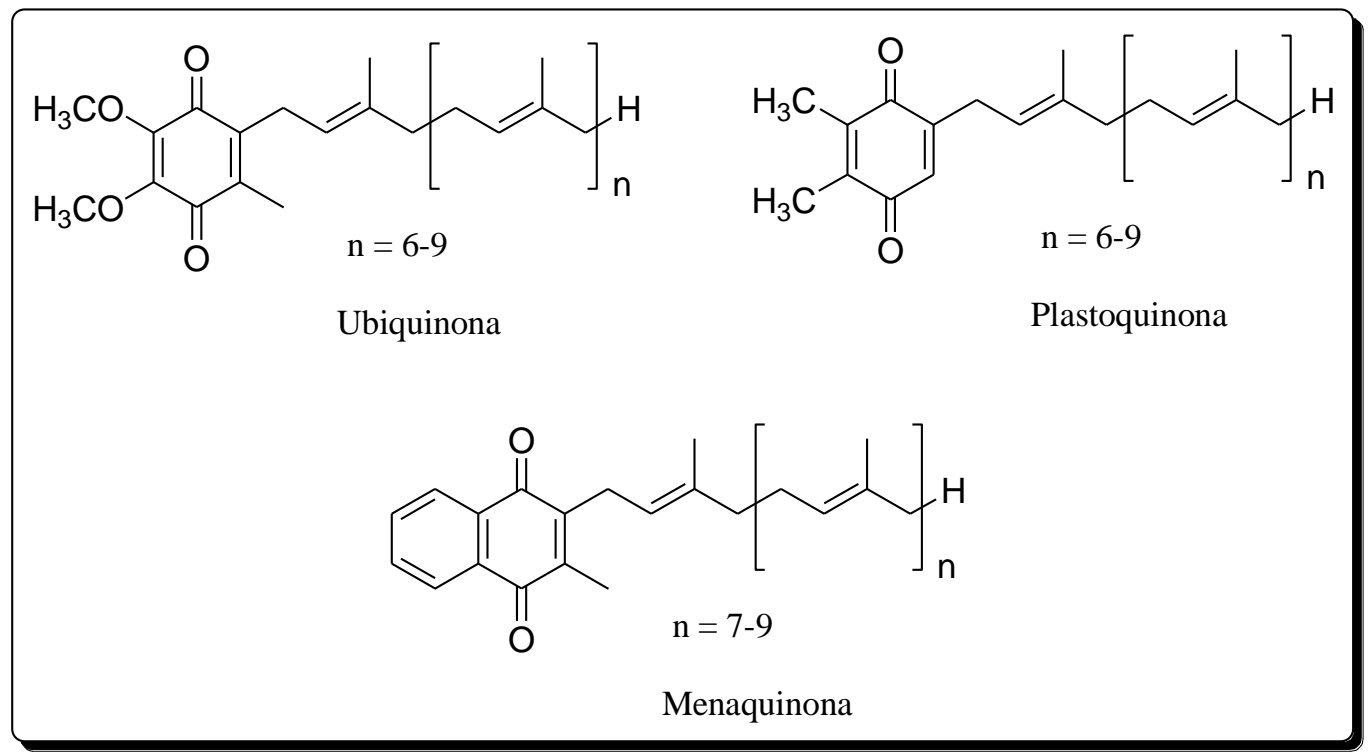

Figura 2 - Estruturas moleculares da ubiquinona, plastoquinona e menaquinona.

A Vitamina K representa um grupo de moléculas quinoidais cuja importância está em todos os seres vivos. Alguns exemplos são as vitaminas $K_{1}$ (filoquinona) e $K_{2}$ (menaquinona). No corpo humano, essas substâncias têm importantes funções na 
coagulação sanguínea ${ }^{11}$ e no metabolismo ósseo ${ }^{12}$. Como já relatado anteriormente, as menaquinonas têm papel importante na respiração celular de organismos procariontes como transportadores de elétrons. ${ }^{10}$

No corpo humano, a vitamina $\mathrm{K}_{1}$ é obtida através da alimentação e é encontrada em vegetais folhosos, legumes e em óleos vegetais, como o óleo de soja. A vitamina $\mathrm{K}_{2}$ é produzida no organismo por bactérias do intestino e é encontrada, principalmente, no fígado. ${ }^{9}$

Um dos processos de biossíntese da vitamina $\mathrm{K}_{2}$ se inicia com a isomerização do ácido corísmico 4 em ácido isocorísmico 5 (Esquema 4). A cadeia lateral necessária à naftoquinona final provém, primeiramente, da tiamina difosfato (TPP) 1 e do ácido 2cetoglutárico 2 , os quais se ligam através do ataque nucleofílico à carbonila cetônica e posterior descarboxilação, gerando um ânion $\mathbf{3}$ que entrará como cadeia lateral do composto 5 através de uma adição de Michael, produzindo o composto 6. A tiamina difosfato é eliminada, assim como ácido pirúvico, fornecendo o composto 7, o qual sofre desidratação, ciclização de Dieckmann e enolização, formando o ácido 1,4dihidroxi-naftanóico $8{ }^{13}$

\footnotetext{
${ }^{11}$ Kurosu, M.; Begari, E. Molecules 2010, 15, 1531

${ }^{12}$ Shearer, M. J. The Lancet 1995, 345, 229.

${ }^{13}$ Meganathan, R. Vitam. Horm., 2001, 61, 173.
} 


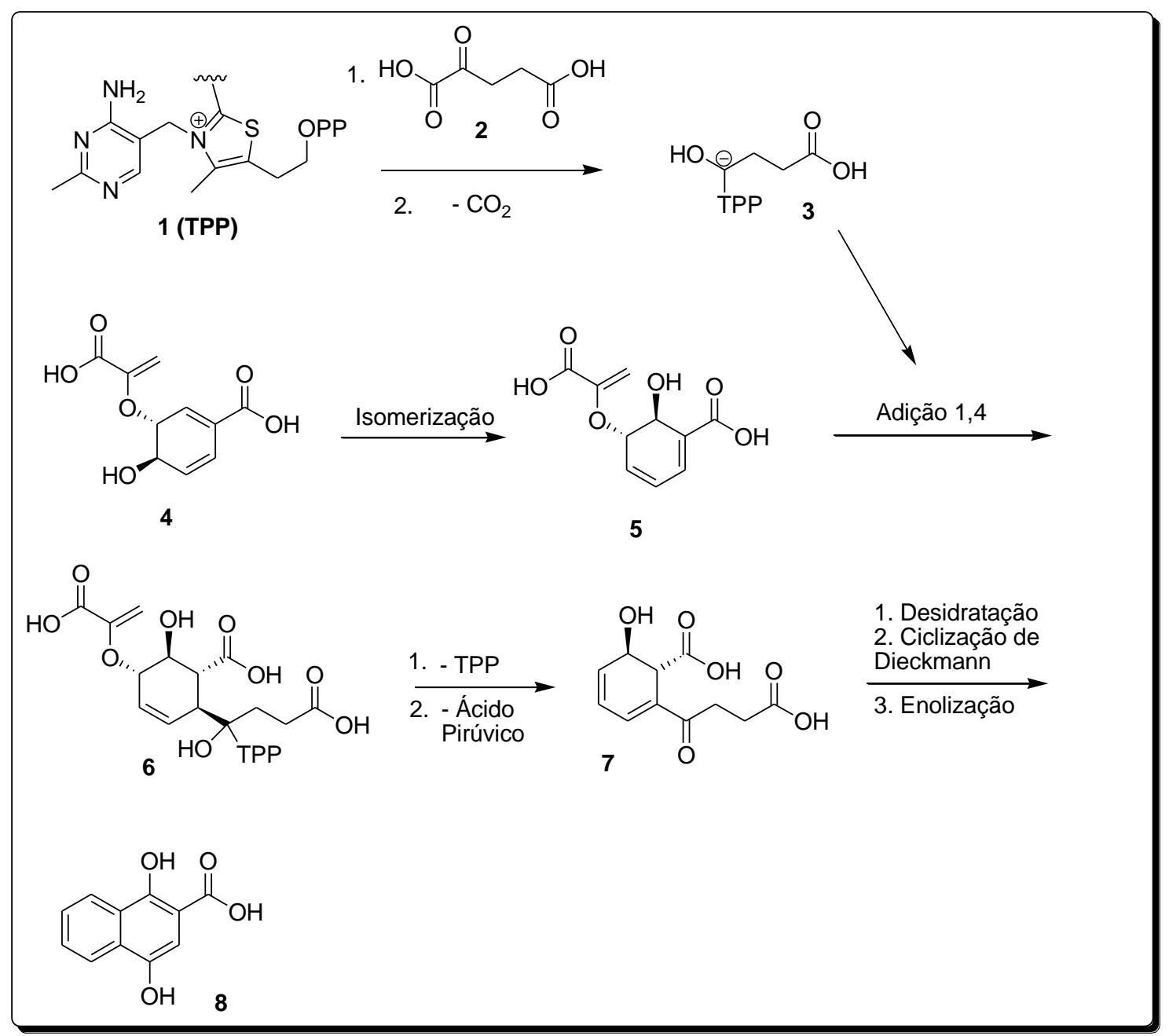

Esquema 4 - Intermediários principais na biossíntese do ácido 1,4-dihidroxinaftanóico.

O composto 8 sofre uma reação de isoprenilação, gerando o composto 9 (Esquema 5). O mesmo passa por descarboxilação e oxidação, formando o núcleo quinoídico 11. Por fim, uma reação de metilação completa a estrutura da vitamina $\mathrm{K}_{2}$ 14. ${ }^{13}$

Outros derivados naftoquinônicos e antraquinônicos podem ser biossintetizados a partir do composto 8, exemplos são a Lausona 12, Lapachol 15 e a Lucidina $16 .{ }^{13}$ 


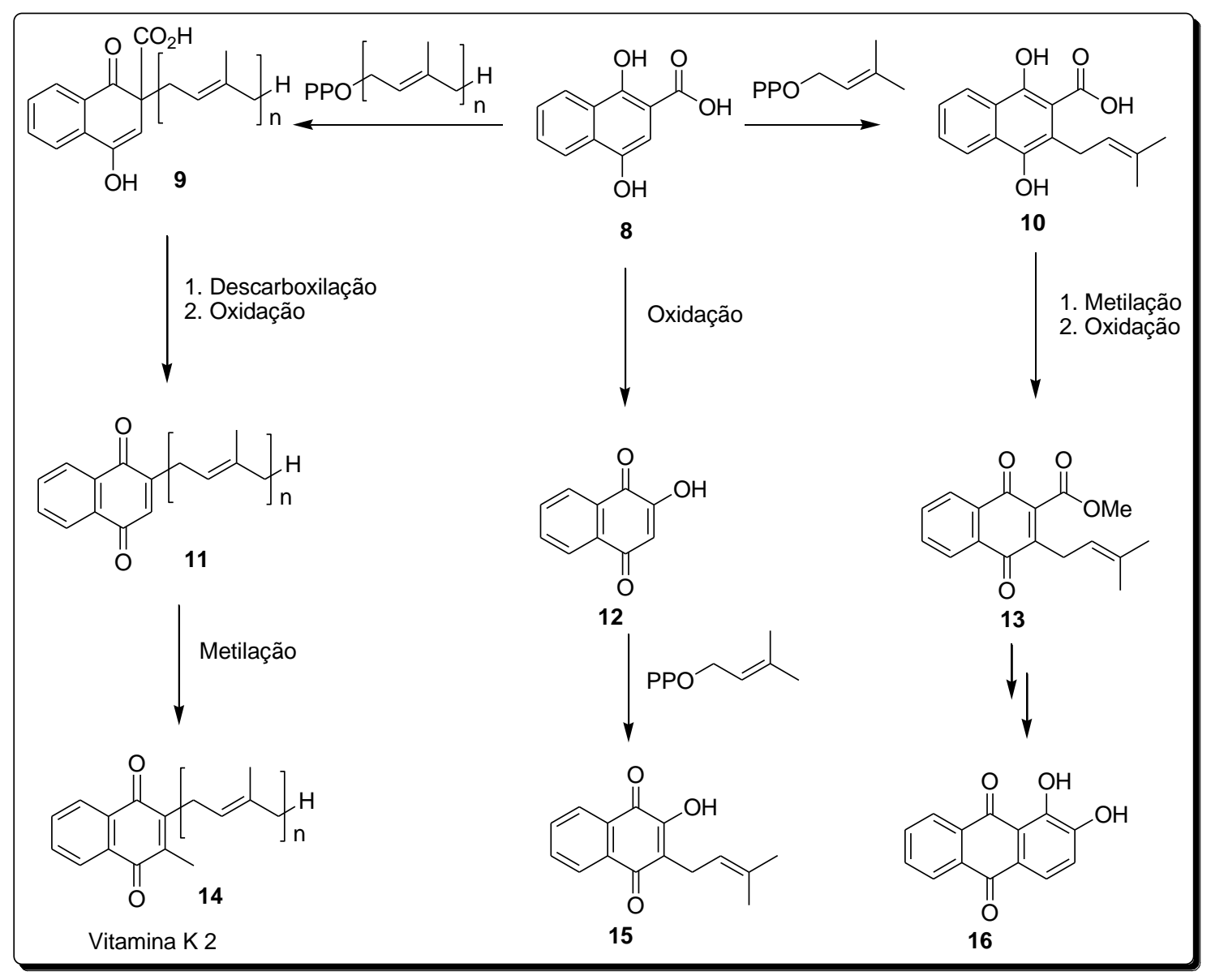

Esquema 5 - Etapas finais principais da biossíntese da Vitamina K2 e de outras importantes quinonas.

Jin e Sato fizeram um estudo sobre possíveis substâncias com atividade antibacteriana encontradas em rebentos da pera chinesa. ${ }^{14}$ Numa primeira análise, extraíram em fase aquosa folhas e hastes da planta e encontraram forte atividade antibacteriana. Os pesquisadores conseguiram identificar duas substâncias principais contidas nessas folhas e hastes: arbutina e hidrobenzoquinona (Figura 3). Estudos posteriores mostraram que essas substâncias apresentavam baixa ou nula atividades biológicas e que era possível que outra substância fosse responsável pela forte atividade antibacteriana, a qual pode ter sido perdida no processo de tratamento do extrato. Outra análise quantitativa foi realizada. Utilizaram $200 \mathrm{~mL}$ de água na extração de substâncias de $10 \mathrm{~g}$ de folhas e hastes da planta e agitaram esse extrato por 2 horas. A fase aquosa passou a ter uma coloração amarelo-alaranjada e foi evaporada a vácuo. Posteriormente, foi tratada com carvão ativado, perdendo sua coloração e sua atividade biológica. Uma

${ }^{14}$ Jin, S.; Sato, N. Phytochem. 2003, 62, 101. 
coluna com carvão foi realizada e eluída em acetona. A solução formada apresentava forte coloração amarela e forte atividade antibacteriana. Essa substância foi caracterizada por CLAE, RMN, EM e foi identificada como sendo a Benzoquinona. Além de sua atividade, seu acúmulo tinha abundância significativa. Observaram também resultados similares em outros tipos de peras, como as japonesas e europeias. ${ }^{14}$

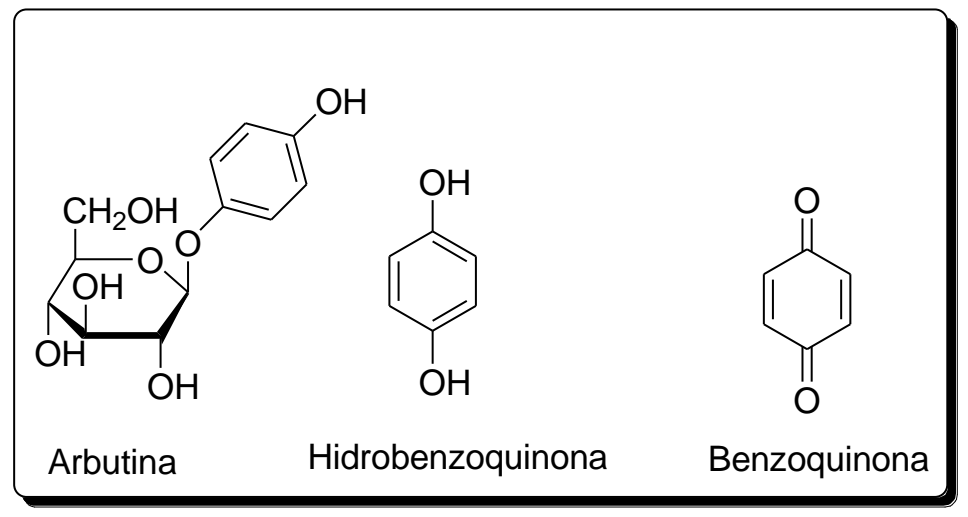

Figura 3 - Estruturas moleculares da arbutina, hidrobenzoquinona e benzoquinona.

Valderrama e colaboradores estudaram a atividade antiprotozoária de alguns compostos quinoídicos e hidroquinoídicos sintéticos. ${ }^{15}$ Para tal, partiram do composto 17, o qual foi oxidado à respectiva quinona 18, reagindo com ácido clorídrico em diclorometano para fornecer a hidroquinona 19 com o cloro na posição 3 (Esquema 6). Sua respectiva quinona $\mathbf{2 0}$ também foi sintetizada através de oxidação com dióxido de manganês. Os compostos $\mathbf{1 9}$ e $\mathbf{2 0}$ foram testados in vitro contra amastigotos intracelulares da espécie Leishmania amazonenses em macrófagos peritoniais de ratos. Utilizaram para efeito de comparação o fármaco Miltefosina, droga utilizada no tratamento da doença. Suas atividades biológicas foram consideradas moderadas.

${ }^{15}$ Valderrama, J. A.; Zamorano, C.; González, M. F.; Prina, E.; Fournet, A. Bioorg.Med. Chem . 2005, 13, 4153. 


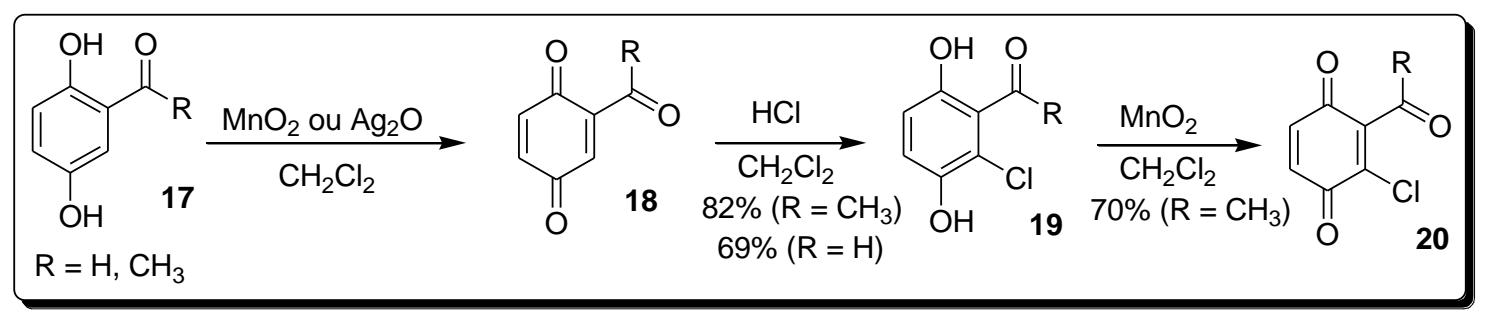

Esquema 6 - Síntese de hidroquinonas e quinonas com cloro na posição $3 .{ }^{15}$

$\mathrm{Na}$ tentativa de aumentar a lipofilicidade dos compostos e, possivelmente, aumentar suas atividades biológicas, fragmentos cicloalifáticos foram adicionados ao composto 20 (Esquema 7). Foi realizada uma reação do tipo Diels-Alder com o ciclopentadieno formando o composto 21. O mesmo sofreu processo de enolização com sílica gel em diclorometano, gerando a hidroquinona 22. Por fim, a hidroquinona 22 foi oxidada à quinona $23 .^{15}$

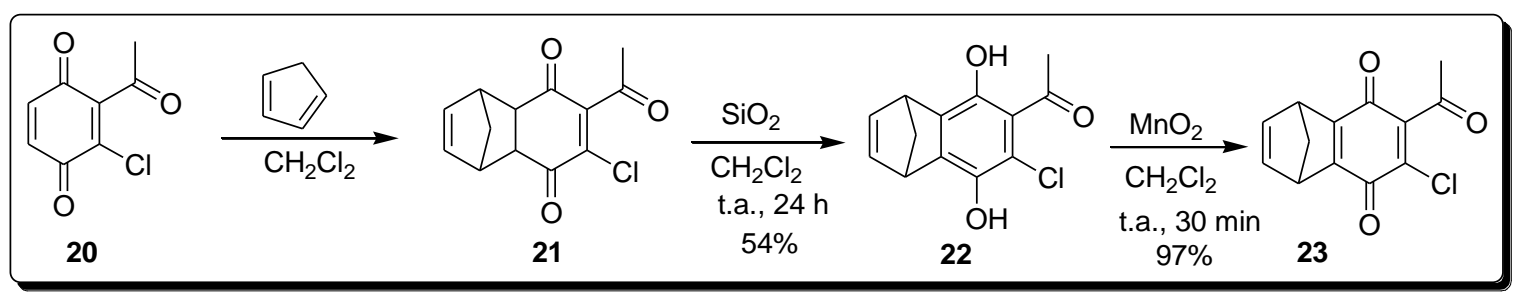

Esquema 7 - Síntese dos compostos 22 e $23 .{ }^{15}$

Os resultados obtidos com as quinonas e hidroquinonas não foram satisfatórios em comparação a Miltefosina. Para tal, utilizaram os parâmetros $\mathrm{IC}_{50}$ (concentração inibitória) e $\mathrm{TC}_{50}$ (citotoxicidade). A Tabela 1 apresenta esses resultados para alguns compostos sintetizados. Os dois parâmetros em questão não superaram, de forma geral, os valores do padrão e, portanto, não caracterizam moléculas com atividade leishmanicida satisfatória. Entretanto, pôde-se concluir que o aumento do caráter lipofílico dos compostos quinônicos e hidroquinônicos (representado na tabela pelo parâmetro $\log \mathrm{P}$, em que $\mathrm{P}$ é o coeficiente de partição) melhorou os parâmetros biológicos se comparado aos seus equivalentes menos lipofílicos. ${ }^{15}$ 
Tabela 1 - Parâmetros de concentração inibitória, citotoxicidade e lipofilicidade de alguns compostos sintetizados em comparação com o fármaco Miltefosina. ${ }^{15}$

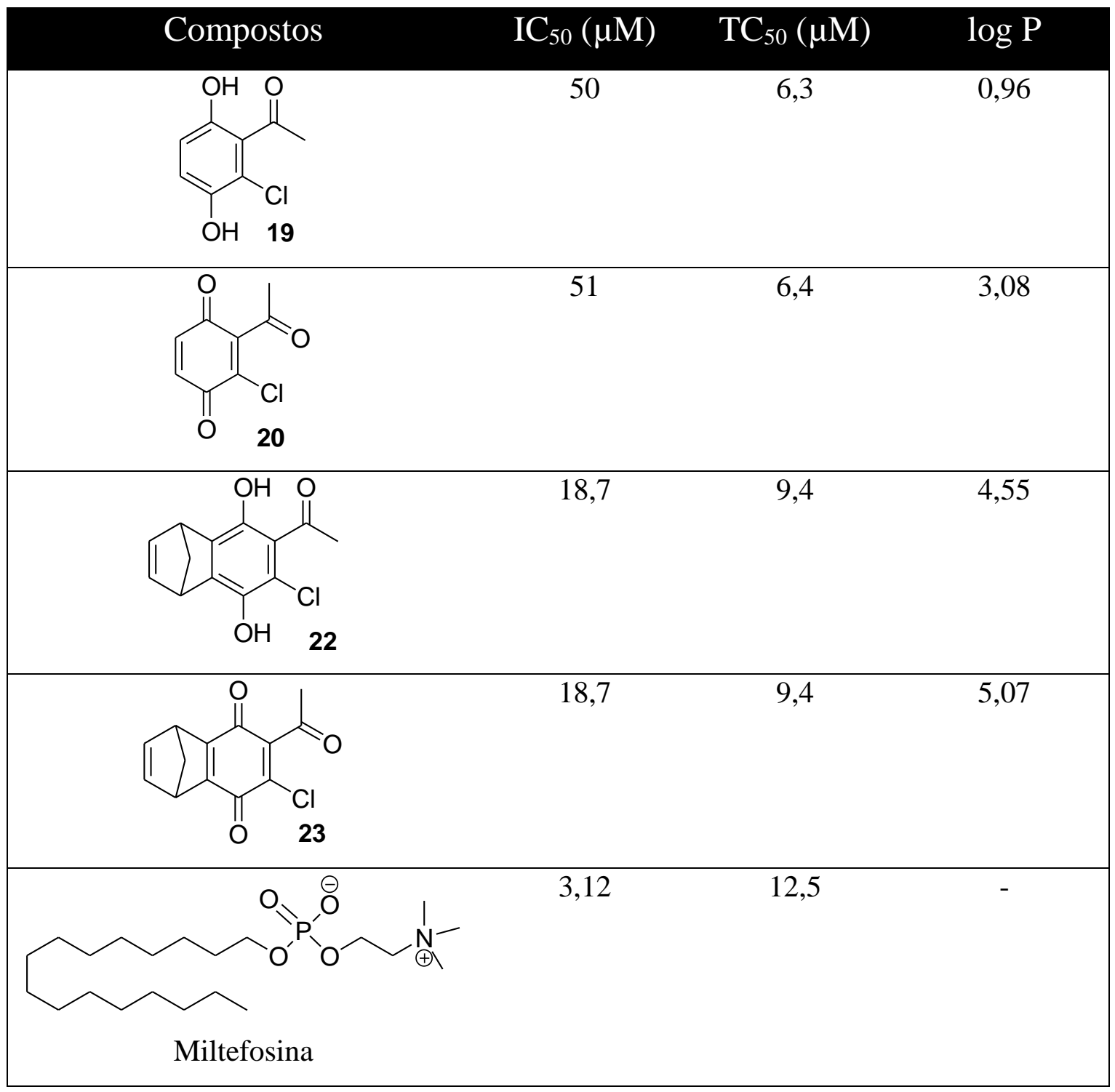

Brimble e colaboradores ${ }^{16}$ realizaram a síntese total enantiosseletiva de uma molécula análoga à Nanaomicina A, molécula isolada do fungo Streptomyces rosa, a qual pertence à classe dos antibióticos piranonaftoquinônicos. O grupo tinha interesse na molécula em questão e em possíveis análogos devido a sua conhecida atividade inibitória contra micoplasmas, fungos, bactérias Gram-positiva e a adenosina difosfato (ADP), um agente inibidor da adesão plaquetária.

\footnotetext{
${ }^{16}$ Brimble, M. A.; Bachu, P.; Sperry, J. Synthesis 2007, 2887.
} 


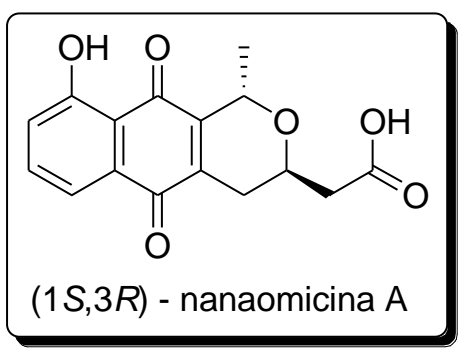

Figura 4 - Estrutura da Nanaomicina A.

Sínteses totais racêmicas da molécula-alvo haviam sido realizadas. O grupo, então, propôs a síntese total enantiosseletiva de um análogo da Nanaomicina A (Esquema 8). Inicialmente, o naftol 24 foi oxidado à 2-bromo-1,4-naftoquinona 25 utilizando NBS em ácido acético e água. Alilação radicalar do composto 25 usando ácido vinilacético catalisado pelo perssulfato de prata (I) (formado in situ) seguido de descarboxilação foram realizadas, levando à formação do composto 27. Posteriormente, o composto 27 sofreu metilação redutiva, gerando o composto 28 seguido de ozonólise para a formação do composto 29. Por fim, foi realizada a adição do grupo alila à carbonila do aldeído de forma enantiosseletiva. Para tal, utilizou-se cloreto de alilmagnésio e (-)-DIP-Cl® [(-)-B-clorodiisopinocanfenilborano], os quais foram misturados a $0{ }^{\circ} \mathrm{C}$ sob atmosfera de nitrogênio durante 1 hora, resultando no composto $30[(+)-B$-alildiisopinocanfenilborano]. O mesmo foi adicionado à solução em dietil éter do respectivo aldeído $\mathbf{2 9}$ levando à formação do composto $\mathbf{3 1}$ com boa enantiosseletividade. ${ }^{16}$ 


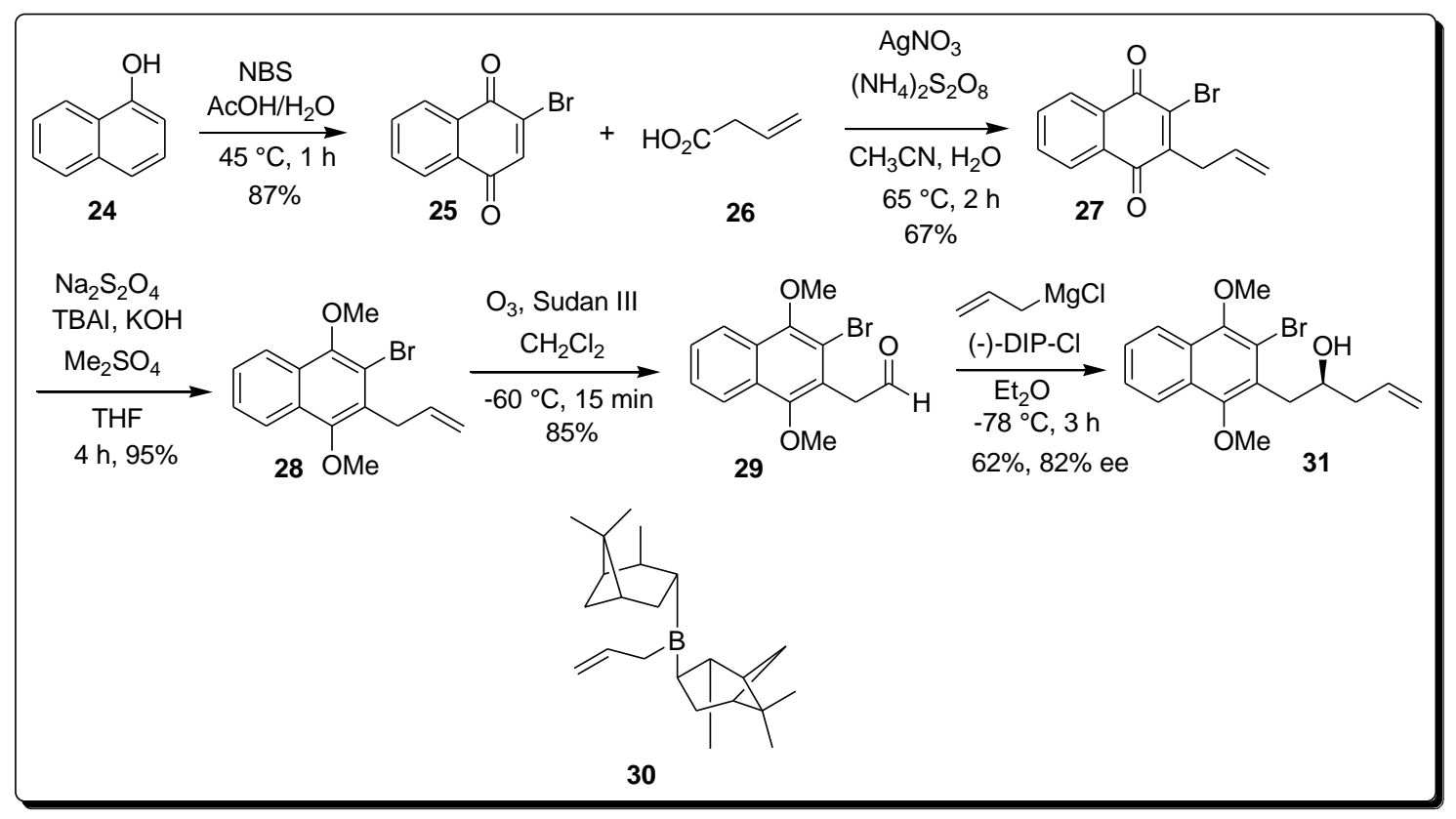

Esquema 8 - Primeiras etapas na síntese enantiosseletiva de uma molécula análoga à Nanaomicina A. ${ }^{16}$

Num segundo momento, o grupo partiu do composto 31 e realizou uma reação de adição nucleofílica do grupo álcool à carbonila do anidrido acético em catálise ácida, formando o composto 32 o qual foi ciclizado, utilizando $t$-butil lítio, formando o lactol 33 (Esquema 9). Devido a sua instabilidade e consequente difícil caracterização, o composto 33 foi convertido ao composto $\mathbf{3 4}$ por meio de redução utilizando TES (trietilsilano) e TFA (ácido trifluoroacético) em diclorometano. O composto 34 foi oxidado de forma diastereomérica ao diol 35 utilizando tetróxido de ósmio e NMO $(N-$ metilmorfolina) em acetona e água. Através de uma clivagem oxidativa, utilizando periodato de sódio, o composto 35 foi convertido ao aldeído 36. O aldeído em questão, por sua vez, foi oxidado a seu respectivo ácido, utilizando clorito de sódio em $t$-butanol, gerando o composto 37 com boa enantiosseletividade. Por fim, o composto final $\mathbf{3 8}$, análogo à nanaomicina $\mathrm{A}$, foi formado a partir de oxidação do anel aromático ao grupo quinônico por meio do uso de CAN (nitrato de amônio e cério (IV)) em acetonitrila e água. Portanto, houve êxito na síntese total do composto alvo através de 12 etapas de reação com um rendimento global de $7 \%$. O grupo não realizou testes biológicos a fim de averiguar as atividades dos compostos análogos. ${ }^{16}$ 


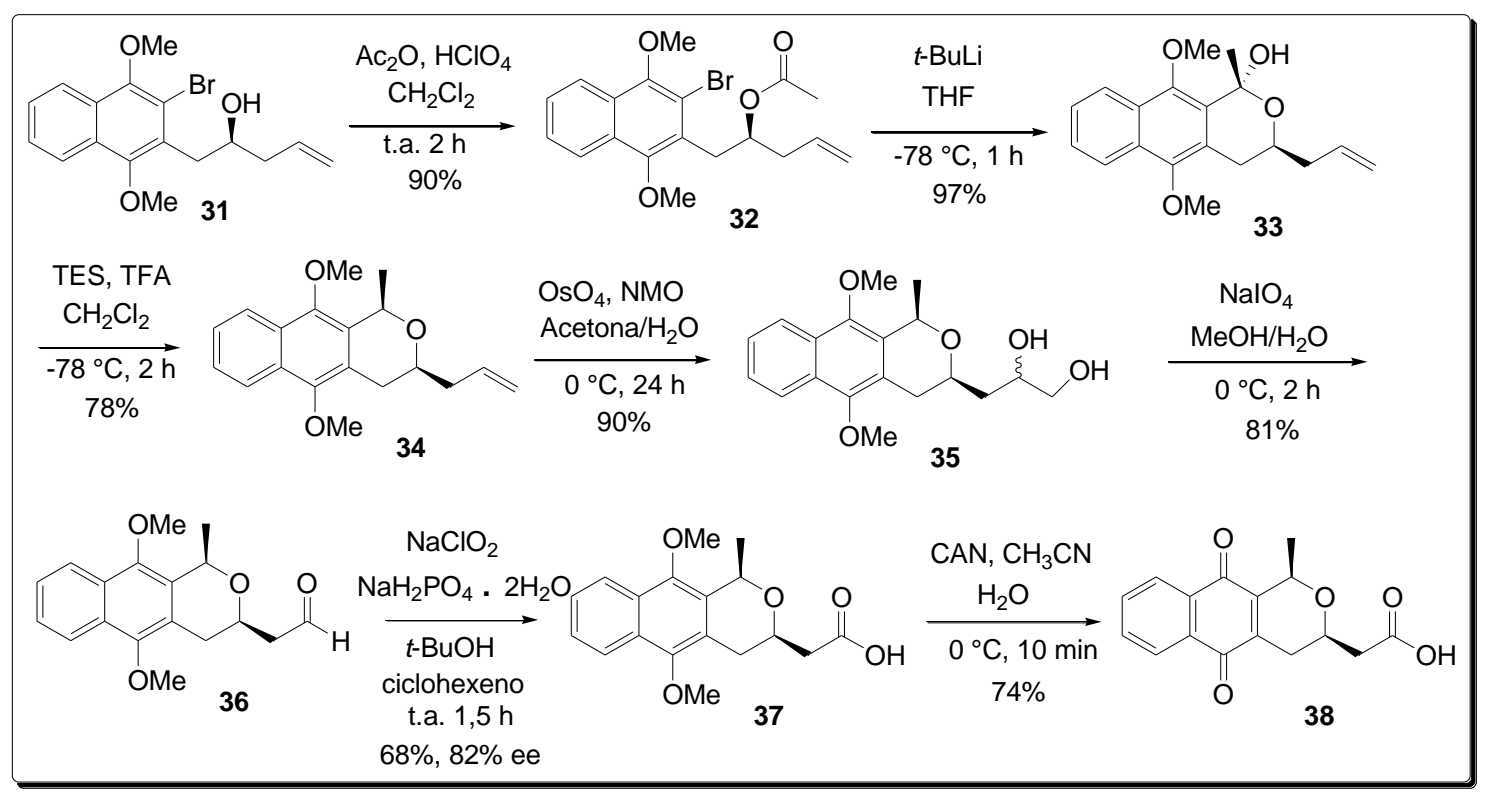

Esquema 9 - Etapas finais na síntese enantiosseletiva de uma molécula análoga à Nanaomicina A. ${ }^{16}$

\subsection{Chalconas}

As chalconas são um grupo de moléculas caracterizadas por conter um núcleo 1,3-diaril-2-propen-1-ona, isto é, apresentam dois anéis aromáticos (A e B) ligados a uma cetona $\alpha, \beta$-insaturada (Figura 5). Nas plantas, são importantes metabólitos e precursores dos flavonoides: substâncias que estão fortemente presentes em nossa dieta, sendo existentes em diversas frutas, vegetais, bebidas etc. ${ }^{17}$

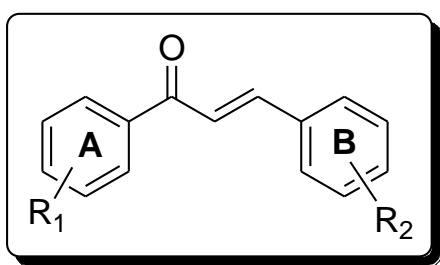

Figura 5 - Estrutura molecular geral de uma chalcona.

\footnotetext{
${ }^{17}$ Zhang, Q.; Raheem, K. S.; Botting, N. P.; Slawin, A. M.; Kay, C. D.; O'Hagan, D. Tetrahedron 2012, $68,4194$.
} 
Segundo a IUPAC ${ }^{18}$, a nomenclatura das chalconas se baseia na cadeia 1,3difenilprop-2-en-1-ona. O anel A está ligado ao carbono 1 e o anel B está ligado ao carbono 3. Os substituintes são discriminados em suas posições em relação à cadeia principal (1 ou 3), assim como suas posições no anel aromático A (2', 3' ou 4') e B (2', , 3"' ou 4"'), seguidos do termo "fenil". Os grupos substituintes do anel são, desse modo, organizados no nome em ordem alfabética, o qual é precedido do símbolo da configuração específica da chalcona $(E$ ou $Z$ ). Por exemplo, uma chalcona com configuração $E$, com um grupo hidroxila na posição para do anel A e um grupo cloro na posição meta do anel B terá a seguinte nomenclatura: E-3-(3-clorofenil)-1-(4hidróxifenil)prop-2-en-1-ona (Figura 6).

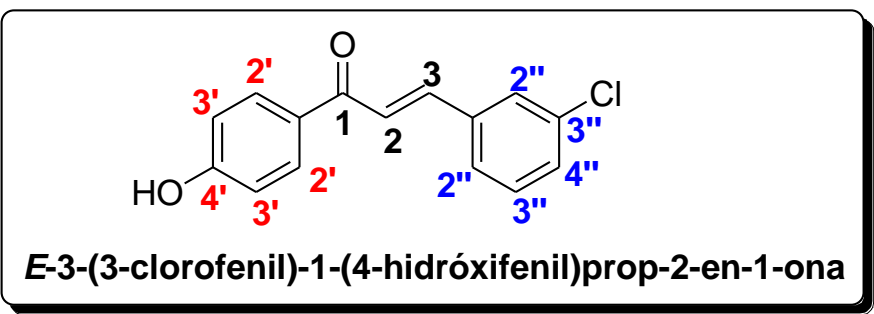

Figura 6 - Exemplo de nomenclatura de chalcona.

A síntese mais comum de chalconas é através de reação aldólica seguida de eliminação do grupo $\mathrm{OH}$ formando cetonas $\alpha, \beta$-insaturadas (condensação de ClaisenSchmidt). A reação envolve uma cetona aromática, um aldeído aromático em meio básico (hidróxido de sódio, por exemplo) e em solvente polar prótico (etanol, por exemplo) (Esquema 10). ${ }^{19}$

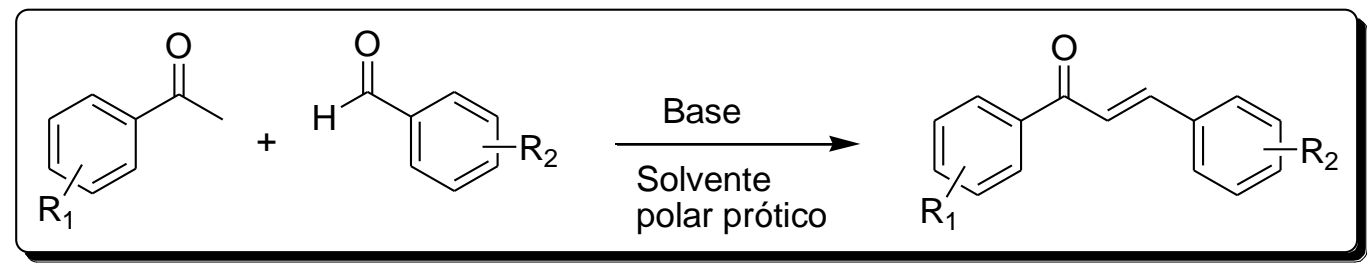

Esquema 10 - Síntese de Chalconas.

\footnotetext{
${ }^{18}$ Glossário de nomes e reatividades de intermediários de classes de compostos orgânicos baseados em suas estruturas. IUPAC. 1995, 67, 1307.

${ }^{19}$ Silva, W. A.; Andrade, C. K. Z.; Napolitano, H. B.; Vencato, I.; Lariucci, C.; Castro, M.; Camargo, A. J. J. Braz. Chem. Soc. 2013, 24, 133.
} 
O mecanismo de formação das chalconas baseia-se, inicialmente, em uma condensação aldólica entre uma cetona e um aldeído aromáticos (Esquema 11). A base desprotona o hidrogênio ácido da cetona aromática formando uma espécie nucleofílica denominada enolato. Posteriormente, há o ataque nucleofílico do enolato à carbonila eletrofílica do aldeído aromático, formando-se o composto aldólico. Por fim, devido à catálise básica, há a eliminação $\left(\mathrm{E}_{1 \mathrm{CB}}\right)$ do grupo hidroxila formando uma ligação dupla conjugada ao sistema, o que é compreendido como uma cetona $\alpha, \beta$-insaturada. ${ }^{20}$

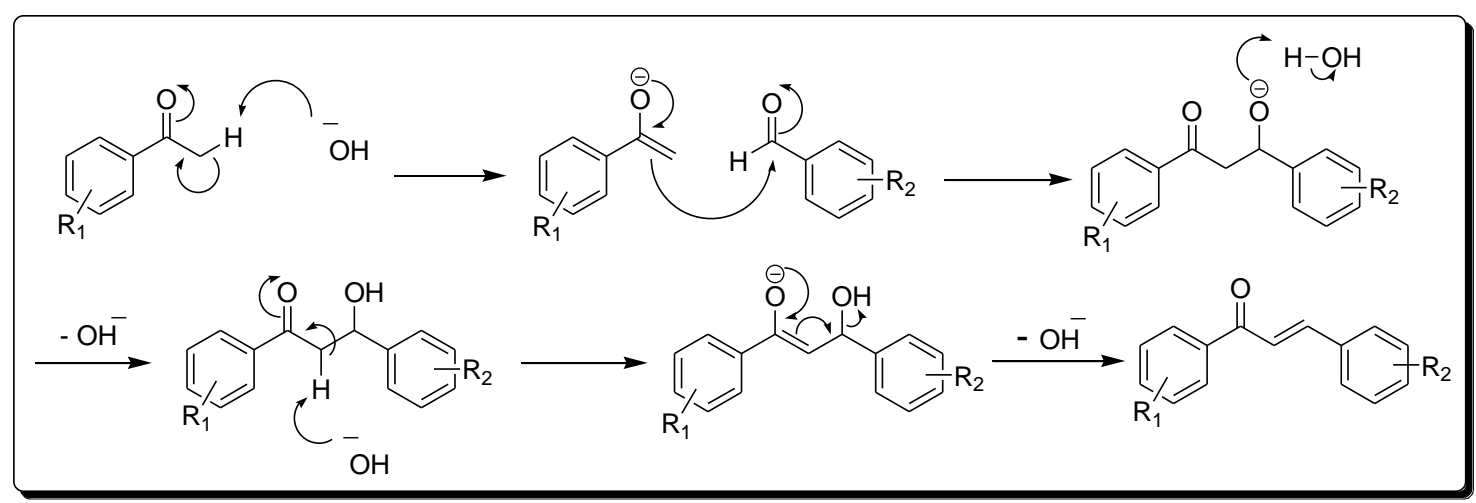

Esquema 11 - Mecanismo de formação da chalcona.

Em relação à configuração da parte olefínica, as chalconas podem adotar configurações $\boldsymbol{E}$ ou $\boldsymbol{Z}$. Contudo, a configuração $\boldsymbol{E}$ é predominante na maioria dos casos por tornar as moléculas termodinamicamente mais estáveis. Estudos de Iwata e colaboradores $^{21}$ mostraram que determinadas chalconas têm a propriedade de converter sua configuração de $\boldsymbol{E}$ para $\boldsymbol{Z}$ a partir da incidência da luz solar em solução metanóica (Esquema 12). Também observaram que 2-hidróxi-chalconas e 4-hidróxi-chalconas tinham maior resistência à foto-conversão. Por fim, observaram que a mudança configuracional das chalconas em $\boldsymbol{Z}$ gerou melhoria em suas atividades anti-tumoriais.

\footnotetext{
${ }^{20}$ Clayden, J.; Warren, W.; Greeves, N.; Wothers, P. Organic Chemistry. Oxford, $2^{\mathrm{a}}$ Ed, 2012, p.521-542. ${ }^{21}$ Iwata, S.; Nishino, T.; Inoue, H.; Nagata, N.; Satomi, Y.; Nishino, H.; Shibata, S. Biol. Pharm. Bull. 1997, 20, 1266.
} 


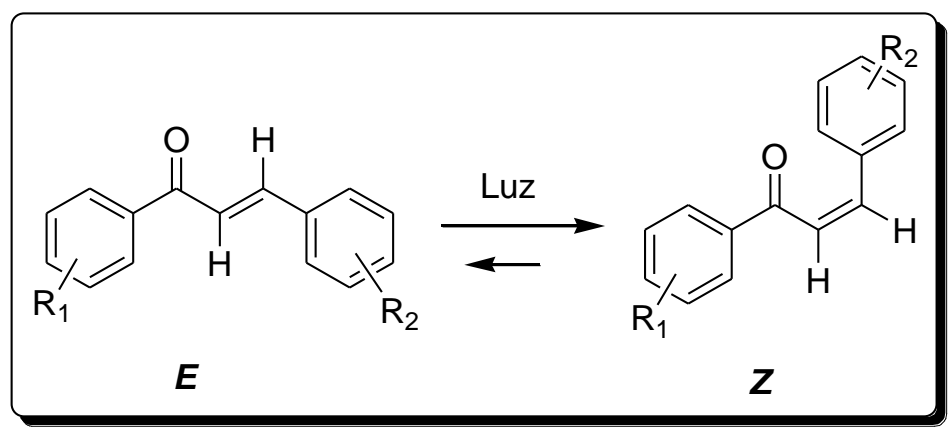

Esquema 12 - Reação de isomerização da chalcona $E$ para a $Z$.

As atividades biológicas das chalconas são diversas e estão muito relacionadas com as diferentes possibilidades de grupos substituintes constituintes dos anéis A e B de sua estrutura. Diversos trabalhos relataram atividades como: anticâncer, ${ }^{22}$ antiinflamatória, ${ }^{23}$ antifúngica, ${ }^{24}$ antimalárica, ${ }^{25}$ antiprotozoária, ${ }^{26}$ antioxidante, ${ }^{27}$ antibacteriana, ${ }^{28}$ antiviral, ${ }^{29}$ dentre outras.

No trabalho de Mello e colaboradores, sintetizaram-se duas chalconas e duas dibenzalacetonas que apresentaram boa atividade leishmanicida contra a espécie Leishmania braziliensis, uma das espécies de protozoário responsável pela Leishmaniose cutânea, uma doença infecciosa, não contagiosa, que afeta a pele e as membranas das mucosas. (Figura 7). ${ }^{26}$

\footnotetext{
${ }^{22}$ Sabzevari, O.; Galati, G.; Moridani, M. Y.; Siraki, A.; O’Brien, P. J. Chem. Biol. Interact. 2004, 148, 57.

${ }^{23}$ Wu, J.; Li, J.; Cai, Y.; Pan, Y.; Ye, F.; Zhang, Y.; Liang, G. J. Med. Chem. 2011, 54, 8110.

${ }^{24}$ Lahtchev, K. L.; Batovska, D. I.; St P, P.; Ubiyvovk, V. M.; Sibirny, A. A. Eur. J. Med. Chem. 2008, 43, 2220.

${ }^{25}$ a) Tadigoppula, N.; Korthikunta, V.; Gupta, S.; Kancharla, P.; Khaliq, T.; Soni, A.; Mohammad, I. S. J. Med. Chem. 2012, 56, 31.; b) Kumar, D.; Kumar, M.; Kumar, A.; Singh, S. M. Mini-Ver. Med. Chem. 2013, 13, 2116.

${ }^{26}$ a) Mello, T. F.; Bitencourt, H. R.; Pedroso, R. B.; Aristides, S. M.; Lonardoni, M. V.; Silveira, T. G. Exp. Parasit. 2014, 136, 27; b) Pacheco, D.; Trilleras, J.; Quiroga, J.; Gutiérrez, J.; Prent, L.; Coavas, T.; Marín, J; C.; Delgado, G. J. Braz. Chem. Soc. 2013, 24, 1685.

${ }^{27}$ Qian, Y. P.; Shang, Y. J.; Teng, Q. F.; Chang, J.; Fan, G. J.; Wei, X.; Zhou, B. Food Chem. 2011,126, 241.

${ }^{28}$ Liu, X. L.; Xu, Y. J.; Go, M. L. Eur. J. Med. Chem. 2008, 43, 1681.

${ }^{29}$ Trivedi, J. C.; Bariwal, J. B.; Upadhyay, K. D.; Naliapara, Y. T.; Joshi, S. K.; Pannecouque, C. C.; Shah, A. K. Tetrahedron. 2007, 48, 8472.
} 


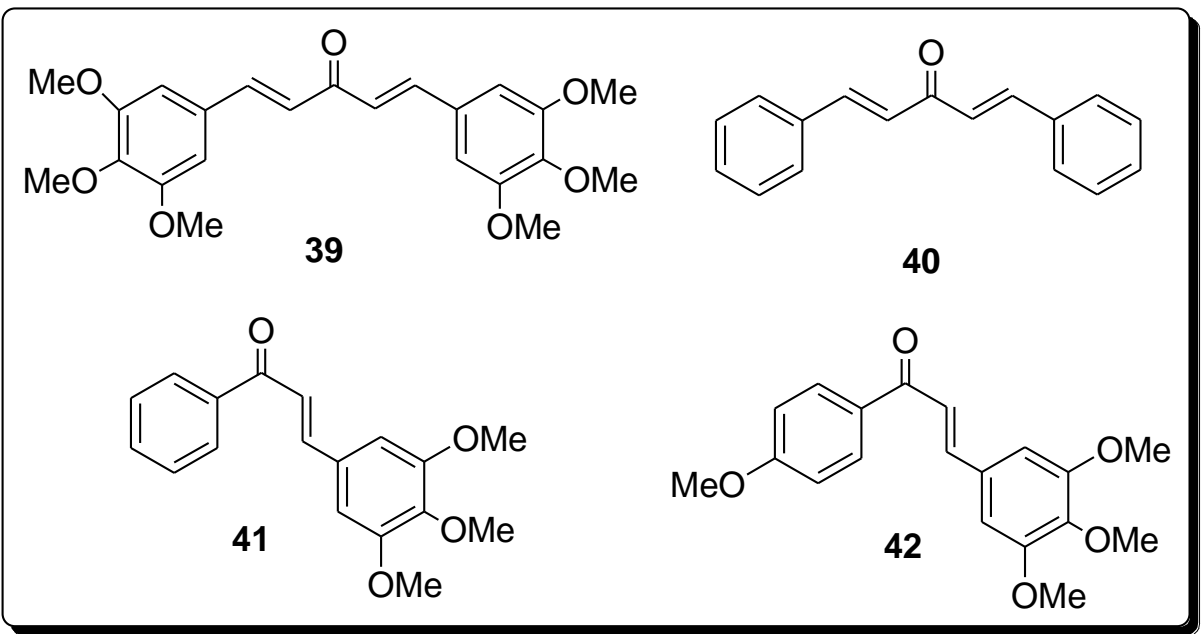

Figura 7 - Estruturas moleculares das chalconas e dibenzalacetonas com atividade leishmanicida. ${ }^{26}$

A doença é tratada atualmente com compostos de antimônio $(\mathrm{Sb})$ pentavalentes e como segundas opções, dependendo da região geográfica, se utilizam compostos como: Anfotericina B, Pentamidina, Paramomicina e Miltefosina (Figura 8). ${ }^{26} \mathrm{O}$ tratamento atual é promovido por injeções diárias durante 20 dias para a leishmaniose cutânea e mais 30 dias para o tratamento das mucosas, o que torna o tratamento bastante desconfortável e incômodo para o paciente. ${ }^{30}$ Além do fato dos fármacos empregados atualmente gerarem uma série de efeitos colaterais graves como: falha aguda nos rins e desordens cardíacas e pancreáticas. ${ }^{30}$

30 Organização Mundial de Saúde, 2010. Relatório Técnico série 949 - Controle da Leishmaniose. http://apps.who.int/iris/bitstream/10665/44412/1/WHO_TRS_949_eng.pdf?ua=1 Acessado em 21 de abril de 2016 


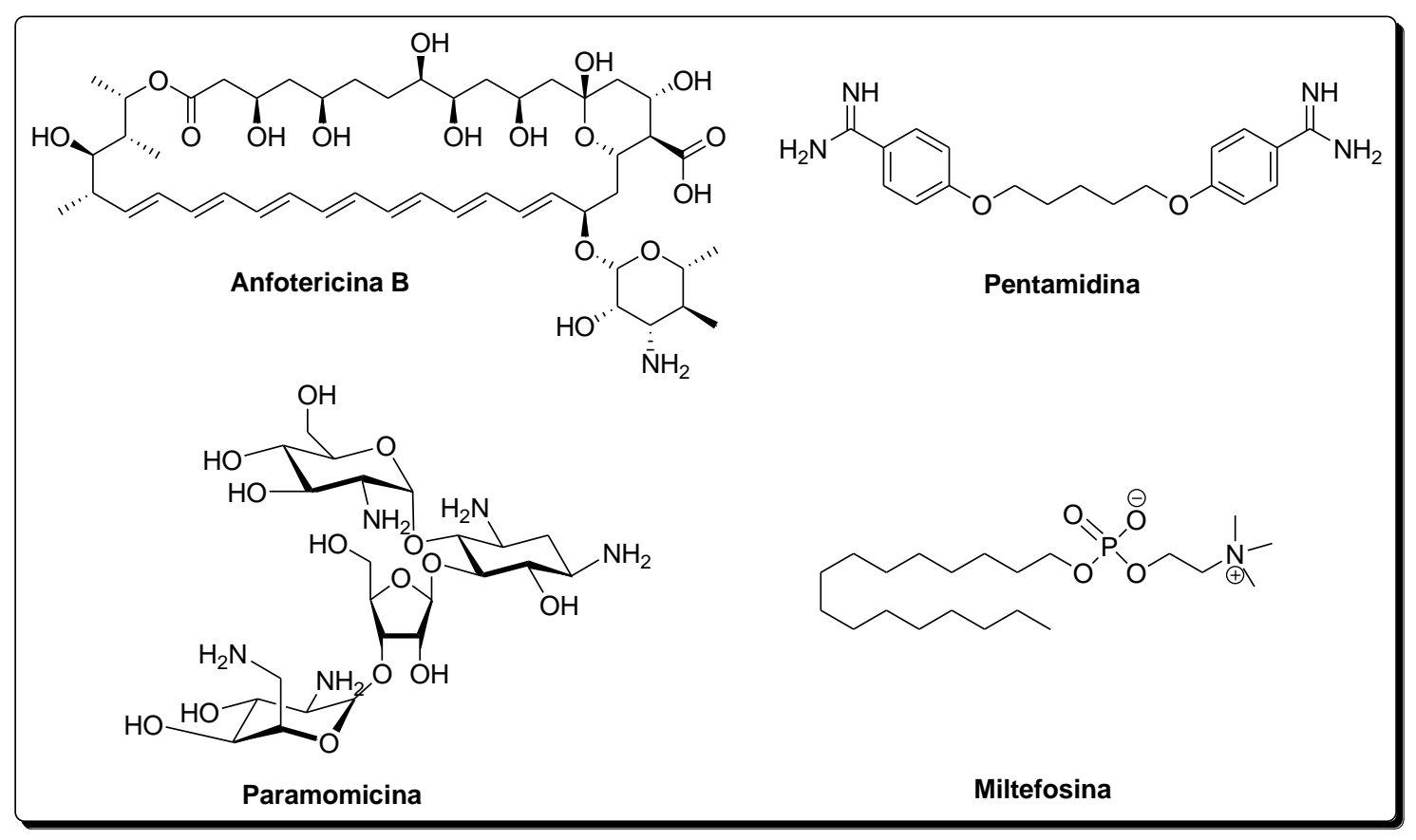

Figura 8 - Estruturas moleculares dos fármacos Anfotericina B, Pentamidina, Paramomicina e Miltefosina.

As quatro moléculas da Figura 7 foram testadas comparando-as com a atividade da Anfotericina B. As moléculas em questão apresentaram atividade inibitória in vitro de promastigotos da Leishmania braziliensis e foram mais seletivas a elas do que a macrófagos. Apresentaram baixa citotoxicidade em macrófagos e em hemácias, reduzindo, assim, a infecção do parasita. A Tabela 2 mostra os valores de concentração inibitória dos compostos em comparação com a Anfotericina B. Os compostos também apresentaram boa atividade anti-inflamatória e este estudo foi o primeiro a apresentar chalconas e curcuminas sintéticas, contendo apenas grupos metoxilas, com promissoras atividades leishmanicida. ${ }^{26}$

Tabela 2 - Dados de concentração inibitória dos compostos sintetizados em comparação com o fármaco Anfotericina B. ${ }^{26}$

$\mathrm{IC}_{50}(\mu \mathrm{M}) \pm \sigma_{\mathrm{m}}$




Anfotericina B

Tadigoppula e colaboradores ${ }^{25}$ realizaram um estudo investigando as atividades antimaláricas de uma série de 88 chalconas sintetizadas como análogas da chalcona Medicagenina e do derivado de chalcona Munchivarina, moléculas naturais extraídas das raízes da Crotalaria medicagenina (Figura 9), uma planta indiana com aplicações medicinais cujas atividades antimaláricas foram promissoras contra a espécie Plasmodium falciparum, protozoário causador da malária.

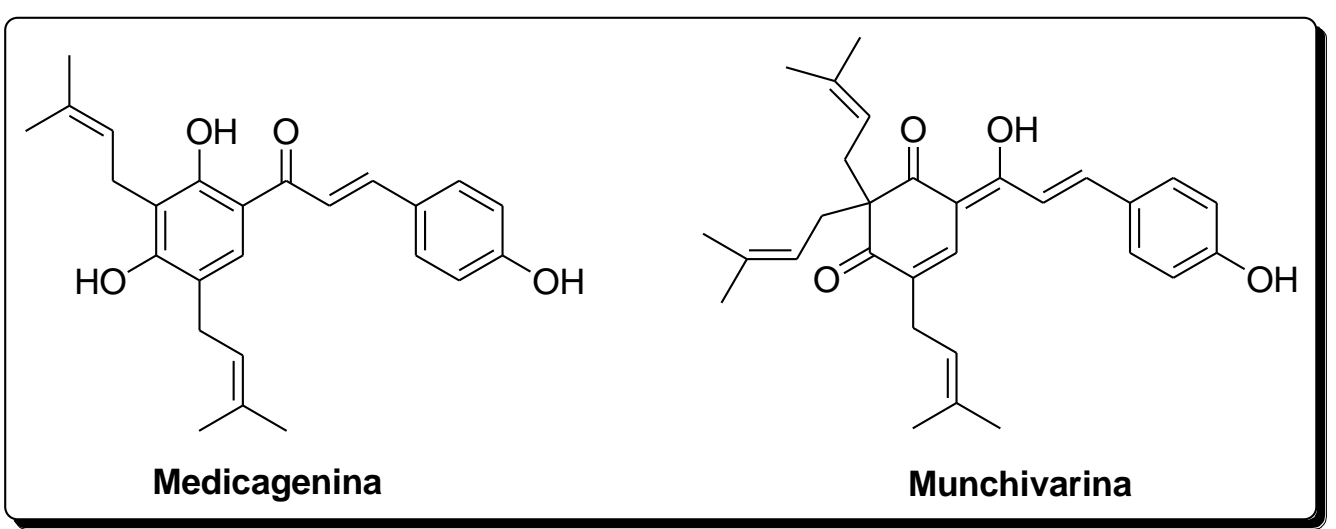

Figura 9 - Moléculas naturais extraídas das raízes da Crotalaria medicagenina com atividades antimaláricas. ${ }^{25}$

As chalconas sintetizadas se dividem basicamente em quatro grupos: chalconas preniladas, cromanochalconas, cromenochalconas e dihidrocromenochalconas (Figura 
10). Estudos in vitro e in vivo foram realizados e, de modo geral, os resultados não foram muito promissores. Contudo, diversas conclusões sobre a influência de grupos substituintes chalcônicos e a atividade antimalárica foram adquiridas, assim como alguns possíveis norteamentos do mecanismo de ação dessas moléculas no combate aos protozoários em questão. ${ }^{25}$

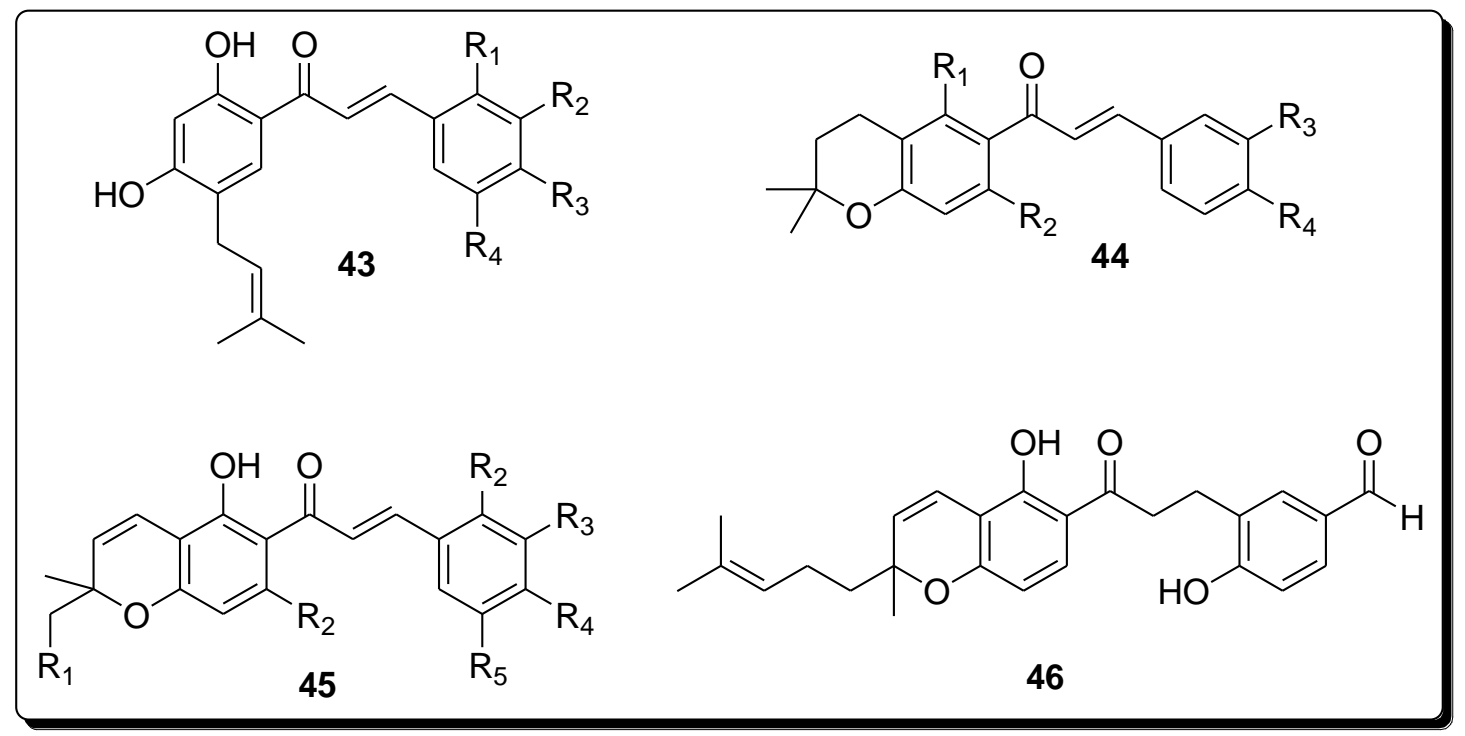

Figura 10 - Grupos de chalconas sintetizadas: chalconas preniladas (43), cromanochalconas (44), cromenochalconas (45) e dihidrocromenochalconas (46). ${ }^{25}$

Os autores concluíram que grupos substituintes, tais quais: hidroxilas e aldeídos (anel A); grupos substituintes prenilas, geranilas e com mais de 5 carbonos no anel benzopirano; aminoalquilas substituídas com grupos hidroxilas e heteroátomos na posição 3 do anel A são condições importantes no melhoramento das atividades antimaláricas de chalconas do gênero. Também sugeriram, a partir de estudos in vivo, que a degradação da hemoglobina é um dos mecanismos que conferem atividades antimaláricas a alguns dos compostos sintetizados. ${ }^{25}$

A fim de apresentar uma parte do segmento sintético-orgânico do trabalho, serão esquematizadas algumas rotas sintéticas do trabalho de Tadigoppula e colaboradores, dando enfoque na síntese dos compostos 43 e dos compostos 44.

A síntese dos compostos 43 se inicia com o composto 47, 2,4-dihidróxiacetofenona, na qual ocorre uma adição eletrofílica ao anel aromático do grupo prenila a partir do álcool 2-metil-but-3-en-2-ol, utilizando fluoreto de boro em solventes etéreos, formando o composto 48 (Esquema 13). Esta primeira etapa deu origem a três diferentes 
moléculas, incluindo a molécula com o grupo prenila na posição entre os grupos hidroxila e a molécula com o grupo em ambas as posições. Essas duas outras cetonas aromáticas preniladas deram origem a outras chalconas. Posteriormente, o composto 48 foi convertido à chalcona 49 por meio da reação de Condensação de Claisen-Schmidt. ${ }^{25}$

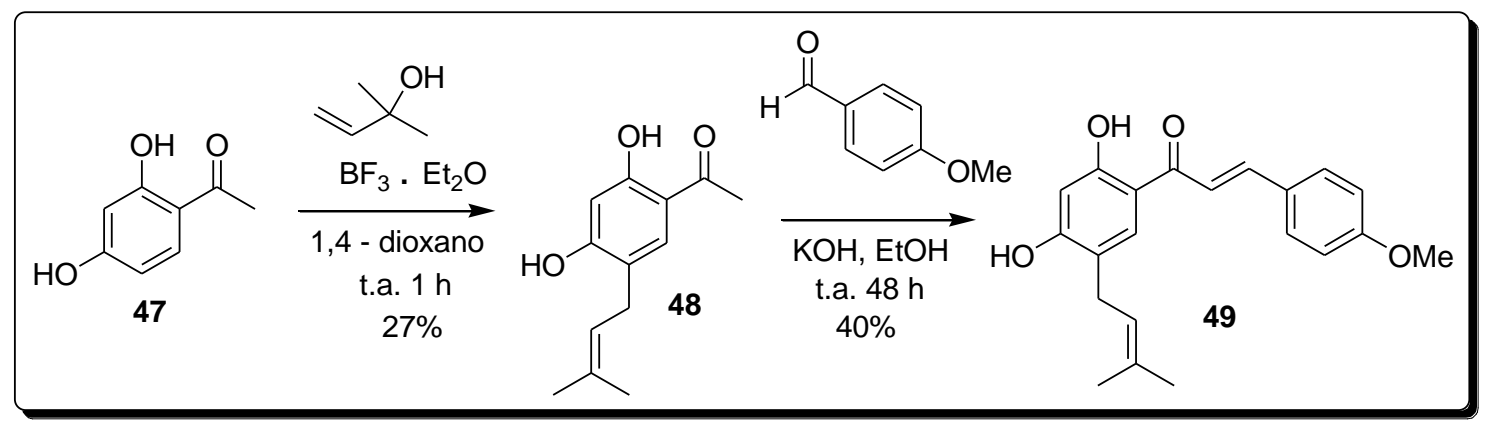

Esquema 13 - Síntese da chalcona prenilada $49 .{ }^{25}$

$\mathrm{Na}$ síntese das cromanochalconas $\mathbf{4 4}$, a cetona 47 reage com o isopreno em dietil éter e 1,4-dioxano de modo a formar o anel benzopirano por ataque nucleofílico do grupo hidroxila, na posição para à carbonila, ao eletrófilo do grupo prenila ligado ao anel após adição eletrofílica do mesmo o anel aromático, formando, assim, o composto 50. Por fim, a condensação de Claisen-Schmidt é realizada com o 4-dimetilaminobenzaldeído formando a cromanochalcona 51, cujo rendimento não se encontra no respectivo trabalho. ${ }^{25}$

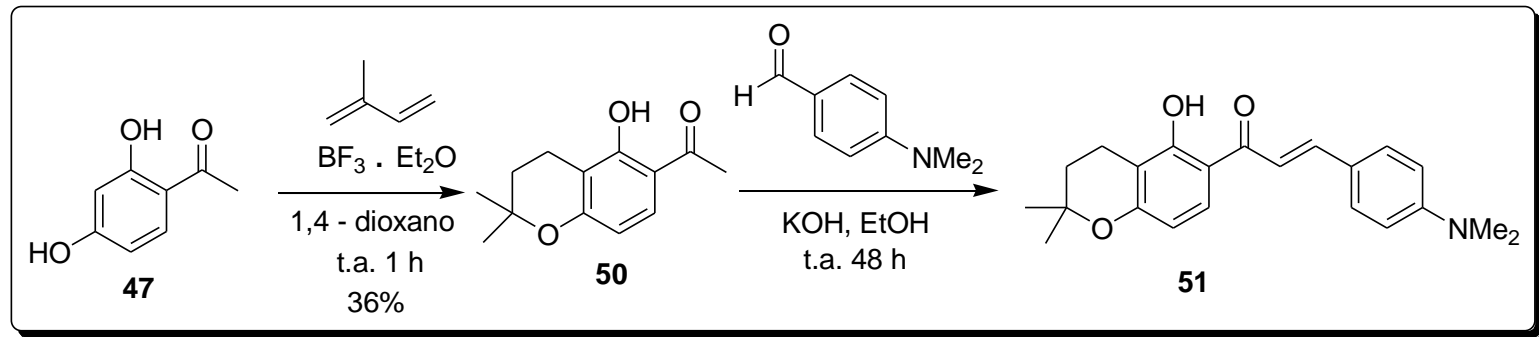

Esquema 14 - Síntese da cromanochalcona 51. ${ }^{25}$ 


\subsection{Reações Click e compostos 1,2,3-Triazólicos}

Em 2001, Sharpless ${ }^{31}$, inspirado na "sabedoria orgânico-sintética" da natureza, desenvolveu a ideia de que uma nova perspectiva na Síntese Orgânica era necessária. Uma perspectiva voltada para a preocupação ambiental e para simplicidade e otimização de processos sintéticos. Um ramo de reações orgânicas cujas moléculas são sintetizadas facilmente e, não obstante, têm grande potencial em suas atividades biológicas. Tais reações foram denominadas reações click.

Dentro do conceito da Química click, Sharpless afirma que essas reações devem ser modulares; com ampla aplicação; favorecidas termodinamicamente (> $20 \mathrm{kcal} / \mathrm{mol}$ ); com altos rendimentos; com geração mínima de subprodutos ofensivos, os quais deveriam ser retirados por métodos não cromatográficos (recristalização, destilação, filtração etc.) e com grande estereo ou regiosseletividade. As reações devem empregar condições reacionais simples, utilizar materiais de partida de fácil acesso, não empregar solventes ou empregar solventes menos tóxicos (como água, por exemplo). Além disso, os produtos devem ser estáveis em condições fisiológicas. ${ }^{31}$

A Química click, dentre as variadas reações que a compõe, tem como reações principais aquelas baseadas na formação de blocos moleculares através de reações que envolvam a formação de ligações carbono-heteroátomo. Dentre as reações que compõem esse grupo, estão as cicloadições envolvendo elétrons $\pi$, especialmente as cicloadições 1,3 dipolarares. As reações que envolvem azidas e alcinos na formação de triazóis são um forte exemplo de tais reações.

O anel 1,2,3-triazólico é uma estrutura essencialmente sintética e não é encontrado na natureza ${ }^{32}$. É formado através da cicloadição térmica entre azido compostos e alcinos levando à produção de heterociclos estáveis com caráter aromático por meio da formação de duas ligações C-N. A primeira reação deste tipo foi feita por Arthur Michael em 1893, na qual utilizou a fenil-azida e o acetilenodicarboxilato de metila (Esquema 15). ${ }^{33}$

\footnotetext{
${ }^{31}$ Kolb, H. C.; Finn, M. G.; Sharpless, K. B. Angew. Chem. Int. Ed. 2001, 40, 2004.

${ }^{32}$ Melo, J. O. F.; Donnici, C. L.; Augusti, R.; Ferreira, V. F.; Souza, M. C. B. V.; Ferreira, M. L. G.; Cunha, A. C. Quim. Nova. 2006, 29, 569.

${ }^{33}$ Michael, A. J. Prakt. Chem. 1893, 46, 94.
} 


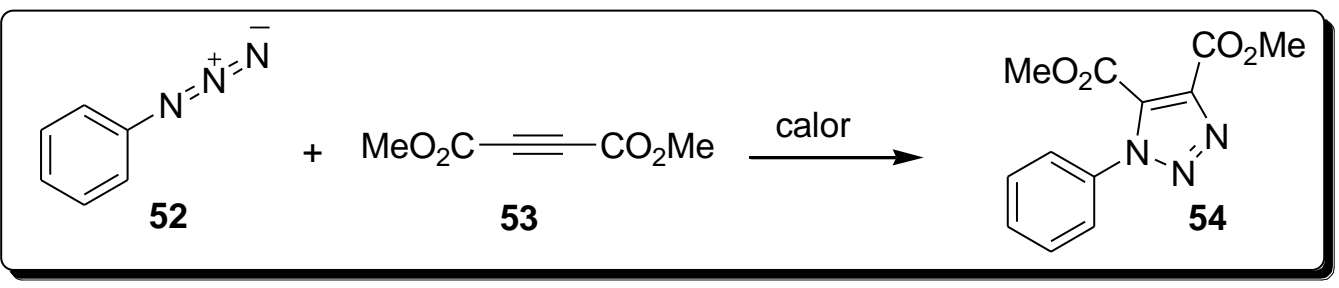

Esquema 15 - Primeira reação de 1,3-cicloadição envolvendo azida e alcino. ${ }^{33}$

Em meados do século XX, Huisgen fez diversos estudos que ampliaram o entendimento destas reações. ${ }^{34}$ Contudo, problemas com a regiosseletividade em elevadas temperaturas foram observados (Esquema 16).

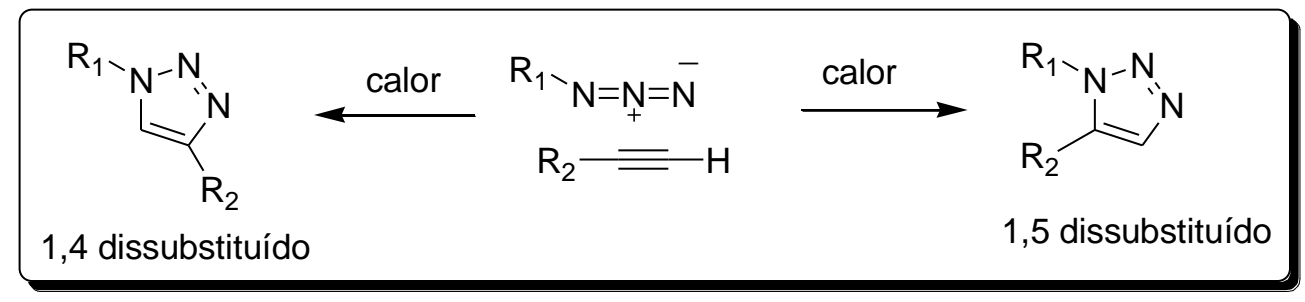

Esquema 16 - Representação geral da cicloadição de Huisgen.

Coube aos grupos de pesquisa de Sharpless ${ }^{35}$ e Meldal $^{36}$ mostrarem, concomitantemente, que sais de cobre (I) tinham a capacidade de catalisar essa reação, aumentando a taxa da reação na ordem de 7 vezes $\left(10^{7}\right)$. Observaram que a regiosseletividade era significativa e formava compostos 1,2,3-triazólicos essencialmente 1,4 dissubstituídos. Com o uso do cobre, as reações eram realizadas em condições mais brandas, levando a altos rendimentos. O êxito dessa reação de cicloadição azida-alcino catalisada por cobre (I) (CuAAC) a conferiu o status de reação click, por representar muito bem esse conceito e ser muito utilizada em Síntese Orgânica. $^{37}$

As fontes de cobre podem ser variadas, contudo, no estudo de Sharpless em $2002^{35}$, a formação in situ do cobre (I) a partir de fontes de cobre (II) se mostrou

\footnotetext{
${ }^{34}$ Huisgen, R. Pure Appl. Chem. 1989, 61, 613.

${ }^{35}$ a) Rostovtsev, V. V.; Green, L. G.; Fokin, V. V.; Sharpless, K. B. Angew. Chem. Int. Ed. 2002, 41, 2596.; b) Himo, F.; Lovell, T.; Hilgraf, R.; Rostovtsev, V. V.; Noodleman, L. Sharpless, K. B.; Fokin, V. V. J. Am. Chem. Soc. 2005, 127, 210.

${ }^{36}$ Tornfe, C. W.; Christensen, C.; Meldal, M. J. Org. Chem. 2002, 67, 3057.

${ }^{37}$ Oliveira, L. B. F.; Ruela, F. A.; Pereira, G. R.; Alves, R. B.; de Freitas, R. P.; Santos, L. J. Quim. Nova 2011, 34, 1791.
} 
bastante eficiente por meio da adição de agentes redutores como o ascorbato de sódio. Essa estratégia é benéfica também no sentido de sais de cobre (II), como o sulfato de cobre pentahidratado, serem mais baratos e mais estáveis que os sais de cobre (I). De qualquer sorte, fontes de cobre (I) também podem ser utilizadas, como por exemplo, iodeto de cobre, brometo de cobre, acetato de cobre e complexos de coordenação como: $\left[\mathrm{Cu}\left(\mathrm{CH}_{3} \mathrm{CN}\right)_{4}\right] \mathrm{PF}_{6}$ e $\left[\mathrm{Cu}\left(\mathrm{CH}_{3} \mathrm{CN}\right)_{4}\right] \mathrm{OTf}^{38}$

No que concerne o uso de solventes, a reação CuAAC pode ser realizada numa variedade de solventes, tais quais: água, álcoois, THF, DMSO, DMF, dioxano, diclorometano, piridina, dentre outros. ${ }^{35,39}$

Estudos recentes de Fokin e colaboradores ${ }^{40}$ indicam que a reação de cicloadição azida-alcino catalisada por cobre (I) (CuAAC) tem grande possibilidade de ser uma reação de segunda ordem em relação à concentração das espécies de cobre (I).

Em seus estudos, Fokin e colaboradores promoveram a reação CuAAC entre o composto 55 (benzil-azida) e o composto 56, um complexo de cobre ligado a um grupo acetileto cujo ligante é um carbeno pertencente ao grupo de carbenos $\mathrm{N}$-heterocíclicos (NHC). Para explorar melhor o real papel do cobre no mecanismo da reação, utilizaram como fonte de cobre (I) o complexo ${ }^{63} \mathrm{Cu}\left(\mathrm{CH}_{3} \mathrm{CN}\right)_{4} \mathrm{PF}_{6}$, enriquecido com o isótopo ${ }^{63} \mathrm{Cu}$. Na reação, observaram que o produto triazólico 57 obteve um enriquecimento isotópico de 50\%, o que fortalecia a ideia de que espécies intermediárias de cobre dinucleares estariam envolvidas no mecanismo das reações CuAAC (Esquema 17). ${ }^{40}$

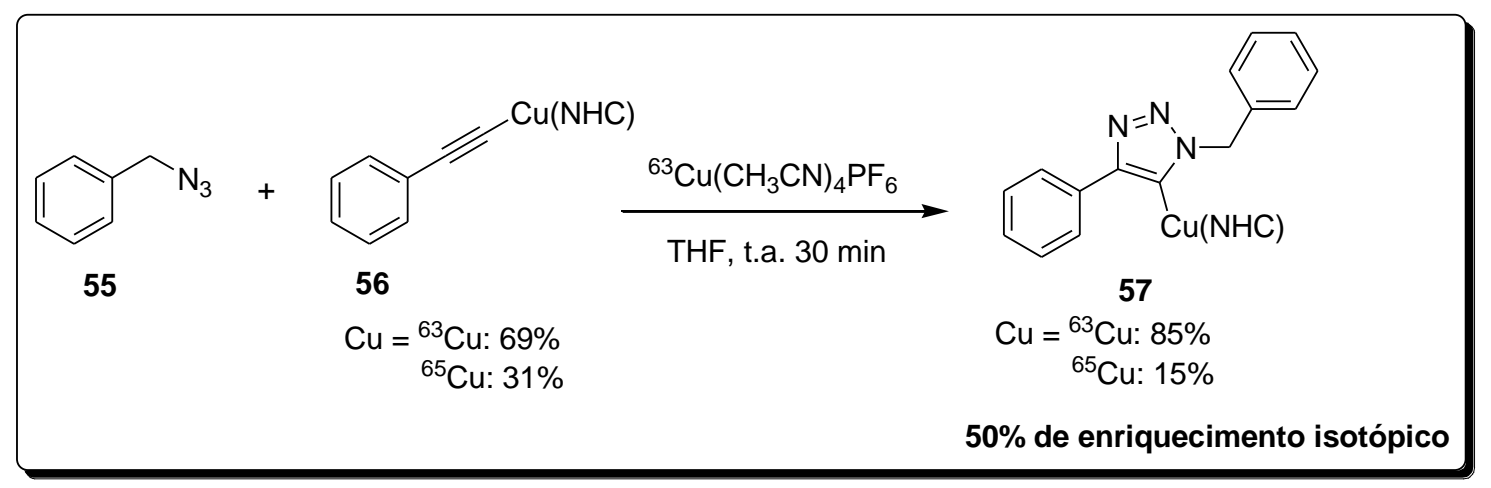

Esquema 17 - Reação CuAAC utilizando isótopos de cobre-63.

\footnotetext{
${ }^{38}$ Berg, R.; Straub, B. F Beilstein J. Org. Chem. 2013, 9, 2715

39 a) Meldal, M.; Tornoe, C. W. Chem. Rev. 2008, 108, 2952.

${ }^{40}$ Worrel, B. T.; Malik, J. A.; Fokin, V. V. Science 2013, 340, 457.
} 
Para dar mais clareza a esta hipótese, adicionaram o triazol 57 e o acetileto 56, separadamente, com quantidade equimolar de ${ }^{63} \mathrm{Cu}\left(\mathrm{CH}_{3} \mathrm{CN}\right)_{4} \mathrm{PF}_{6}$ em THF à temperatura ambiente durante 30 minutos. Como resultado, não observaram o enriquecimento isotópico das moléculas (Esquema 18), o que leva à conclusão de que um segundo átomo de cobre está envolvido no mecanismo das reações $\mathrm{CuAAC}^{40}$, pois, através dos resultados obtidos, o enriquecimento isotópico somente ocorreria nas etapas intermediárias da cicloadição, corroborando a hipótese inicial.

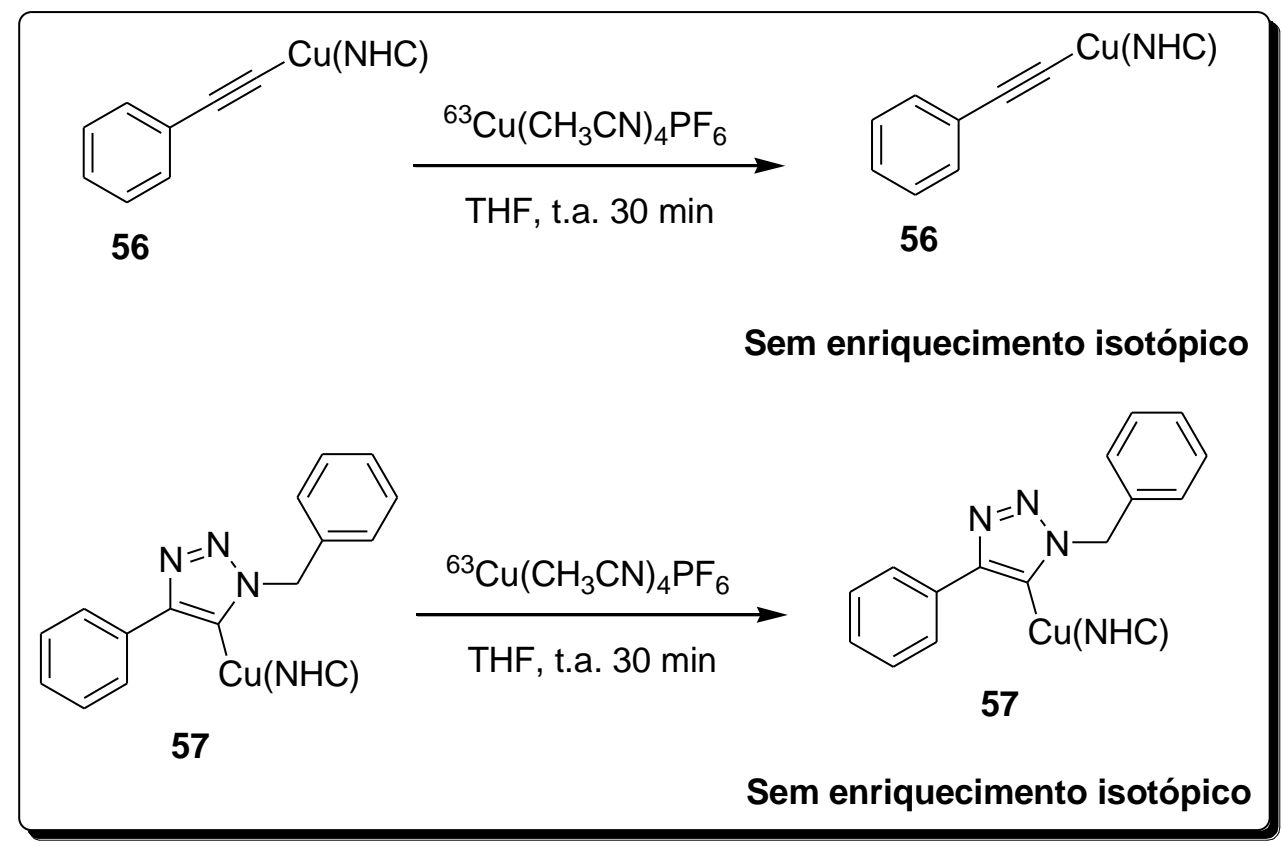

Esquema 18 - Ausência de enriquecimento isotópico nas moléculas 56 e 57.

A partir dos resultados, o grupo propôs um mecanismo que se torna mais condizente com os resultados experimentais (Esquema 19). A coordenação do sal de cobre (I) nos elétrons $\pi$ do alcino leva à diminuição do $\mathrm{pKa}$ do mesmo, tornando-o mais ácido (i). Uma consequente desprotonação ocorre, mesmo na presença de uma base fraca ou do próprio solvente, levando à formação do acetileto de cobre ii que se encontra em equilíbrio com o acetileto iii. $\mathrm{O}$ acetileto de cobre formado se complexa ao azido composto levando à formação do complexo azida-acetileto iv. A formação deste complexo faz com que o cobre, por sua vez, aumente a nucleofilicidade do átomo de nitrogênio terminal do azido composto e aumente a eletrofilicidade do carbono $\beta$ vinilidênico, promovendo, assim, o ataque nucleofílico do átomo de nitrogênio 3 ao carbono 4 , formando o intermediário metalocíclico $\mathbf{v}$, sendo esta a etapa que define a 
regioespecificidade 1,4 da reação $\mathrm{CuAAC}$. Por fim, há uma contração do metalociclo $\mathbf{v}$ com posterior formação do composto triazolila de cobre (vi - vii), o qual sofre protonação, originando o composto 1,2,3-triazólico 1,4-dissubstituído viii e $\mathrm{o}$ restabelecimento do cobre ao ciclo catalítico. ${ }^{40}$

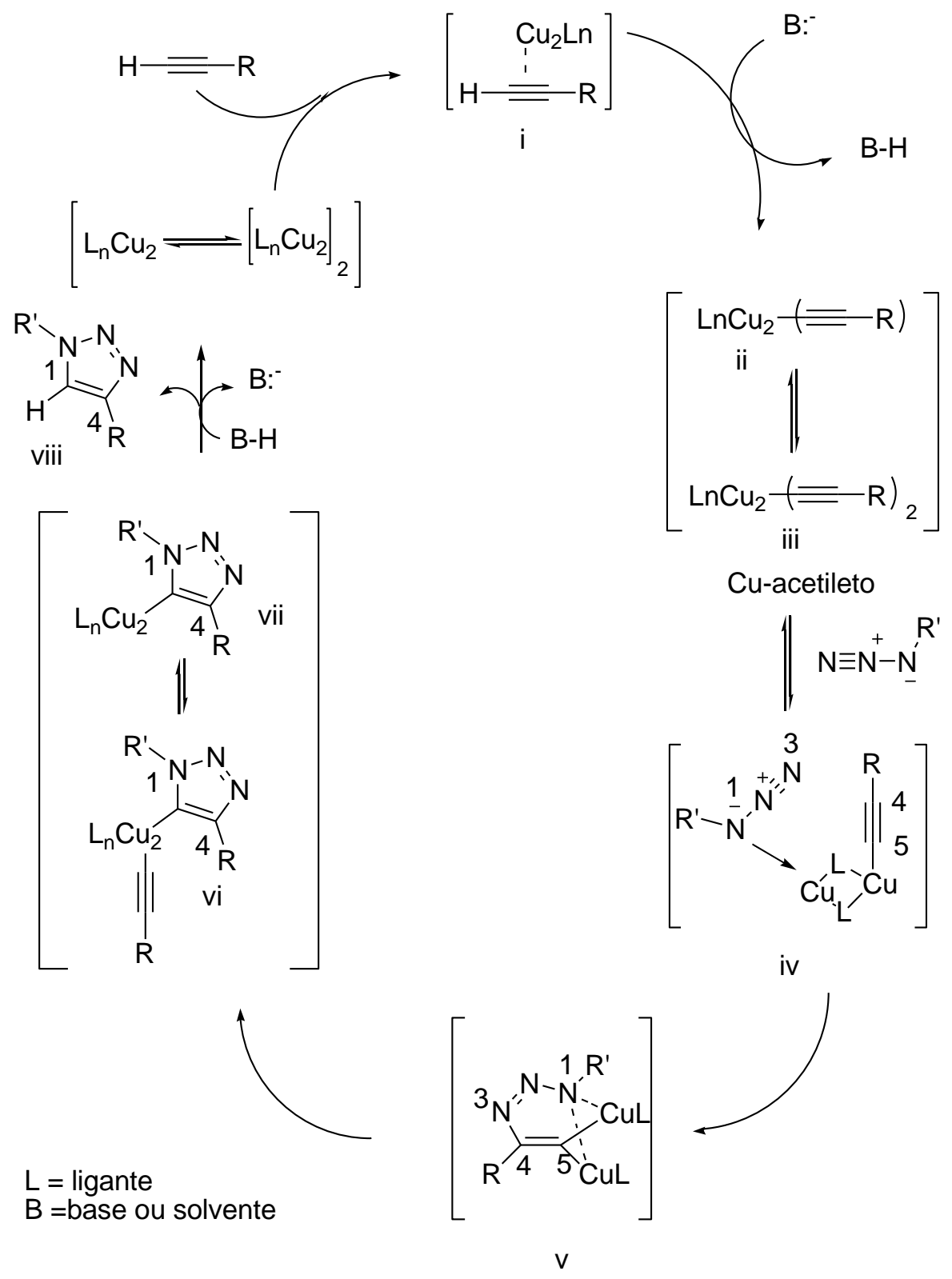

Esquema 19 - Proposta mecanística para as reações CuAAC. ${ }^{40}$

Os compostos 1,2,3-triazólicos resultantes das reações CuAAC são quimicamente estáveis em variadas condições reacionais: na presença de agentes oxidantes, redutores, hidrolíticos etc. Sua natureza química confere a ele muita 
similaridade com a função amida, portanto, são bioisósteros de ligações peptídicas e de outros núcleos, como tetrazóis e imidazóis. ${ }^{37}$

Todas essas propriedades tornam os triazóis, em geral, núcleos com grande aplicação tanto na área medicinal, quanto de ciência dos materiais. ${ }^{41}$ Alguns exemplos na área medicinal são a tazobactama sódica 58, um fármaco que tem ação inibidora da $\beta$-lactamase ${ }^{42}$ e a rufinamida 59, a qual tem ação antiepilética, ${ }^{43}$ ambas têm núcleos 1,2,3-triazólicos (Figura 11).

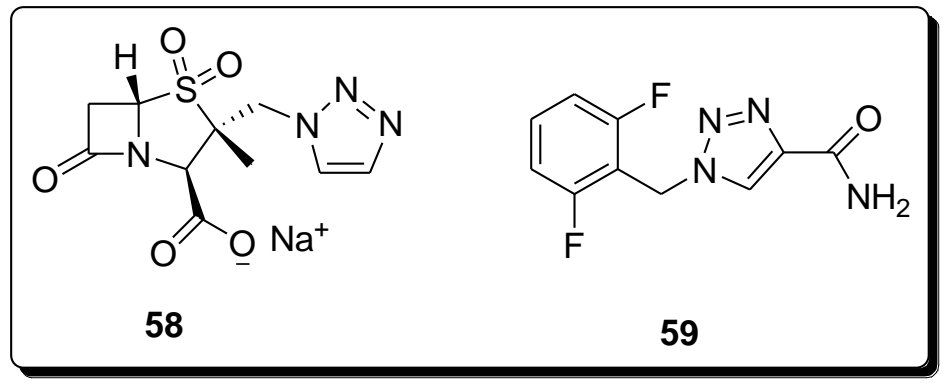

Figura 11 - Estruturas moleculares da tazobactama sódica e da rufinamida.

Reddy e colaboradores realizaram um estudo no qual modificaram a estrutura da podofilotoxina 60, uma ciclolignana muito abundante na natureza que apresenta consideráveis atividades biológicas (Figura 12). ${ }^{44}$ Como agente anticâncer, ela apresenta significativa toxicidade, contudo certos derivados seus, como a etoposida 61, representam drogas úteis no tratamento de determinados tipos de câncer.

\footnotetext{
${ }^{41}$ Hein, C. D.; Liu, X. M.; Wang, D. Pharm. Res. 2008, 25, 2216.

${ }^{42}$ Melo, J. O. F.; Donnici, C. L.; Augusti, R.; Ferreira, V. F.; de Souza, M. C. B. V.; Ferreira, M. L. G.; Cunha, A. C.; Quim. Nova 2006, 29, 569.

${ }^{43}$ Mudd, W. H.; Stevens, E. P; Tetrahedron Lett. 2010, 51, 3229

${ }^{44}$ Reddy, D. M.; Srinivas, J.; Chashoo, G.; Saxena, A. K.; Kumar, H. S. Eur. J. Med. Chem. 2011, 46, 1983.
} 


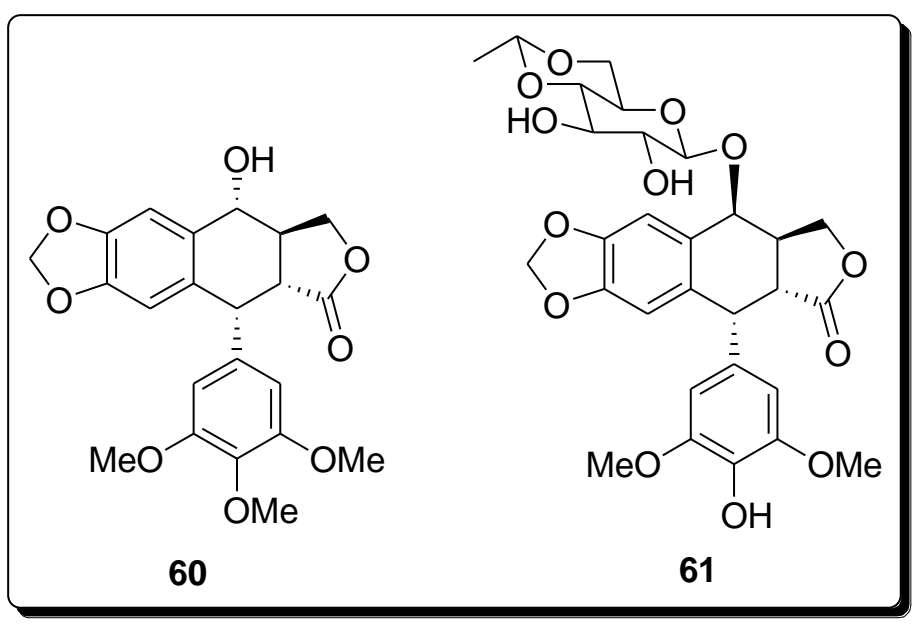

Figura 12 - Estruturas moleculares da podofilotoxina e etoposida.

O grupo sintetizou uma série de 18 derivados 1,2,3-triazólicos através de reações $\mathrm{CuAAC}$ a partir da podofilotoxina (Esquema 20) e foram obtidos resultados muito positivos quanto a sua atividade anticâncer, comparando com a atividade da etoposida em seis tipos de câncer (neuroblastoma, pulmão, mama, cólon, fígado e próstata). Todas mostraram serem moléculas pró-apoptóticas.

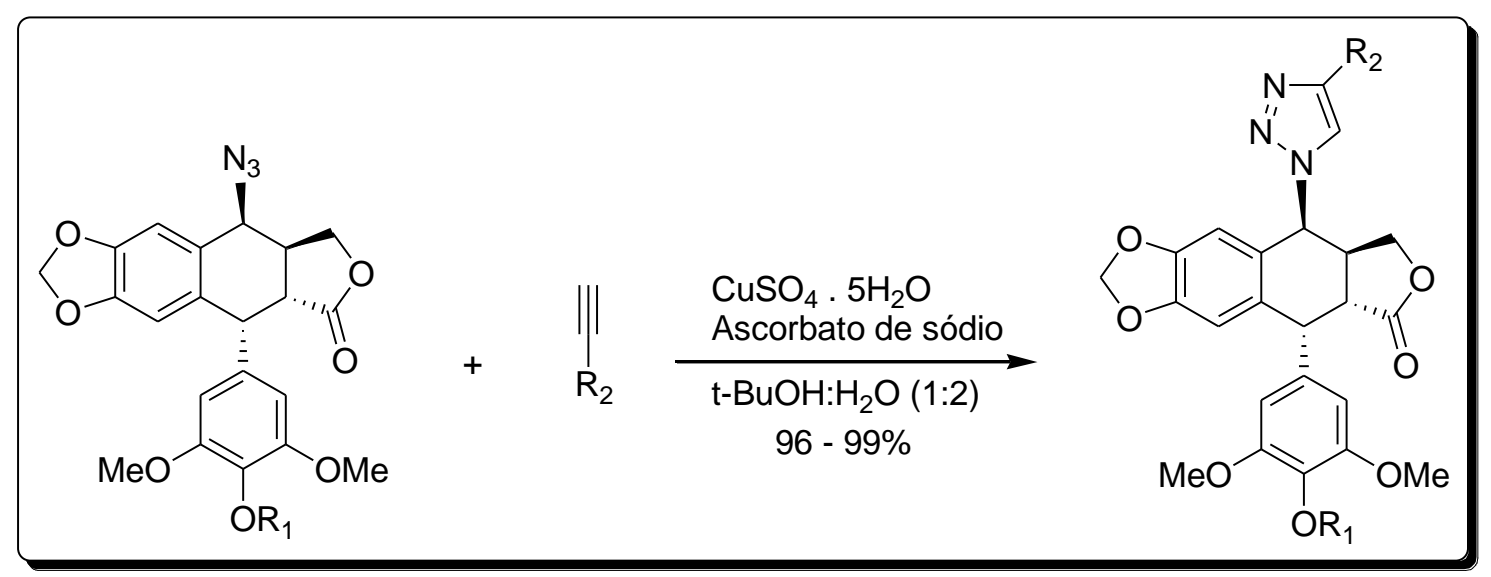

Esquema 20 - Reações click na síntese de podofilotoxinas 1,2,3-triazólicas. ${ }^{44}$ 


\subsection{Hibridização Molecular}

Uma boa estratégia para superar a resistência que determinados microorganismos adquirem aos fármacos utilizados no combate às doenças é a hibridização molecular. Ela consiste na conjugação de características estruturais definidas de compostos bioativos na formação de uma nova substância, cujas moléculas são constituídas desses diferentes compostos. ${ }^{45}$

Essa estratégia orgânico-sintética tem o potencial de gerar fármacos cada vez mais eficientes em seu uso, pois as possibilidades de hibridização são inúmeras. Redução de efeitos colaterais, multi-aplicação terapêutica e melhoria na seletividade são alguns benefícios gerados pela hibridização molecular na síntese de novos fármacos. ${ }^{46}$

Minh e colaboradores exploraram o princípio da hibridização molecular na busca de novos fármacos com atividade anticâncer. ${ }^{47}$ Eles modificaram a estrutura do AZT (azidotimidina), droga utilizada no tratamento da AIDS e de alguns tipos de cânceres, por meio de reações click (CuAAC) com chalconas e flavonoides funcionalizados com alcinos (Esquema 21). Obtiveram 28 compostos a partir de tais reações e realizaram estudos sobre suas atividades biológicas. Analisaram suas atividades anticâncer in vitro contra 5 tipos de células diferentes. De modo geral, os resultados foram satisfatórios, sendo o composto 65 o que apresentou melhor atividade anticâncer.

\footnotetext{
${ }^{45}$ Barreiro, E. J.; Fraga, C. A. M. Química Medicinal: As bases moleculares da ação dos fármacos. Artmed Editora, 2014.

${ }^{46}$ Junior, C. V.; Danuello, A.; Bolzani, V. S.; Barreiro, E. J.; Fraga, C. A. M. Curr. Med. Chem . 2007, 14, 1829.

${ }^{47}$ Van Minh, N.; Le Anh, N.; Thi Thao, D.; Khac Vu, T. Lett. Drug Des. Discov. 2014,11, 297.
} 


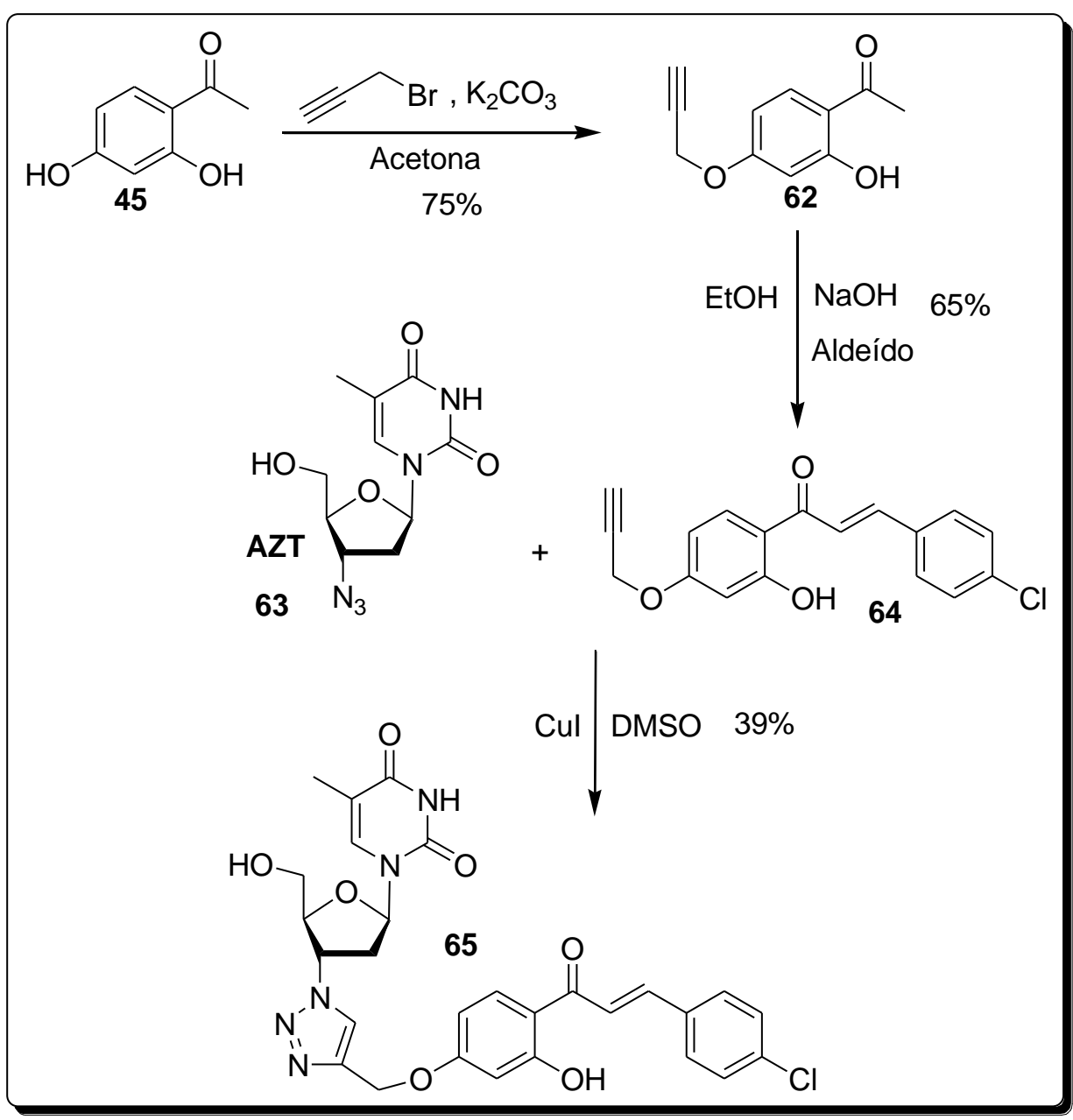

Esquema 21 - Síntese de uma molécula contendo os grupos AZT, chalcona e 1,2,3-triazol com potente atividade anticâncer. ${ }^{47}$

Bala e colaboradores exploraram a hibridização molecular na busca de fármacos com melhores atividades antibacterianas para a Mycobacterium tuberculosis, bactéria envolvida na tuberculose. ${ }^{48}$ No trabalho, sintetizaram 38 híbridos triazólicosnaftoquinônicos (Esquema 22) a partir da reação CuAAC utilizando iodeto de cobre(I) e trietilamina em água.

${ }^{48}$ Bala, B. D.; Muthusaravanan, S.; Choon, T. S.; Ali, M. A.; Perumal, S. Eur. J. Med. Chem. 2014, 85, 737. 


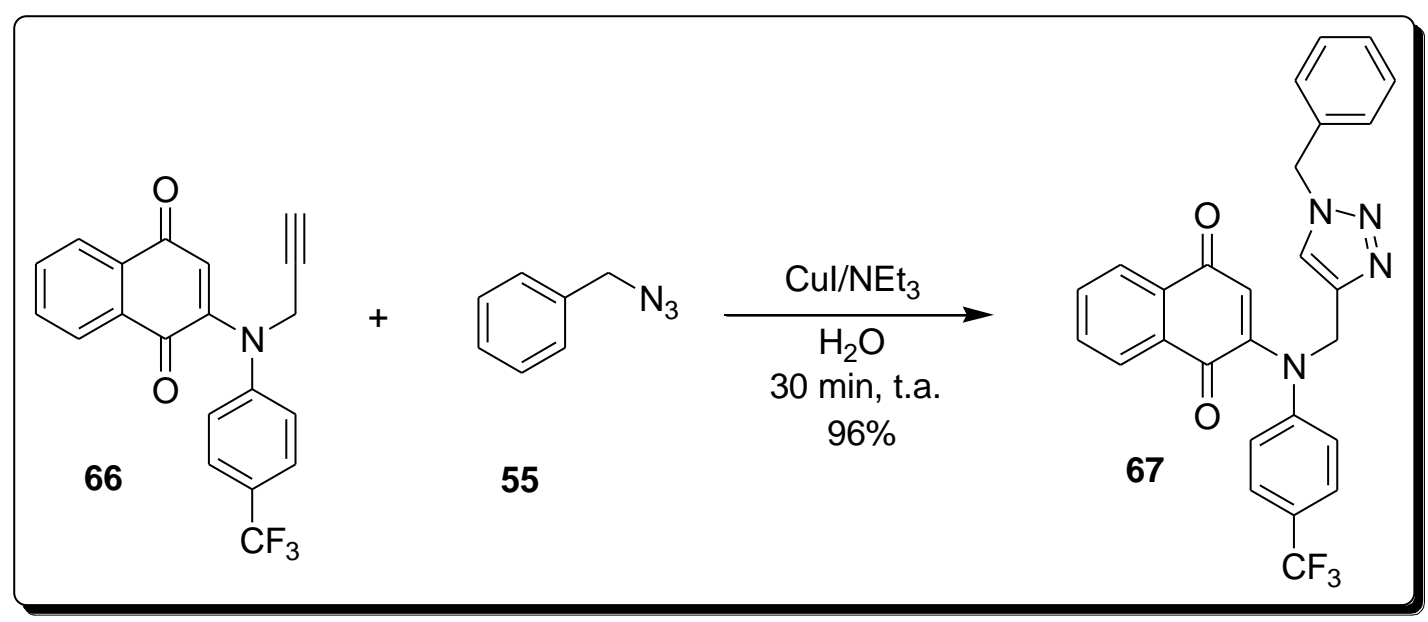

Esquema 22 - Síntese de uma molécula com núcleos naftoquinônico e 1,2,3-triazólico com grande atividade antituberculosa. ${ }^{48}$

Realizaram estudos in vitro contra a bactéria em questão e tiveram bons resultados. Uma substância em específico, composto 67, apresentou melhor atividade que as outras ${ }^{48}$, sendo mais potente que certas drogas antituberculose como a cicloserina e pirimetamina e equiparada à droga etambutol (Figura 13).<smiles>N[C@@H]1CONC1=O</smiles>

Cicloserina<smiles>CCc1nc(N)nc(N)c1-c1ccc(Cl)cc1</smiles>

Pirimetamina<smiles>CCC(CO)NCCNC(CC)CO</smiles>

Etambutol Etambutol.

Figura 13 - Estruturas moleculares dos fármacos Cicloserina, Pirimetamina e

Chinthala e colaboradores ${ }^{49}$ desenvolveram um estudo de hibridização molecular de chalconas e formação de anéis 1,2,3-triazólicos por meio de reações CuAAC (Esquema 23). Ao todo foram sintetizadas 20 moléculas híbridas. Inicialmente, sintetizaram os cromanos 68a e 68b a partir do aldeído 45 e isopreno. Os dois cromanos formaram suas respectivas chalconas através da Condensação de Claisen-Schmidt utilizando o aldeído 69b. Previamente, o aldeído 69b fora sintetizado através de reação

${ }^{49}$ Chinthala, Y.; Thakur, S.; Tirunagari, S.; Chinde, S.; Domatti, A. K.; Arigari, N. K.; Srinivas, K. V. N. S.; Alam, S.; Jonnala, K. K.; Khan, F.; Tiwari, A.; Grover, P. Euro. J. Med. Chem. 2015, 93, 564. 
de substituição nucleofílica do grupo propargila ao grupo fenólico do aldeído 69a. Por fim, as chalconas 70a participaram de reação click (CuAAC) com o azido composto com 10 diferentes grupos, originando os compostos híbridos $\mathbf{7 0 b}$ em bons rendimentos.

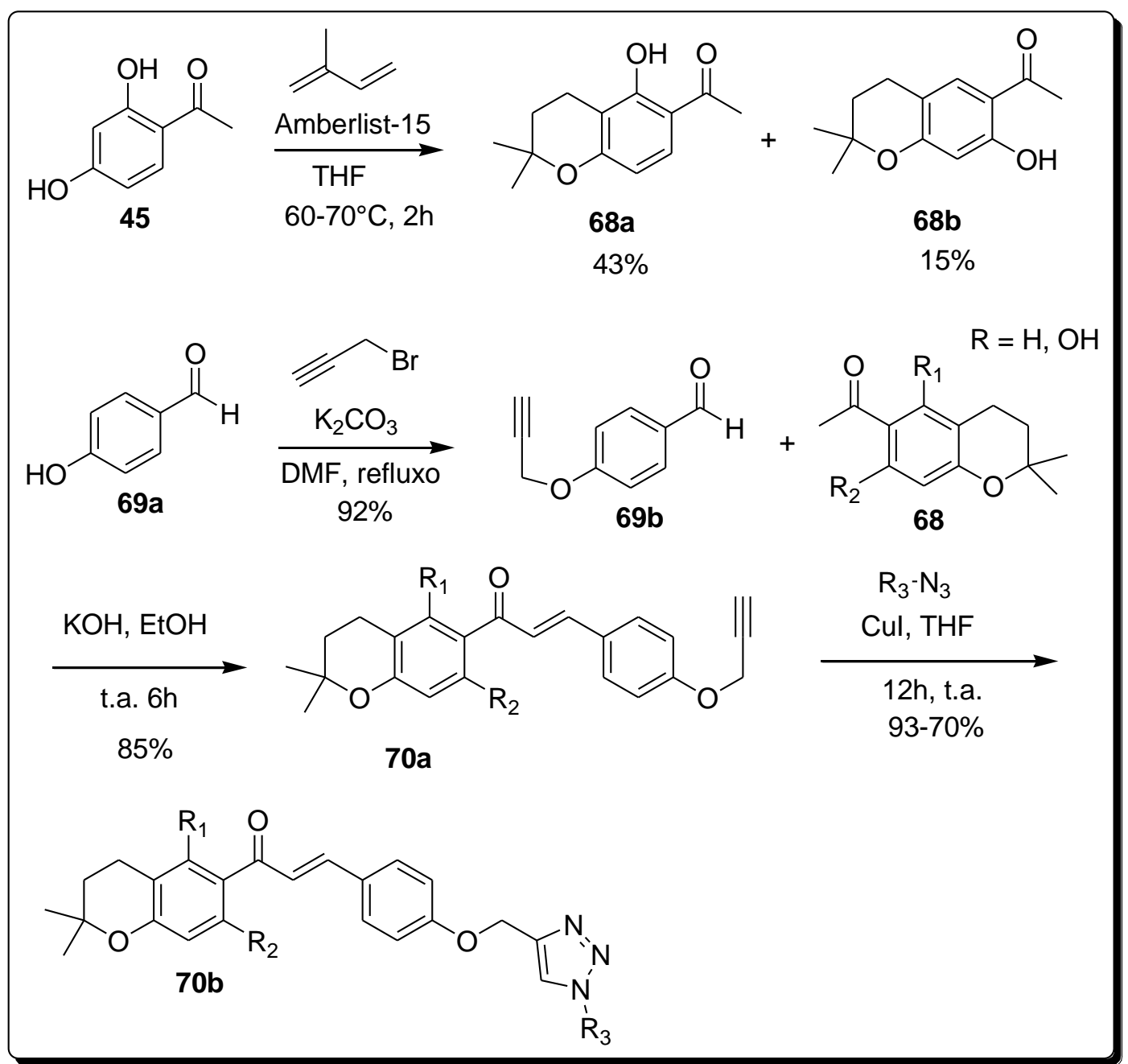

Esquema 23 - Etapas envolvidas na síntese dos compostos híbridos 70.

O grupo direcionou o estudo medicinal das moléculas híbridas sintetizadas às possíveis atividades anticâncer e antidiabetes. ${ }^{49}$ Em relação às atividades anticâncer, estudos in vitro foram realizados em 5 tipos de células diferentes (MCF-7, DU-145, IMR-32, A-549 e Hep-G2). Em geral, os resultados não foram muito satisfatórios, porém o composto híbrido $\mathbf{7 0 b}\left(\mathrm{R}_{1}=\mathrm{H}, \mathrm{R}_{2}=\mathrm{OH}\right.$ e $\mathrm{R}_{3}=4-\mathrm{NO}_{2}$-benzil) $\left(\mathrm{IC}_{50}=35,81\right.$ $\mu \mathrm{M})$ teve comportamento melhor que o padrão $\left(\mathrm{IC}_{50}=37,65 \mu \mathrm{M}\right)$ somente em relação às células do tipo A-549. ${ }^{49}$ 
A fim de se estudar as atividades antidiabetes, o grupo focou nas atividades inibitórias das moléculas em relação à $\alpha$-glucosidase, enzima importante na digestão de carboidratos, localizada no intestino delgado, cuja inibição é um importante tratamento para pacientes com diabetes mellitus do tipo $2 .{ }^{49}$ Os testes in vitro foram considerados insatisfatórios em comparação ao padrão, contudo puderam concluir que grupos com mais de 5 carbonos ligados ao anel 1,2,3-triazólico aumentavam significativamente as atividades inibitórias da $\alpha$-glucosidase das moléculas. ${ }^{49}$

Diversos outros trabalhos ${ }^{50}$ mostram como a hibridização molecular (sobretudo aquelas que envolvem triazol-chalcona e triazol-naftoquinona) é uma interessante estratégia na busca de fármacos cada vez mais eficientes no tratamento de doenças.

${ }^{50}$ a) Guantai, E. M.; Ncokazi, K.; Egan, T. J.; Gut, J.; Rosenthal, P. J.; Smith, P. J.; Chibale, K. Bioorg. Med. Chem. 2014,18, 8243.; b) Khanage, S. G.; Raju, A. S. J. Curr. Res. Sci. 2013, 1, 521.; c) Guimarães, T. T.; do Carmo, F. R. M.; Lanza, J. S.; Melo, M. N.; Rubens, L.; de Melo, I. M.; Diogo, E. B. T.; Ferreira, V. F.; Camara, C. A.; Valença, W. O.; de Oliveira, R. N.; Frézard, F.; da Silva Júnior, E. N. Eur. J. Med. Chem. 2013, 63, 523. 


\section{Objetivo}

O objetivo deste projeto é o desenvolvimento de uma rota sintética que conjugue os núcleos farmacofóricos naftoquinônico, chalcônico e triazólico em uma mesma molécula (Figura 14).

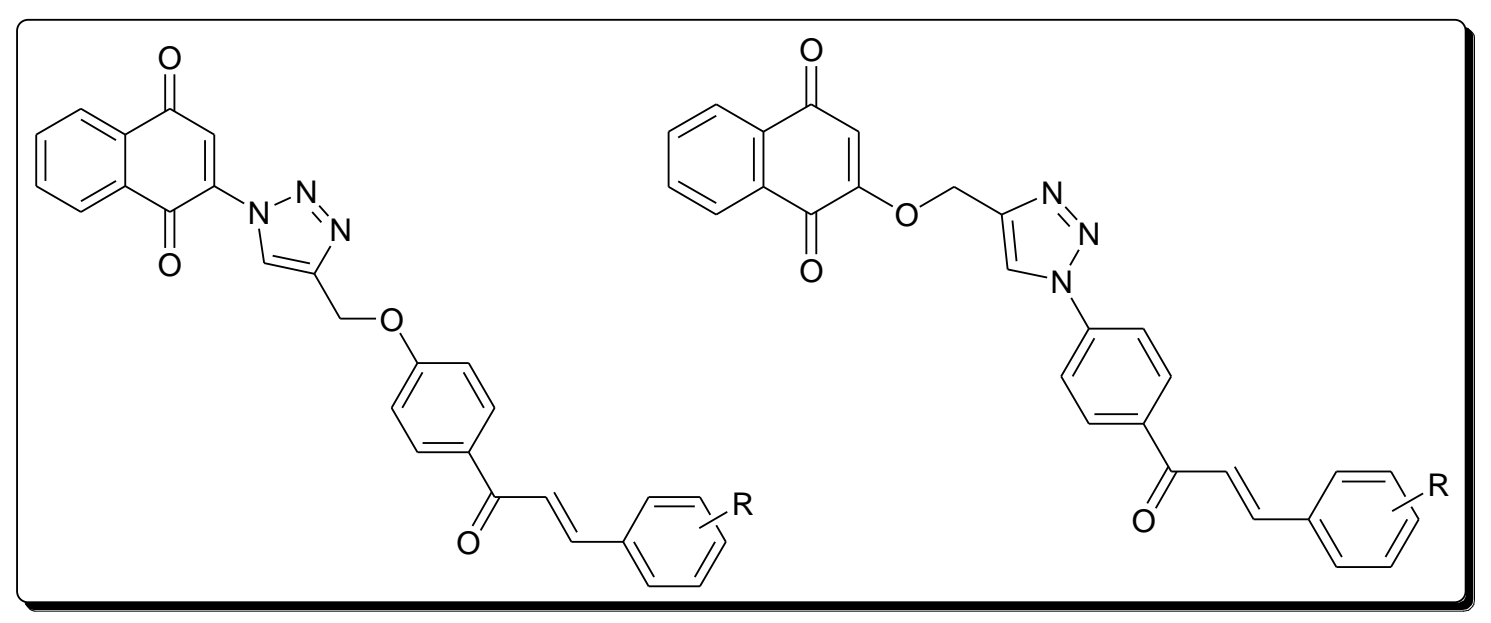

Figura 14 - Moléculas contendo os núcleos naftoquinônico, chalcônico e triazólico. 


\section{Metodologia}

O trabalho é baseado em 3 metodologias gerais que visam à síntese de moléculas que contêm os três núcleos em questão, gerando 3 grupos de moléculas distintos que detêm tais características.

A primeira metodologia geral se iniciou pela síntese do composto 2-azido-1,4naftoquinona $\mathbf{7 1}$ a partir da 2-bromo-1,4-naftoquinona 25 em uma reação de substituição nucleofílica com azida de sódio em água e etanol (Esquema 24). Paralelamente, o alcino foi formado a partir de uma hidróxi-acetofenona reagida com brometo de propargila, carbonato de potássio, em DMF, em uma reação de substituição nucleofílica. A chalcona foi, então, sintetizada a partir de um aldeído aromático e a propargiloxi-acetofenona, em uma solução de etanol e solução de hidróxido de sódio $10 \%$ em água. Tendo o alcino e o azido composto preparados, a reação click (CuAAC) foi realizada formando o anel 1,2,3-triazólico e unindo os três núcleos.

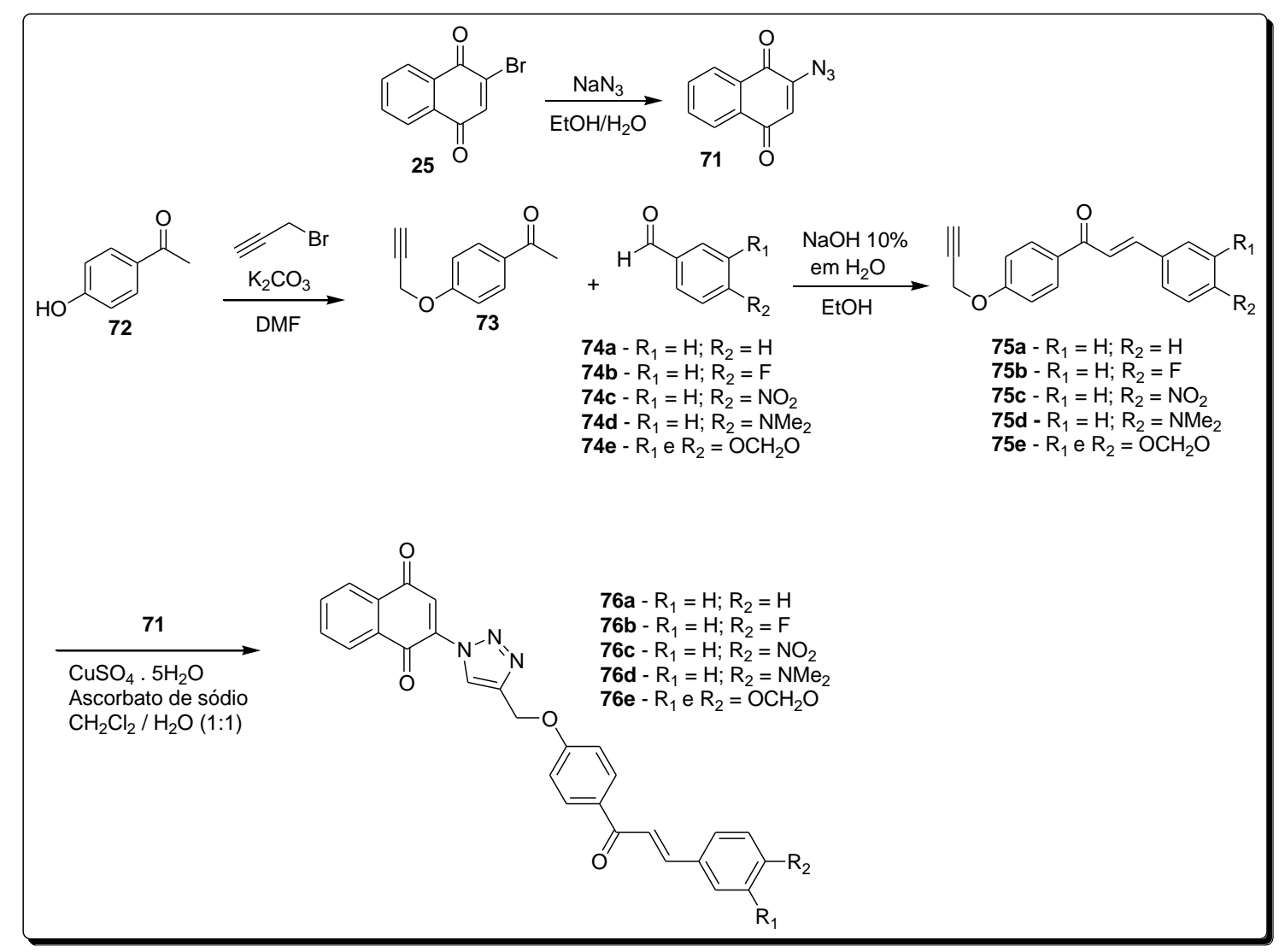

Esquema 24 - Rota sintética para a primeira metodologia geral. 
A segunda metodologia geral se baseou na utilização da Lausona 12 (2-hidroxi 1,4-naftoquinona) em uma reação de substituição nucleofílica realizada com brometo de propargila e carbonato de potássio em DMF, gerando o alcino 77 (Esquema 25). Paralelamente, um composto amino-acetofenônico foi convertido em azidoacetofenônico por meio de uma reação de diazotação e azidação utilizando azida de sódio, nitrito de sódio, ácido sulfúrico e ácido acético glacial. O composto azidoacetofenônico foi então submetido à condensação de Claisen-Schmidt na formação da respectiva chalcona, utilizando um aldeído aromático, solução de hidróxido de sódio $10 \%$ em água e etanol. O alcino e o azido composto foram submetidos à reação click (CuAAC), formando o anel 1,2,3-triazólico.

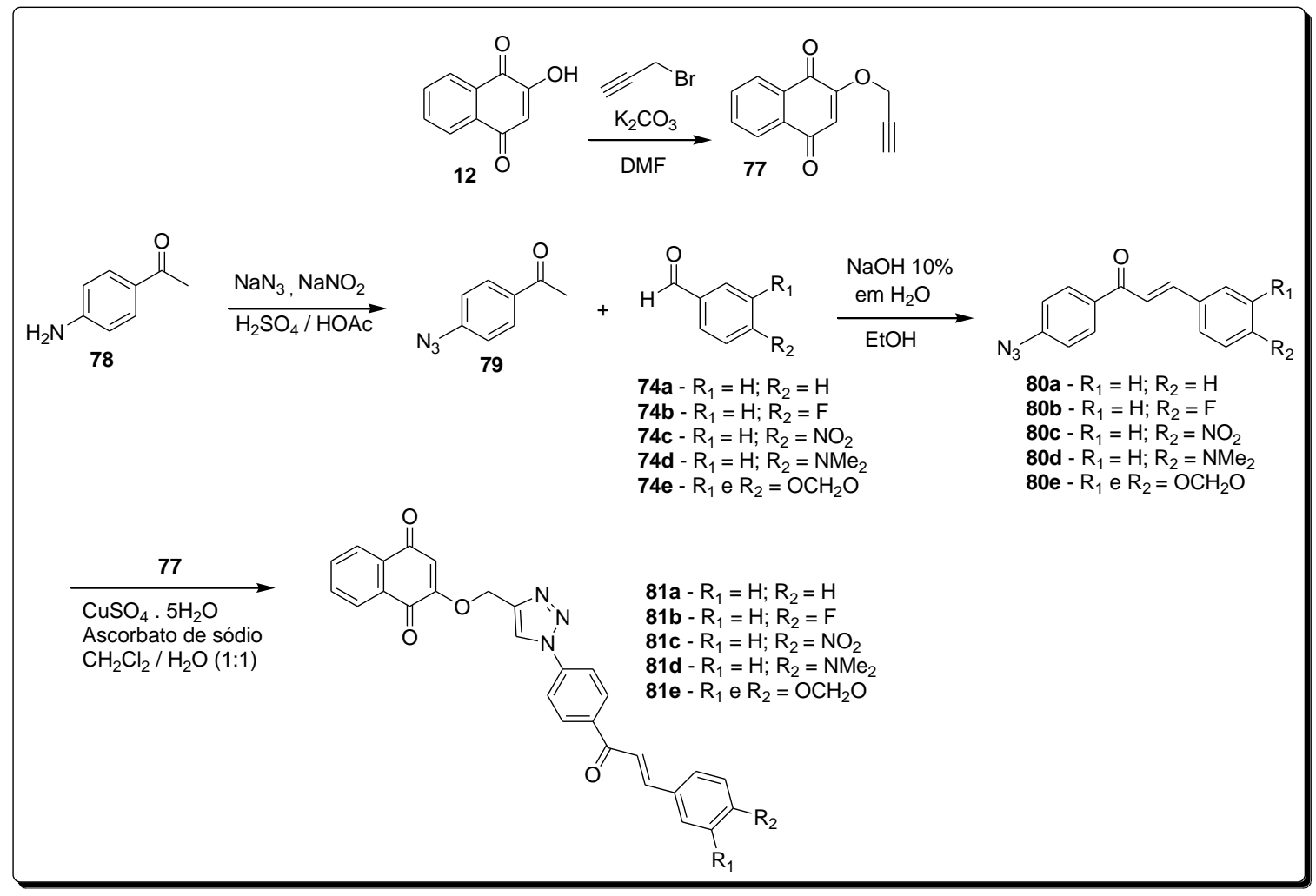

Esquema 25 - Rota sintética para a segunda metodologia geral. 


\section{Resultados e Discussão}

\subsection{Síntese da 2-azido-1,4-naftoquinona}

A metodologia de síntese da 2-azido-1,4-naftoquinona foi baseada no trabalho de Radaeva e colaboradores. ${ }^{51}$ Em um balão, foram adicionadas a 2-bromo-1,4naftoquinona (a qual já havia sido sintetizada pelo grupo em períodos anteriores em grande quantidade e armazenada apropriadamente) e a azida de sódio em etanol e água (Esquema 26). A reação foi mantida sob agitação magnética por 4 horas à temperatura ambiente. Posteriormente, o produto formado foi extraído com diclorometano, seco com sulfato de sódio anidro e evaporado. O sólido foi purificado por coluna cromatográfica com rendimento de $92 \%$ (sólido vermelho). Sua caracterização foi realizada utilizando métodos espectroscópicos de análise ( $\mathrm{RMN} \mathrm{de}{ }^{1} \mathrm{H}$ e $\left.{ }^{13} \mathrm{C}\right)$.

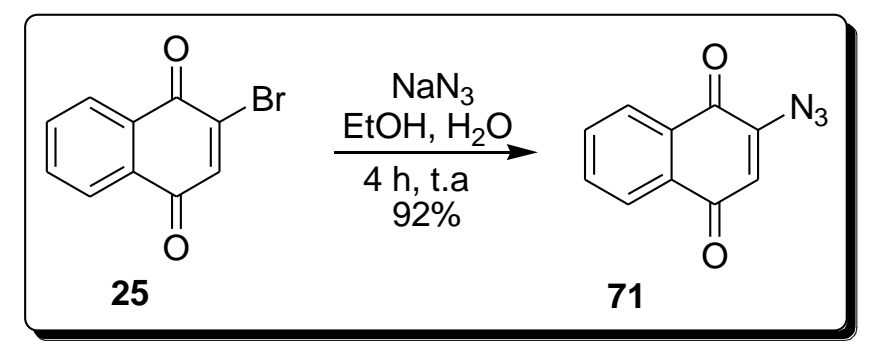

Esquema 26 - Formação da 2-azido-1,4-naftoquinona.

$\mathrm{O}$ espectro de $\mathrm{RMN}{ }^{1} \mathrm{H}$ do composto 71 apresenta na região entre 8,13 - 8,08 ppm dois dupletos de dupletos com integração de 1 hidrogênio aromático cada (a e b) (Figura 15). Apresenta também dois tripletos de dupletos na região entre 7,83 - 7,70 ppm com integração de 1 hidrogênio aromático cada (c e d). Um simpleto com integração de 1 hidrogênio aparece em torno de 6,45 ppm (e). Dados da literatura confirmam os dados obtidos do produto (Tabela 3$).^{52}$

\footnotetext{
${ }^{51}$ Radaeva, N. Y.; Dolgushina, L. V.; Sakilidi, V. T.; Gornostaev, L. M. Russ. J, Org. Chem. 2005, 41, 9267.

${ }^{52}$ Molina, P.; Pastor, A.; Vilaplana, M. J. Tetrahedron 1995, 51, 1265.
} 


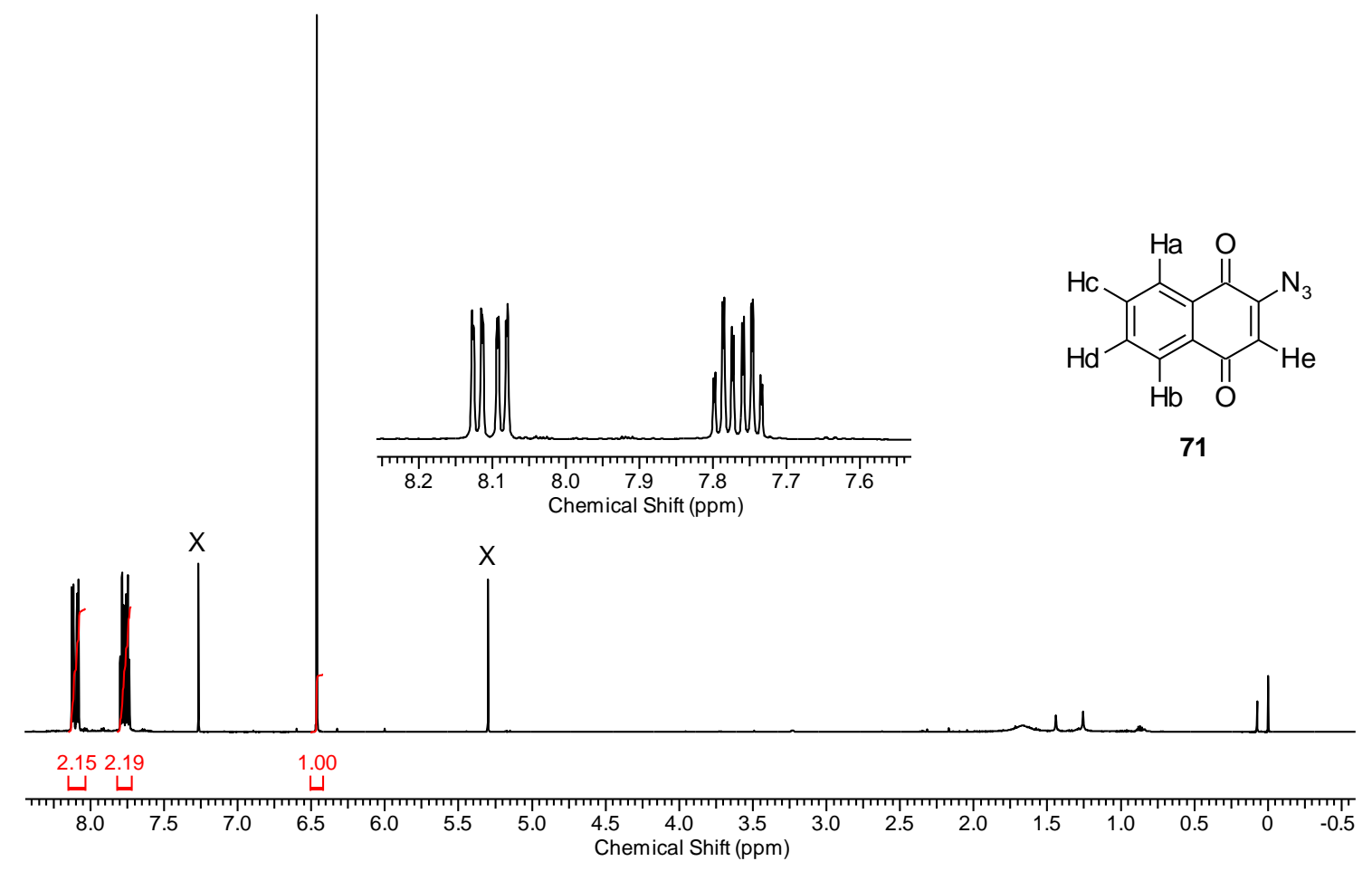

Figura 15 - Espectro de $\mathrm{RMN}{ }^{1} \mathrm{H}\left(600 \mathrm{MHz}, \mathrm{CDCl}_{3}\right)$ do composto 71.

Tabela 3 - Dados de $\mathrm{RMN}{ }^{1} \mathrm{H}\left(600 \mathrm{MHz}, \mathrm{CDCl}_{3}\right)$ do composto 71.

\begin{tabular}{ccccc}
\hline $\boldsymbol{\delta} \mathbf{h}(\mathbf{p p m})$ & $\boldsymbol{\delta}_{\mathbf{h}}(\mathbf{l i t} .)^{\mathbf{5 2}}$ & Multiplicidade & $\begin{array}{c}\text { Hidrogênios } \\
\text { Correspondentes }\end{array}$ & $\boldsymbol{J ( H z )}$ \\
\hline 8,12 & $8,09-8,05$ & dupleto de dupleto & $1 \mathrm{CH}$ aromático (a) & 7,3 e 1,1 \\
8,09 & $8,09-8,05$ & dupleto de dupleto & $1 \mathrm{CH}$ aromático (b) & 7,3 e 1,1 \\
7,79 & $7,79-7,73$ & tripleto de dupleto & $1 \mathrm{CH}$ aromático (c) & 7,3 e 1,1 \\
7,75 & $7,79-7,73$ & tripleto de dupleto & $1 \mathrm{CH}$ aromático (d) & 7,3 e 1,1 \\
6,45 & 6,45 & simpleto & $1 \mathrm{CH}$ olefínico (e) & - \\
\hline
\end{tabular}

$\mathrm{O}$ espectro de $\mathrm{RMN}$ de ${ }^{13} \mathrm{C}$ do produto apresenta 10 picos (Figura 16). Os picos em 183,7 e 180,8 ppm correspondem aos carbonos das carbonilas a e b, respectivamente. O pico em 146,3 ppm se refere ao carbono olefínico ligado ao grupo azida c. Os picos em 134,8 e 133,5 ppm são dos carbonos aromáticos d e e. Os picos em 132,2 e 131,0 ppm se referem aos carbonos aromáticos f e g. Os picos em 126,9 e 126,4 ppm correspondem aos carbonos aromáticos h e i. O pico em 120,2 ppm indica o carbono olefínico j. Dados da literatura confirmam os dados do produto (Tabela 4). ${ }^{52}$ 


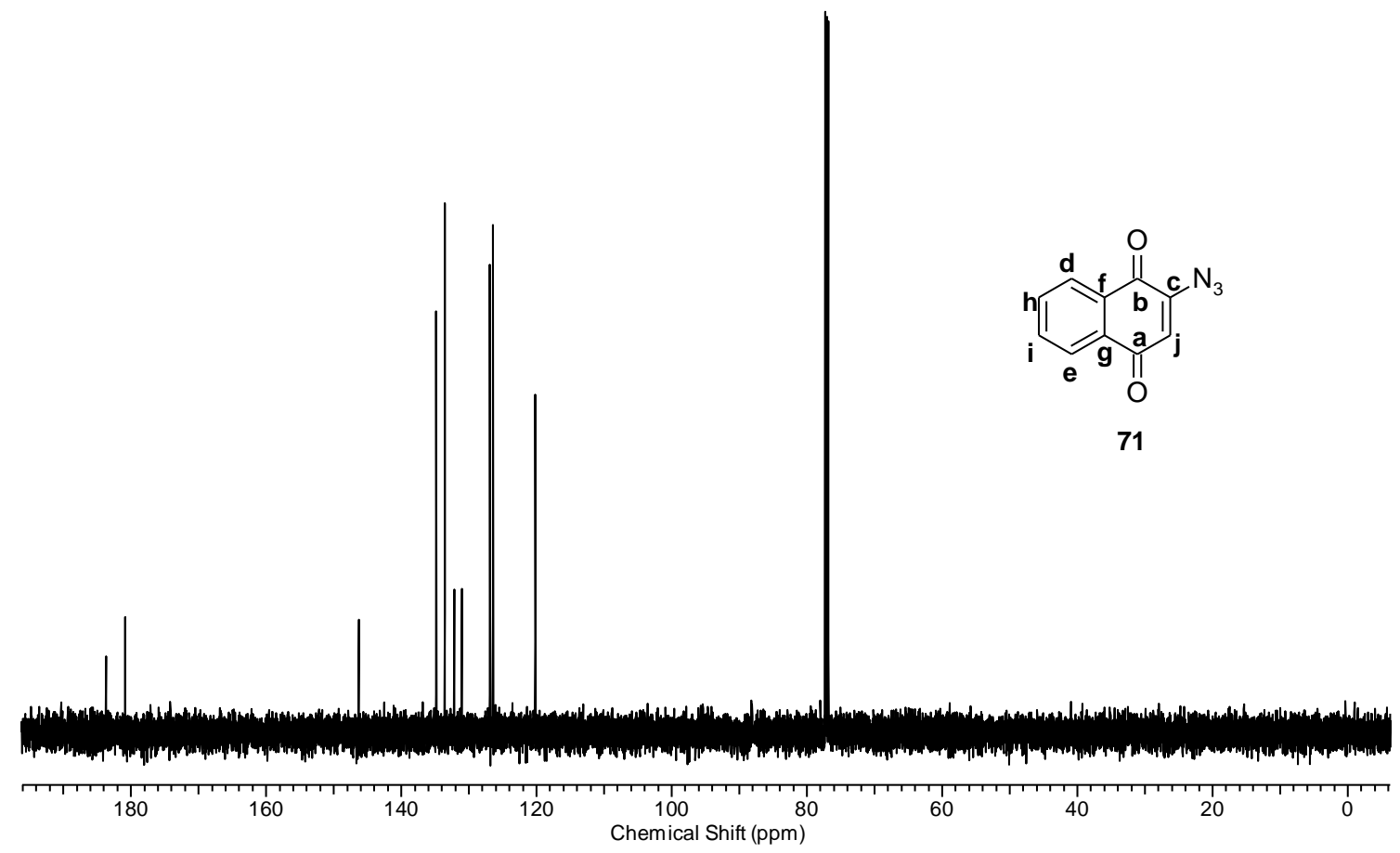

Figura 16 - Espectro de $\mathrm{RMN}{ }^{13} \mathrm{C}\left(150 \mathrm{MHz}, \mathrm{CDCl}_{3}\right)$ do composto 71.

Tabela 4 - Dados de $\mathrm{RMN}{ }^{13} \mathrm{C}\left(600 \mathrm{MHz}, \mathrm{CDCl}_{3}\right)$ do composto 71.

\begin{tabular}{ccc}
\hline $\boldsymbol{\delta} \mathbf{c}(\mathbf{p p m})$ & $\boldsymbol{\delta}_{\mathbf{c}(\mathbf{l i t})^{\mathbf{5 2}}}$ & $\begin{array}{c}\text { Carbonos } \\
\text { Correspondentes }\end{array}$ \\
\hline 183,7 & 183,6 & $\mathrm{C}=\mathrm{O}(\mathrm{a})$ \\
180,8 & 180,8 & $\mathrm{C}=\mathrm{O}(\mathrm{b})$ \\
146,3 & 146,2 & $\mathrm{C}^{-N_{3}}$ quinônico (c) \\
134,8 & 134,8 & $\mathrm{C}$ aromático (d) \\
133,5 & 133,6 & $\mathrm{C}$ aromático (e) \\
132,2 & 132,1 & $\mathrm{C}_{0}$ aromático (f) \\
131,0 & 131,0 & $\mathrm{C}$ aromático (g) \\
126,9 & 126,9 & $\mathrm{C}$ aromático (h) \\
126,4 & 126,4 & $\mathrm{C}$ aromático (i) \\
120,2 & 120,1 & $\mathrm{C}-\mathrm{H}$ quinônico (j) \\
\hline
\end{tabular}




\subsection{Síntese da 4-propargiloxi-acetofenona}

A metodologia da síntese da 4-propargiloxi-acetofenona foi baseada no trabalho de Rajakumar e colaboradores. ${ }^{53}$ Uma mistura da 4-hidróxi-acetofenona e carbonato de potássio (2 equivalentes) foi agitada à temperatura ambiente em DMF por 20 minutos. Após esse tempo, brometo de propargila foi adicionado à mistura reacional (1,5 equivalente) e a reação foi agitada por 24 horas à temperatura ambiente (Esquema 27). Após o completar da reação, água gelada foi adicionada à mistura reacional, formandose um precipitado, o qual foi extraído com diclorometano, seco com sulfato de sódio anidro e o solvente evaporado. O produto foi purificado por recristalização em metanol, gerando um sólido branco com $85 \%$ de rendimento. Sua caracterização foi através de $\mathrm{RMN}$ de ${ }^{1} \mathrm{He}^{13} \mathrm{C}$.

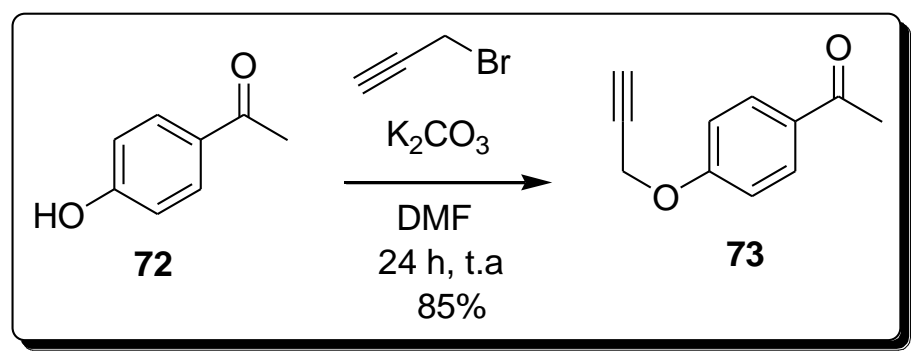

Esquema 27- Síntese da 4-propargiloxi-acetofenona.

$\mathrm{O}$ espectro de $\mathrm{RMN}{ }^{1} \mathrm{H}$ do composto 73 apresenta um dupleto em 7,95 ppm com integração de 2 hidrogênios (a) (Figura 17 e Tabela 5). Em 7,02 ppm, apresenta-se um dupleto com integração de 2 hidrogênios (b). Em 4,76 ppm, encontra-se um dupleto com integração de 2 hidrogênios (c). Na região entre 2,57-2,55 ppm, há um multipleto com integração de 4 hidrogênios (d e e). Dados da literatura confirmam os resultados obtidos. $^{54}$

\footnotetext{
${ }^{53}$ Rajakumar, P.; Raja, S. Synth. Commun. 2009, 39, 3888

${ }^{54}$ Hans, R. H.; Guantai, E. M.; Lategan, C.; Smith, P. J.; Wan, B.; Franzblau, S. G.; Gut, J.; Rosenthal, P. J.; Chibale, K. Bioorg. Med. Chem. Lett. 2010, 20, 942.
} 


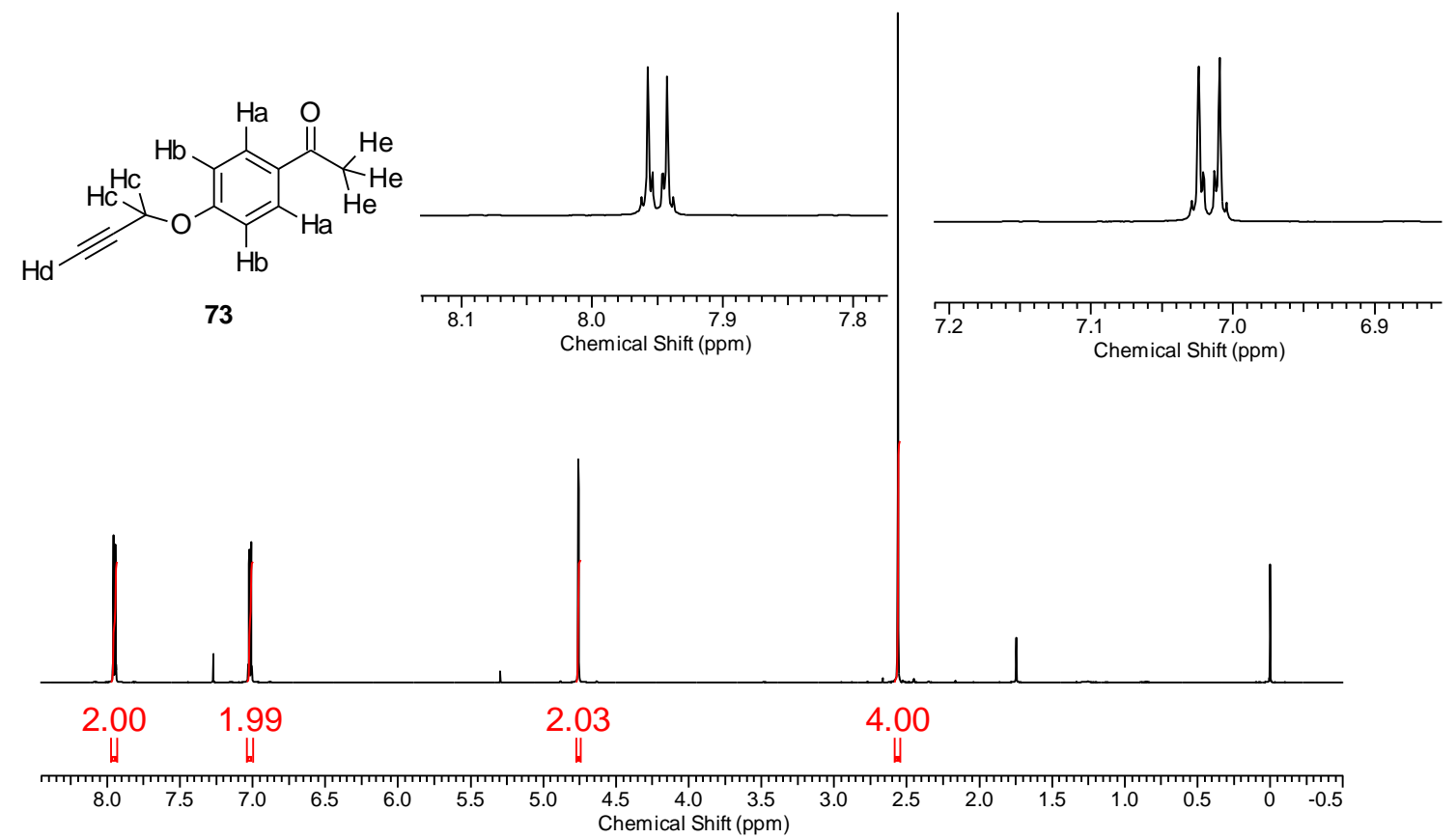

Figura 17- Espectro de $\mathrm{RMN}{ }^{1} \mathrm{H}\left(600 \mathrm{MHz}, \mathrm{CDCl}_{3}\right)$ do composto 73.

Tabela 5- Dados de $\mathrm{RMN}{ }^{1} \mathrm{H}\left(600 \mathrm{MHz}, \mathrm{CDCl}_{3}\right)$ do composto 73.

\begin{tabular}{ccccc}
\hline $\boldsymbol{\delta} \mathbf{h}(\mathbf{p p m})$ & $\boldsymbol{\delta}_{\mathbf{h}}(\mathbf{l i t} .)^{\mathbf{5 4}}$ & Multiplicidade & $\begin{array}{c}\text { Hidrogênios } \\
\text { Correspondentes }\end{array}$ & $\boldsymbol{J}(\mathbf{H z})$ \\
\hline 7,95 & 7,95 & dupleto & $2 \mathrm{CH}$ aromáticos (a) & 8,8 \\
7,02 & 7,02 & dupleto & $2 \mathrm{CH}$ aromáticos (b) & 8,8 \\
4,76 & 4,76 & dupleto & $1 \mathrm{CH}_{2}(\mathrm{c})$ & 2,6 \\
$2,57-2,55$ & 2,56 & multipleto & $1 \mathrm{CH}$ de alcino (d) & - \\
& & & terminal e $1 \mathrm{CH}_{3}(\mathrm{e})$ & \\
\hline
\end{tabular}

O espectro de RMN de ${ }^{13} \mathrm{C}$ apresenta 9 picos (Figura 18). O pico em 196,7 ppm corresponde ao carbono da carbonila (a). O pico em 161,3 ppm se refere ao carbono aromático ligado ao oxigênio do grupo propargiloxi (b). Em 131,1 ppm se encontra o pico referente ao carbono aromático ligado ao grupo carbonila (c). Em 130,5 ppm aparece o pico correspondente aos carbonos aromáticos $\mathbf{d}$. Os carbonos aromáticos e se encontram no pico em 114,6 ppm. Os picos em 77,8 ppm e 76,2 ppm são referentes aos carbonos $\mathbf{g}$ e $\mathbf{h}$ do grupo alcino, respectivamente. Em 55,8 ppm, tem-se o pico do grupo metileno (f). Por fim, em 26,4 ppm, encontra-se o pico relativo ao grupo metila (i) (Tabela 6). Dados da literatura confirmam os resultados. ${ }^{54}$ 


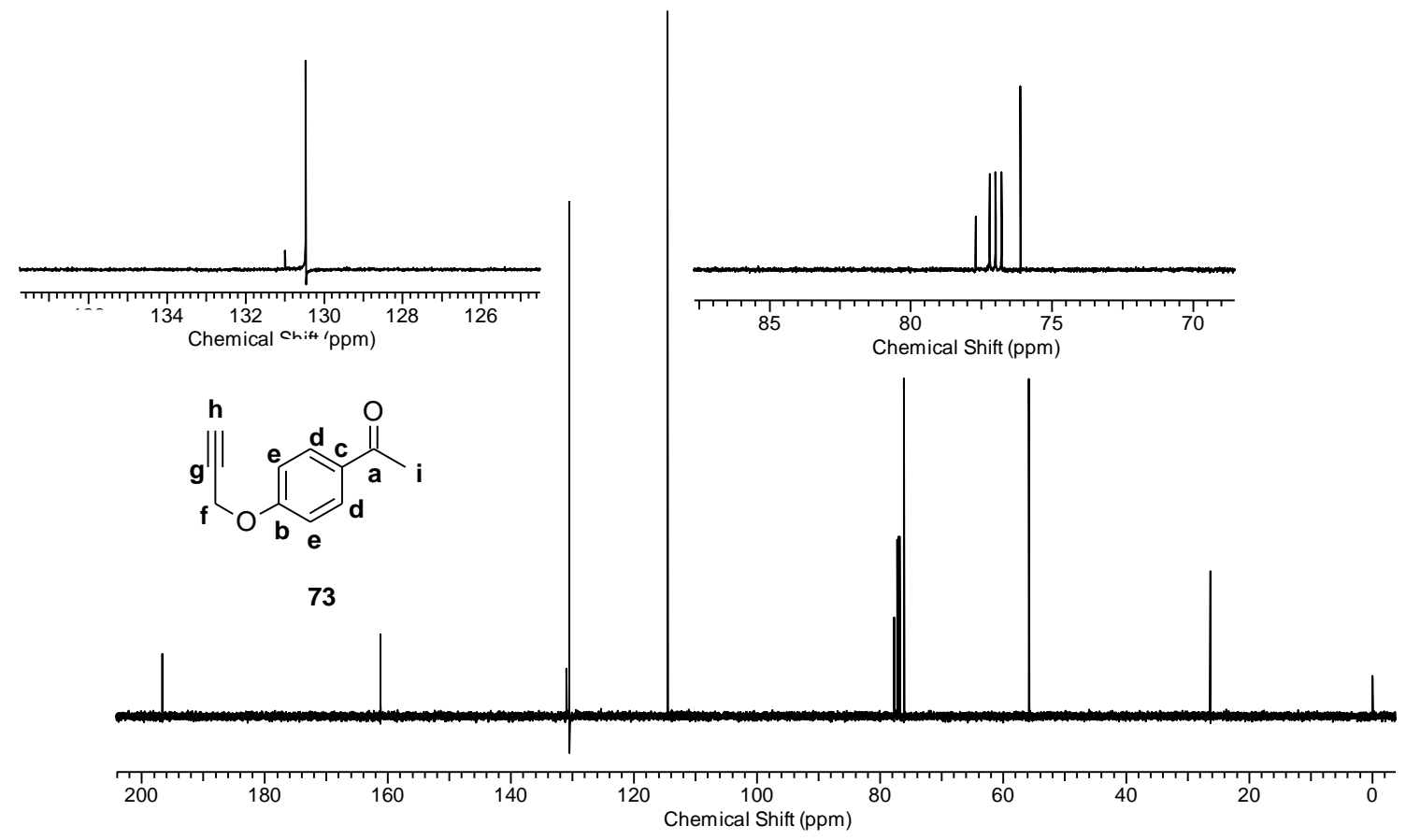

Figura 18- Espectro de $\mathrm{RMN}{ }^{13} \mathrm{C}\left(150 \mathrm{MHz}, \mathrm{CDCl}_{3}\right)$ do composto 73.

Tabela 6- Dados de $\mathrm{RMN}{ }^{13} \mathrm{C}\left(150 \mathrm{MHz}, \mathrm{CDCl}_{3}\right)$ do composto 73.

\begin{tabular}{ccc}
\hline $\boldsymbol{\delta} \mathbf{c}(\mathbf{p p m})$ & $\boldsymbol{\delta}_{\mathbf{c}(\mathbf{l i t} .)^{\mathbf{5 4}}}$ & $\begin{array}{c}\text { Carbonos } \\
\text { Correspondentes }\end{array}$ \\
\hline 196,7 & 196,6 & $\mathrm{C}=\mathrm{O}(\mathrm{a})$ \\
161,3 & 161,3 & $\mathrm{C}_{0}$ aromático (b) \\
131,1 & 131,1 & $\mathrm{C}_{0}$ aromático (c) \\
130,5 & 130,5 & $\mathrm{C}$ aromático (d) \\
114,6 & 114,6 & $\mathrm{C}$ aromático (e) \\
77,8 & 77,8 & $\mathrm{C} \equiv \mathrm{C}(\mathrm{g})$ \\
76,2 & 76,1 & $\mathrm{C} \equiv \mathrm{C}(\mathrm{h})$ \\
55,8 & 55,9 & $\mathrm{CH}(\mathrm{f})$ \\
26,4 & 26,3 & $\mathrm{CH}_{3}(\mathrm{i})$ \\
\hline
\end{tabular}




\subsection{Síntese das Chalconas 75}

A metodologia da síntese das chalconas 75a-e foi baseada no trabalho de Silva e colaboradores (Esquema 28) ${ }^{19}$. Em um balão foram adicionados a 4-propargiloxiacetofenona, solução de hidróxido de sódio (2 equivalentes) $10 \%$ em água e etanol à temperatura ambiente por $20 \mathrm{~min}$. Posteriormente, os respectivos aldeídos 74a-e (devidamente purificados) foram adicionados à mistura reacional, a qual foi agitada por 24 horas à temperatura ambiente.

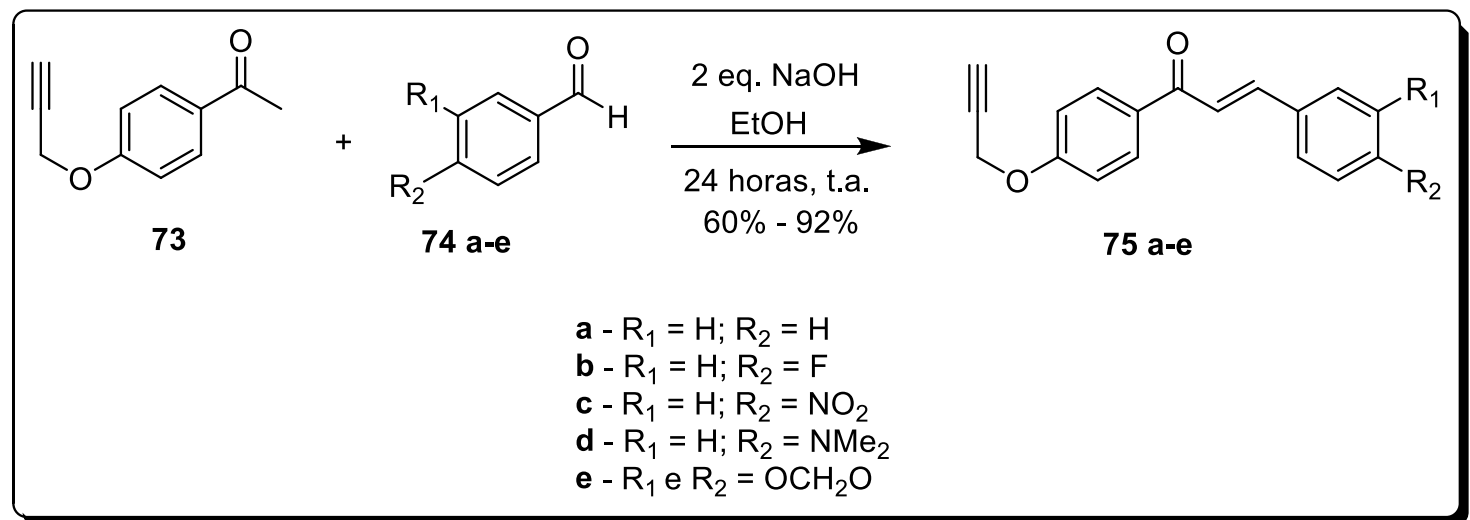

Esquema 28 - Síntese das chalconas 75.

$\mathrm{Na}$ síntese da chalcona 75a foi necessária a extração do produto com diclorometano, secagem com sulfato de sódio anidro e evaporação. O sólido foi purificado por recristalização em acetona, gerando um sólido amarelo claro com $60 \%$ de rendimento.

Na síntese das chalconas $\mathbf{7 5 b}-\mathbf{e}$, houve precipitação dos sólidos ao término da reação. Logo, os produtos foram simplesmente filtrados e lavados com etanol gelado (com exceção da chalcona 75d, a qual foi lavada com éter dietílico gelado), conferindo altos rendimentos e pureza.

A caracterização dos produtos se deu através de espectros de $\mathrm{RMN}$ de ${ }^{1} \mathrm{He}{ }^{13} \mathrm{C}$. Para elucidação dos espectros em questão, será utilizado o composto 75c como exemplo, as demais chalconas apresentam espectros de semelhante elucidação e entendimento.

O espectro de RMN de ${ }^{1} \mathrm{H}$ do composto $75 \mathrm{c}$ apresenta um dupleto em 8,29 ppm com integração de 2 hidrogênios, correspondente aos hidrogênios aromáticos a (Figura 19). Em 8,22 ppm, encontra-se um dupleto com integração de 2 hidrogênios correspondente aos hidrogênios aromáticos b. Em 8,17 ppm se apresenta um dupleto 
com integração de 2 hidrogênios referente aos hidrogênios aromáticos c. Um dupleto com integração de 1 hidrogênio se encontra em 8,14 ppm, o qual se refere ao hidrogênio olefínico d. Em 7,79 ppm, se apresenta um dupleto com integração de 1 hidrogênio, correspondente ao hidrogênio olefínico e. Um dupleto com integração de 2 hidrogênios se encontra em 7,17 ppm e este pico corresponde aos hidrogênios aromáticos f. Em 4,96 ppm, encontra-se um dupleto com integração de 2 hidrogênios referente ao grupo metileno g. Por fim, em 3,64 ppm, apresenta-se um tripleto com integração de 1 hidrogênio que corresponde ao hidrogênio do alcino terminal h. Dados da literatura confirmam os resultados obtidos (Tabela 7). ${ }^{55}$

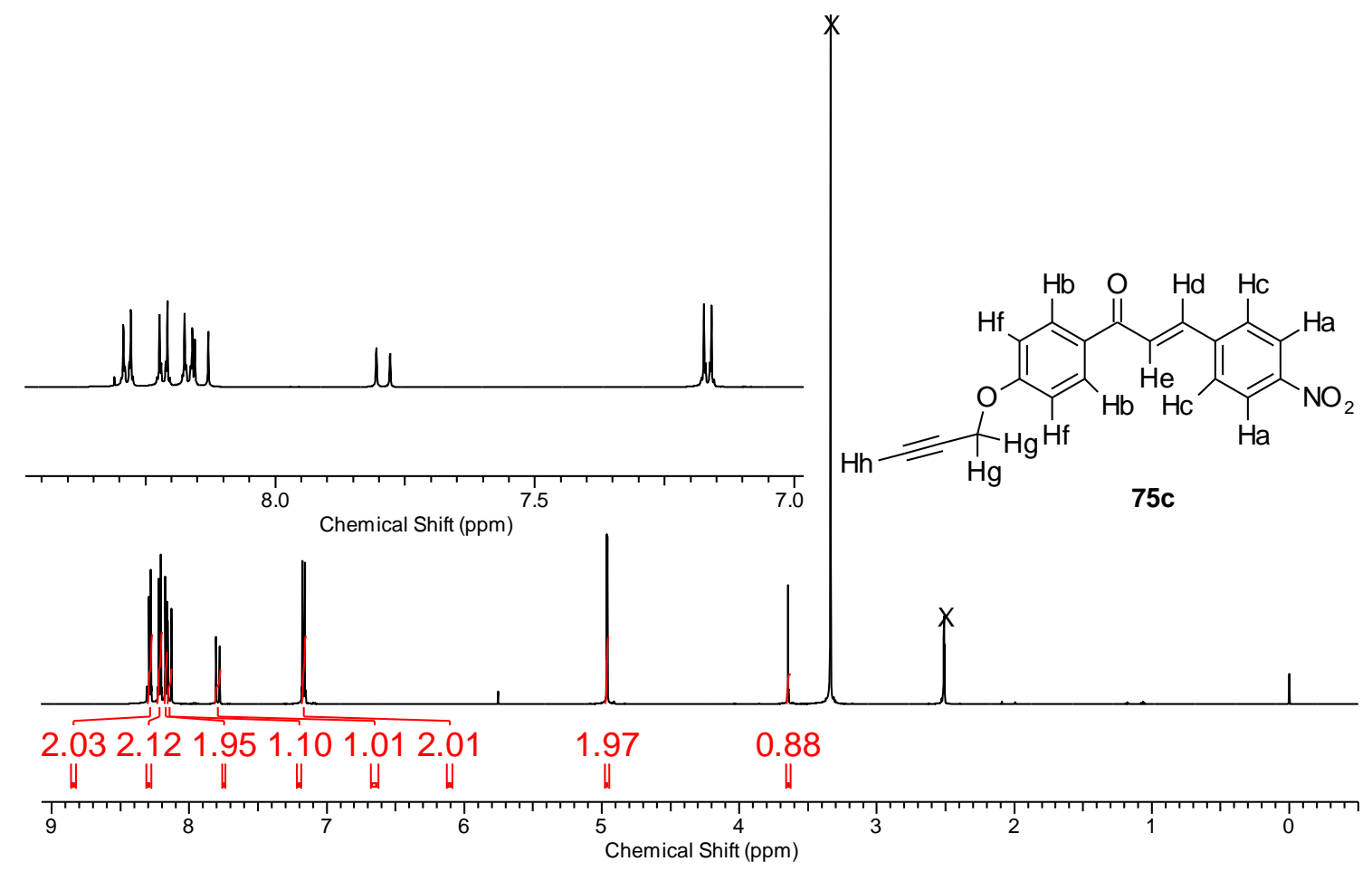

Figura 19 - Espectro de RMN ${ }^{1} \mathrm{H}\left(600 \mathrm{MHz}, \mathrm{DMSO}-d_{6}\right)$ do composto 75c.

${ }^{55}$ Zhao, L.; Mao, L.; Hong, G.; Yang, X.; Liu, T. Bioorg. Med. Chem. Lett. 2015, 25, 2540. 
Tabela 7 - Dados de RMN ${ }^{1} \mathrm{H}\left(600 \mathrm{MHz}\right.$, DMSO- $\left.d_{6}\right)$ do composto 75c.

\begin{tabular}{ccccc}
\hline $\boldsymbol{\delta} \mathbf{h}(\mathbf{p p m})$ & $\boldsymbol{\delta}_{\mathbf{h}}(\mathbf{l i t} .)^{\mathbf{5 5}}$ & Multiplicidade & $\begin{array}{c}\text { Hidrogênios } \\
\text { Correspondentes }\end{array}$ & $\boldsymbol{J}(\mathbf{H z})$ \\
\hline 8,29 & 8,30 & dupleto & $2 \mathrm{CH}$ aromáticos (a) & 8,8 \\
8,22 & 8,22 & dupleto & $2 \mathrm{CH}$ aromáticos (b) & 9,2 \\
8,17 & 8,18 & dupleto & $2 \mathrm{CH}$ aromáticos (c) & 8,8 \\
8,14 & 8,16 & dupleto & 1 CH olefínico (d) & 15,8 \\
7,79 & 7,79 & dupleto & 1 CH olefínico (e) & 15,8 \\
7,17 & 7,17 & dupleto & 2 CH aromáticos (f) & 9,2 \\
4,96 & 4,97 & dupleto & 1 CH $(\mathrm{g})$ & 2,6 \\
3,64 & 3,67 & tripleto & 1 CH de alcino (h) & 2,6 \\
\hline
\end{tabular}

O espectro de RMN de ${ }^{13} \mathrm{C}$ do composto $75 \mathrm{c}$ apresenta 14 picos (Figura 20). O pico em 187,2 ppm corresponde ao carbono da carbonila. Os picos entre 161,3 - 114,9 ppm representam os carbonos aromáticos e os da ligação dupla conjugada. Os picos em 78,7 ppm e 78,6 ppm correspondem aos carbonos do alcino terminal. Por fim, o pico em $55,8 \mathrm{ppm}$ representa o grupo metileno.

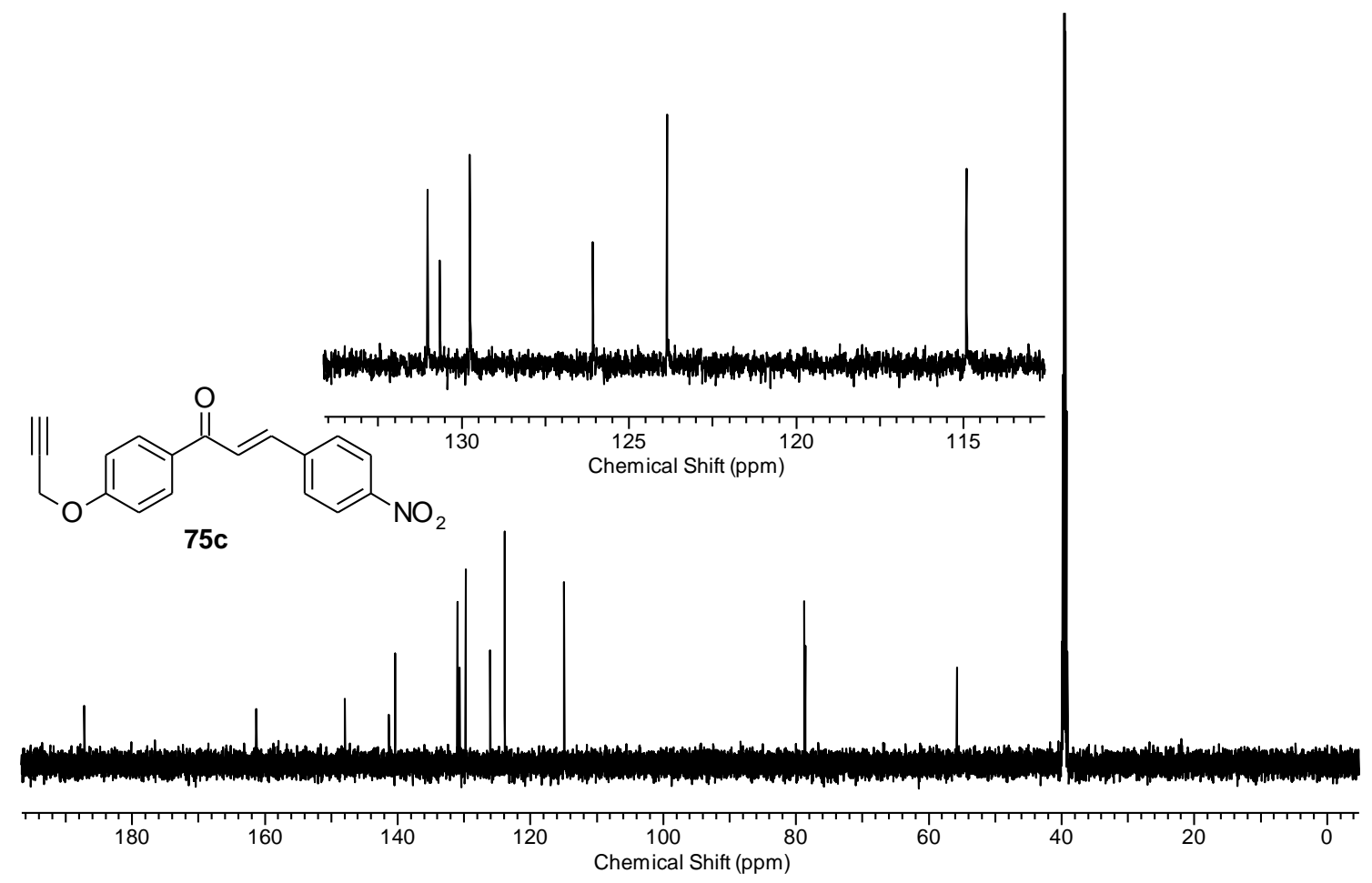

Figura 20 - Espectro de $\mathrm{RMN}{ }^{13} \mathrm{C}\left(150 \mathrm{MHz}\right.$, DMSO-d $\left.d_{6}\right)$ do composto 75c.

Das quatro chalconas descritas acima, a chalcona 75e é a única inédita na literatura e, portanto, faz-se necessária também a sua elucidação. 
O espectro de RMN de ${ }^{1} \mathrm{H}$ do composto 75e apresenta um dupleto em 8,03 ppm com integração de 2 hidrogênios, correspondente aos hidrogênios aromáticos a (Figura 21). Em 7,73 ppm, encontra-se um dupleto com integração de 1 hidrogênio correspondente ao hidrogênio olefínico b. Em 7,37 ppm, apresenta-se um dupleto com integração de 1 hidrogênio correspondente ao hidrogênio olefínico c. Um dupleto com integração de 1 hidrogênio se encontra em 7,16 ppm, o qual se refere ao hidrogênio aromático d. Em 7,12 ppm, apresenta-se um dupleto de dupleto com integração de 1 hidrogênio, correspondente ao hidrogênio aromático e. Um dupleto com integração de 2 hidrogênios se encontra em 7,06 ppm e se refere aos hidrogênios aromáticos f. Em 6,84 ppm, apresenta-se um dupleto com integração de 1 hidrogênio, o qual corresponde ao hidrogênio aromático g. Um simpleto aparece em 6,02 ppm com integração de 2 hidrogênios referente aos hidrogênios do grupo metilenodioxi h. Em 4,78 ppm, encontra-se um dupleto com integração de 2 hidrogênios, referente ao grupo metileno i. Por fim, em 2,56 ppm, apresenta-se um tripleto com integração de 1 hidrogênio que corresponde ao hidrogênio do alcino terminal $\mathbf{j}$ (Tabela 8).

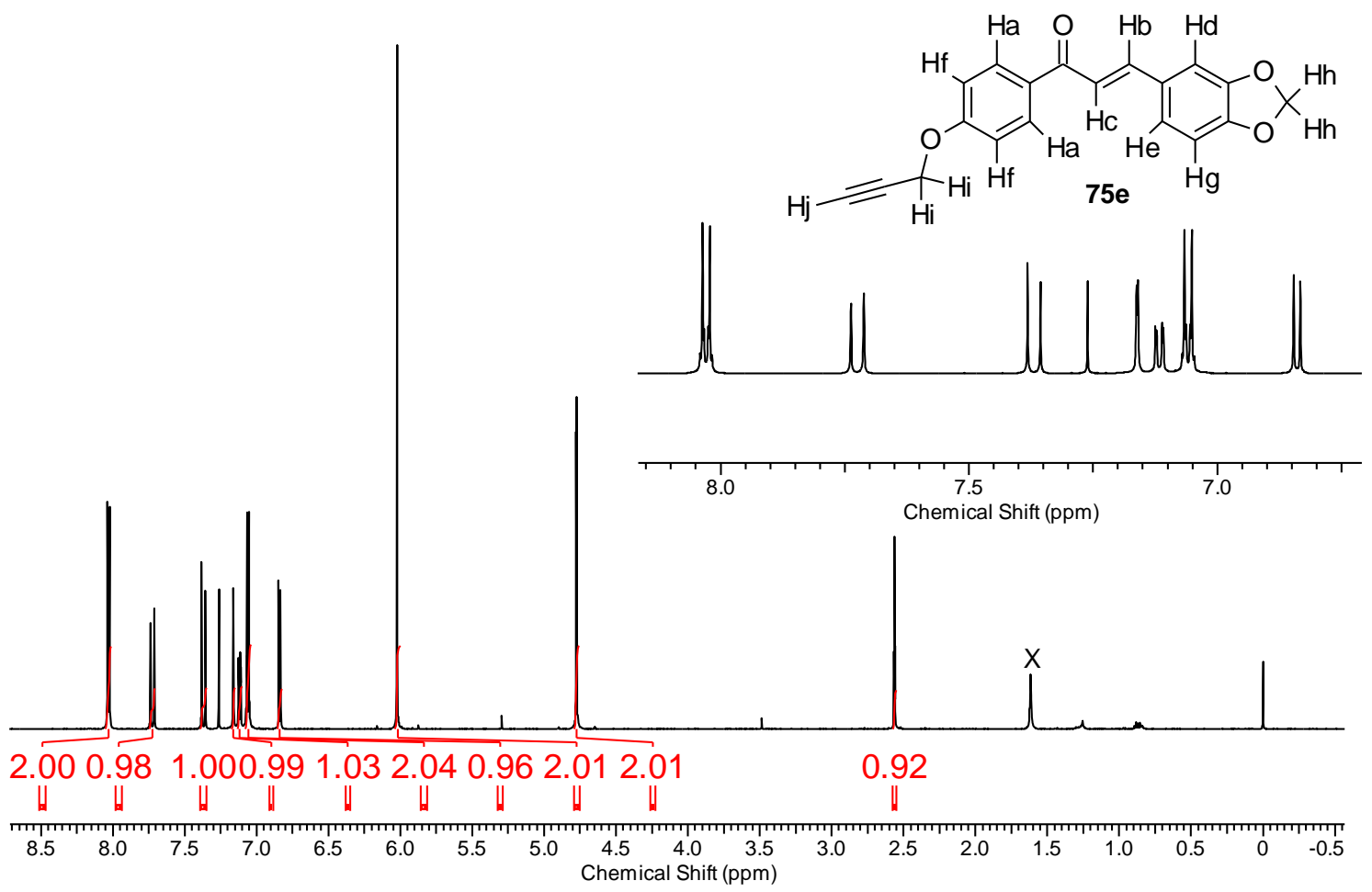

Figura 21 - Espectro de $\mathrm{RMN}{ }^{1} \mathrm{H}\left(600 \mathrm{MHz}, \mathrm{CDCl}_{3}\right)$ do composto $75 \mathbf{e}$. 
Tabela 8 - Dados de $\mathrm{RMN}{ }^{1} \mathrm{H}\left(600 \mathrm{MHz}, \mathrm{CDCl}_{3}\right)$ do composto $75 \mathrm{e}$.

\begin{tabular}{cccc}
\hline $\boldsymbol{\delta}_{\mathbf{h}}(\mathbf{p p m})$ & Multiplicidade & $\begin{array}{c}\text { Hidrogênios } \\
\text { Correspondentes }\end{array}$ & $\boldsymbol{J}(\mathbf{H z})$ \\
\hline 8,03 & dupleto & $2 \mathrm{CH}$ aromáticos (a) & 8,8 \\
7,73 & dupleto & $1 \mathrm{CH}$ olefínico (b) & 15,4 \\
7,37 & dupleto & $1 \mathrm{CH}$ olefínico (c) & 15,4 \\
7,16 & dupleto & $1 \mathrm{CH}$ aromático (d) & 1,8 \\
7,12 & duplo dupleto & $1 \mathrm{CH}$ aromático (e) & 8,$1 ; 1,8$ \\
7,06 & dupleto & $2 \mathrm{CH}$ aromáticos (f) & 8,8 \\
6,84 & dupleto & $1 \mathrm{CH}$ aromático (g) & 8,1 \\
6,02 & simpleto & $1 \mathrm{CH} 2($ metilenodioxi) (h) & - \\
4,78 & dupleto & $1 \mathrm{CH}$ (propargiloxi) (i) & 2,6 \\
2,56 & tripleto & $1 \mathrm{CH}$ de alcino (j) & 2,6 \\
\hline
\end{tabular}

$\mathrm{O}$ espectro de $\mathrm{RMN}$ de ${ }^{13} \mathrm{C}$ do composto 75e apresenta 17 picos (Figura 22). O pico em 188,6 ppm corresponde ao carbono da carbonila. Os picos entre 161,1 - 106,6 ppm representam os carbonos aromáticos e os da ligação dupla conjugada. O pico em 101,6 se refere ao metileno do grupo metilenodioxi. Os picos em 77,8 ppm e 76,1 ppm correspondem aos carbonos do alcino terminal. Por fim, o pico em 55,9 ppm representa o metileno do grupo propargiloxi.

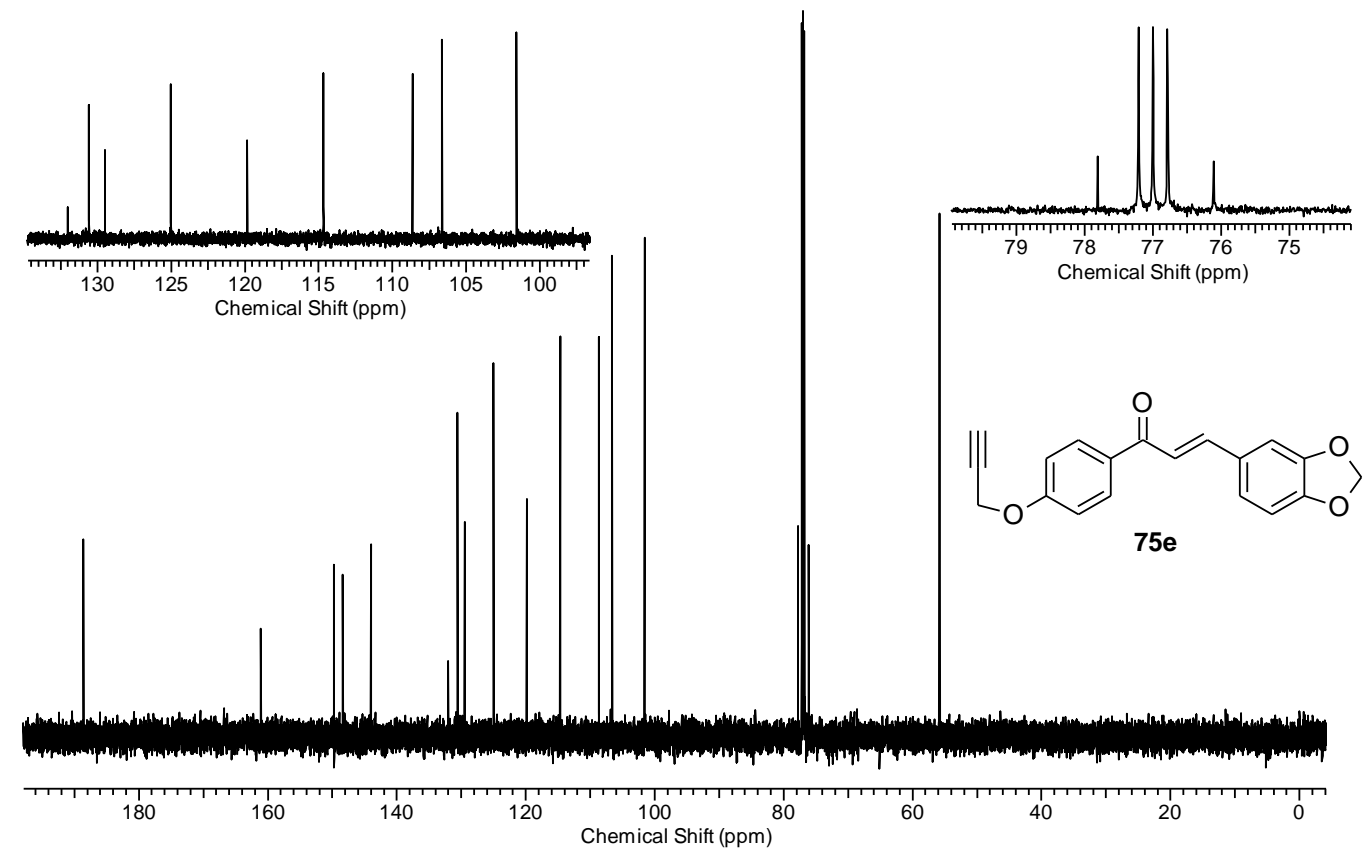

Figura 22 - Espectro de $\mathrm{RMN}{ }^{13} \mathrm{C}\left(150 \mathrm{MHz}, \mathrm{CDCl}_{3}\right)$ do composto $75 \mathrm{e}$. 


\subsection{Síntese dos compostos híbridos 76}

Para a síntese dos compostos em questão, foram utilizadas diversas metodologias:

- Metodologia I: baseada na metodologia de Kumar e colaboradores ${ }^{56}$ (Esquema 29). Uma mistura do alcino (1 equivalente) e do azido composto (1,1 equivalente) foi realizada em $\mathrm{THF} / \mathrm{H}_{2} \mathrm{O}(2: 1)$ na presença de sulfato de cobre pentahidratado $(20 \mathrm{~mol} \%)$ e D-glicose (40 mol\%). A mistura reacional foi aquecida por irradiação de micro-ondas a $70{ }^{\circ} \mathrm{C}$, por 15 minutos. Após extração com diclorometano, secagem com sulfato de sódio anidro e evaporação do solvente, o espectro de $\mathrm{RMN}$ de ${ }^{1} \mathrm{H}$ indicou que o produto esperado não foi formado.

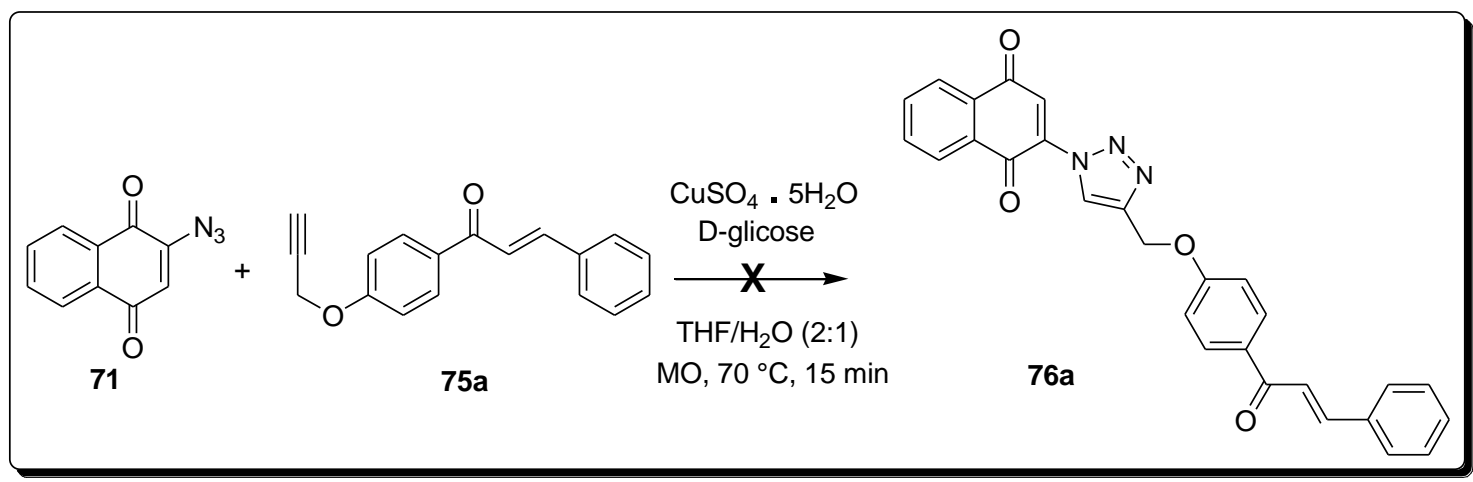

Esquema 29 - Tentativa de reação click entre os compostos 71 e 75a.

- Metodologia II: baseada na metodologia de Barreto e colaboradores. ${ }^{57}$ Uma mistura 1:1 do alcino 75a e do azido composto 71 foi preparada em uma solução de diclorometano e água (1:1), juntamente com sulfato de cobre pentahidratado (1 equivalente) e ascorbato de sódio (15 mol\%). A mistura reacional foi, então, aquecida com irradiação de micro-ondas a $40{ }^{\circ} \mathrm{C}$ por 5 min. Após extração com diclorometano, secagem com sulfato de sódio anidro e evaporação do solvente, o sólido formado foi purificado em coluna cromatográfica. O espectro de RMN de

\footnotetext{
${ }^{56}$ Kumar, Y.; Bahadur, V.; Singh, A. K.; Parmar, V. S.; Van der Eycken, E. V.; Singh, B. K. Beilstein. J. Org. Chem. 2014, 10, 1413.

${ }^{57}$ Barreto, A. F. S.; Vercillo, O. E.; Birkett, M. A.; Caulfied, J. C.; Wessjohann, L. A.; Andrade, C. K. Z. Org. Biom. Chem. 2011, 9, 5024.
} 
${ }^{1} \mathrm{H}$ do bruto da reação indicou a boa formação do produto, mas os rendimentos pós colunas foram muito baixos em duas tentativas de síntese e purificação.

- Metodologia III: baseada e adaptada a partir da metodologia de Júnior e colaboradores $^{58}$ (Esquema 30). Uma mistura do alcino 46a (1,2 equivalente), do azido composto 42 (1 equivalente) e de acetato de cobre I (CuOAc) (10 mol\%) foi preparada em acetonitrila. A mistura reacional foi agitada à temperatura ambiente por 24 horas. Após o término da reação, ácido clorídrico $10 \%$ foi adicionado à mistura reacional, formando um precipitado. $\mathrm{O}$ mesmo foi filtrado, seco e purificado por coluna cromatográfica. Desta vez, a coluna cromatográfica foi realizada por gradiente variando os eluentes de $30 \%$ acetato de etila em hexano a $10 \%$ metanol em acetato de etila. Quantidade significativa do produto foi purificada gerando um rendimento de 55\%. A caracterização foi feita por RMN de ${ }^{1} \mathrm{H}$.

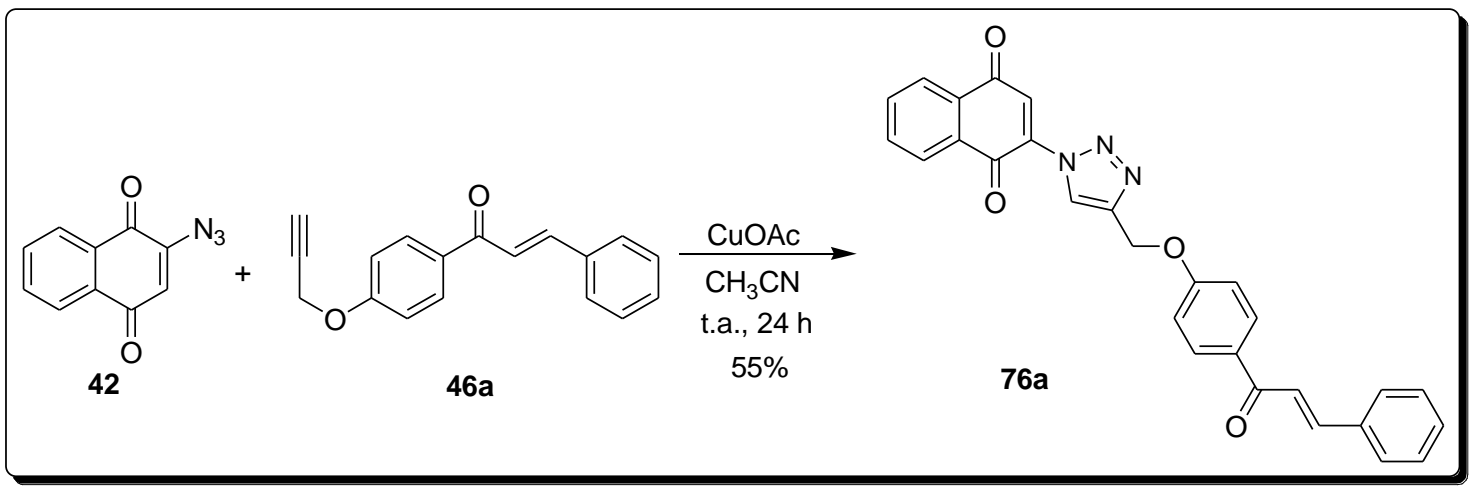

Esquema 30 - Reação click entre os compostos 42 e 46a usando a metodologia III.

O espectro de RMN de ${ }^{1} \mathrm{H}$ do composto 47a apresenta como pico mais característico e fundamental para a elucidação da estrutura o simpleto em 8,79 ppm, com integração de 1 hidrogênio, referente ao hidrogênio do anel triazólico a (Figura 23 e Tabela 9). Na faixa de 8,23 - 8,15 ppm, encontra-se um multipleto com integração de 2 hidrogênios, correspondente aos dois hidrogênios aromáticos b. Em 8,06 ppm, aparece um dupleto com integração de 2 hidrogênios, referente aos dois hidrogênios aromáticos c. Na faixa de 7,88 - 7,82 ppm, encontra-se um multipleto

\footnotetext{
${ }^{58}$ da Cruz, E. H. G.; Hussene, C. M. B.; Dias, G. G.; Diogo, E. B. T.; de Melo, I. M. M.; Rodrigues, B. L.; Silva, M. G.; Valença, W. O.; Camara, C. A.; Oliveira, R. N.; Paiva, Y. G.; Goulart, M. O. F.; Cavalcanti, B. C.; Pessoa, C.; Júnior, E. N. S. Bioorg. Med. Chem. 2014, 22, 1608.
} 
com integração de 2 hidrogênios, correspondente aos hidrogênios aromáticos d. Em 7,80 ppm, observa-se um dupleto com integração de 1 hidrogênio, referente ao hidrogênio olefínico e. Em 7,78 ppm, encontra-se um simpleto com integração de 1 hidrogênio, correspondente ao hidrogênio olefínico f. Na faixa de 7,66 - 7,62 ppm, apresenta-se um multipleto com integração de 2 hidrogênios, referente aos hidrogênios aromáticos g. Em 7,54 ppm, aparece um dupleto com integração de 1 hidrogênio, correspondente ao hidrogênio olefínico $\mathbf{h}$. Na faixa de 7,44 - 7,39 ppm, encontra-se um multipleto com integração de 3 hidrogênios, correspondente aos três hidrogênios aromáticos i. Em 7,12 ppm, aparece um dupleto com integração de 2 hidrogênios, referente aos hidrogênios aromáticos j. Por fim, em 5,40 ppm, encontra-se um simpleto com integração de 2 hidrogênios, correspondente ao grupo metileno ligado ao oxigênio e ao anel triazólico k.

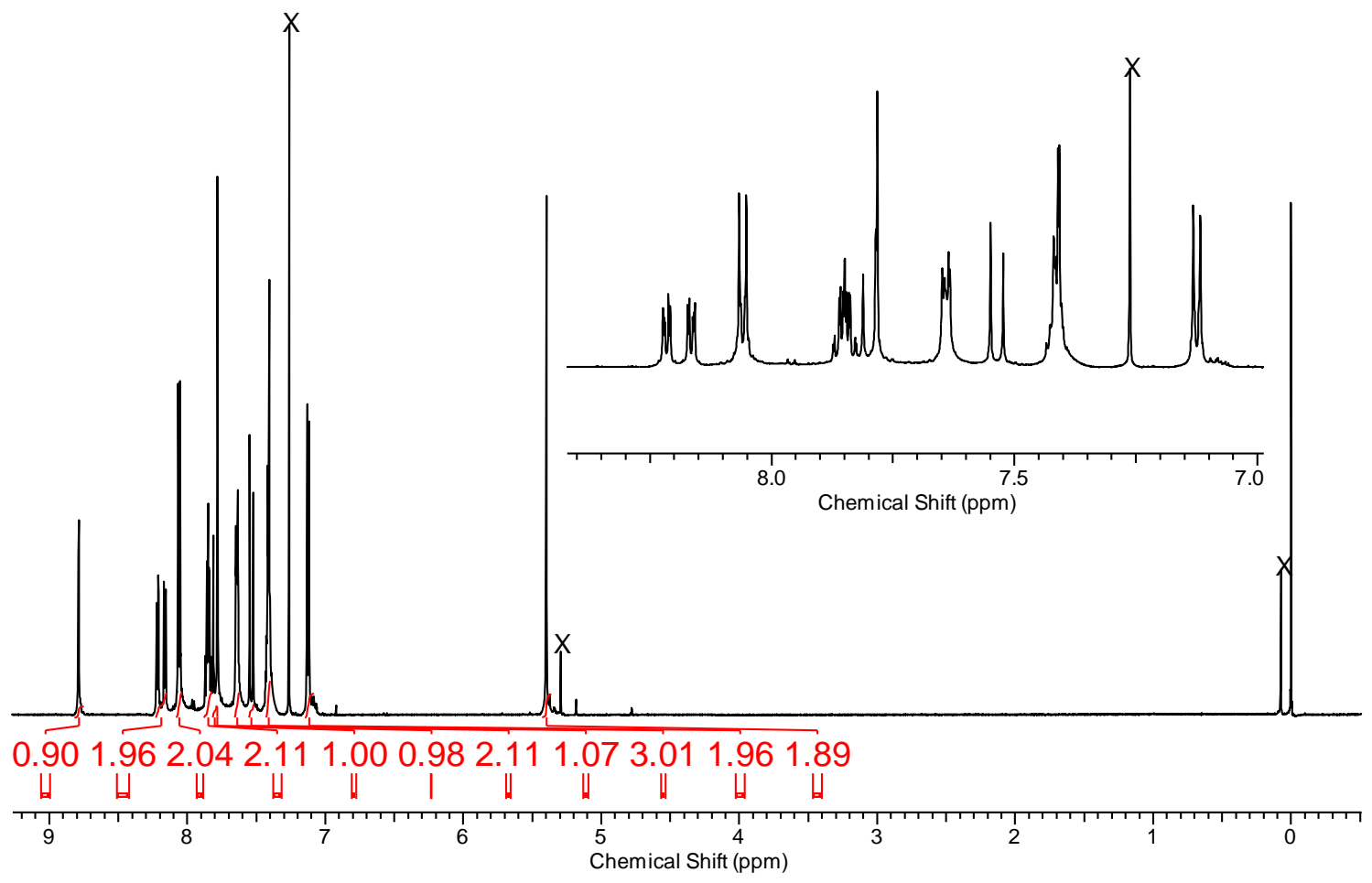

Figura 23 - Espectro de $\mathrm{RMN}{ }^{1} \mathrm{H}\left(600 \mathrm{MHz}, \mathrm{CDCl}_{3}\right)$ do composto 76a. 


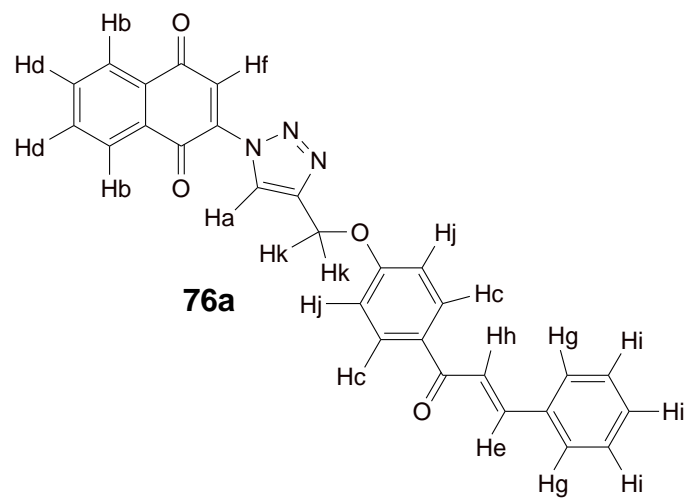

Tabela 9 - Dados de $\mathrm{RMN}{ }^{1} \mathrm{H}\left(600 \mathrm{MHz}, \mathrm{CDCl}_{3}\right)$ do composto 76a.

\begin{tabular}{cccc}
\hline $\boldsymbol{\delta} \mathbf{h}(\mathbf{p p m})$ & Multiplicidade & $\begin{array}{c}\text { Hidrogênios } \\
\text { Correspondentes }\end{array}$ & $\boldsymbol{J}(\mathbf{H z})$ \\
\hline 8,79 & simpleto & $1 \mathrm{CH}$ triazólico (a) & - \\
$8,23-8,15$ & multipleto & $2 \mathrm{CH}$ aromáticos (b) & - \\
8,06 & dupleto & $2 \mathrm{CH}$ aromáticos (c) & 8,8 \\
$7,88-7,82$ & multipleto & $2 \mathrm{CH}$ aromáticos (d) & - \\
7,80 & dupleto & $1 \mathrm{CH}$ olefínico (e) & 15,8 \\
7,78 & simpleto & $1 \mathrm{CH}$ olefínico (f) & - \\
$7,66-7,62$ & multipleto & $2 \mathrm{CH}$ aromáticos $(\mathrm{g})$ & - \\
7,54 & dupleto & $1 \mathrm{CH}$ olefínico $(\mathrm{h})$ & 15,8 \\
$7,44-7,39$ & multipleto & $3 \mathrm{CH}$ aromáticos $(\mathrm{i})$ & - \\
7,12 & dupleto & $2 \mathrm{CH}$ aromáticos $(\mathrm{j})$ & 8,8 \\
5,40 & simpleto & $\mathrm{CH}_{2}(\mathrm{k})$ & - \\
\hline
\end{tabular}

- Metodologia IV: a presente metodologia passou a ser empregada numa combinação de tudo que foi entendido ao longo das reações anteriores. Ficou entendido que os derivados naftoquinônicos são relativamente instáveis, logo a metodologia com micro-ondas foi deixada de lado a priori, dando lugar à reação em temperatura ambiente e overnight. Contudo, devido ao alto custo e instabilidade dos sais de cobre I ( $\mathrm{CuOAc}$ ), a utilização de sais de cobre II, como o sulfato de cobre pentahidratado, e um agente redutor, como o ascorbato de sódio, foi vista como a melhor estratégia para as condições da reação (Esquema 31), proposta que mais tarde se viu verdadeira. Portanto, a metodologia se baseia na mistura equimolar do alcino e do azido composto em diclorometano/água (1:1), juntamente com $20 \mathrm{~mol} \%$ de sulfato de cobre penta hidratado e $40 \mathrm{~mol} \%$ 
de ascorbato de sódio. A mistura reacional é agitada à temperatura ambiente por 24 horas. Ao término da reação, ácido clorídrico $10 \%$ é adicionado à mistura reacional, levando à formação de um precipitado. O mesmo é extraído em diclorometano, seco com sulfato de sódio anidro e o solvente é evaporado. $\mathrm{O}$ sólido é então purificado via coluna cromatográfica em sílica gel, utilizando como eluentes mistura de acetato de etila em hexano, fornecendo o produto com $88 \%$ de rendimento (sólido marrom avermelhado). Sua caracterização foi feita por RMN de ${ }^{1} \mathrm{H}$ e ${ }^{13} \mathrm{C}$.

A purificação do composto híbrido 76a e dos demais sintetizados posteriormente apresentou certas dificuldades. Parte do produto permanecia na sílica gel mesmo utilizando eluentes com alta polaridade. Outras fases estacionárias foram utilizadas (Florisil e alumina neutra) a fim de investigar se era devido ao uso de sílica gel. Os mesmos rendimentos baixos foram obtidos. A solução veio na utilização de pouca sílica gel na coluna cromatográfica (cerca de 4,5 gramas ou $3 \mathrm{~cm}$ de sílica em uma coluna de $20 \mathrm{~mm}$ de diâmetro). Portanto, utilizando esse procedimento, bons rendimentos foram obtidos após purificação dos diversos compostos híbridos.

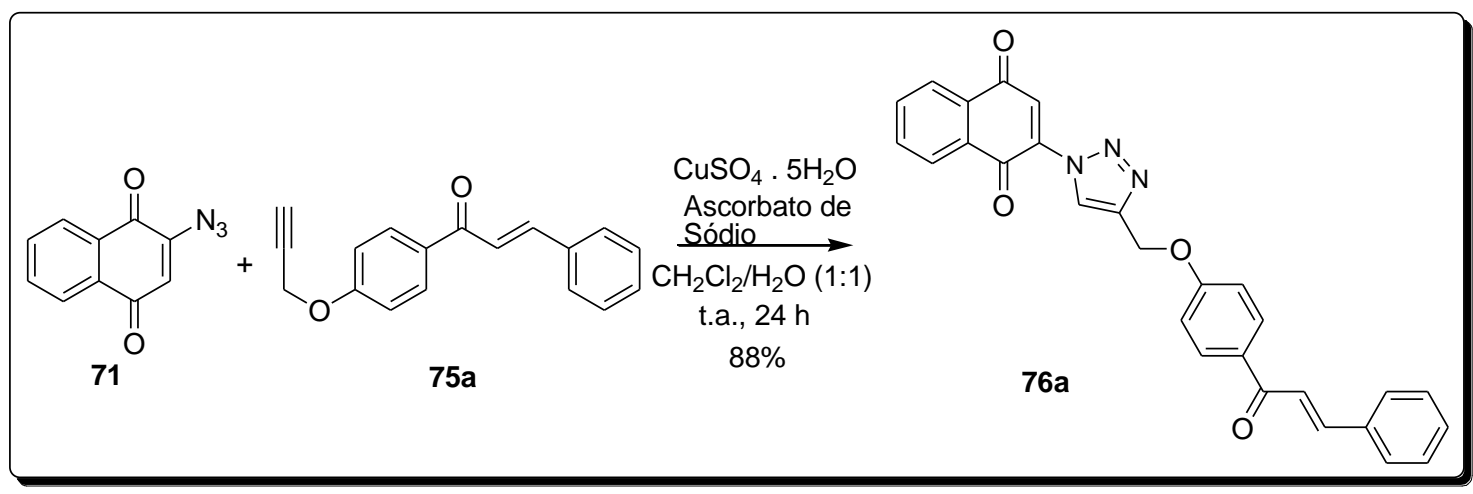

Esquema 31 - Reação click entre os compostos 71 e 75a usando a metodologia IV.

O espectro de RMN de ${ }^{1} \mathrm{H}$ e seus respectivos dados são equivalentes ao da Figura 23 e Tabela 9. O espectro de RMN de ${ }^{13} \mathrm{C}$ apresenta 24 picos (Figura 24). Os picos em 188,7, 183,7 e 179,3 ppm correspondem aos carbonos das carbonilas. Os picos entre 161,8 - 114,7 ppm correspondem aos carbonos aromáticos e das duplas ligações. Por fim, em 61,8 ppm, encontra-se o pico relativo ao metileno. 


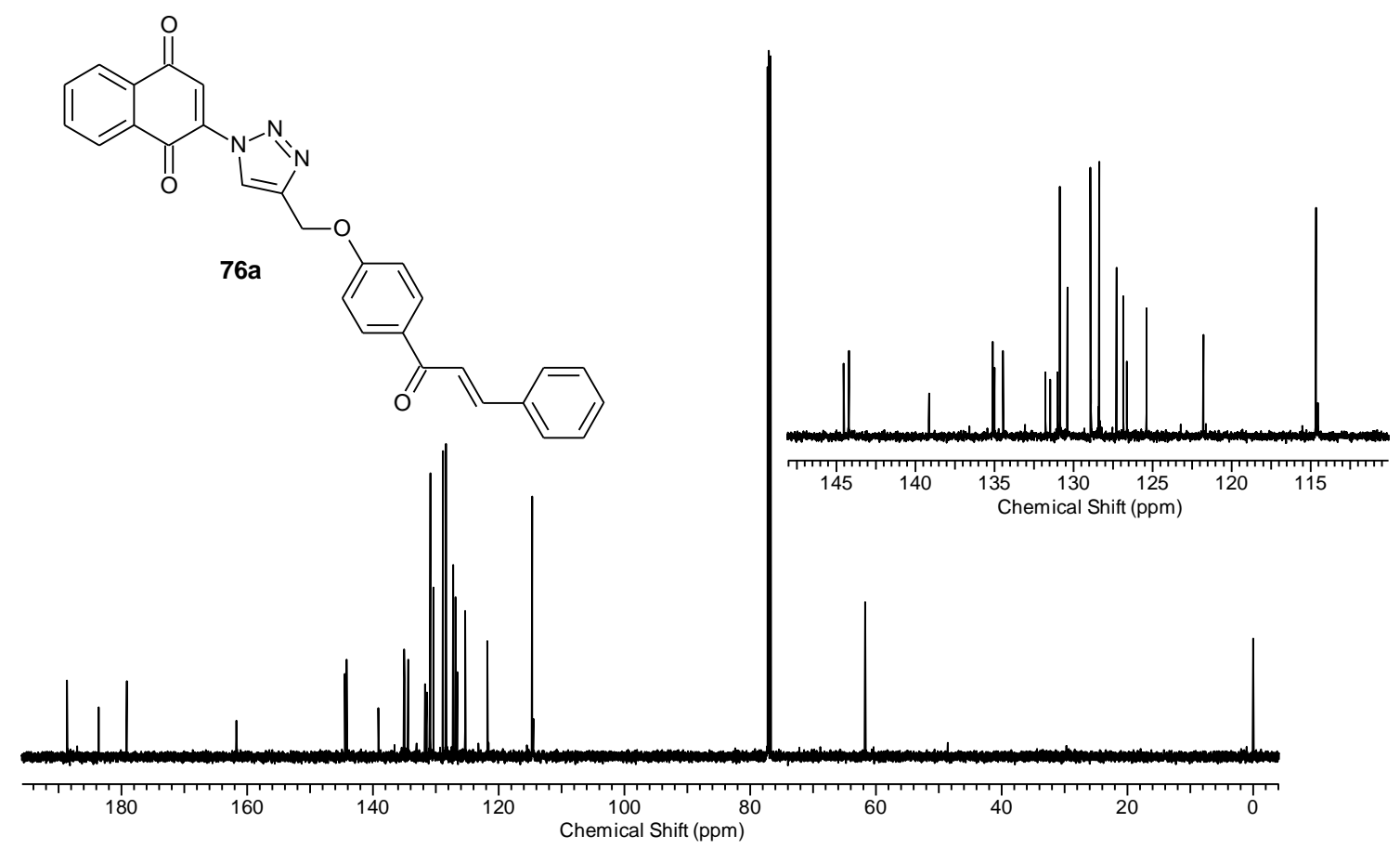

Figura 24 - Espectro de $\mathrm{RMN}{ }^{13} \mathrm{C}\left(150 \mathrm{MHz}, \mathrm{CDCl}_{3}\right)$ do composto $76 \mathbf{a}$.

- Metodologia V: essa metodologia consiste na mesma da metodologia IV, porém adicionando à mistura reacional 1 gota de trietilamina, conforme metodologia do trabalho de Júnior e colaboradores. ${ }^{58}$ Esse diferencial proporcionou bons rendimentos nas reações click (CuAAC) para a formação dos compostos híbridos 76 e em tempos reacionais muito menores (Esquema 32). A purificação dos compostos híbridos foi realizada com pequena quantidade de sílica, proporcionando a saída dos produtos desejados com mínima degradação e mínima perda na coluna cromatográfica em sílica gel, descartando, assim, o emprego de eluentes muito polares. Os demais compostos híbridos $\mathbf{7 6}$ foram caracterizados através de espectroscopia de $\mathrm{RMN}$ de ${ }^{1} \mathrm{H}$ e ${ }^{13} \mathrm{C}$ e suas elucidações espectrais são similares às do composto $\mathbf{7 6 a}$. 


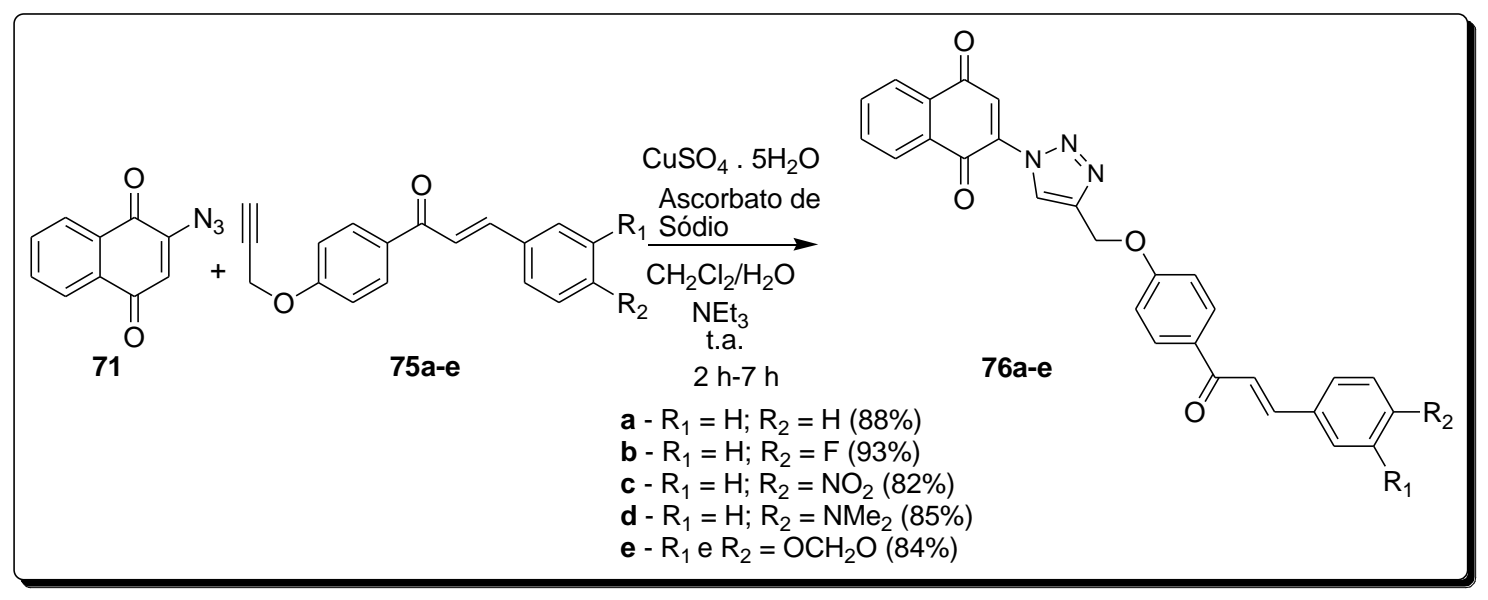

Esquema 32 - Reação click entre os compostos 71 e 75a-e usando a metodologia V.

\subsection{Síntese do composto híbrido $76 f$}

Uma sexta molécula desse grupo foi sintetizada no início do projeto, o composto 76f. Inicialmente, o intuito era explorar as cetonas com o grupo propargiloxi em diferentes posições no anel. Contudo, devido ao tempo disponível e à falta de reagentes, foi concluído que seria melhor utilizar somente a cetona com o grupo propargiloxi na posição para e variar os diferentes aldeídos. Mesmo assim, a molécula 76f foi sintetizada com sucesso utilizando a metodologia V ( Esquema 33).

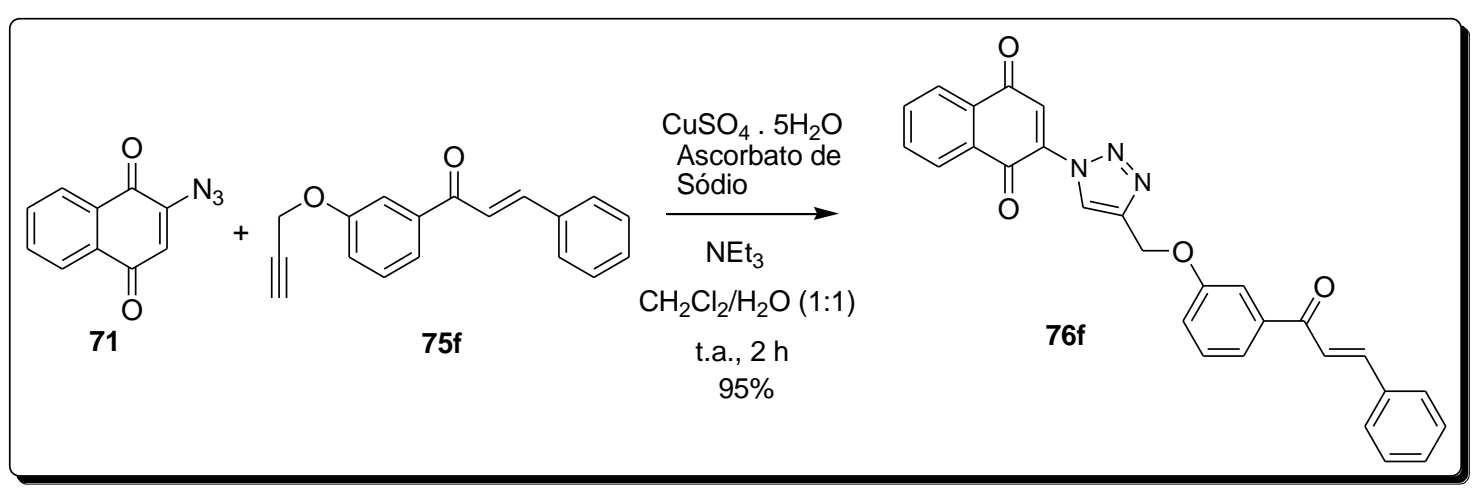

Esquema 33 - Reação click entre os compostos 71 e $75 f$ usando a metodologia V.

A caracterização do composto $\mathbf{7 6 f}$ foi realizada através de espectroscopia de ressonância magnética nuclear $(\mathrm{RMN})$ de hidrogênio $\left({ }^{1} \mathrm{H}\right)$ e de carbono $\left({ }^{13} \mathrm{C}\right)$. O espectro de RMN de ${ }^{1} \mathrm{H}$ do composto $76 \mathbf{f}$ apresenta como pico mais característico e fundamental para a elucidação da estrutura o simpleto em 8,79 ppm com integração de 1 
hidrogênio, referente ao hidrogênio do anel triazólico a (Figura 25 e Tabela 10). Na faixa de 8,21 - 8,15 ppm, encontra-se um multipleto com integração de 2 hidrogênios, correspondente aos hidrogênios aromáticos b. Em 7,87 - 7,82 ppm, aparece um multipleto com integração de 2 hidrogênios, referente aos hidrogênios aromáticos c. Em 7,81 ppm, aparece um dupleto com integração de 1 hidrogênio, referente ao hidrogênio olefínico d. Em 7,77 ppm, encontra-se um simpleto com integração de 1 hidrogênio, correspondente ao hidrogênio olefínico e. Na faixa de 7,69-7,68 ppm, apresenta-se um multipleto com integração de 1 hidrogênio, referente ao pico do hidrogênio aromático f. $\mathrm{Na}$ faixa de 7,67 - 7,64 ppm, encontra-se um multipleto com integração de 3 hidrogênios, o qual corresponde aos 2 hidrogênios aromáticos $\mathbf{g}$, sobreposto ao pico referente do hidrogênio aromático $\mathbf{h}$. Em 7,52 ppm, aparece um dupleto com integração de 1 hidrogênio, correspondente ao hidrogênio olefínico i. Em 7,45 ppm, encontra-se um tripleto com integração de 1 hidrogênio, referente ao hidrogênio aromático j. $\mathrm{Na}$ faixa de 7,43 - 7,40 ppm, encontra-se um multipleto com integração de 3 hidrogênios, correspondente aos hidrogênios aromáticos k. Em 7,25 ppm, aparece um dupleto de dupleto com integração de 1 hidrogênio, referente ao hidrogênio aromático $\mathbf{l}$. Por fim, em 5,38 ppm, encontra-se um simpleto com integração de 2 hidrogênios, correspondente ao grupo metileno $\mathbf{m}$.

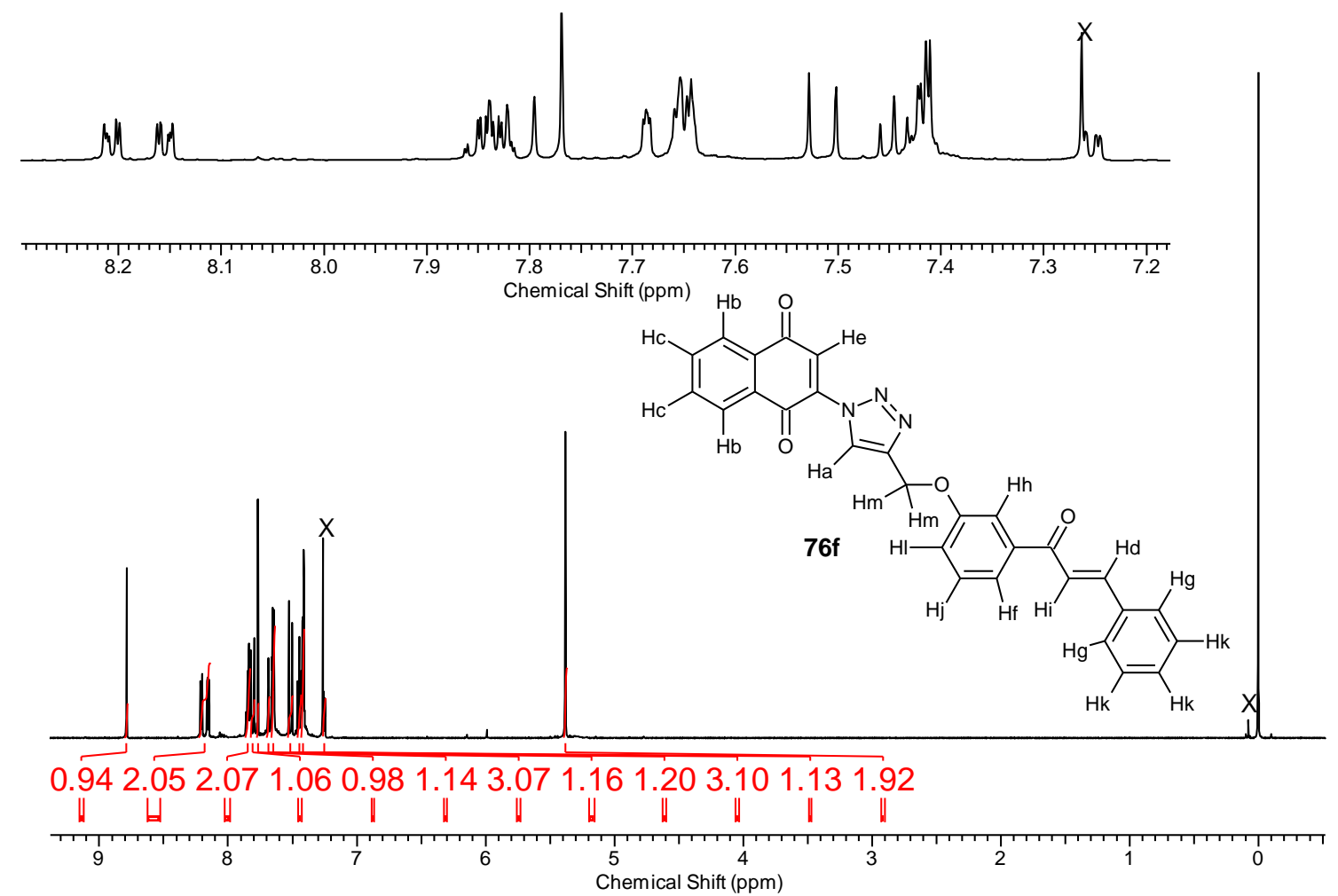

Figura 25 - Espectro de $\mathrm{RMN}{ }^{1} \mathrm{H}\left(600 \mathrm{MHz}, \mathrm{CDCl}_{3}\right)$ do composto $76 \mathbf{f}$. 
Tabela 10 - Dados de $\mathrm{RMN}{ }^{1} \mathrm{H}\left(600 \mathrm{MHz}, \mathrm{CDCl}_{3}\right)$ do composto $76 \mathbf{f}$.

\begin{tabular}{cccc}
\hline $\boldsymbol{\delta}_{\mathbf{h}}(\mathbf{p p m})$ & Multiplicidade & $\begin{array}{c}\text { Hidrogênios } \\
\text { Correspondentes }\end{array}$ & $\boldsymbol{J ( H z )}$ \\
\hline 8,79 & simpleto & $1 \mathrm{CH}$ triazólico (a) & - \\
$8,21-8,15$ & multipleto & $2 \mathrm{CH}$ aromáticos (b) & - \\
$7,87-7,82$ & multipleto & $2 \mathrm{CH}$ aromáticos (c) & - \\
7,81 & dupleto & $1 \mathrm{CH}$ olefínico (d) & 15,8 \\
7,77 & simpleto & $1 \mathrm{CH}$ olefínico (e) & - \\
$7,69-7,68$ & multipleto & $1 \mathrm{CH}$ aromático (f) & - \\
$7,67-7,64$ & multipleto & $3 \mathrm{CH}$ aromáticos (g e h) & - \\
7,52 & dupleto & $1 \mathrm{CH}$ olefínico (i) & 15,8 \\
7,45 & tripleto & $1 \mathrm{CH}$ aromático (j) & 8,1 \\
$7,43-7,40$ & multipleto & $3 \mathrm{CH}$ aromáticos (k) & - \\
7,25 & dupleto de dupleto & $1 \mathrm{CH}$ aromático (l) & 6,$2 ; 2,2$ \\
5,38 & simpleto & $\mathrm{CH}$ (m) & - \\
\hline
\end{tabular}

O espectro de RMN de ${ }^{13} \mathrm{C}$ apresenta 26 picos (Figura 26). Os picos em 190,0; 183,7 e 179,3 ppm correspondem aos carbonos das carbonilas. Os picos entre 158,4 114,3 ppm correspondem aos carbonos aromáticos e das duplas ligações. Por fim, em 61,8 ppm, encontra-se o pico relativo ao metileno.

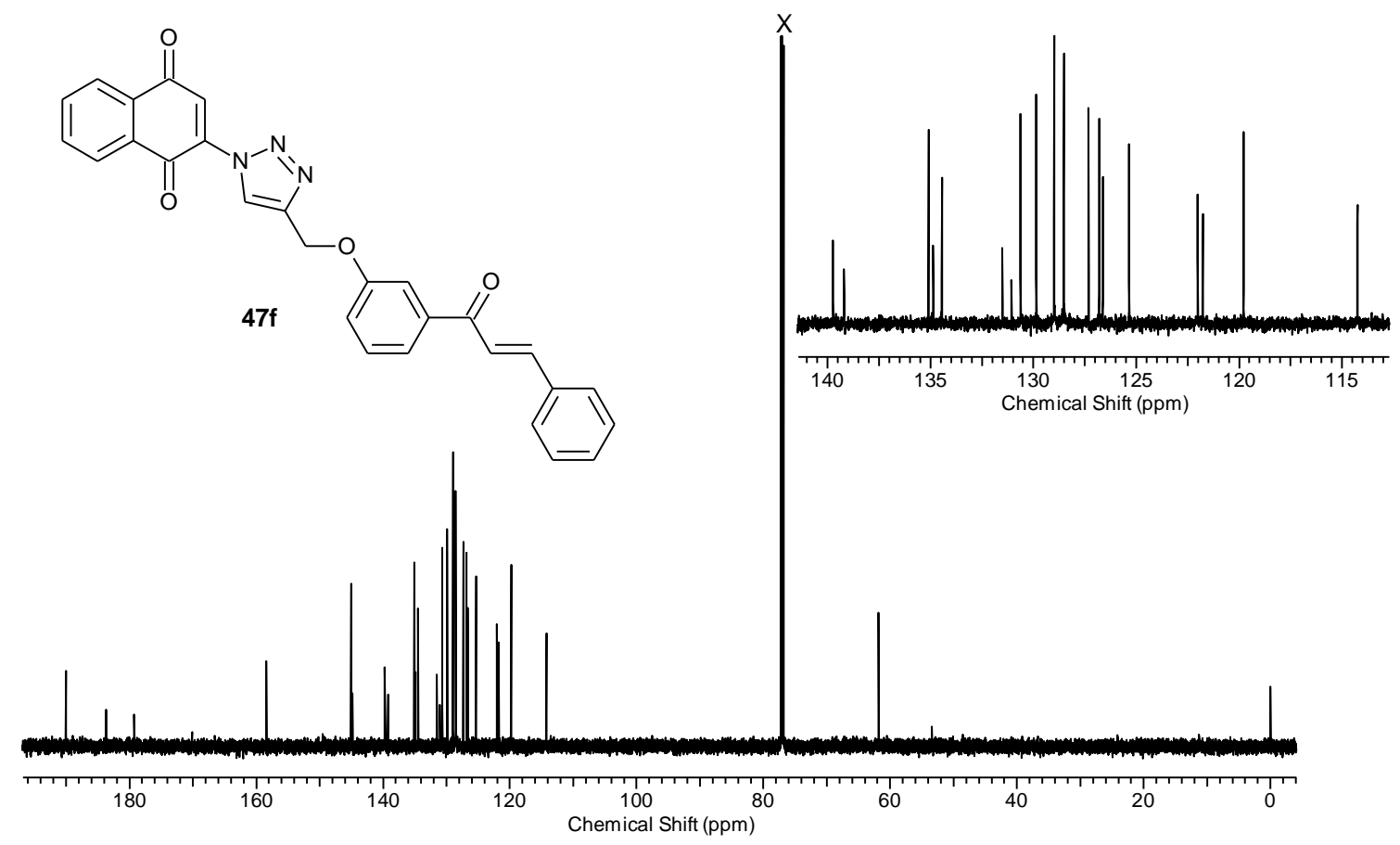

Figura 26- Espectro de $\mathrm{RMN}{ }^{13} \mathrm{C}\left(150 \mathrm{MHz}, \mathrm{CDCl}_{3}\right)$ do composto $76 \mathbf{f}$. 
Para a síntese da chalcona 75f, material de partida para a síntese do composto 76f, foi utilizada uma rota distinta das demais. Primeiramente, sintetizou-se a chalcona 83 (E-1-(3-hidróxifenil)-3-fenil-prop-2-en-1-ona) com a mesma metodologia já empregada na síntese das chalcona anteriores. ${ }^{19}$ Para tal, foram utilizados a 3-hidróxiacetofenona 82, solução aquosa de $10 \%$ de hidróxido de sódio e benzaldeído $\mathbf{7 4 a} \mathrm{em}$ etanol (Esquema 34). A caracterização do composto $\mathbf{8 3}$ foi realizada através de RMN de ${ }^{1} \mathrm{H} \mathrm{e}{ }^{13} \mathrm{C}$.

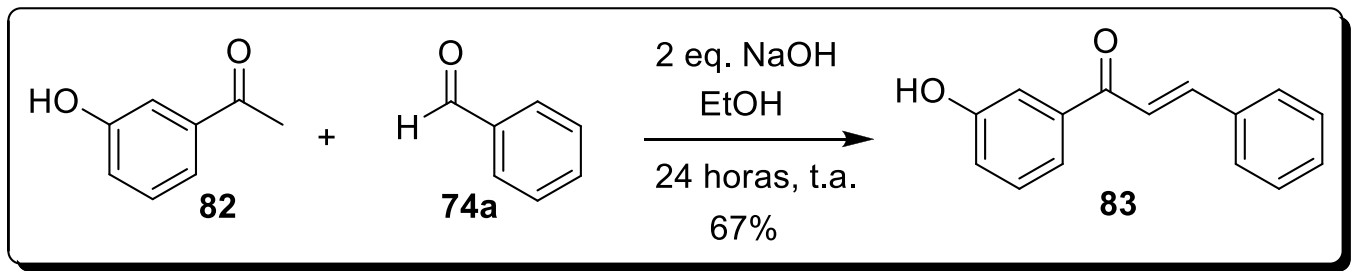

Esquema 34 - Síntese da chalcona 83.

O espectro de RMN de ${ }^{1} \mathrm{H}$ do composto $\mathbf{8 3}$ apresenta um simpleto em 9,87 ppm com integração de 1 hidrogênio correspondente à hidroxila a (Figura 27). Na região de 7,94 - 7,85 ppm, encontra-se um multipleto e um dupleto com integração total de 3 hidrogênios correspondentes aos hidrogênios aromáticos $\mathbf{b}$ e ao hidrogênio olefínico $\mathbf{c}$, respectivamente. Em 7,75 ppm, encontra-se um dupleto com integração de 1 hidrogênio, correspondente hidrogênio olefínico d. Em 7,66 ppm, encontra-se um multipleto com integração de 1 hidrogênio correspondente ao hidrogênio aromático e. $\mathrm{Na}$ faixa de 7,49 - 7,44 ppm, encontra-se um multipleto com integração total de 4 hidrogênios correspondentes aos hidrogênios aromáticos f e $\mathbf{g}$ (4 hidrogênios). Um tripleto em 7,38 ppm é correspondente ao hidrogênio aromático $\mathbf{h}$ (1 hidrogênio). Por fim, em 7,10 ppm, com integração de 1 hidrogênio, encontra-se um dupleto de dupleto de dupleto relacionado ao hidrogênio aromático i. Dados da literatura confirmam os resultados obtidos (Tabela 11). ${ }^{19}$ 


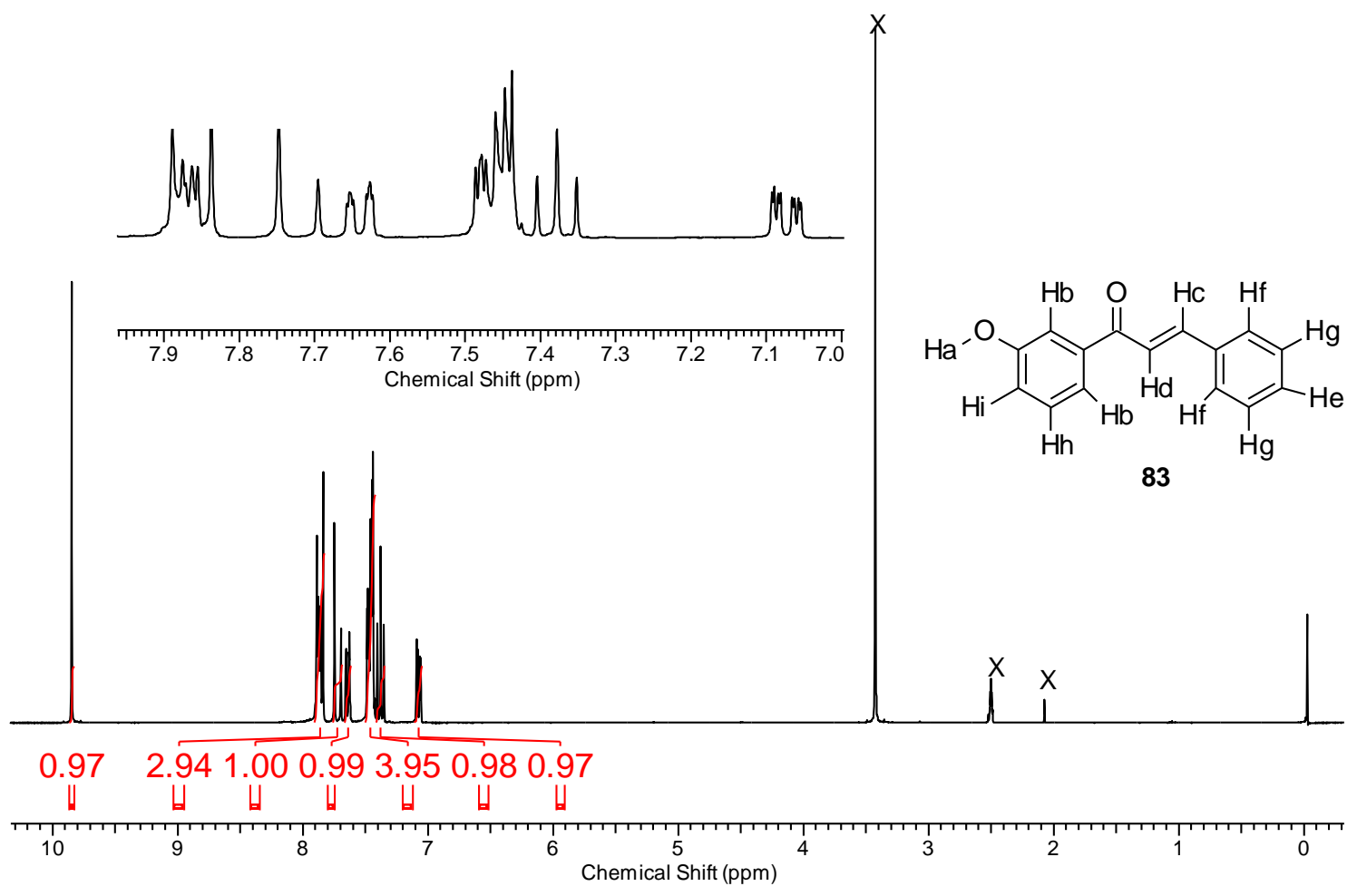

Figura 27 - Espectro de RMN ${ }^{1} \mathrm{H}\left(300 \mathrm{MHz}, \mathrm{DMSO}-d_{6}\right)$ do composto 83.

Tabela 11 - Dados de RMN ${ }^{1} \mathrm{H}$ (300 MHz, DMSO-d $)$ do composto 83.

\begin{tabular}{ccccc}
\hline $\boldsymbol{\delta}_{\mathbf{h}}(\mathbf{p p m})$ & $\boldsymbol{\delta}_{\mathbf{h}}$ (lit.) $^{\mathbf{1 9}}$ & Multiplicidade & $\begin{array}{c}\text { Hidrogênios } \\
\text { Correspondentes }\end{array}$ & $\boldsymbol{J ( H z )}$ \\
\hline 9,87 & 9,89 & simpleto & $1 \mathrm{OH}$ fenólico (a) & - \\
$7,94-7,85$ & $7,92-7,85$ & multipleto e & $2 \mathrm{CH}$ aromáticos (b) e & 15,7 \\
& & dupleto & $1 \mathrm{CH}$ olefínico (c) & (dupleto) \\
7,75 & 7,75 & dupleto & $1 \mathrm{CH}$ olefínico (d) & 15,7 \\
7,66 & 7,65 & multipleto & $1 \mathrm{CH}$ aromático (e) & - \\
$7,49-7,44$ & $7,50-7,38$ & multipleto & $4 \mathrm{CH}$ aromáticos (f e g) & - \\
7,38 & $7,50-7,38$ & tripleto & $1 \mathrm{CH}$ aromático (h) & 7,9 \\
7,10 & 7,09 & dupleto de & $1 \mathrm{CH}$ aromático (i) & 7,$9 ; 2,5 ; 0,9$ \\
& & dupleto de & & \\
\hline
\end{tabular}

$\mathrm{O}$ espectro de RMN de ${ }^{13} \mathrm{C}$ apresenta 13 picos (Figura 28 e Erro! Fonte de referência não encontrada.). O pico 189,2 ppm corresponde ao carbono da carbonila. O pico em 157,8 ppm é referente ao carbono aromático ligado ao grupo hidroxila. Os 
picos entre 143,9 - 114,7 ppm representam os carbonos aromáticos e os da ligação dupla conjugada.
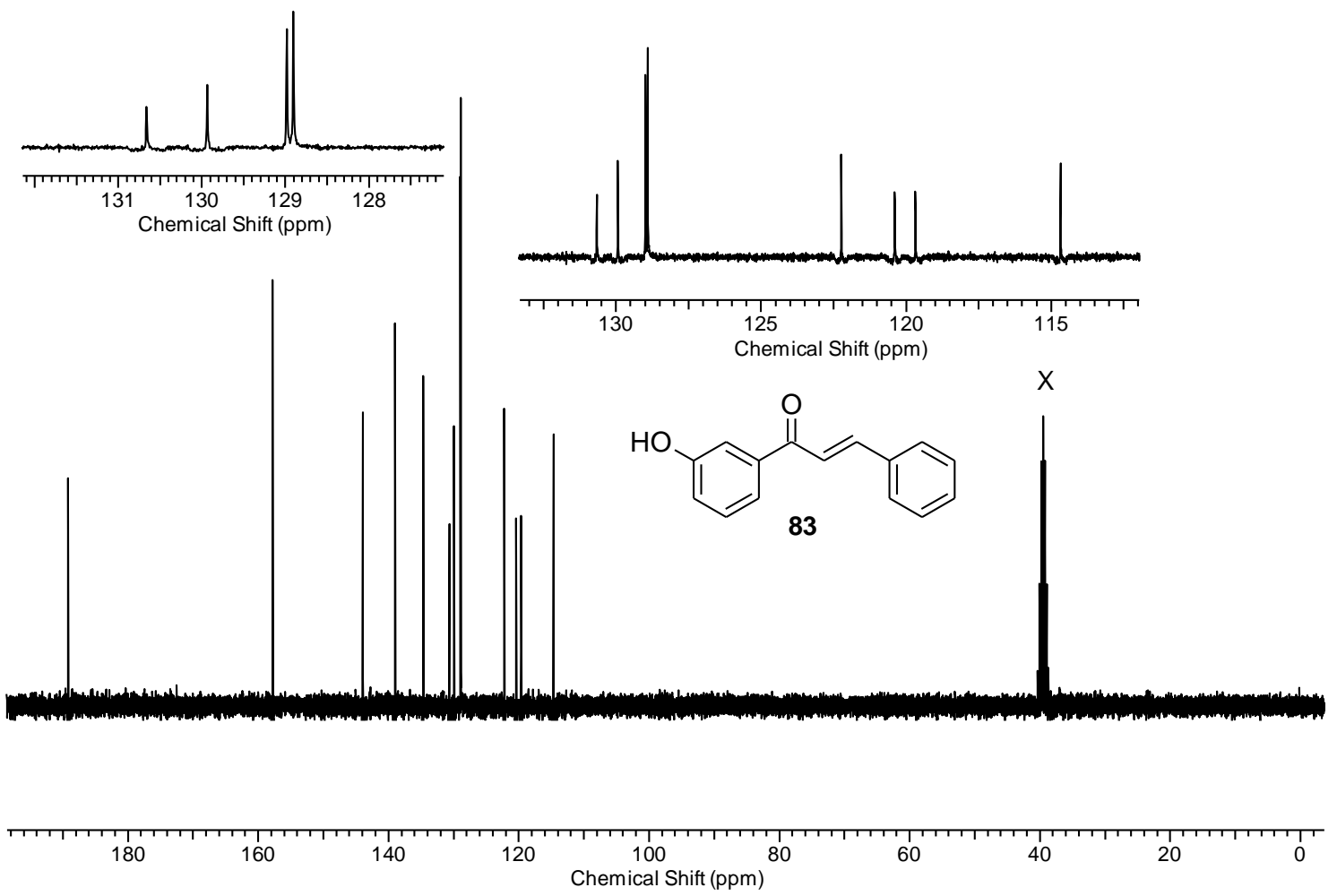

Figura 28 - Espectro de RMN ${ }^{13} \mathrm{C}$ (75 MHz, DMSO-d6) do composto 83.

Posteriormente, a chalcona $\mathbf{7 5 f}$ foi preparada a partir da metodologia de Rajakumar e colaboradores. ${ }^{53} \mathrm{Em} 3 \mathrm{ml}$ de DMF foram adicionados a chalcona 83, brometo de propargila e carbonato de potássio. A mistura reacional foi agitada por 24 horas à temperatura ambiente (Esquema 35). A caracterização do composto $\mathbf{7 5 f}$ foi realizada através de $\mathrm{RMN}$ de ${ }^{1} \mathrm{H}$ e ${ }^{13} \mathrm{C}$.

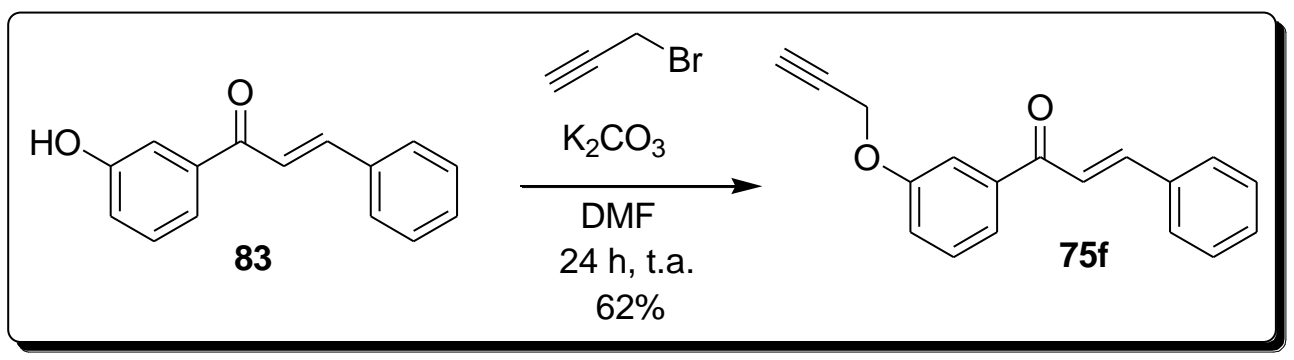

Esquema 35 - Preparação da chalcona 75f.

O espectro de RMN de ${ }^{1} \mathrm{H}$ apresenta um dupleto em 7,81 ppm com integração de 1 hidrogênio, referente ao hidrogênio olefínico a (Figura 29 e Tabela 12). Em 7,66 7,61 ppm, encontra-se um multipleto com integração de 4 hidrogênios, correspondente 
ao pico dos dois hidrogênios aromáticos b sobreposto ao pico dos dois hidrogênios aromáticos c. Em 7,50 ppm, aparece um dupleto com integração de 1 hidrogênio referente ao hidrogênio olefínico d. Em 7,45 - 7,40 ppm, encontra-se um multipleto com integração de 4 hidrogênios, correspondente ao pico do hidrogênio aromático e sobreposto com o pico dos hidrogênios aromáticos f. Em 7,20 ppm, aparece um multipleto com integração de 1 hidrogênio, referente ao hidrogênio aromático g. O pico em 4,77 ppm se apresenta como um dupleto com integração de 2 hidrogênios, correspondente ao hidrogênios do grupo metileno h. Por fim, em 2,55 ppm, encontra-se um tripleto com integração de 1 hidrogênio que se refere ao hidrogênio do alcino terminal $\mathbf{i}$.

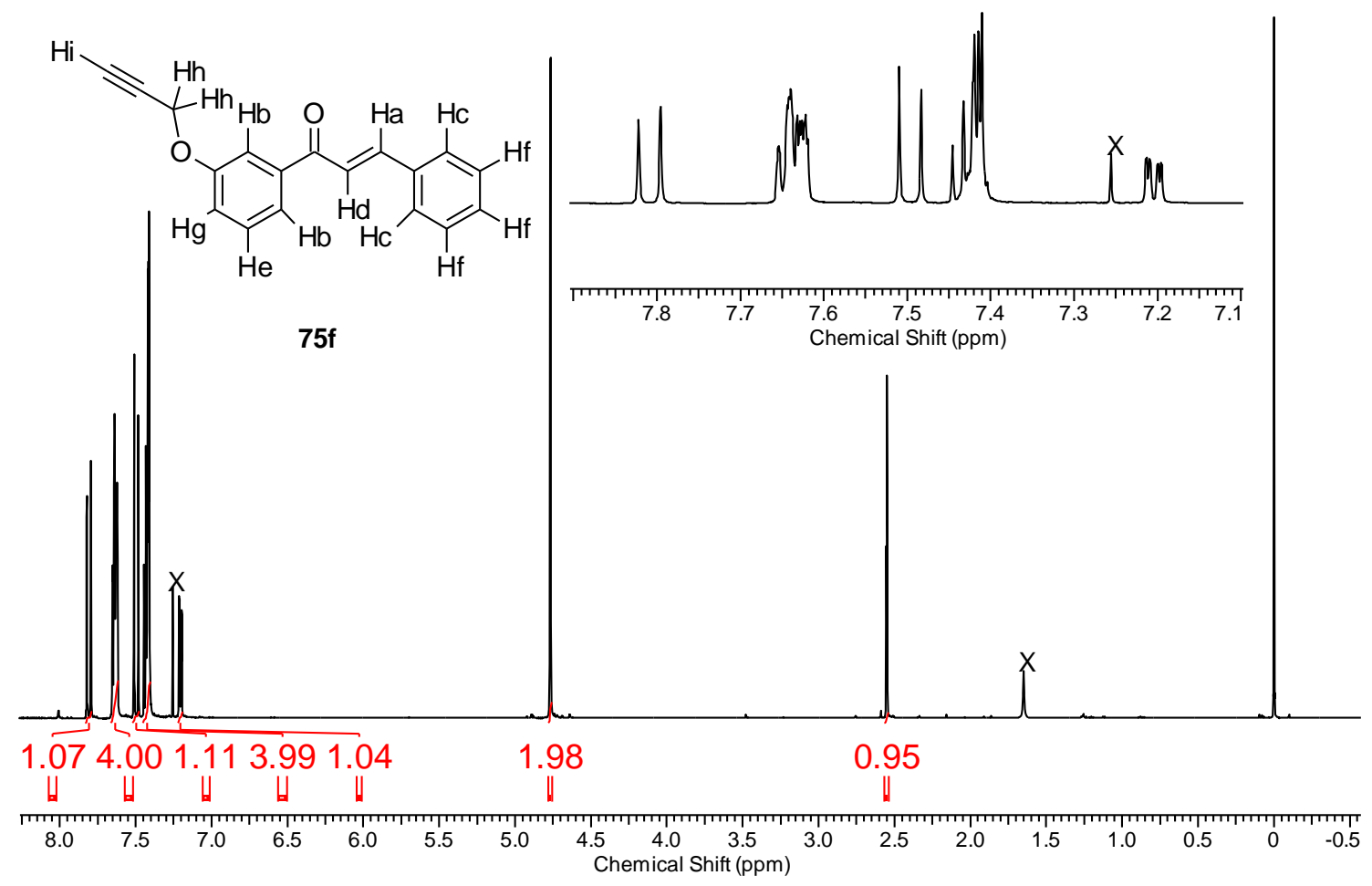

Figura 29 - Espectro de $\mathrm{RMN}{ }^{1} \mathrm{H}\left(600 \mathrm{MHz}, \mathrm{CDCl}_{3}\right)$ do composto $75 f$.

Tabela 12 - Dados de $\mathrm{RMN}{ }^{1} \mathrm{H}\left(600 \mathrm{MHz}, \mathrm{CDCl}_{3}\right)$ do composto $75 f$.

\begin{tabular}{cccc}
\hline $\boldsymbol{\delta} \mathbf{h}(\mathbf{p p m})$ & Multiplicidade & $\begin{array}{c}\text { Hidrogênios } \\
\text { Correspondentes }\end{array}$ & $\boldsymbol{J}(\mathbf{H z})$ \\
\hline 7,81 & dupleto & $1 \mathrm{CH}$ olefínico $(\mathrm{a})$ & 15,8 \\
$7,66-7,61$ & multipleto & $4 \mathrm{CH}$ aromáticos $(\mathrm{b}$ e c) & - \\
7,50 & dupleto & $1 \mathrm{CH}$ olefínico $(\mathrm{d})$ & 15,8 \\
$7,45-7,40$ & multipleto & $4 \mathrm{CH}$ aromáticos $(\mathrm{e}, \mathrm{f})$ & - \\
7,20 & multipleto & $1 \mathrm{CH}$ aromático $(\mathrm{g})$ & - \\
\hline
\end{tabular}




\begin{tabular}{cccc}
\hline 4,77 & dupleto & $\mathrm{CH}_{2}(\mathrm{~h})$ & 2,2 \\
2,55 & tripleto & $1 \mathrm{CH}$ de alcino (i) & 2,2 \\
\hline O espectro de $\mathrm{RMN} \mathrm{de}{ }^{13} \mathrm{C}$ apresenta & 16 picos (Figura 30 e Erro! Fonte de
\end{tabular}

referência não encontrada.). O pico em 190,1 ppm corresponde ao carbono da carbonila. Os picos entre 157,8 - 114,2 ppm representam os carbonos aromáticos e os da ligação dupla conjugada. Os carbonos do alcino terminal se localizam em 78,2 ppm e 76,0 ppm. O carbono do grupo metileno se encontra em 56,0 ppm.

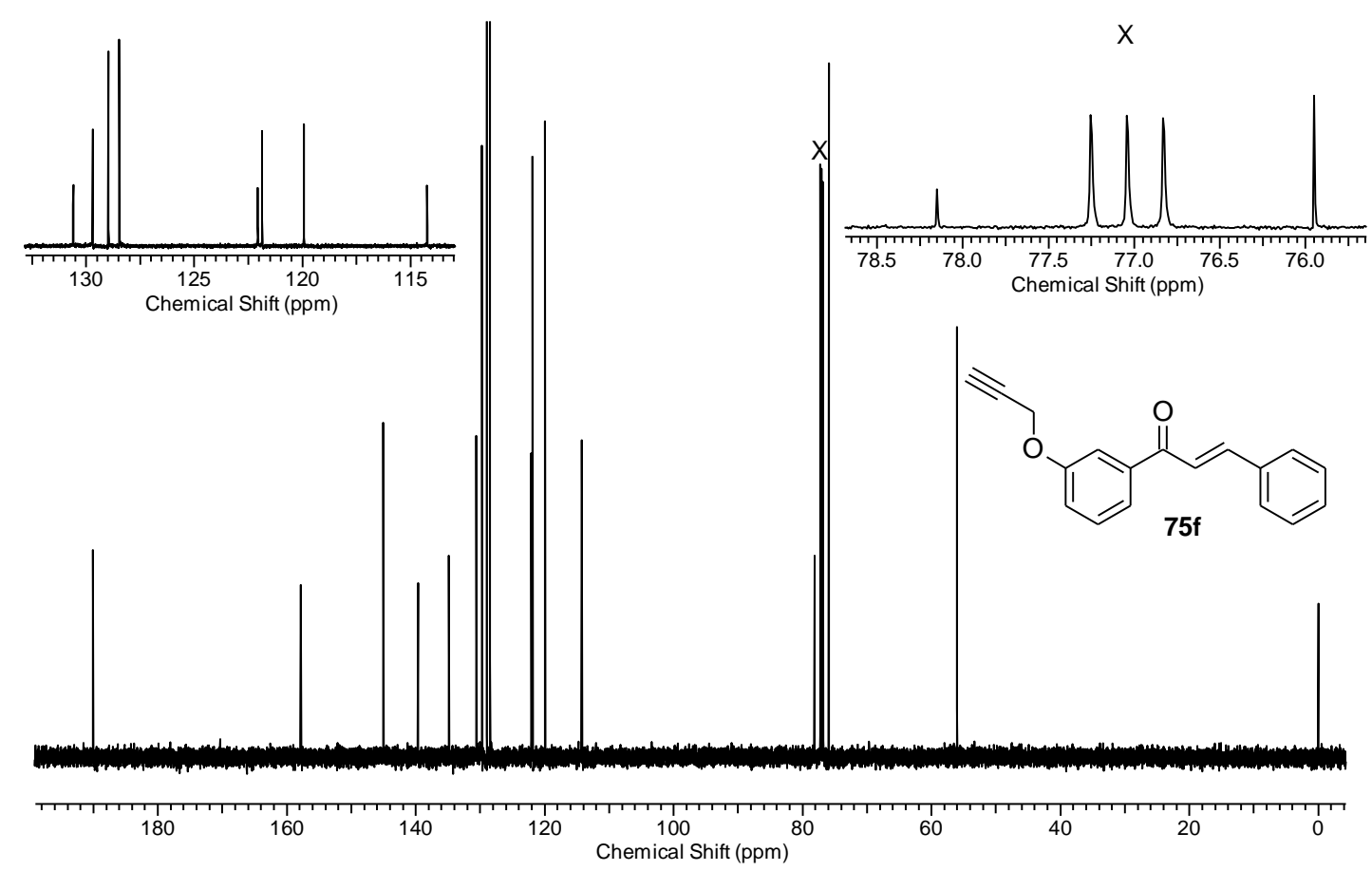

Figura 30 - Espectro de $\mathrm{RMN}{ }^{13} \mathrm{C}\left(150 \mathrm{MHz}, \mathrm{CDCl}_{3}\right)$ do composto $75 f$. 


\subsection{Síntese da 2-propargiloxi-1,4-naftoquinona}

A metodologia de síntese da 2-propargiloxi-1,4-naftoquinona foi baseada no trabalho de Bian e colaboradores. ${ }^{59}$ Em um balão, foram adicionadas a 2-hidróxi-1,4naftoquinona 12 (lausona) e carbonato de potássio em DMF. Após 20 minutos de agitação, brometo de propargila foi adicionado à mistura reacional, a qual foi posteriormente aquecida a $50{ }^{\circ} \mathrm{C}$ durante 4 horas (Esquema 36). Posteriormente, o produto formado foi extraído com diclorometano, lavado com água (5 x $20 \mathrm{ml}$ ), seco com sulfato de sódio anidro e evaporado. O sólido foi purificado por coluna cromatográfica em sílica gel com rendimento de 72\% (sólido amarelo). Sua caracterização foi realizada utilizando métodos espectroscópicos de análise (RMN de ${ }^{1} \mathrm{H}$ $\left.\mathrm{e}^{13} \mathrm{C}\right)$.

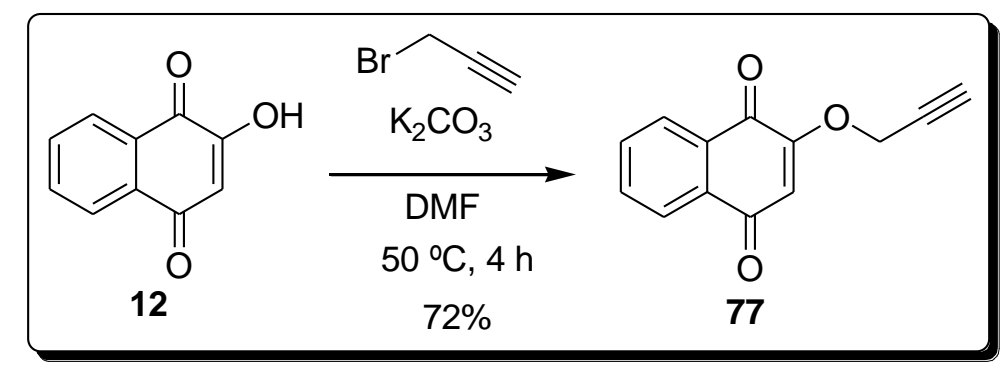

Esquema 36 - Síntese da 2-propargiloxi-1,4-naftoquinona.

$\mathrm{O}$ espectro de $\mathrm{RMN}{ }^{1} \mathrm{H}$ do composto 77 apresenta na região entre 8,14 - 8,09 ppm dois dupletos de dupletos com integração de 1 hidrogênio aromático cada, correspondentes aos hidrogênios aromáticos a e b (Figura 31 e Tabela 13). Apresenta também dois tripletos de dupletos na região entre 7,77 - 7,71 ppm com integração de 1 hidrogênio aromático cada, correspondentes aos hidrogênios aromáticos c e d. Um simpleto com integral de 1 hidrogênio aparece em torno de 6,36 ppm e corresponde ao hidrogênio olefínico e. Os hidrogênios do metileno do grupo propargiloxi (f) aparecem como um dupleto em 4,80 ppm com integração de 2 hidrogênios. Por fim, o hidrogênio do alcino terminal (g) do mesmo grupo se apresenta como um tripleto em 2,65 ppm com integração de 1 hidrogênio. A molécula em questão é inédita na literatura.

\footnotetext{
${ }^{59}$ Bian, J.; Xu, L.; Deng, B.; Qian, X.; Fan, J.; Yang, X.; Liu, F.; Xu, X.; Guo, X.; Li, X.; Sun, H.; You, Q.; Zhang, X. Bioorg. Med. Chem. Lett. 2015, 25, 1244.
} 


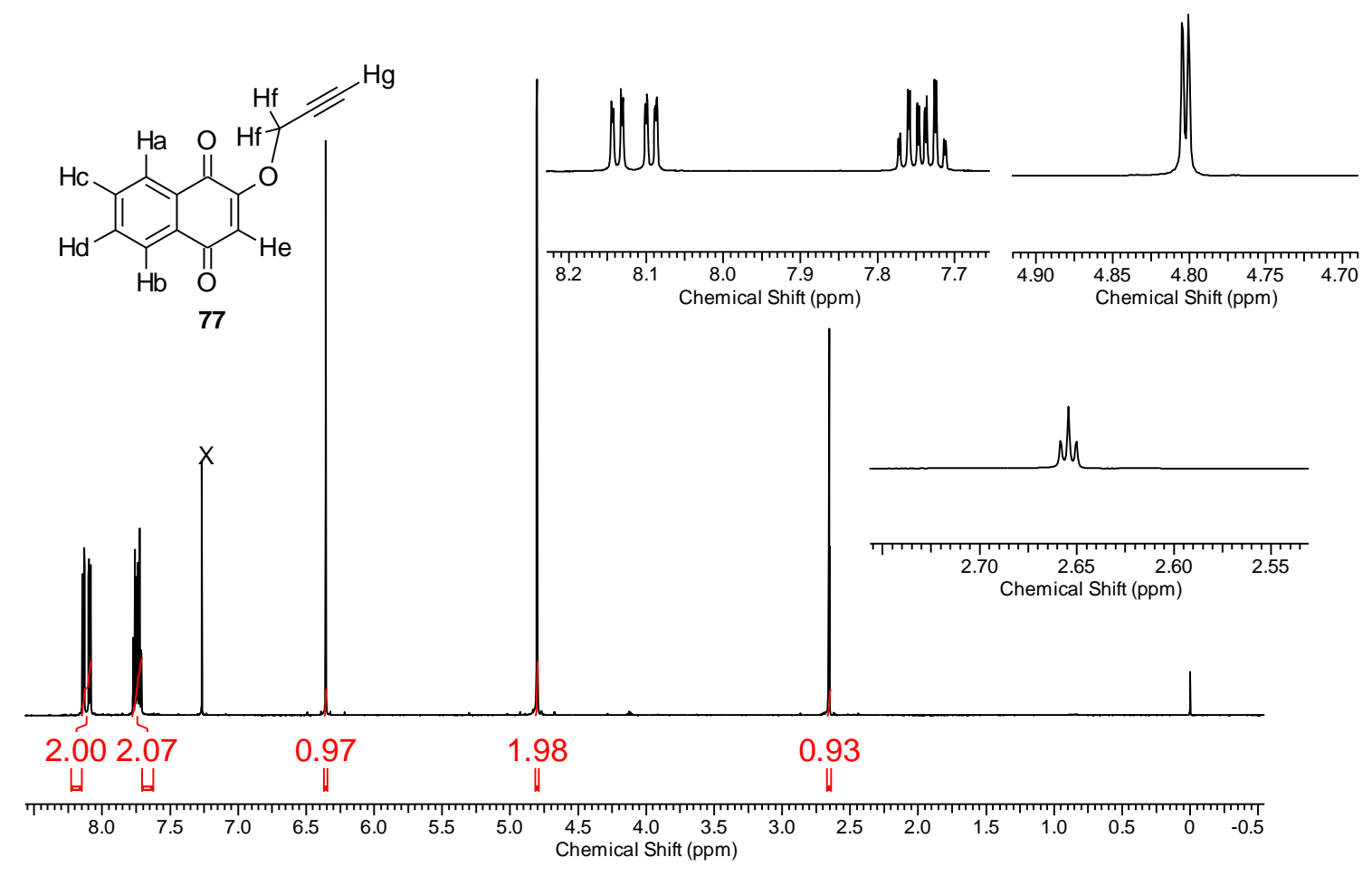

Figura 31 - Espectro de $\mathrm{RMN}{ }^{1} \mathrm{H}\left(600 \mathrm{MHz}, \mathrm{CDCl}_{3}\right)$ do composto 77.

Tabela 13 - Dados de $\mathrm{RMN}{ }^{1} \mathrm{H}\left(600 \mathrm{MHz}, \mathrm{CDCl}_{3}\right)$ do composto 77.

\begin{tabular}{cccc}
\hline $\boldsymbol{\delta}_{\mathbf{h}}(\mathbf{p p m})$ & Multiplicidade & $\begin{array}{c}\text { Hidrogênios } \\
\text { Correspondentes }\end{array}$ & $\mathbf{J}(\mathbf{H z})$ \\
\hline 8,14 & dupleto de dupleto & $1 \mathrm{CH}$ aromático (a) & 7,5 e 1,3 \\
8,09 & dupleto de dupleto & $1 \mathrm{CH}$ aromático (b) & 7,5 e 1,3 \\
7,76 & tripleto de dupleto & $1 \mathrm{CH}$ aromático (c) & 7,5 e 1,3 \\
7,73 & tripleto de dupleto & $1 \mathrm{CH}$ aromático (d) & 7,5 e 1,3 \\
6,45 & simpleto & $1 \mathrm{CH}$ olefínico (e) & - \\
4,80 & dupleto & $1 \mathrm{CH}(\mathrm{f})$ & 2,6 \\
2,65 & tripleto & $1 \mathrm{CH}$ de alcino $(\mathrm{g})$ & 2,6 \\
\hline
\end{tabular}

O espectro de RMN de ${ }^{13} \mathrm{C}$ do produto apresenta 13 picos (Figura 32). Os picos em 184,7 e 179,8 ppm correspondem aos carbonos das carbonilas a e b, respectivamente. O pico em 158,1 ppm corresponde ao carbono olefínico ligado ao grupo propargiloxi c. Entre 134,3 e 126,2 ppm, localizam-se os 6 picos dos carbonos aromáticos d-i. Em 111,6 ppm, encontra-se o pico referente ao carbono olefínico j. Os 
picos em 78,2 e 75,4 ppm correspondem aos carbonos da ligação tripla $\mathbf{k}$ e $\mathbf{l}$. Por fim, em 56,7 ppm se apresenta o pico relativo ao carbono do grupo metileno m (Tabela 14).
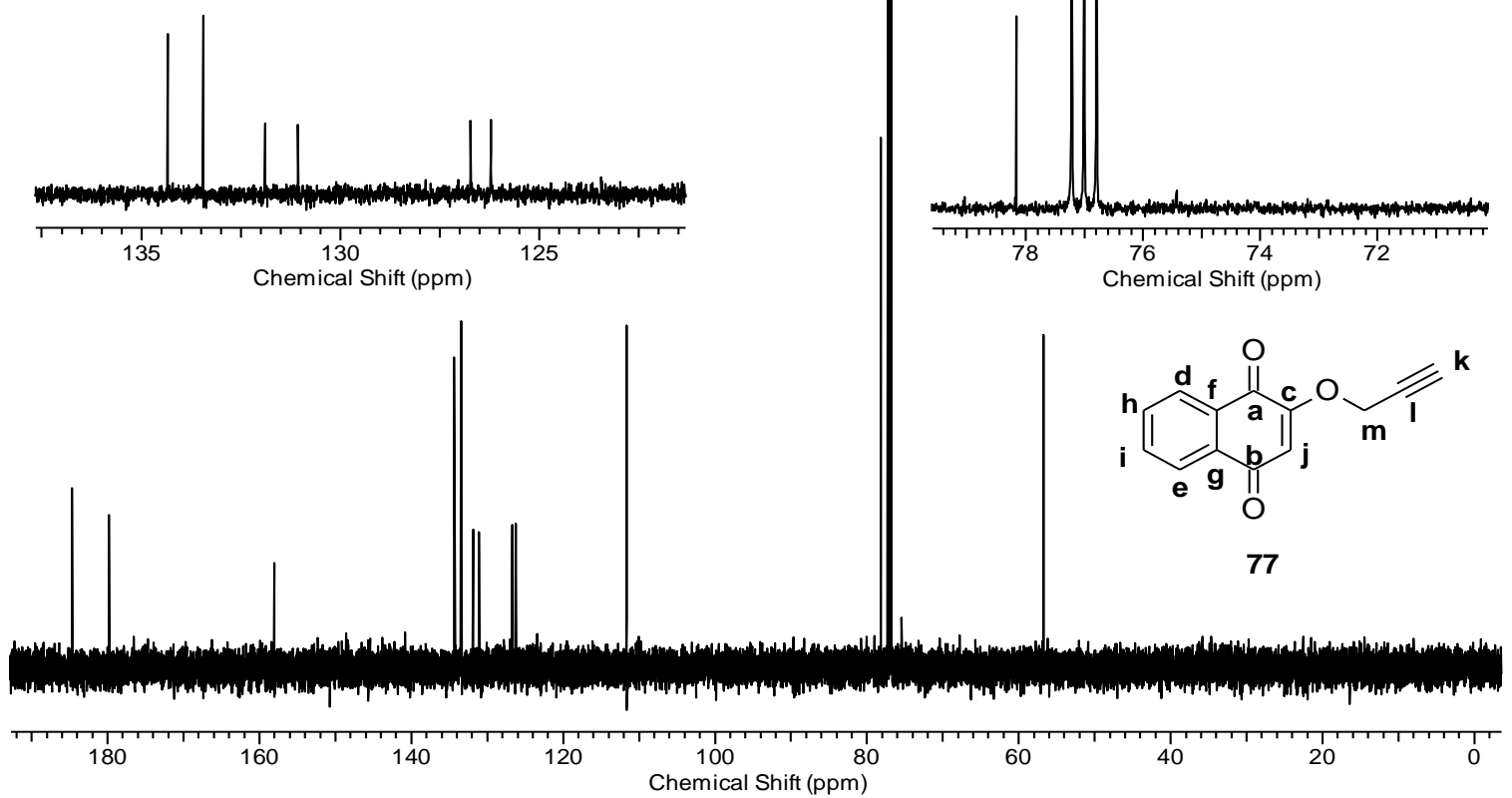

Figura 32 - Espectro de $\mathrm{RMN}{ }^{13} \mathrm{C}\left(150 \mathrm{MHz}, \mathrm{CDCl}_{3}\right)$ do composto 77.

Tabela 14 - Dados de $\mathrm{RMN}{ }^{13} \mathrm{C}\left(150 \mathrm{MHz}, \mathrm{CDCl}_{3}\right)$ do composto 77.

\begin{tabular}{cc}
\hline $\boldsymbol{\delta}_{\mathbf{c}}(\mathbf{p p m})$ & $\begin{array}{c}\text { Carbonos } \\
\text { Correspondentes }\end{array}$ \\
\hline 184,7 & $\mathrm{C}=\mathrm{O}$ \\
179,8 & $\mathrm{C}=\mathrm{O}$ \\
158,1 & $\mathrm{C}-\mathrm{OR}$ quinônico \\
134,3 & $\mathrm{C}$ aromático \\
133,4 & $\mathrm{C}$ aromático \\
131,9 & $\mathrm{C}$ aromático \\
131,1 & $\mathrm{C}$ aromático \\
126,7 & $\mathrm{C}$ aromático \\
126,2 & $\mathrm{C}$ aromático \\
111,6 & $\mathrm{C}-\mathrm{H}$ quinônico \\
78,2 & $\mathrm{C} \equiv \mathrm{C}$ \\
75,4 & $\mathrm{C} \equiv \mathrm{C}$ \\
56,7 & $\mathrm{CH}{ }_{2}$ \\
\hline
\end{tabular}




\subsection{Síntese da 4-azido-acetofenona}

A metodologia de síntese da 4-azido-acetofenona foi baseada no trabalho de Balamurugan e colaboradores (Esquema 37). ${ }^{60} \mathrm{Em}$ um balão foram adicionados a 4amino-acetofenona, ácido acético glacial e ácido sulfúrico. A mistura reacional foi, então, colocada em um banho de gelo, próximo de $0{ }^{\circ} \mathrm{C}$. Gota a gota, foi adicionado uma solução de nitrito de sódio em quantidade mínima de água. Após 30 minutos, uma solução de azida de sódio em quantidade mínima de água foi adicionada à solução lentamente. Após mais 30 minutos de reação, a mistura reacional foi neutralizada com solução de hidróxido de sódio e um precipitado foi formado. O sólido foi filtrado a vácuo e lavado com água. Sua purificação foi através de coluna cromatográfica em sílica gel fornecendo o composto 79, um sólido amarelo claro, com rendimento de $95 \%$. Sua caracterização foi realizada utilizando métodos espectroscópicos de análise (RMN de $\left.{ }^{1} \mathrm{H} \mathrm{e}{ }^{13} \mathrm{C}\right)$.

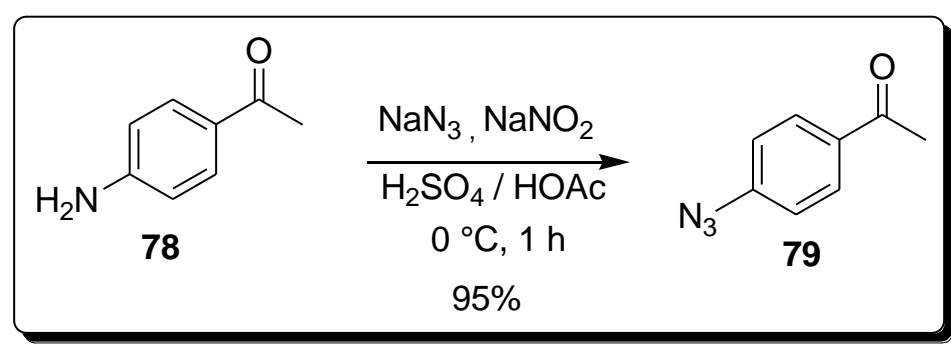

Esquema 37 - Formação da 4-azido-acetofenona.

O espectro de RMN ${ }^{1} \mathrm{H}$ do composto 79 apresenta em 7,96 ppm um dupleto com integração de 2 hidrogênios correspondente aos hidrogênios aromáticos a (Figura 33). Em 7,08 ppm, encontra-se um dupleto com integração de 2 hidrogênios referente aos hidrogênios aromáticos b. Por fim, em 2,58 ppm aparece um simpleto com integração de 3 hidrogênios que corresponde aos hidrogênios do grupo metila c (Tabela 15). Dados da literatura confirmam os resultados. ${ }^{61}$

\footnotetext{
${ }^{60}$ Balamurugan, S.; Nithyanandan, S.; Selvarasu, C.; Yeap, G. Y.; Kannan, P. Polymer 2012, 53, 4104.

${ }^{61}$ Tian, H.; Qian, J.; Sun, Q.; Jiang, C.; Zhang, R.; Zhang, W. R. Soc. Chem. 2014, 139, 3373.
} 


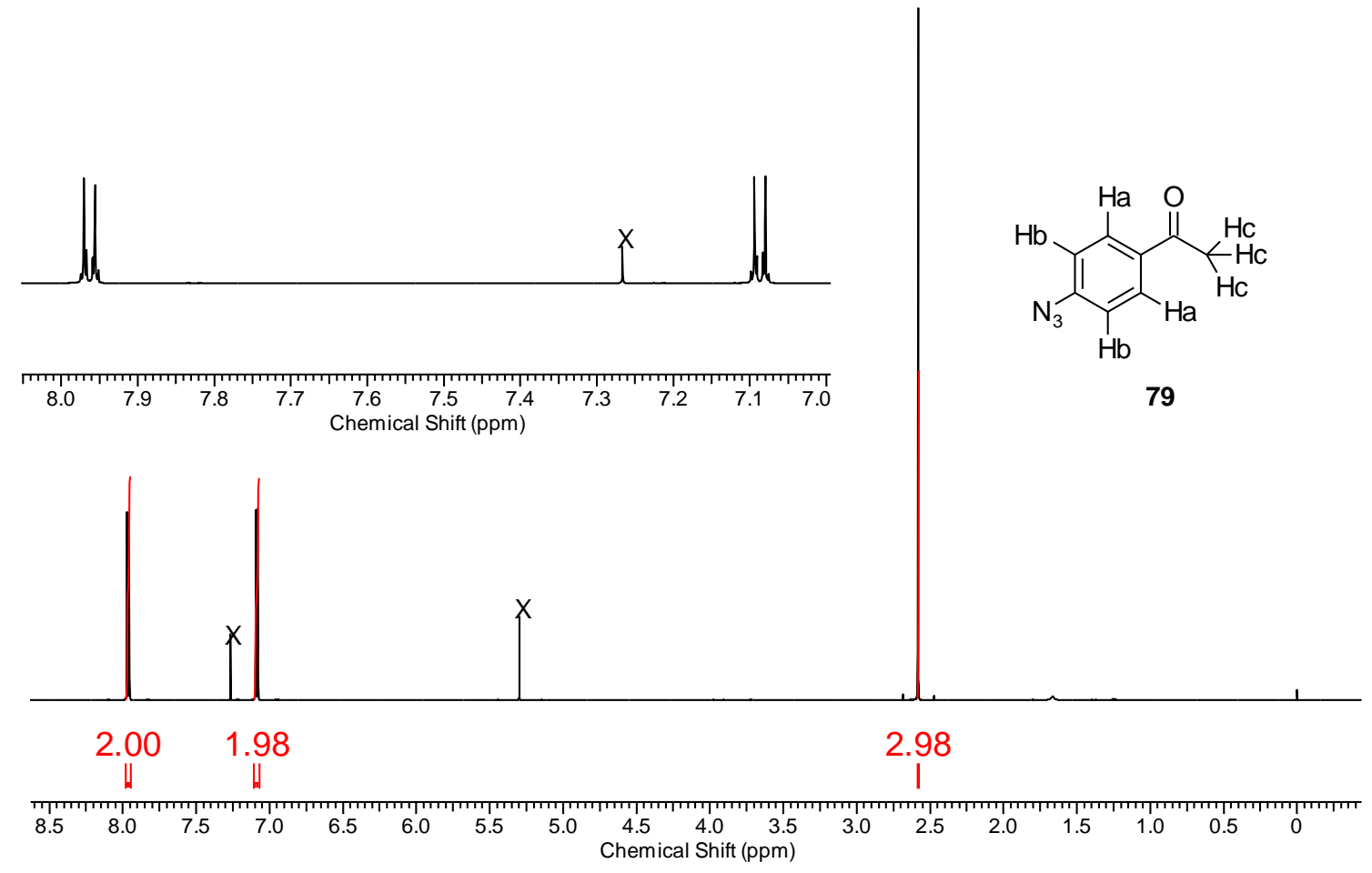

Figura 33 - Espectro de $\mathrm{RMN}{ }^{1} \mathrm{H}\left(600 \mathrm{MHz}, \mathrm{CDCl}_{3}\right)$ do composto 79.

Tabela 15- Dados de $\mathrm{RMN}{ }^{1} \mathrm{H}\left(600 \mathrm{MHz}, \mathrm{CDCl}_{3}\right)$ do composto 79.

\begin{tabular}{ccccc}
\hline $\boldsymbol{\delta}_{\mathbf{h}}$ (ppm) & $\boldsymbol{\delta}_{\mathbf{h}}$ (lit.) $^{\mathbf{6 1}}$ & Multiplicidade & $\begin{array}{c}\text { Hidrogênios } \\
\text { Correspondentes }\end{array}$ & $\boldsymbol{J ( H z )}$ \\
\hline 7,96 & 7,97 & dupleto & 2 CH's aromáticos (a) & 8,8 \\
7,08 & 7,09 & dupleto & 2 CH's aromáticos (b) & 8,8 \\
2,58 & 2,59 & simpleto & 3 CH's do grupo metila (c) & - \\
\hline
\end{tabular}

$\mathrm{O}$ espectro de $\mathrm{RMN}$ de ${ }^{13} \mathrm{C}$ do produto apresenta 6 picos (Figura 34). $\mathrm{O}$ pico em 196,5 ppm corresponde ao carbono da carbonila a. O pico em 144,9 ppm corresponde ao carbono aromático ligado ao grupo azida b. O pico em 133,9 ppm é referente ao carbono aromático ligado ao grupo carbonila c. Os picos em 130,2 e 118,9 ppm estão associados aos carbonos aromáticos restante do anel d e e. Por fim, em 26,4 ppm, encontra-se o pico referente ao carbono do grupo metila f (Tabela 16). Dados da literatura confirmam os resultados. ${ }^{62}$

${ }^{62}$ Kimatura, M.; Kato, S.; Yano, M.; Tashiro, N.; Shiratake, Y.; Sando, M.; Okauchi, T. Org. Biomol. Chem. 2014, 12, 4397. 


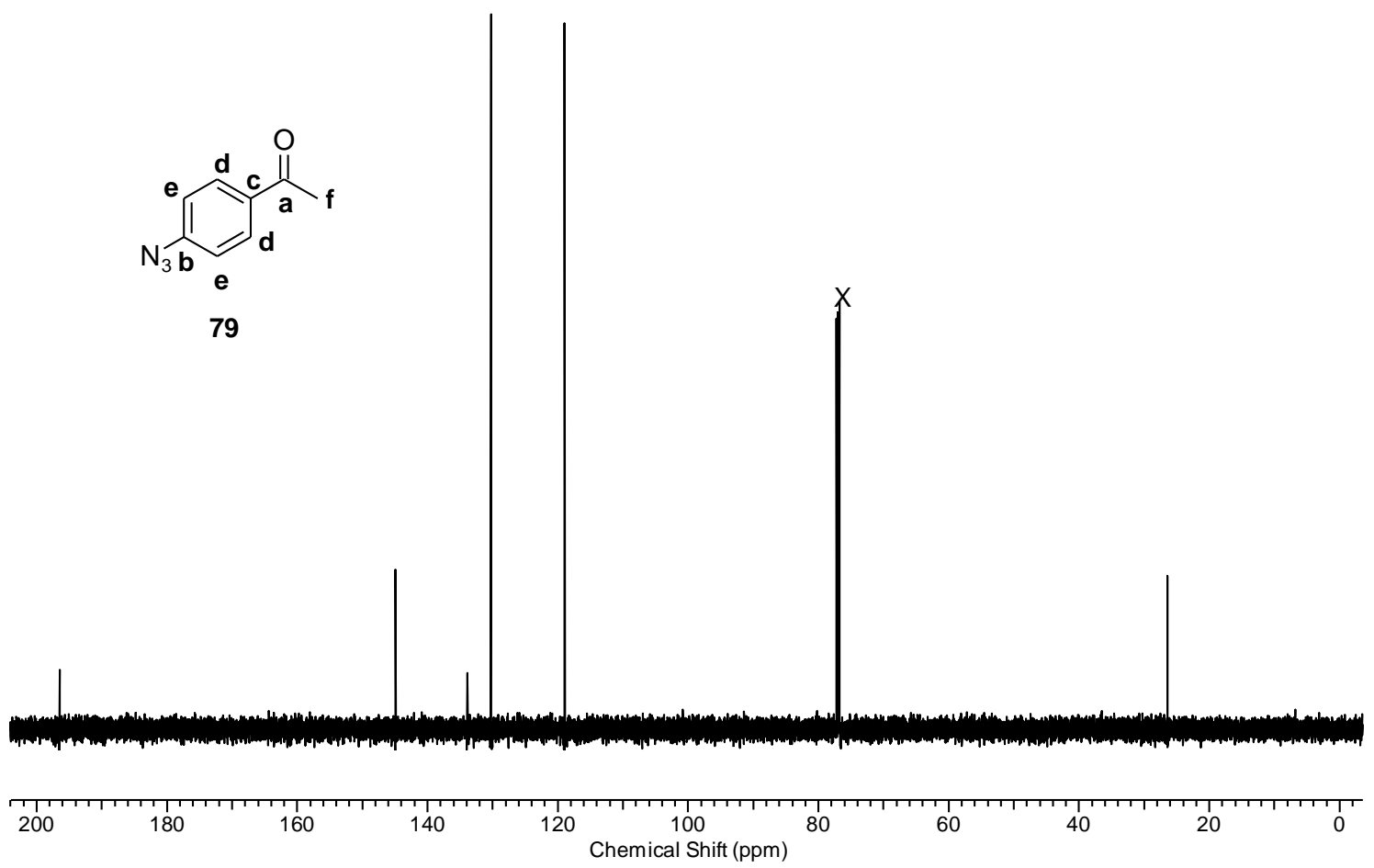

Figura 34 - Espectro de $\mathrm{RMN}{ }^{13} \mathrm{C}\left(150 \mathrm{MHz}, \mathrm{CDCl}_{3}\right)$ do composto 79.

Tabela 16 - Dados de $\mathrm{RMN}{ }^{13} \mathrm{C}\left(150 \mathrm{MHz}, \mathrm{CDCl}_{3}\right)$ do composto 79.

\begin{tabular}{ccc}
\hline $\boldsymbol{\delta} \mathbf{c}(\mathbf{p p m})$ & $\boldsymbol{\delta}_{\mathbf{c}(\mathbf{l i t} .)^{\mathbf{6 2}}}$ & $\begin{array}{c}\text { Carbonos } \\
\text { Correspondentes }\end{array}$ \\
\hline 196,5 & 196,5 & $\mathrm{C}=\mathrm{O}(\mathrm{a})$ \\
144,9 & 144,9 & ${\mathrm{C}-\mathrm{N}_{3} \text { aromático (b) }}$ \\
133,9 & 133,8 & $\mathrm{C}_{0}$ aromático (c) \\
130,2 & 130,2 & $\mathrm{C}$ aromático (d) \\
118,9 & 118,9 & $\mathrm{C}$ aromático (e) \\
26,4 & 26,5 & $\mathrm{CH}_{3}(\mathrm{f})$ \\
\hline
\end{tabular}




\subsection{Síntese das Chalconas 80}

A metodologia da síntese das chalconas 80a-e foi baseada no trabalho de Silva e colaboradores. ${ }^{19}$ Em um balão, foram adicionados a 2-propargiloxi-1,4-naftoquinona, solução de hidróxido de sódio (2 equivalentes) $10 \%$ em água e etanol à temperatura ambiente por $20 \mathrm{~min}$. Posteriormente, os respectivos aldeídos 74a-e (devidamente purificados) foram adicionados à mistura reacional, a qual foi agitada por 24 horas à temperatura ambiente (Esquema 38).

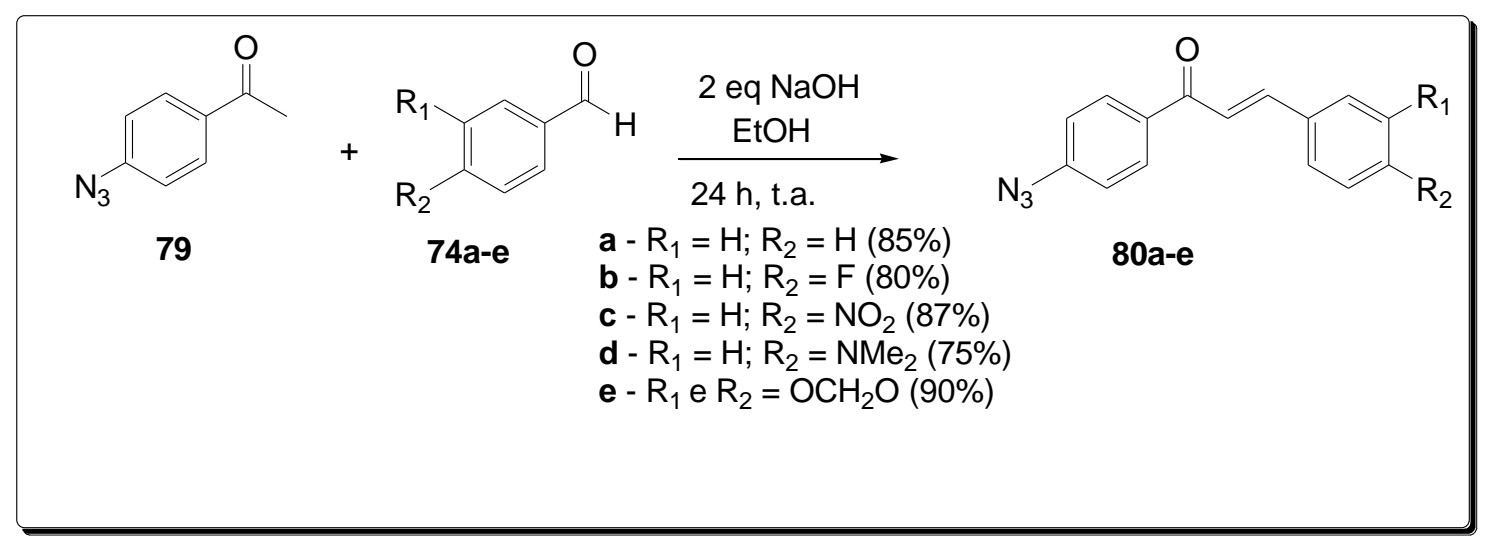

Esquema 38 - Síntese das chalconas 80.

$\mathrm{Na}$ síntese das chalconas $\mathbf{8 0}$, houve precipitação dos sólidos ao término da reação. Logo, os produtos foram simplesmente filtrados e lavados com etanol gelado, conferindo bons rendimentos e pureza. A caracterização dos produtos se deu através de espectros de RMN de ${ }^{1} \mathrm{H}$ e ${ }^{13} \mathrm{C}$.

Para elucidação dos espectros em questão, será utilizado o composto 80a como exemplo. As demais chalconas apresentam espectros de semelhante elucidação e entendimento.

O espectro de RMN de ${ }^{1} \mathrm{H}$ do composto 80a apresenta um dupleto em 8,05 ppm com integração de 2 hidrogênios, correspondente aos hidrogênios aromáticos a (Figura 35 e Tabela 17). Em 7,82 ppm, encontra-se um dupleto com integração de 1 hidrogênio, correspondente ao hidrogênio olefínico b. Na faixa entre 7,65 - 7,64 ppm, encontra-se um multipleto com integração de 2 hidrogênios os quais se referem aos hidrogênios aromáticos c. Em 7,51 ppm, apresenta-se um dupleto com integração de 1 hidrogênio, correspondente ao hidrogênio olefínico d. Na faixa de 7,45-7,41 ppm, aparece um multipleto com integração de 3 hidrogênios que está associado aos 3 hidrogênios aromáticos e. Por fim, em 7,14 ppm, encontra-se um dupleto com integração de 2 
hidrogênios, referente aos hidrogênios aromáticos f. Dados da literatura confirmam os resultados obtidos. ${ }^{63}$

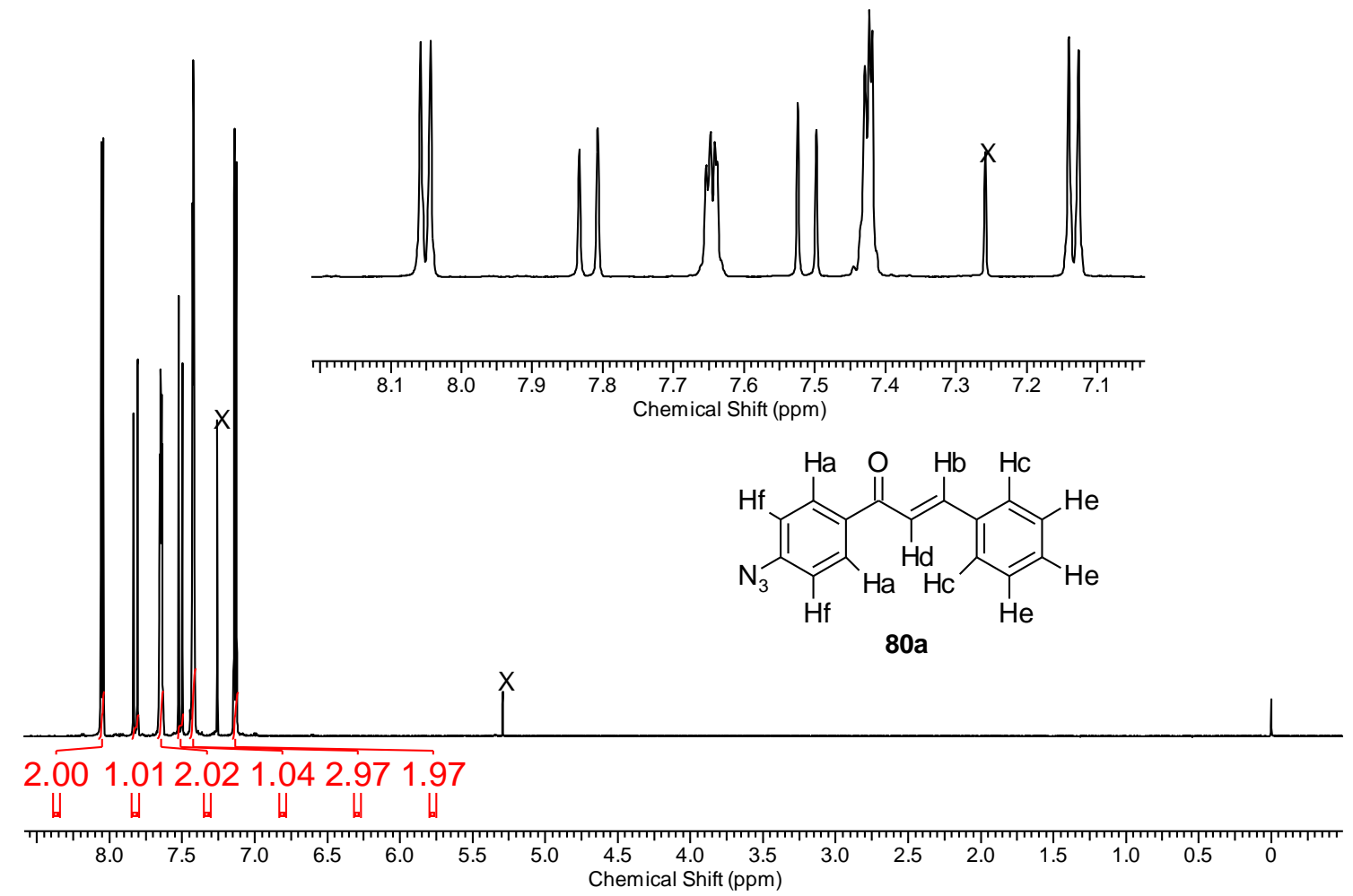

Figura 35- Espectro de $\mathrm{RMN}{ }^{1} \mathrm{H}\left(600 \mathrm{MHz}, \mathrm{CDCl}_{3}\right)$ do composto 80a.

Tabela 17 - Dados de $\mathrm{RMN}{ }^{1} \mathrm{H}\left(600 \mathrm{MHz}, \mathrm{CDCl}_{3}\right)$ do composto 80a.

\begin{tabular}{ccccc}
\hline $\boldsymbol{\delta}_{\mathbf{h}}(\mathbf{p p m})$ & $\boldsymbol{\delta}_{\mathbf{h}}$ (lit.) $^{\mathbf{6 3}}$ & Multiplicidade & $\begin{array}{c}\text { Hidrogênios } \\
\text { Correspondentes }\end{array}$ & $\boldsymbol{J}(\mathbf{H z})$ \\
\hline 8,05 & 8,05 & dupleto & $2 \mathrm{CH}$ aromáticos (a) & 8,4 \\
7,82 & 7,82 & dupleto & 1 CH olefínico (b) & 15,8 \\
$7,65-7,64$ & $7,66-7,64$ & multipleto & $2 \mathrm{CH}$ aromáticos (c) & - \\
7,51 & 7,52 & dupleto & 1 CH olefínico (d) & 15,8 \\
$7,45-7,41$ & $7,44-7,42$ & multipleto & 3 CH aromáticos (e) & - \\
7,14 & 7,13 & dupleto & 2 CH aromáticos (f) & 8,4 \\
\hline
\end{tabular}

$\mathrm{O}$ espectro de $\mathrm{RMN}$ de ${ }^{13} \mathrm{C}$ do produto apresenta 10 picos (Figura 36). O pico em 188,7 ppm corresponde ao carbono da carbonila. Os demais picos em 144,9 - 119,1

\footnotetext{
${ }^{63}$ a) Zarghi, A.; Zebardast, T.; Hakimion, F.; Shirazi, F. H.; Rao, P. N. P.; Knaus, E. E. Bioorg. Med. Chem. 2006, 14, 7044.; b) Iqbal, H.; Prabhakar, V.; Sangith, A.; Chandrika, B.; Balasubramanian, R. Med. Chem. Res. 2014, 23, 4383.
} 
ppm correspondem aos carbonos aromáticos e os dois olefínicos (Tabela 18). Dados da literatura confirmam os resultados. ${ }^{63}$

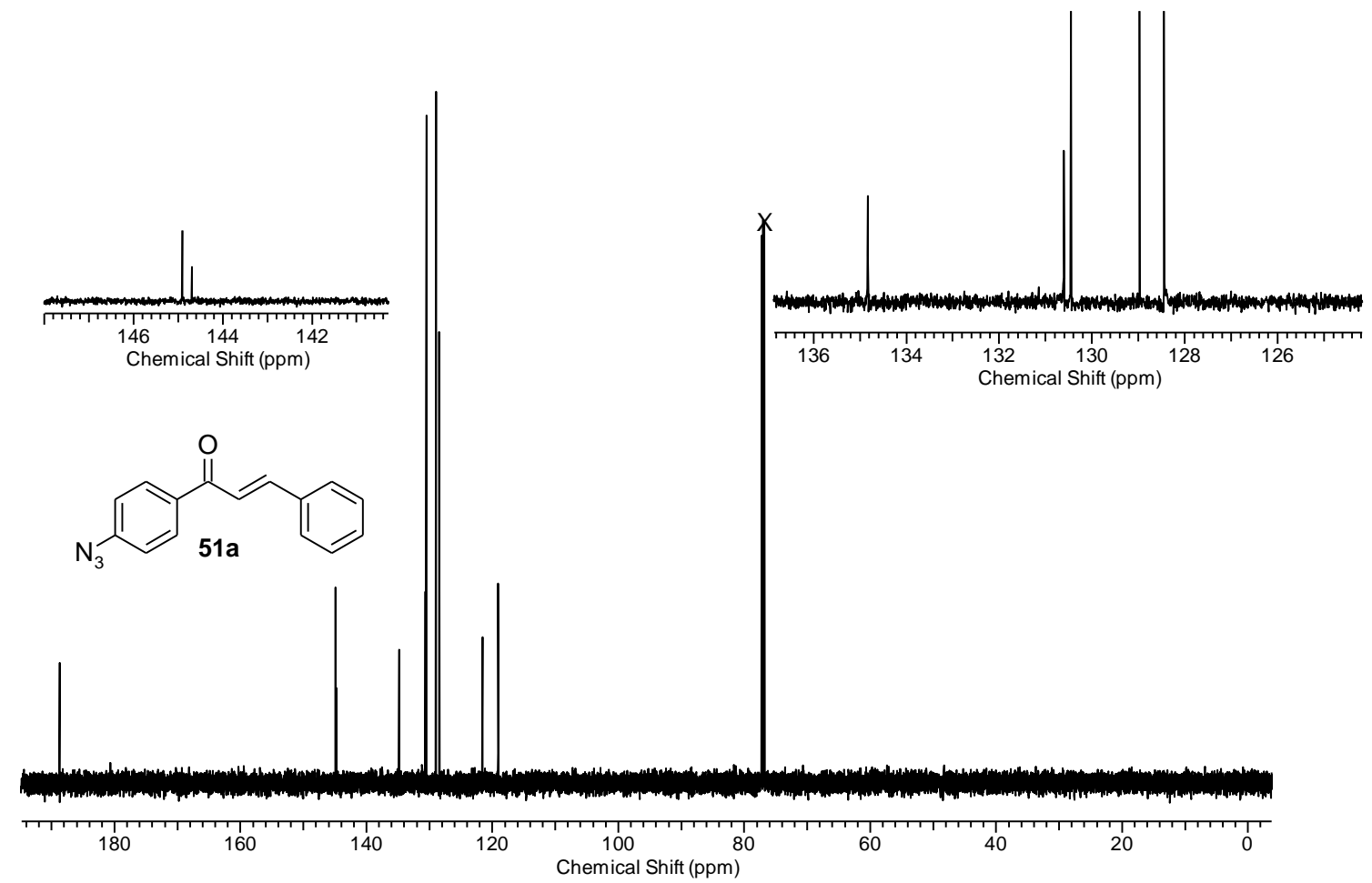

Figura 36 - Espectro de $\mathrm{RMN}{ }^{13} \mathrm{C}\left(150 \mathrm{MHz}, \mathrm{CDCl}_{3}\right)$ do composto 80a.

Tabela 18 - Dados de $\mathrm{RMN}{ }^{13} \mathrm{C}\left(150 \mathrm{MHz}, \mathrm{CDCl}_{3}\right)$ do composto 80a.

\begin{tabular}{ccc}
\hline $\boldsymbol{\delta}_{\mathbf{c}}(\mathbf{p p m})$ & $\boldsymbol{\delta}_{\mathbf{c}}(\mathbf{l i t})^{\mathbf{6 3}}$ & $\begin{array}{c}\text { Carbonos } \\
\text { Correspondentes }\end{array}$ \\
\hline 188,7 & 188,6 & $\mathrm{C}=\mathrm{O}$ \\
144,9 & 144,9 & $\mathrm{C}-\mathrm{N}_{3}$ aromático \\
144,7 & 144,7 & $\mathrm{C}_{0}$ aromático \\
134,8 & 134,8 & $\mathrm{C}$ aromático \\
130,6 & 130,6 & $\mathrm{C}$ aromático \\
130,5 & 130,4 & $\mathrm{C}$ olefínico \\
129,0 & 129,0 & $\mathrm{C}$ olefínico \\
128,4 & 128,4 & $\mathrm{C}$ aromático \\
121,6 & 121,5 & $\mathrm{C}$ aromático \\
119,1 & 119,0 & $\mathrm{C}$ aromático \\
\hline
\end{tabular}


Por ser inédita na literatura, faz-se necessário a elucidação dos dados espectroscópicos da chalcona 80e. O espectro de $\mathrm{RMN}{ }^{1} \mathrm{H}$ do composto 80e apresenta um dupleto com integração de 2 hidrogênios em 8,03 ppm, que está associado aos hidrogênios aromáticos a (Figura 37 e Tabela 19). Em 7,74 ppm, encontra-se um dupleto com integração de 1 hidrogênio, referente ao hidrogênio olefínico b. Um dupleto com integração de 1 hidrogênio aparece em 7,34 ppm, correspondente ao hidrogênio olefínico c. Em 7,16 ppm, apresenta-se um dupleto com integração de 1 hidrogênio que se refere ao hidrogênio aromático d. Na faixa de 7,14-7,11 ppm, existe um multipleto com integração de 3 hidrogênios que corresponde aos dois hidrogênios aromáticos e, sobreposto ao pico do hidrogênio aromático f. Em 6,85 ppm, apresenta-se um dupleto com integração de 1 hidrogênio o qual corresponde ao hidrogênio aromático g. Por fim, um simpleto com integração de 2 hidrogênios aparece em 6,03 ppm, referente aos hidrogênios do grupo metileno $\mathbf{h}$.

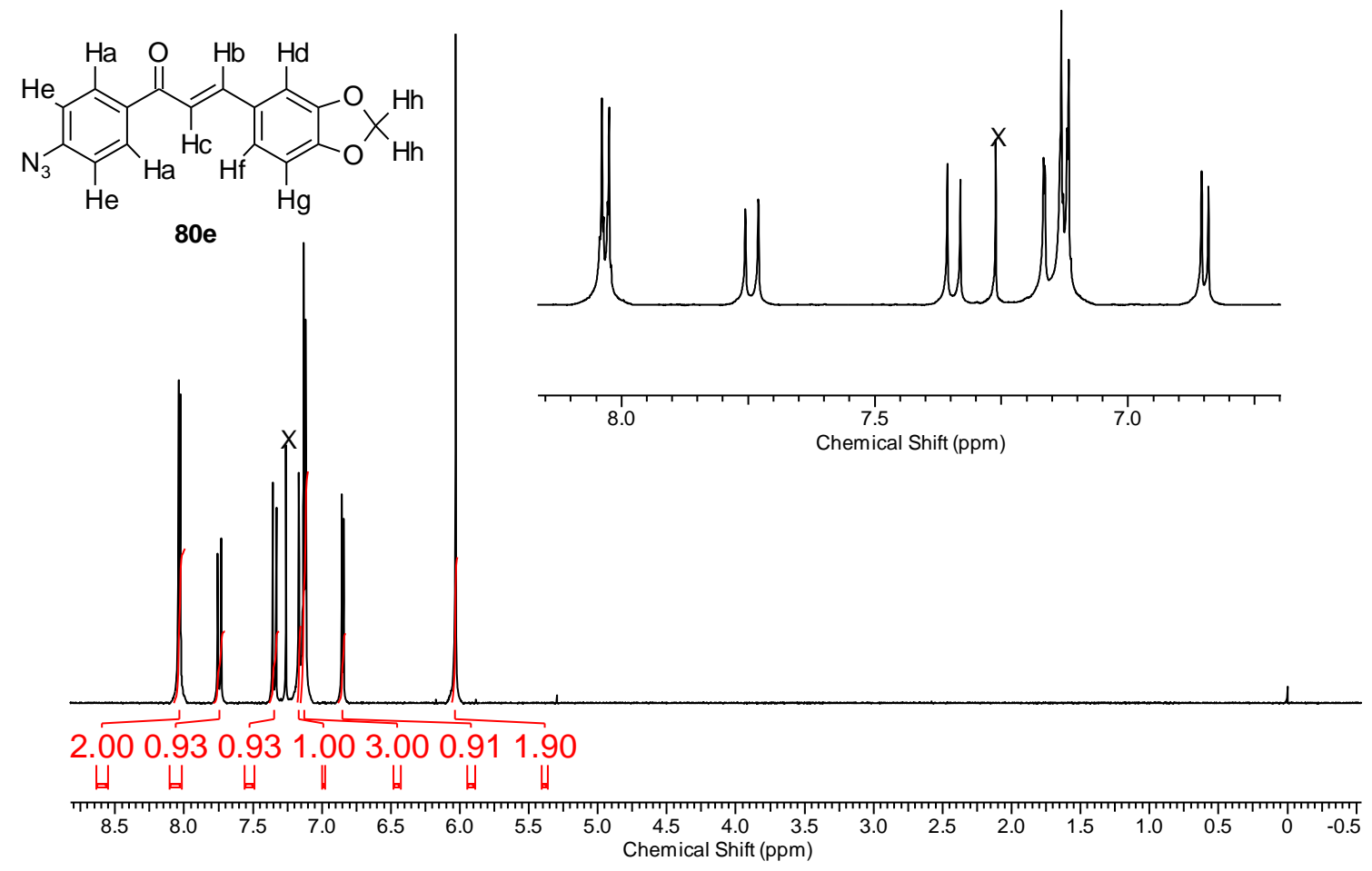

Figura 37 - Espectro de $\mathrm{RMN}{ }^{1} \mathrm{H}\left(600 \mathrm{MHz}, \mathrm{CDCl}_{3}\right)$ do composto 80e. 
Tabela 19 - Dados de $\mathrm{RMN}{ }^{1} \mathrm{H}\left(600 \mathrm{MHz}, \mathrm{CDCl}_{3}\right)$ do composto 80e.

\begin{tabular}{cccc}
\hline $\boldsymbol{\delta}_{\mathbf{h}}(\mathbf{p p m})$ & $\begin{array}{c}\text { Multiplicidad } \\
\text { e }\end{array}$ & $\begin{array}{c}\text { Hidrogênios } \\
\text { Correspondentes }\end{array}$ & $\boldsymbol{J ( H z )}$ \\
\hline 8,03 & dupleto & $2 \mathrm{CH}$ aromáticos (a) & 8,8 \\
7,74 & dupleto & $1 \mathrm{CH}$ olefínico (b) & 15,4 \\
7,34 & dupleto & $1 \mathrm{CH}$ olefínico (c) & 15,4 \\
7,16 & dupleto & $1 \mathrm{CH}$ aromático (d) & 1,5 \\
$7,14-7,11$ & multipleto & $3 \mathrm{CH}$ aromáticos (e, f) & - \\
6,85 & dupleto & $1 \mathrm{CH}$ aromático (g) & 8,1 \\
6,03 & simpleto & $\mathrm{CH}_{2}(\mathrm{~h})$ & - \\
\hline
\end{tabular}

$\mathrm{O}$ espectro de $\mathrm{RMN}$ de ${ }^{13} \mathrm{C}$ do produto apresenta 14 picos (Figura 38). O pico em 188,5 ppm corresponde ao carbono da carbonila. Os demais picos entre 150,0 106,6 ppm correspondem aos carbonos aromáticos e os dois olefínicos. O pico em 101,6 ppm é referente ao carbono do grupo metileno.

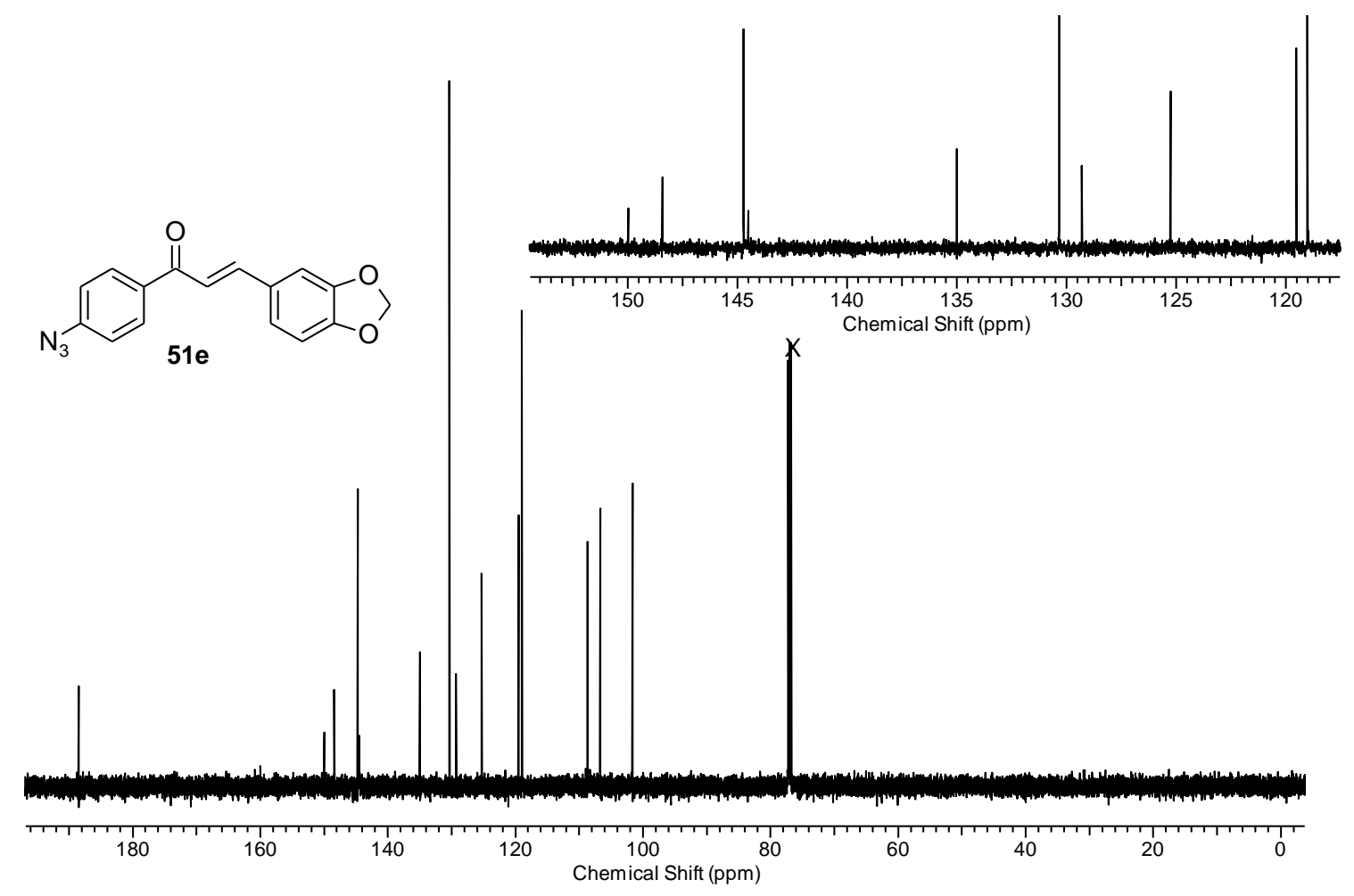

Figura 38 - Espectro de $\mathrm{RMN}{ }^{13} \mathrm{C}\left(150 \mathrm{MHz}, \mathrm{CDCl}_{3}\right)$ do composto 80e. 


\subsection{Síntese dos compostos híbridos 81}

A síntese dos compostos híbridos $\mathbf{8 1}$ foi baseada na mesma metodologia $\mathrm{V}$ da síntese dos compostos híbridos $\mathbf{7 6}^{58}$ (Esquema 39).

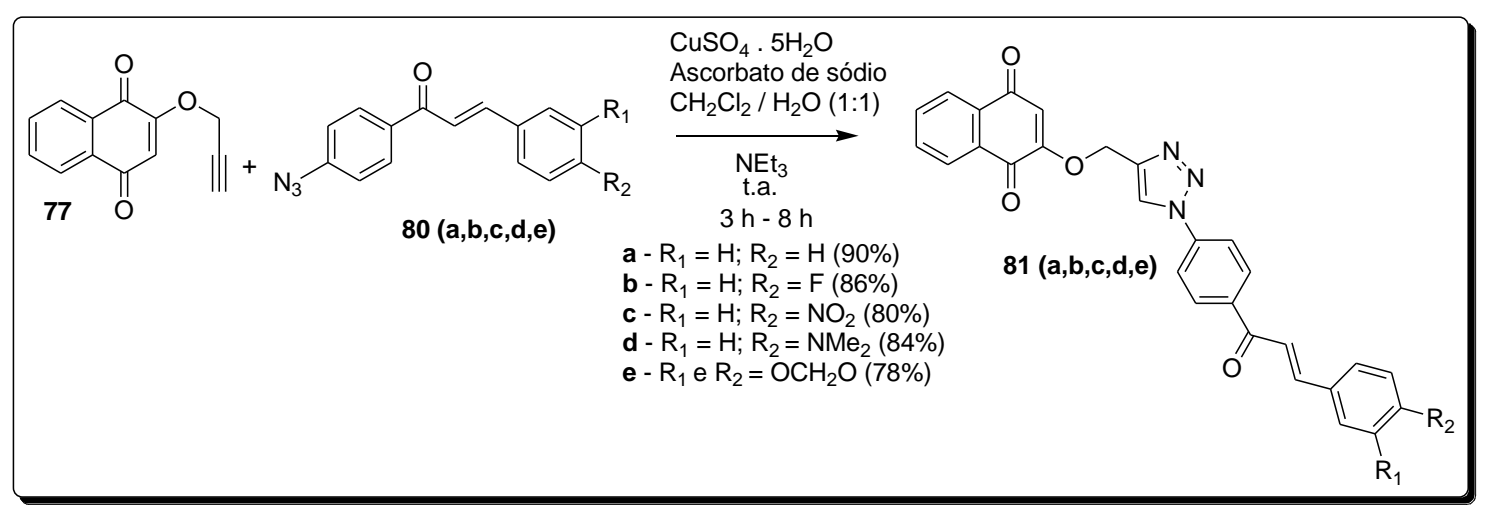

Esquema 39 - Reação click (CuAAC) entre os compostos 77 e 80a-e usando a metodologia $\mathrm{V}$.

Os compostos em questão foram caracterizados a partir de espectroscopia de RMN de ${ }^{1} \mathrm{H}$ e ${ }^{13} \mathrm{C}$. Para a elucidação espectral, utilizar-se-á o composto $\mathbf{8 1 b}$ como exemplo. Os demais compostos apresentam espectros de RMN de semelhante elucidação e entendimento.

$\mathrm{O}$ espectro de $\mathrm{RMN}$ de ${ }^{1} \mathrm{H}$ do composto $\mathbf{8 1 b}$ apresenta como pico mais característico e fundamental para a elucidação da estrutura o simpleto em 9,19 ppm, com integração de 1 hidrogênio, referente ao hidrogênio do anel triazólico a (Figura 39 e Tabela 20). Em 8,39 ppm, encontra-se um dupleto com integração de 2 hidrogênios, correspondente aos dois hidrogênios aromáticos b. Em 8,16 ppm, aparece um dupleto com integração de 2 hidrogênios, referente aos dois hidrogênios aromáticos c. Na faixa de 8,03 - 7,99 ppm, encontra-se um multipleto com integração de 4 hidrogênios, correspondente ao pico dos 2 hidrogênios aromáticos $\mathbf{d}$, sobreposto ao pico referente aos 2 hidrogênios aromáticos e. Em 7,98 ppm, aparece um dupleto com integração de 1 hidrogênio, referente ao hidrogênio olefínico f. Na faixa de 7,89-7,83 ppm, existe um multipleto com integração de 2 hidrogênios correspondente aos 2 hidrogênios aromáticos g. Em 7,80 ppm, encontra-se um dupleto com integração de 1 hidrogênio, correspondente ao hidrogênio olefínico $\mathbf{h}$. Em 7,32 ppm, apresenta-se um tripleto com integração de 2 hidrogênios, referente aos hidrogênios aromáticos i. Este último pico aparece como um tripleto provavelmente devido ao acoplamento $\left({ }^{3} \mathrm{~J}\right){ }^{1} \mathrm{H}-{ }^{19} \mathrm{~F}\left(\operatorname{spin}{ }^{19} \mathrm{~F}\right.$ = 1/2). Em 6,68 ppm aparece um simpleto com integração de 1 hidrogênio, correspondente ao hidrogênio olefínico j. Por fim, em 5,40 ppm, encontra-se um 
simpleto com integração de 2 hidrogênios, correspondente aos hidrogênios do grupo metileno k ligado ao oxigênio e ao anel triazólico.

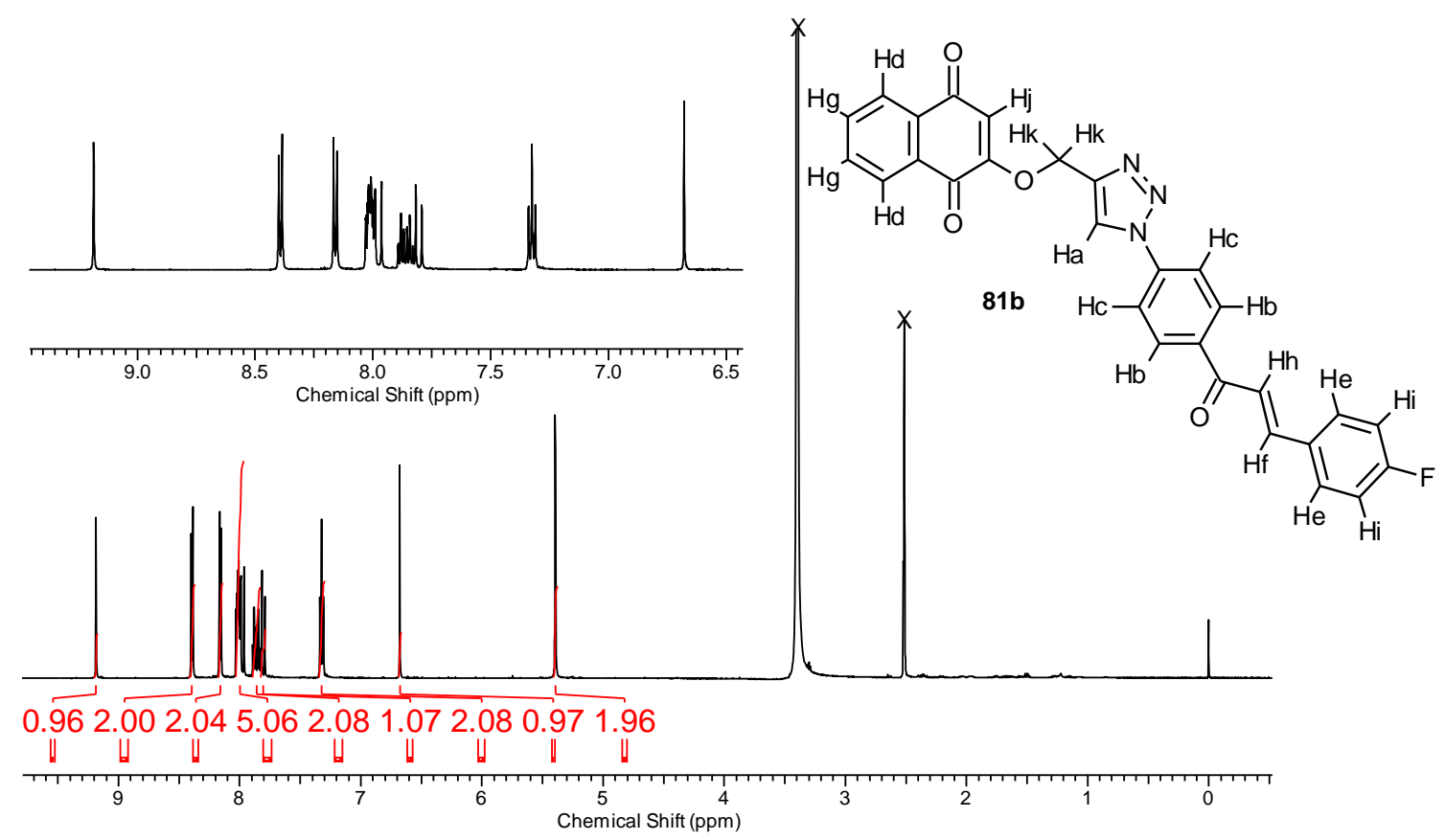

Figura 39 - Espectro de RMN ${ }^{1} \mathrm{H}\left(600 \mathrm{MHz}, \mathrm{DMSO}-d_{6}\right)$ do composto 81b.

Tabela 20 - Dados de RMN ${ }^{1} \mathrm{H}\left(600 \mathrm{MHz}, \mathrm{DMSO}-d_{6}\right)$ do composto $81 \mathbf{b}$.

\begin{tabular}{cccc}
\hline $\boldsymbol{\delta}_{\mathbf{h}}(\mathbf{p p m})$ & Multiplicidade & $\begin{array}{c}\text { Hidrogênios } \\
\text { Correspondentes }\end{array}$ & $\boldsymbol{J}(\mathbf{H z})$ \\
\hline 9,19 & simpleto & $1 \mathrm{CH}$ triazólico (a) & - \\
8,39 & dupleto & $2 \mathrm{CH}$ aromáticos (b) & 8,8 \\
8,16 & dupleto & $2 \mathrm{CH}$ aromáticos (c) & 8,8 \\
$8,03-7,99$ & multipleto & $4 \mathrm{CH}$ aromáticos (d, e) & - \\
7,98 & dupleto & $1 \mathrm{CH}$ olefínico (f) & 15,8 \\
$7,89-7,83$ & multipleto & $2 \mathrm{CH}$ aromáticos (g) & - \\
7,80 & dupleto & $1 \mathrm{CH}$ olefínico (h) & 15,8 \\
7,32 & tripleto & $2 \mathrm{CH}$ aromáticos (i) & 8,4 \\
6,68 & simpleto & $1 \mathrm{CH}$ olefínico (j) & - \\
5,40 & simpleto & $\mathrm{CH}_{2}(\mathrm{k})$ & - \\
\hline
\end{tabular}


O espectro de RMN de ${ }^{13} \mathrm{C}$ apresenta 24 picos (Figura 40). Os picos em 188,0; 184,6 e 179,5 ppm correspondem aos carbonos das carbonilas a, b, e c. Existem quatros picos peculiares no espectro, peculiaridades essas denotadas pelo fato de serem 4 dupletos. Esse fenômeno é devido ao acoplamento heteronuclear ${ }^{13} \mathrm{C}-{ }^{19} \mathrm{~F}$. O padrão desses dupletos segue a mesma regra do $\mathrm{n}+1$ pelo fato do átomo de ${ }^{19} \mathrm{~F}$ possuir spin igual a $1 \frac{1}{2}$. Portanto, os quatros carbonos equivalentes do anel aromático ligado ao átomo do elemento flúor se apresentam como dupletos. Em 163,6 ppm, encontra-se um dupleto $(J=247,5 \mathrm{~Hz})$ correspondente ao carbono aromático ligado diretamente ao flúor $\mathbf{d}$. Em 131,4 ppm, apresenta-se um dupleto $(J=9,0 \mathrm{~Hz})$, correspondente aos carbonos aromáticos v. Em 131,3 ppm, existe um dupleto $(J=3,0 \mathrm{~Hz})$ o qual se refere ao carbono aromático u. Em 116,0 ppm, encontra-se o último dupleto $(J=21,0 \mathrm{~Hz})$, o qual corresponde aos carbonos aromáticos w. Os demais picos entre 158,9 - 111,1 se referem aos carbonos aromáticos restantes e olefínicos (e-t). Por fim, em 62,2 ppm, encontra-se o pico relativo ao carbono do metileno $\mathbf{x}$.

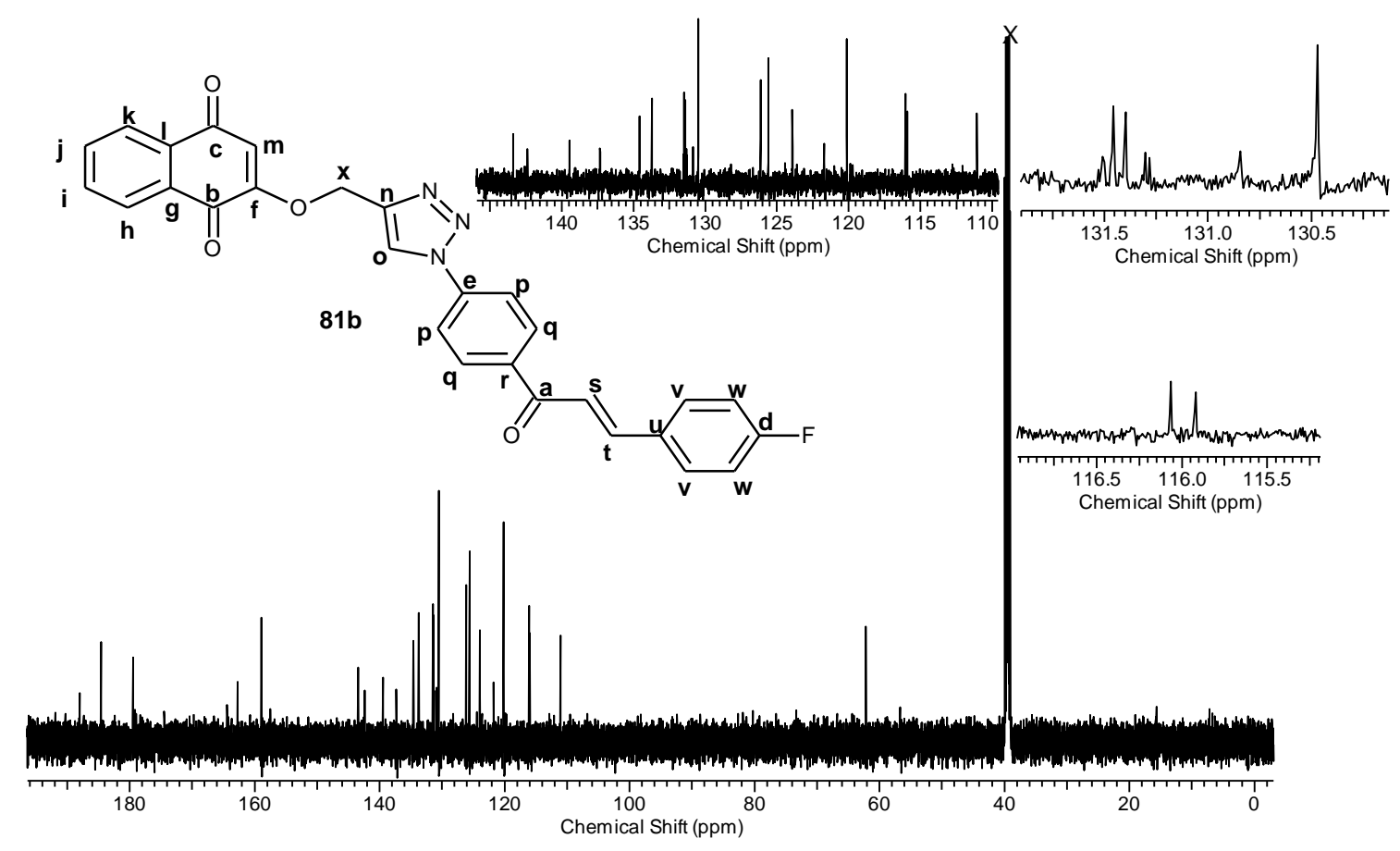

Figura 40 - Espectro de $\mathrm{RMN}{ }^{13} \mathrm{C}\left(150 \mathrm{MHz}, \mathrm{DMSO}-d_{6}\right)$ do composto $81 \mathbf{b}$. 


\section{Conclusão e Perspectivas}

O presente trabalho buscou a síntese de moléculas híbridas formadas por núcleos naftoquinônicos, triazólicos e chalcônicos. O intuito maior no desenvolvimento do trabalho era, tendo em vista as diversas atividades biológicas dos núcleos em questão, sintetizar moléculas com grande potencial farmacológico por meio do processo de hibridização molecular. No presente momento, não há registros de tais moléculas na literatura o que deu grande potencial ao trabalho.

As moléculas propostas foram sintetizadas com sucesso, totalizando 11 moléculas híbridas possuindo grupos doadores ou retiradores de elétrons no anel aromático (compostos 76, compostos 81 e composto 76f), inéditas e com grande potencial farmacológico (Esquema 40). O estudo de possíveis atividades biológicas dos compostos é um objetivo do prosseguimento do trabalho.

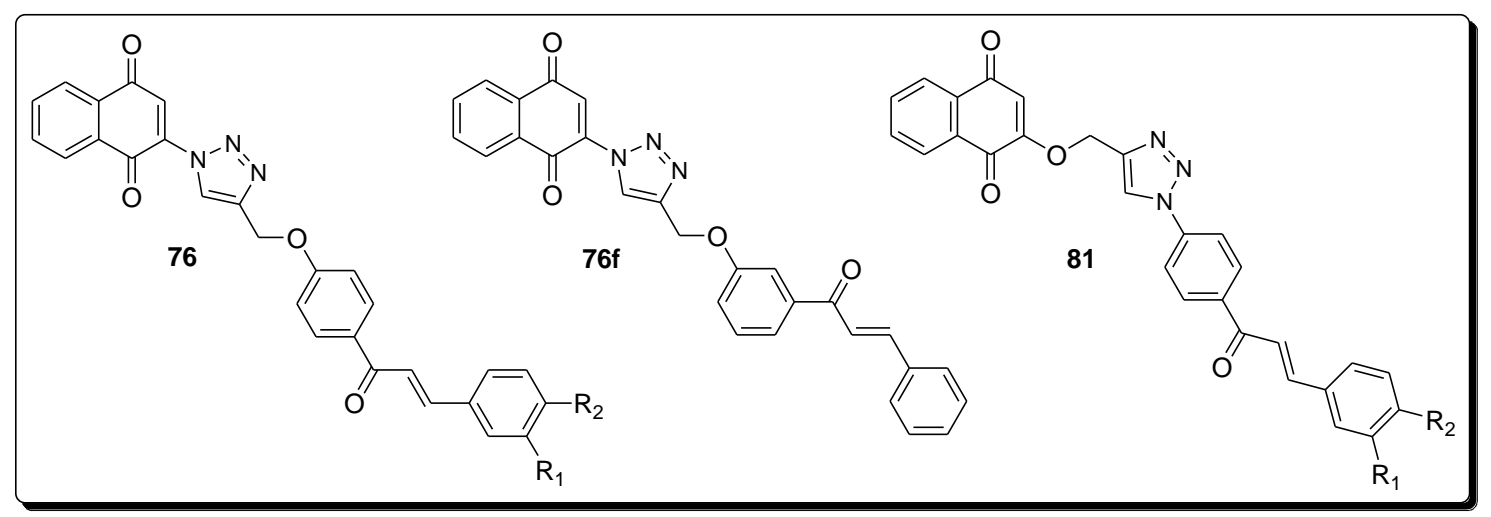

Esquema 40 - Estruturas moleculares dos compostos híbridos 76, 76f e 81.

Alguns compostos intermediários representaram moléculas inéditas na literatura. Alguns exemplos são a 2-propargiloxi-1,4-naftoquinona (composto 77) e as chalconas 75e e 80e (Esquema 41).

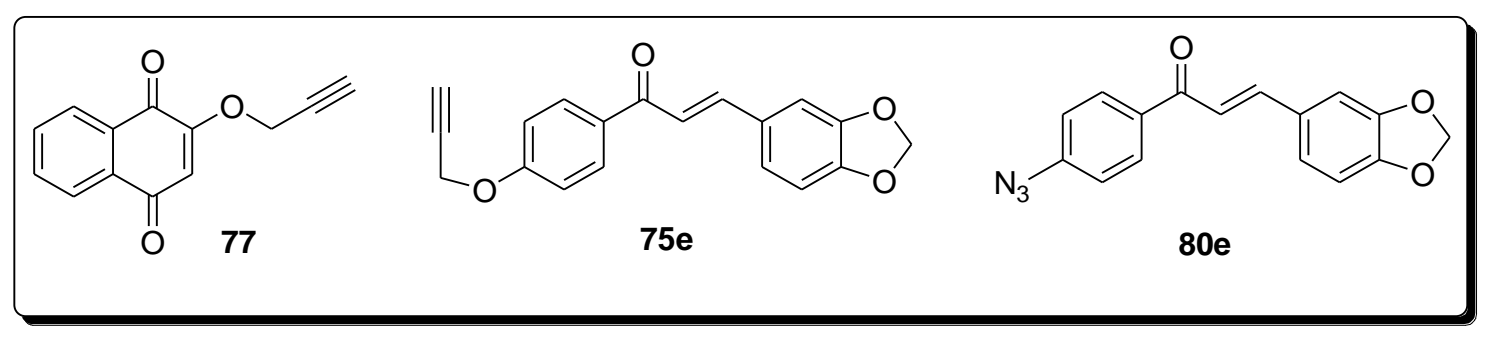

Esquema 41 - Estruturas moleculares dos compostos 77, 75e e 80e. 
As moléculas-alvo foram caracterizadas por meio de técnicas espectroscópicas de ressonância magnética nuclear $\left(\mathrm{RMN}{ }^{1} \mathrm{H}\right.$ e $\left.{ }^{13} \mathrm{C}\right)$ e por meio da medida dos seus pontos de fusão, pois são moléculas constituintes de substâncias sólidas. Contudo, há a necessidade de outras técnicas de caracterização como infravermelho, espectrometria de massa, dentre outras para uma caracterização mais completa dos compostos híbridos, visando, assim, à elaboração de trabalhos científicos.

Por fim, o estudo corroborou a eficiência das reações click, especificamente as cicloadições azida/alcino catalisadas por cobre (I) (CuAAC), mostrando sua grande capacidade sintética na busca de moléculas que possam ser aplicadas nas mais diversas áreas, visando ao desenvolvimento científico e, por consequência, da humanidade. 


\section{Parte Experimental}

\subsection{Reagentes e solventes}

Alguns solventes (diclorometano, acetato de etila e hexano) foram devidamente destilados anteriormente ao seu uso. Outros solventes (etanol, metanol, acetona, dietil éter, trietilamina e água) foram utilizados sem tratamento prévio. O solvente DMF foi utilizado em diversas reações e foi, para tal, devidamente seco conforme procedimento da literatura. ${ }^{64}$

Os reagentes líquidos benzaldeído e 4-flúor-benzaldeído foram purificados através de destilação a vácuo. O reagente líquido brometo de propargila não foi purificado, mas sim utilizado em excesso. Os reagentes sólidos azida de sódio; ascorbato de sódio; hidróxido de sódio; carbonato de potássio; sulfato de cobre II penta hidratado; 2-bromo-1,4-naftoquinona; 4-nitro-benzaldeído; 4-dimetilaminobenzaldeído; 3,4-metilenodioxi-benzaldeído (piperonal) e 2-hidróxi-1,4-naftoquinona (lausona) foram utilizados sem tratamento prévio.

\subsection{Métodos cromatográficos}

O acompanhamento das reações foi realizado por meio de cromatografia em camada delgada. Para tal, foram utilizadas placas de cromatofolhas de alumínio revestidas com sílica gel $60 \mathrm{~F}_{254}$, da Merck. As placas foram visualizadas utilizando irradiação ultravioleta e reveladas em solução de ácido fosfomolíbdico 10\% em etanol.

Foi utilizada para a purificação de alguns compostos a técnica de cromatografia de adsorção em coluna (gravidade). A fase estacionária utilizada nesta técnica foi sílica gel (70-230 mesh) e as diferentes fases móveis (eluentes) estão devidamente descritas na seção "Procedimentos".

${ }^{64}$ Perrin, D. D.; Armarego, W. L. F. Purification of Laboratory Chemicals, $3^{\text {a }}$ Ed. Pergamon Press, New York, 1998. 


\subsection{Métodos Analíticos}

Os espectros de Ressonância Magnética Nuclear de hidrogênio $\left(\mathrm{RMN}{ }^{1} \mathrm{H}\right)$ e de carbono $\left(\mathrm{RMN}{ }^{13} \mathrm{C}\right)$ foram obtidos no aparelho Buker Avance III HD operando nas frequências de $600 \mathrm{MHz}$ para ${ }^{1} \mathrm{H}$ e $150 \mathrm{MHz}$ para ${ }^{13} \mathrm{C}$. Alguns espectros foram obtidos no aparelho Varian Mercury Plus operando nas frequências de $300 \mathrm{MHz}$ para ${ }^{1} \mathrm{H}$ e 75 $\mathrm{MHz}$ para ${ }^{13} \mathrm{C}$. Os deslocamentos químicos $(\delta)$ foram expressos em partes por milhão $(\mathrm{ppm})$, tendo como referência interna o tetrametilsilano - TMS - $(0,00$ ppm para RMN ${ }^{1} \mathrm{H}$ e $\left.\mathrm{RMN}{ }^{13} \mathrm{C}\right)$, clorofórmio deuterado $-\mathrm{CDCl}_{3}-\left(7,26 \mathrm{ppm}\right.$ para $\mathrm{RMN}{ }^{1} \mathrm{H}$ e 77,0 para o $\left.{ }^{13} \mathrm{C}\right)$ e dimetilssulfóxido deuterado - DMSO-d 6 - (2,50 ppm para RMN ${ }^{1} \mathrm{H}$ e 39,51 ppm para $\mathrm{RMN}{ }^{13} \mathrm{C}$ ). As multiplicidades dos sinais de emissão dos hidrogênios nos espectros de $\mathrm{RMN}{ }^{1} \mathrm{H}$ foram indicadas segundo a convenção: s (simpleto), $\mathrm{d}$ (dupleto), $\mathrm{t}$ (tripleto), m (multipleto), dd (dupleto de dupleto), ddd (dupleto de dupleto de dupleto) e dt (tripleto de dupleto). Os dados espectroscópicos referentes aos espectros de RMN ${ }^{1} \mathrm{H}$ estão organizados segundo a convenção: deslocamento químico $(\delta)$ (multiplicidade, constante de acoplamento $(J)$ em hertz $(\mathrm{Hz})$, número de hidrogênios). Os referentes aos espectros de $\mathrm{RMN}{ }^{13} \mathrm{C}$ estão organizados apenas discriminando seus deslocamentos químicos $(\delta)$, com exceção de alguns compostos nos quais ocorrem acoplamentos heteronucleares ${ }^{13} \mathrm{C}-{ }^{19} \mathrm{~F}$ gerando-se dupletos. Esses estão organizados da seguinte forma: deslocamento químico $(\delta)$ (multiplicidade, constante de acoplamento $(J)$ em hertz (Hz)).

A determinação dos pontos de fusão dos compostos sólidos foi realizada utilizando o equipamento de ponto de fusão a seco, modelo Q340S. 


\section{Procedimentos}

\subsection{Procedimento para a síntese da 2-azido-1,4-naftoquinona 71}<smiles>NC1=CC(=O)c2ccccc2C1=O</smiles>

71

Em um balão de fundo redondo de $50 \mathrm{ml}$, foram adicionados 2-bromo-

1,4-naftoquinona (4,15 mmol; 1,00 g) e azida de sódio (7,47 mmol; $0,49 \mathrm{~g}$ ) em uma mistura de $10 \mathrm{ml}$ de etanol e $3 \mathrm{ml}$ de água. A solução foi agitada à temperatura ambiente por $4 \mathrm{~h}$. Após o término da reação, foi realizada extração com diclorometano (3 x $20 \mathrm{ml})$, secagem com sulfato de sódio anidro, rotaevaproação e, por fim, purificação do produto através de coluna cromatográfica de sílica gel com uma mistura de solventes de 2,5\% de acetato de etila/hexano.

Sólido vermelho

Rendimento: $92 \%$

Ponto de Fusão: $110-114^{\circ} \mathrm{C}$ (Literatura ${ }^{52}: 111-114{ }^{\circ} \mathrm{C}$ )

(E.1.1) $\mathrm{RMN}{ }^{1} \mathrm{H}\left(600 \mathrm{MHz} ; \mathrm{CDCl}_{3}\right): \delta 8,13-8,08(\mathrm{dd}, J=7,3 ; 1,1 \mathrm{~Hz}, 2 \mathrm{H}) ; 7,80-$ $7,73(\mathrm{dt}, J=7,3 ; 1,1 \mathrm{~Hz}, 2 \mathrm{H}) ; 6,45(\mathrm{~s}, 1 \mathrm{H})$.

(E.1.2) $\mathrm{RMN}{ }^{13} \mathrm{C}\left(150 \mathrm{MHz} ; \mathrm{CDCl}_{3}\right): \delta 183,7 ; 180,8 ; 146,3 ; 134,8 ; 133,5 ; 132,2 ; 131,0$; 126,$9 ; 126,4 ; 120,2$.

\subsection{Procedimento para a síntese da 4-propargiloxi-acetofenona 73}<smiles>C#CCOc1ccc(C(C)=O)cc1</smiles>

73

Em um balão de fundo redondo de $25 \mathrm{ml}$, foram adicionados 4hidróxi-acetofenona $(17,23 \mathrm{mmol} ; 2,35 \mathrm{~g})$ e carbonato de potássio (34,46 mmol, 4,76 g) em $10 \mathrm{ml}$ de DMF seco. Em seguida, foi adicionado lentamente brometo de propargila $(25,85 \mathrm{mmol}, 2 \mathrm{ml}) \mathrm{sob}$ atmosfera de nitrogênio e agitado durante 24 horas à temperatura ambiente. Após a reação se completar, água gelada foi adicionada à mistura, formando um precipitado. $\mathrm{O}$ 
sólido foi filtrado a vácuo e lavado com água gelada. A purificação foi realizada por meio de recristalização em metanol.

Sólido branco

Rendimento: $85 \%$

Ponto de Fusão: $72-75{ }^{\circ} \mathrm{C}$ (Literatura $\left.{ }^{54}: 73{ }^{\circ} \mathrm{C}\right)$

(E.2.1) $\mathrm{RMN}{ }^{1} \mathrm{H}\left(600 \mathrm{MHz} ; \mathrm{CDCl}_{3}\right): \delta 7,95(\mathrm{~d}, J=8,8 \mathrm{~Hz}, 2 \mathrm{H}) ; 7,02(\mathrm{~d}, J=8,8 \mathrm{~Hz}$, $2 \mathrm{H}) ; 4,76(\mathrm{~d}, J=2,6 \mathrm{~Hz}, 2 \mathrm{H}) ; 2,57-2,55(\mathrm{~m}, 4 \mathrm{H})$.

(E.2.2) $\mathrm{RMN}{ }^{13} \mathrm{C}\left(150 \mathrm{MHz} ; \mathrm{CDCl}_{3}\right): \delta 196,7 ; 161,3 ; 131,1 ; 130,5 ; 114,6 ; 77,8 ; 76,2 ;$ 55,$9 ; 26,4$.

\subsection{Procedimento para a síntese da 2-propargiloxi-1,4-naftoquinona} 77<smiles>C#CCOC1=CC(=O)c2ccccc2C1=O</smiles>

Em um balão de fundo redondo de $25 \mathrm{ml}$, foram adicionados a 2-hidróxi-1,4-naftoquinona - lausona - (5,58 mmol; 1,00 g) e carbonato de potássio $(8,37 \mathrm{mmol}, 1,16 \mathrm{~g})$ em $25 \mathrm{ml}$ de DMF seco. Em seguida, foi adicionado lentamente brometo de propargila $(13,95 \mathrm{mmol}, 1,1 \mathrm{ml})$ sob atmosfera de nitrogênio. A mistura reacional foi aquecida a $50{ }^{\circ} \mathrm{C}$ durante 4 horas. Após a reação se completar, água gelada foi adicionada à mistura, assim como diclorometano. A extração foi realizada e a fase orgânica foi lavada com água $(3 \times 20 \mathrm{ml})$. Posteriormente, a fase orgânica foi seca com sulfato de sódio anidro e o solvente evaporado. O produto foi purificado através de coluna cromatográfica em sílica gel utilizando como eluente uma mistura de acetato de etila $20 \%$ em hexano.

Sólido amarelo

Rendimento: $72 \%$

Ponto de Fusão: $155-157^{\circ} \mathrm{C}$ 
(E.3.1) $\mathrm{RMN}{ }^{1} \mathrm{H}\left(600 \mathrm{MHz} ; \mathrm{CDCl}_{3}\right): \delta 8,14-8,09$ (dd, $J=7,5$ e $\left.1,3 \mathrm{~Hz}, 2 \mathrm{H}\right) ; 7,77-$ $7,71(\mathrm{dt}, J=7,5$ e $1,3 \mathrm{~Hz}, 2 \mathrm{H}) ; 6,45(\mathrm{~s}, 1 \mathrm{H}) ; 4,80(\mathrm{~d}, J=2,6 \mathrm{~Hz}, 2 \mathrm{H}) ; 2,65$ (t, $J=2,6$ $\mathrm{Hz}, 1 \mathrm{H})$.

(E.3.2) $\mathrm{RMN}{ }^{13} \mathrm{C}\left(150 \mathrm{MHz} ; \mathrm{CDCl}_{3}\right): \delta 184,7 ; 179,8 ; 158,1 ; 134,3 ; 133,4 ; 131,9 ; 131,1$; 126,$7 ; 126,2 ; 111,6 ; 78,2 ; 75,4 ; 56,7$.

\subsection{Procedimento para a síntese da 4-azido-acetofenona 79}<smiles>CC(=O)c1ccc(N)cc1</smiles>

79

Em um balão de $250 \mathrm{ml}$, foram adicionados a 4-aminoacetofenona $(29,62 \mathrm{mmol} ; 4,00 \mathrm{~g})$, ácido acético glacial $(19,6 \mathrm{ml})$ e ácido sulfúrico (1,96 ml). A mistura reacional foi, então, colocada em um banho de gelo, próximo de $0{ }^{\circ} \mathrm{C}$. Gota a gota, foi adicionado uma solução de nitrito de sódio (32,66 mmol, 2,26 g) em quantidade mínima de água. Após 30 minutos, uma solução de azida de sódio (32,66 mmol, 2,12 g) em quantidade mínima de água foi adicionada à solução lentamente. Após mais 30 minutos de reação, a mistura reacional foi neutralizada com solução de hidróxido de sódio e um precipitado foi formado. O sólido foi filtrado a vácuo e lavado com água. Sua purificação foi através de coluna cromatográfica com sílica gel, utilizando como eluente mistura de $10 \%$ acetato de etila em hexano.

Sólido amarelo

Rendimento: $95 \%$

Ponto de Fusão: $43-46{ }^{\circ} \mathrm{C}$ (Literatura ${ }^{65}: 44-46^{\circ} \mathrm{C}$ )

(E.4.1) $\mathrm{RMN}{ }^{1} \mathrm{H}\left(600 \mathrm{MHz} ; \mathrm{CDCl}_{3}\right): \delta 7,96(\mathrm{~d}, J=8,8 \mathrm{~Hz}, 2 \mathrm{H}) ; 7,08(\mathrm{~d}, J=8,8 \mathrm{~Hz}$, $2 \mathrm{H}) ; 2,58(\mathrm{~s}, 3 \mathrm{H})$.

(E.4.2) $\mathrm{RMN}{ }^{13} \mathrm{C}\left(150 \mathrm{MHz} ; \mathrm{CDCl}_{3}\right): \delta 196,5 ; 144,9 ; 133,9 ; 130,2 ; 118,9 ; 26,4$.

\footnotetext{
${ }^{65}$ Pokhodylo, N. T.; Savka, R. D.; Matiichuk, V. S.; Obushak, N. D. Russ. J. Gen. Chem. 2009, 79, 309.
} 


\subsection{Procedimento geral para síntese de chalconas:}

Método A: Em um balão de fundo redondo de $50 \mathrm{ml}$, foram adicionados a 4propargiloxi-acetofenona $(1,72 \mathrm{mmol} ; 0,30 \mathrm{~g}), 15 \mathrm{ml}$ de etanol e solução de hidróxido de sódio $10 \%$ em água $(5,16 \mathrm{mmol} ; 0,21 \mathrm{~g})$. Após agitação por 20 minutos, foi adicionado o aldeído $(1,72 \mathrm{mmol})$ e a mistura reacional foi agitada por 24 horas à temperatura ambiente. Após o término da reação, foi realizada extração utilizando diclorometano ( 3 x $20 \mathrm{ml}$ ), secagem com sulfato de sódio anidro e evaporação do solvente. $\mathrm{O}$ sólido foi purificado por recristalização utilizando acetona.

Método B: Em um balão de fundo redondo de $50 \mathrm{ml}$, foram adicionados a 4propargiloxi-acetofenona (1,72 mmol; 0,30 g), $15 \mathrm{ml}$ de etanol e solução de hidróxido de sódio $10 \%$ em água $(5,16 \mathrm{mmol} ; 0,21 \mathrm{~g})$. Após agitação por 20 minutos, foi adicionado o aldeído $(1,72 \mathrm{mmol})$ e a mistura reacional foi agitada por 24 horas à temperatura ambiente. Devido à formação de precipitado, o balão foi deixado em banho de gelo por 30 minutos. O sólido então foi filtrado a vácuo, lavado com solvente gelado apropriado (etanol ou dietil éter) e seco ao ar.

Método C: Em um balão de fundo redondo de $50 \mathrm{ml}$, foram adicionados a 4azido-acetofenona ( $1,86 \mathrm{mmol} ; 0,30 \mathrm{~g}), 10 \mathrm{ml}$ de etanol e solução de hidróxido de sódio $10 \%$ em água (5,58 mmol; 0,22 g). Após agitação por 20 minutos, foi adicionado o aldeído $(1,86 \mathrm{mmol})$ e a mistura reacional foi agitada por 24 horas à temperatura ambiente. Devido à formação de precipitado, o balão foi deixado em banho de gelo por 30 minutos. O sólido então foi filtrado a vácuo, lavado com solvente gelado apropriado (etanol) e seco ao ar. 


\subsection{Procedimento para a síntese da (E)-3-(fenil)-1-(4- propargiloxifenil)prop-2-en-1-ona 75 a}<smiles>C#CCOc1ccc(C(=O)/C=C/c2ccccc2)cc1</smiles>

$75 a$
Preparado seguindo o método A do procedimento geral para síntese de chalconas, obtendo-se o composto 75a (1,03 mmol, 0,27 g).

Sólido amarelo-claro

Rendimento: $60 \%$

Ponto de Fusão: $85-88{ }^{\circ} \mathrm{C}$ (Literatura ${ }^{55}: 85,2-85,4{ }^{\circ} \mathrm{C}$ )

(E.5.1) $\mathrm{RMN}{ }^{1} \mathrm{H}\left(600 \mathrm{MHz} ; \mathrm{CDCl}_{3}\right): \delta 8,05(\mathrm{~d}, J=8,8 \mathrm{~Hz}, 2 \mathrm{H}) ; 7,80(\mathrm{~d}, J=15,8 \mathrm{~Hz}$, 1H); 7,65-7,62 (m, 2H); 7,53 (d, $J=15,8 \mathrm{~Hz}, 1 \mathrm{H}) ; 7,44-7,39(\mathrm{~m}, 3 \mathrm{H}) ; 7,07$ (d, $J=8,8$ $\mathrm{Hz}, 2 \mathrm{H}) ; 4,78(\mathrm{~d}, J=2,2 \mathrm{~Hz}, 2 \mathrm{H}) ; 2,56(\mathrm{t}, J=2,2 \mathrm{~Hz}, 1 \mathrm{H})$.

(E.5.2) $\mathrm{RMN}{ }^{13} \mathrm{C}\left(150 \mathrm{MHz} ; \mathrm{CDCl}_{3}\right): \delta 188,7 ; 161,2 ; 144,2 ; 135,0 ; 131,9 ; 130,7 ; 130,4$; 128,$4 ; 128,4 ; 121,8 ; 114,7 ; 77,8 ; 76,1 ; 55,9$.

\subsection{Procedimento para a síntese da (E)-3-(fluorofenil)-1-(4- propargiloxifenil)prop-2-en-1-ona $75 b$}<smiles>C#CCOc1ccc(C(=O)/C=C/c2ccc(F)cc2)cc1</smiles>

$75 b$

Preparado seguindo o método B do procedimento geral para síntese de chalconas, obtendo-se o composto $\mathbf{7 5 b}$ (1,55 mmol, 0,43 g).

Sólido branco

Rendimento: $90 \%$

Ponto de Fusão: $106-108{ }^{\circ} \mathrm{C}$

(E.6.1) $\mathrm{RMN}{ }^{1} \mathrm{H}\left(600 \mathrm{MHz} ; \mathrm{CDCl}_{3}\right): \delta 8,04(\mathrm{~d}, J=8,8 \mathrm{~Hz}, 2 \mathrm{H}) ; 7,77(\mathrm{~d}, J=15,4 \mathrm{~Hz}$, $1 \mathrm{H}) ; 7,63$ (dd, $J=8,6 ; 5,3 \mathrm{~Hz}, 2 \mathrm{H}) ; 7,46(\mathrm{~d}, J=15,4 \mathrm{~Hz}, 1 \mathrm{H}) ; 7,11(\mathrm{t}, J=8,6 \mathrm{~Hz}, 2 \mathrm{H})$; $7,07(\mathrm{~d}, J=8,8 \mathrm{~Hz}, 2 \mathrm{H}) ; 4,78(\mathrm{~d}, J=2,6 \mathrm{~Hz}, 2 \mathrm{H}) ; 2,57(\mathrm{t}, J=2,4 \mathrm{~Hz}, 1 \mathrm{H})$. 
(E.6.2) $\mathrm{RMN}{ }^{13} \mathrm{C}\left(150 \mathrm{MHz} ; \mathrm{CDCl}_{3}\right): \delta 188,5 ; 164,0(\mathrm{~d}, J=250,5 \mathrm{~Hz}) ; 161,2 ; 142,8$; $131,7 ; 131,3$ (d, $J=4,5 \mathrm{~Hz}) ; 130,7 ; 130,2$ (d, $J=7,5 \mathrm{~Hz}) ; 121,5(\mathrm{~d}, J=3,0 \mathrm{~Hz}) ; 116,1$ $(\mathrm{d}, J=19,5 \mathrm{~Hz}) ; 114,7 ; 77,7 ; 76,2 ; 55,9$.

7.8 Procedimento para a síntese da (E)-3-(4-nitrofenil)-1-(4propargiloxifenil)prop-2-en-1-ona $75 \mathrm{c}$<smiles>C#CCOc1ccc(C(=O)/C=C/c2ccc([N+](=O)[O-])cc2)cc1</smiles>

$75 c$
Preparado seguindo o método B do procedimento geral para síntese de chalconas, obtendo-se o composto $75 \mathrm{c}(1,53 \mathrm{mmol}, 0,47 \mathrm{~g})$.

Sólido amarelo-escuro

Rendimento: $89 \%$

Ponto de Fusão: $167-170{ }^{\circ} \mathrm{C}$ (Literatura ${ }^{55}: 170,1-170,5^{\circ} \mathrm{C}$ )

(E.7.1) $\mathrm{RMN}{ }^{1} \mathrm{H}(600 \mathrm{MHz}$; DMSO-d $)$ : $\delta 8,29$ (d, $\left.J=8,8 \mathrm{~Hz}, 2 \mathrm{H}\right) ; 8,22(\mathrm{~d}, J=9,2 \mathrm{~Hz}$, 2H); 8,17 (d, $J=8,8 \mathrm{~Hz}, 2 \mathrm{H}) ; 8,14(\mathrm{~d}, J=15,8 \mathrm{~Hz}, 1 \mathrm{H}) ; 7,79(\mathrm{~d}, J=15,8 \mathrm{~Hz}, 1 \mathrm{H}) ; 7,17$ (d, $J=9,2 \mathrm{~Hz}, 2 \mathrm{H}) ; 4,96$ (d, $J=2,6 \mathrm{~Hz}, 2 \mathrm{H}) ; 3,64$ (t, $J=2,6 \mathrm{~Hz}, 1 \mathrm{H})$.

(E.7.2) $\mathrm{RMN}{ }^{13} \mathrm{C}\left(150 \mathrm{MHz}\right.$; DMSO- $\left.d_{6}\right): \delta 187,2 ; 161,3 ; 148,0 ; 141,3 ; 140,4 ; 131,0$; 130,$7 ; 129,8 ; 126,1 ; 123,9 ; 114,9 ; 78,7 ; 78,6 ; 55,8$.

\subsection{Procedimento para a síntese da $(E)-3-(4-d i m e t i l a m i n o f e n i l)-1-(4-$ propargiloxifenil)prop-2-en-1-ona $75 d$}<smiles>C#CCOc1ccc(C(=O)/C=C/c2ccc(N(C)C)cc2)cc1</smiles>

Preparado seguindo o método $\mathrm{B}$ do procedimento geral para síntese de chalconas, obtendo-se o composto 75d (1,46 mmol, 0,45 g).

Sólido laranja

Rendimento: $85 \%$

Ponto de Fusão: $87-90{ }^{\circ} \mathrm{C}$ 
(E.8.1) $\mathrm{RMN}{ }^{1} \mathrm{H}\left(600 \mathrm{MHz} ; \mathrm{CDCl}_{3}\right): \delta 8,03(\mathrm{~d}, J=8,8 \mathrm{~Hz}, 2 \mathrm{H}) ; 7,78(\mathrm{~d}, J=15,4 \mathrm{~Hz}$, 1H); 7,54 (d, $J=8,8 \mathrm{~Hz}, 2 \mathrm{H}) ; 7,34(\mathrm{~d}, J=15,4 \mathrm{~Hz}, 1 \mathrm{H}) ; 7,05$ (d, $J=8,8 \mathrm{~Hz}, 2 \mathrm{H}) ; 6,69$ $(\mathrm{d}, J=8,8 \mathrm{~Hz}, 2 \mathrm{H}) ; 4,76(\mathrm{~d}, J=2,6 \mathrm{~Hz}, 2 \mathrm{H}) ; 3,03$ (s, 6H); 2,56 (t, $J=2,6 \mathrm{~Hz}, 1 \mathrm{H})$.

(E.8.2) $\mathrm{RMN}{ }^{13} \mathrm{C}\left(150 \mathrm{MHz} ; \mathrm{CDCl}_{3}\right): \delta 188,9 ; 160,7 ; 151,9 ; 145,1 ; 132,7 ; 130,4 ; 130,3$; 116,$7 ; 114,5 ; 111,9 ; 77,9 ; 76,0 ; 55,8 ; 40,1$.

\subsection{Procedimento para a síntese da $(E)-3-(3,4-$}

\section{metilenodioxifenil)-1-(4-propargiloxifenil)prop-2-en-1-ona 75e}<smiles>C#CCOc1ccc(C(=O)/C=C/c2ccc3c(c2)OCO3)cc1</smiles>

$75 e$
Preparado seguindo o método B do procedimento geral para síntese de chalconas, obtendo-se o composto 75e $(1,58 \mathrm{mmol}, 0,48 \mathrm{~g})$.

Sólido amarelo-claro

Rendimento: $92 \%$

Ponto de Fusão: $129-132{ }^{\circ} \mathrm{C}$

(E.9.1) $\mathrm{RMN}{ }^{1} \mathrm{H}\left(600 \mathrm{MHz} ; \mathrm{CDCl}_{3}\right): \delta 8,03(\mathrm{~d}, J=8,8 \mathrm{~Hz}, 2 \mathrm{H}) ; 7,73(\mathrm{~d}, J=15,4 \mathrm{~Hz}$, $1 \mathrm{H}) ; 7,37(\mathrm{~d}, J=15,4 \mathrm{~Hz}, 1 \mathrm{H}) ; 7,16(\mathrm{~d}, J=1,8 \mathrm{~Hz}, 1 \mathrm{H}) ; 7,12(\mathrm{dd}, J=8,1 ; 1,8 \mathrm{~Hz}, 1 \mathrm{H})$; $7,06(\mathrm{~d}, J=8,8 \mathrm{~Hz}, 2 \mathrm{H}) ; 6,84(\mathrm{~d}, J=8,1 \mathrm{~Hz}, 1 \mathrm{H}) ; 6,02(\mathrm{~s}, 2 \mathrm{H}) ; 4,78(\mathrm{~d}, J=2,6 \mathrm{~Hz}, 2 \mathrm{H})$; $2,56(\mathrm{t}, J=2,6 \mathrm{~Hz}, 1 \mathrm{H})$.

(E.9.2) $\mathrm{RMN}{ }^{13} \mathrm{C}\left(150 \mathrm{MHz} ; \mathrm{CDCl}_{3}\right): \delta 188,6 ; 161,1 ; 149,7 ; 148,4 ; 144,0 ; 132,0 ; 130,6$; 129,$5 ; 125,0 ; 119,9 ; 114,7 ; 108,6 ; 106,6 ; 101,6 ; 77,8 ; 76,1 ; 55,9$. 


\subsection{Procedimento para a síntese da (E)-3-fenil-1-(3- hidróxifenil)prop-2-en-1-ona 83}<smiles>O=C(/C=C/c1ccccc1)c1cccc(O)c1</smiles>

83

Preparado seguindo o método A do procedimento geral (adaptado) para síntese de chalconas, utilizando 3-hidróxiacetofenona (1,72 mmol; 0,23 g), solução de hidróxido de sódio $10 \%$ em água $(5,16 \mathrm{mmol} ; 0,21 \mathrm{~g})$, etanol $(15 \mathrm{ml}) \mathrm{e}$ benzaldeído (1,72 mmol; 0,18 g), obtendo-se o composto 83 (1,15 mmol, 0,26 g). O sólido foi recristalizado em acetona.

Sólido amarelo-claro

Rendimento: $67 \%$

Ponto de Fusão: $119-120{ }^{\circ} \mathrm{C}$ (Literatura ${ }^{66}: 120,2-120,6{ }^{\circ} \mathrm{C}$ )

(E.10.1) $\mathrm{RMN}{ }^{1} \mathrm{H}\left(300 \mathrm{MHz}\right.$; DMSO- $\left.d_{6}\right)$ : $\delta$ 9,87 (s, 1H); 7,94-7,85 (m, 3H); 7,75 (d, $J=$ $15,7 \mathrm{~Hz}, 1 \mathrm{H}) ; 7,66(\mathrm{~m}, 1 \mathrm{H}) ; 7,49-7,44(\mathrm{~m}, 4 \mathrm{H}) ; 7,38$ (t, $J=7,9 \mathrm{~Hz}, 1 \mathrm{H}) ; 7,10$ (ddd, $J=$ $7,9 ; 2,5 ; 0,9 \mathrm{~Hz}, 1 \mathrm{H})$.

(E.10.2) $\mathrm{RMN}{ }^{13} \mathrm{C}\left(75 \mathrm{MHz} ; \mathrm{DMSO}-d_{6}\right): \delta 189,2 ; 157,8 ; 143,9 ; 139,0 ; 134,7 ; 130,7$; 129,$9 ; 129,0 ; 128,9 ; 122,2 ; 120,4 ; 119,7 ; 114,7$.

\subsection{Procedimento para a síntese da (E)-3-fenil-1-(3- propargiloxifenil)prop-2-en-1-ona $75 f$}<smiles>C#CCOc1cccc(C(=O)/C=C/c2ccccc2)c1</smiles>

Em um balão de fundo redondo de $25 \mathrm{ml}$, foram adicionados (E)-1-(3-hidróxifenil)-3-fenil-prop-2-en-1ona $83(2,94 \mathrm{mmol} ; 0,40 \mathrm{~g})$ e carbonato de potássio (5,88 mmol, 0,81 g) em $3 \mathrm{ml}$ de DMF seco. Em seguida, foi adicionado lentamente brometo de propargila $(4,41 \mathrm{mmol}, 0,4 \mathrm{ml})$ e agitado, sob atmosfera de nitrogênio, durante 24 horas. Após a reação se completar, água gelada foi

${ }^{66}$ Karki, R.; Thapa, P.; Kang M. J.; Jeong, T. C.; Nam. J. M.; Kim, H. L.; Na, Y.; Cho, W. J.; Kwon, Y.; Lee, E. S. Bioorg. Med Chem. 2010, 18, 3066. 
adicionada à mistura, formando um precipitado. O sólido foi filtrado a vácuo e lavado com água gelada. A purificação foi realizada por meio de recristalização em acetona.

Sólido amarelo-claro

Rendimento: $62 \%$

Ponto de Fusão: $83-85{ }^{\circ} \mathrm{C}$

(E.11.1) $\mathrm{RMN}{ }^{1} \mathrm{H}\left(600 \mathrm{MHz} ; \mathrm{CDCl}_{3}\right): \delta 7,81(\mathrm{~d}, J=15,8 \mathrm{~Hz}, 1 \mathrm{H}) ; 7,66-7,61(\mathrm{~m}, 4 \mathrm{H})$; 7,50 (d, $J=15,8 \mathrm{~Hz}, 1 \mathrm{H}) ; 7,45-7,40(\mathrm{~m}, 4 \mathrm{H}) ; 7,20(\mathrm{~m}, 1 \mathrm{H}) ; 4,77(\mathrm{~d}, J=2,2 \mathrm{~Hz}, 2 \mathrm{H})$; $2,55(\mathrm{t}, J=2,2 \mathrm{~Hz}, 1 \mathrm{H})$.

(E.11.2) $\mathrm{RMN}{ }^{13} \mathrm{C}\left(150 \mathrm{MHz} ; \mathrm{CDCl}_{3}\right): \delta 190,1 ; 157,8 ; 145,0 ; 139,7 ; 134,9 ; 130,6$; 129,$7 ; 129,0 ; 128,5 ; 122,1 ; 121,9 ; 120,0 ; 114,2 ; 78,2 ; 76,0 ; 56,0$.

\subsection{Procedimento para a síntese da $(E)$-1-(4-azidofenil)-3-fenil- prop-2-en-1-ona 80a}<smiles>Nc1ccc(C(=O)/C=C/c2ccccc2)cc1</smiles>

Preparado seguindo o método $\mathrm{C}$ do procedimento geral para síntese de chalconas, obtendo-se o composto $\mathbf{8 0 a}(1,58$ mmol, 0,39 g).

Sólido amarelo-claro

Rendimento: $85 \%$

Ponto de Fusão: $113-115^{\circ} \mathrm{C}$ (Literatura ${ }^{63}: 115-116^{\circ} \mathrm{C}$ )

(E.12.1) RMN ${ }^{1} \mathrm{H}\left(600 \mathrm{MHz} ; \mathrm{CDCl}_{3}\right): \delta 8,05(\mathrm{~d}, J=8,5 \mathrm{~Hz}, 2 \mathrm{H}) ; 7,82(\mathrm{~d}, J=15,8 \mathrm{~Hz}$, $1 \mathrm{H}) ; 7,65-7,64(\mathrm{~m}, 2 \mathrm{H}) ; 7,51(\mathrm{~d}, J=15,8 \mathrm{~Hz}, 1 \mathrm{H}) ; 7,45-7,41(\mathrm{~m}, 3 \mathrm{H}) ; 7,14(\mathrm{~d}, J=$ $8,4 \mathrm{~Hz}, 2 \mathrm{H})$.

(E.12.2) $\mathrm{RMN}{ }^{13} \mathrm{C}\left(150 \mathrm{MHz} ; \mathrm{CDCl}_{3}\right): \delta 188,7 ; 144,9 ; 144,7 ; 134,8 ; 130,6 ; 130,5$; 129,$0 ; 128,4 ; 121,6 ; 119,1$. 


\subsection{Procedimento para a síntese da $(E)$-1-(4-azidofenil)-3-(4-}

\section{fluorofenil)prop-2-en-1-ona $80 \mathrm{~b}$}<smiles>Nc1ccc(C(=O)/C=C/c2ccc(F)cc2)cc1</smiles>

Preparado seguindo o método $\mathrm{C}$ do procedimento geral para síntese de chalconas, obtendo-se o composto $\mathbf{8 0 b}$ $(1,49 \mathrm{mmol}, 0,40 \mathrm{~g})$.

Sólido rosa-claro

Rendimento: $80 \%$

Ponto de Fusão: $138-140{ }^{\circ} \mathrm{C}$ (Literatura ${ }^{66}: 138-139{ }^{\circ} \mathrm{C}$ )

(E.13.1) $\mathrm{RMN}{ }^{1} \mathrm{H}\left(600 \mathrm{MHz} ; \mathrm{CDCl}_{3}\right): \delta 8,04(\mathrm{~d}, J=8,8 \mathrm{~Hz}, 2 \mathrm{H}) ; 7,78(\mathrm{~d}, J=15,8 \mathrm{~Hz}$, $1 \mathrm{H}) ; 7,64$ (dd, $J=8,4$ e 5,5 Hz, 2H); 7,45 (d, $J=15,8 \mathrm{~Hz}, 1 \mathrm{H}) ; 7,14-7,10$ (m, 4H).

(E.13.2) $\mathrm{RMN}{ }^{13} \mathrm{C}\left(150 \mathrm{MHz} ; \mathrm{CDCl}_{3}\right): \delta 188,4 ; 164,1(\mathrm{~d}, J=250,5 \mathrm{~Hz}) ; 144,8 ; 143,6$; $134,7 ; 131,1(\mathrm{~d}, J=3 \mathrm{~Hz}) ; 130,4 ; 130,3$ (d, $J=7,5 \mathrm{~Hz}) ; 121,2(\mathrm{~d}, J=3 \mathrm{~Hz}) ; 119,1$; $116,2(\mathrm{~d}, J=22,5 \mathrm{~Hz})$.

7.15 Procedimento para a síntese da (E)-1-(4-azidofenil)-3-(4nitrofenil)prop-2-en-1-ona 80c<smiles>Nc1ccc(C(=O)/C=C/c2ccc([N+](=O)[O-])cc2)cc1</smiles>
Preparado seguindo o método $\mathrm{C}$ do procedimento geral para síntese de chalconas, obtendo-se o composto 80c (1,62 mmol, 0,48 g).

Sólido Amarelo-escuro

Rendimento: $87 \%$

Ponto de Fusão: $149-151{ }^{\circ} \mathrm{C}$

(E.14.1) $\mathrm{RMN}{ }^{1} \mathrm{H}\left(600 \mathrm{MHz} ; \mathrm{CDCl}_{3}\right): \delta 8,28(\mathrm{~d}, J=8,8 \mathrm{~Hz}, 2 \mathrm{H}) ; 8,07$ (d, $J=8,4 \mathrm{~Hz}$, $2 \mathrm{H}) ; 7,83(\mathrm{~d}, J=15,8 \mathrm{~Hz}, 1 \mathrm{H}) ; 7,79(\mathrm{~d}, J=8,8 \mathrm{~Hz}, 2 \mathrm{H}) ; 7,62(\mathrm{~d}, J=15,8 \mathrm{~Hz}, 1 \mathrm{H}) ; 7,16$ $(\mathrm{d}, J=8,4 \mathrm{~Hz}, 2 \mathrm{H})$.

(E.14.2) $\mathrm{RMN}{ }^{13} \mathrm{C}\left(150 \mathrm{MHz} ; \mathrm{CDCl}_{3}\right): \delta 187,8 ; 148,6 ; 145,3 ; 141,6 ; 141,0 ; 134,1$; 130,$6 ; 128,9 ; 125,2 ; 124,2 ; 119,2$. 


\subsection{Procedimento para a síntese da (E)-1-(4-azidofenil)-3-(4-}

dimetilaminofenil)prop-2-en-1-ona 80d<smiles>CN(C)c1ccc(/C=C/C(=O)c2ccc(N)cc2)cc1</smiles>

Preparado seguindo o método $\mathrm{C}$ do procedimento geral para síntese de chalconas, obtendo-se o composto 80d (1,40 mmol, 0,41 g).

Sólido vermelho

Rendimento: $75 \%$

Ponto de Fusão: $119-122{ }^{\circ} \mathrm{C}$

(E.15.1) $\mathrm{RMN}{ }^{1} \mathrm{H}\left(600 \mathrm{MHz} ; \mathrm{CDCl}_{3}\right): \delta 8,03(\mathrm{~d}, J=8,4 \mathrm{~Hz}, 2 \mathrm{H}) ; 7,80(\mathrm{~d}, J=15,4 \mathrm{~Hz}$, $1 \mathrm{H}) ; 7,55(\mathrm{~d}, J=8,8 \mathrm{~Hz}, 2 \mathrm{H}) ; 7,31(\mathrm{~d}, J=15,4 \mathrm{~Hz}, 1 \mathrm{H}) ; 7,11(\mathrm{~d}, J=8,8 \mathrm{~Hz}, 2 \mathrm{H}) ; 6,70$ $(\mathrm{d}, J=8,4 \mathrm{~Hz}, 2 \mathrm{H})$.

(E.15.2) $\mathrm{RMN}{ }^{13} \mathrm{C}\left(150 \mathrm{MHz} ; \mathrm{CDCl}_{3}\right): \delta 188,8 ; 152,1 ; 145,9 ; 144,0 ; 135,7 ; 130,4 ;$ 130,$2 ; 122,6 ; 118,9 ; 116,3 ; 111,9 ; 40,1$.

7.17 Procedimento para a síntese da $(E)-1-(4-a z i d o f e n i l)-3-(3,4-$ metilenodioxifenil)prop-2-en-1-ona 80e<smiles>Nc1ccc(C(=O)/C=C/c2ccc3c(c2)OCO3)cc1</smiles>
Preparado seguindo o método $\mathrm{C}$ do procedimento geral para síntese de chalconas, obtendo-se o composto 80e (1,67 mmol, 0,49 g).

Sólido amarelo-claro

Rendimento: $90 \%$

Ponto de Fusão: $134-136{ }^{\circ} \mathrm{C}$

(E.16.1) $\mathrm{RMN}{ }^{1} \mathrm{H}\left(600 \mathrm{MHz} ; \mathrm{CDCl}_{3}\right): \delta 8,03(\mathrm{~d}, J=8,4 \mathrm{~Hz}, 2 \mathrm{H}) ; 7,74(\mathrm{~d}, J=15,4 \mathrm{~Hz}$, $1 \mathrm{H}) ; 7,34(\mathrm{~d}, J=15,4 \mathrm{~Hz}, 1 \mathrm{H}) ; 7,17(\mathrm{~d}, J=1,5 \mathrm{~Hz}, 1 \mathrm{H}) ; 7,14-7,11(\mathrm{~m}, 3 \mathrm{H}) ; 6,85(\mathrm{~d}, J=$ $8,1 \mathrm{~Hz}, 1 \mathrm{H}) ; 6,03(\mathrm{~s}, 2 \mathrm{H})$.

(E.16.2) $\mathrm{RMN}{ }^{13} \mathrm{C}\left(150 \mathrm{MHz} ; \mathrm{CDCl}_{3}\right): \delta 188,5 ; 150,0 ; 148,4 ; 144,7 ; 144,5 ; 135,0$; 130,$3 ; 129,3 ; 125,3 ; 119,5 ; 119,0 ; 108,7 ; 106,6 ; 101,6$. 


\subsection{Procedimento geral para a síntese de compostos híbridos através de reações click.}

Método A: Em um balão de fundo redondo de $25 \mathrm{ml}$, foram adicionados a 2azido-1,4-naftoquinona $(0,50 \mathrm{mmol} ; 0,10 \mathrm{~g})$, a propargiloxi-chalcona $(0,50$ $\mathrm{mmol})$, sulfato de cobre penta hidratado $(0,10 \mathrm{mmol} ; 0,025 \mathrm{~g})$, ascorbato de sódio $(0,20 \mathrm{mmol} ; 0,04 \mathrm{~g})$ e 1 gota de trietilamina em uma mistura $(1: 1)$ de diclorometano $(2 \mathrm{ml})$ e água $(2 \mathrm{ml})$. A mistura reacional foi agitada à temperatura ambiente, variando seu tempo reacional de $2 \mathrm{~h}$ até $7 \mathrm{~h}$. Após o término da reação, à mistura reacional foram adicionados $10 \mathrm{ml}$ de solução de ácido clorídrico $10 \%$. Foi realizada, então, extração utilizando diclorometano (3 x $10 \mathrm{ml}$ ), secagem da fase orgânica com sulfato de sódio anidro e evaporação do solvente. A purificação dos produtos foi realizada através de coluna cromatográfica em sílica gel $(4,5 \mathrm{~g}$ ou $3 \mathrm{~cm}$ de altura em uma coluna de $20 \mathrm{~mm}$ ) utilizando como eluente uma mistura de acetato de etila em hexano, variando entre $10 \%$ até $100 \%$ de acetato de etila.

Método B: Em um balão de fundo redondo de $25 \mathrm{ml}$, foram adicionados a 2propargiloxi-1,4-naftoquinona $(0,50 \mathrm{mmol} ; 0,11 \mathrm{~g})$, a azido-chalcona $(0,50$ $\mathrm{mmol})$, sulfato de cobre penta hidratado $(0,10 \mathrm{mmol} ; 0,025 \mathrm{~g})$, ascorbato de sódio $(0,20 \mathrm{mmol} ; 0,04 \mathrm{~g})$ e 1 gota de trietilamina em uma mistura (1:1) de diclorometano $(2 \mathrm{ml})$ e água $(2 \mathrm{ml})$. A mistura reacional foi agitada à temperatura ambiente, variando seu tempo reacional de $3 \mathrm{~h}$ até $8 \mathrm{~h}$. Após o término da reação, à mistura reacional foram adicionados $10 \mathrm{ml}$ de solução de ácido clorídrico $10 \%$. Foi realizada, então, extração utilizando acetato de etila (3 x $10 \mathrm{ml}$ ), secagem da fase orgânica com sulfato de sódio anidro e evaporação do solvente. A purificação dos produtos foi realizada através de coluna cromatográfica em sílica gel (4,5 g ou $3 \mathrm{~cm}$ de altura em uma coluna de $20 \mathrm{~mm}$ ) utilizando como eluente uma mistura de acetato de etila em hexano, variando entre $10 \%$ até $100 \%$ de acetato de etila. 


\subsection{Procedimento para a síntese do composto híbrido 76a}

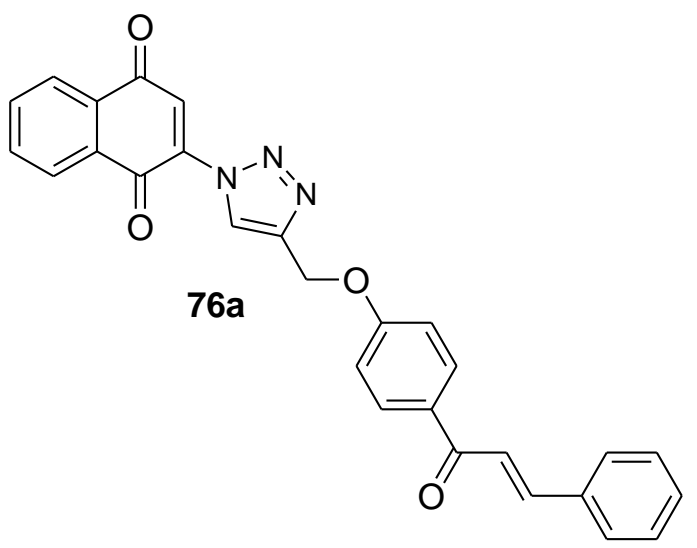

Preparado seguindo o método A do procedimento geral para síntese de compostos híbridos através de reações click. Após 2 horas de reação, obteve-se o composto $76 \mathbf{a}(0,44 \mathrm{mmol}, 0,20 \mathrm{~g})$.

Sólido marrom

Rendimento: $88 \%$

Ponto de Fusão: 169 - $171{ }^{\circ} \mathrm{C}$

(E.17.1) RMN ${ }^{1} \mathrm{H}\left(600 \mathrm{MHz} ; \mathrm{CDCl}_{3}\right): \delta 8,79(\mathrm{~s}, 1 \mathrm{H}) ; 8,23-8,15(\mathrm{~m}, 2 \mathrm{H}) ; 8,06(\mathrm{~d}, J=$ $8,8 \mathrm{~Hz}, 2 \mathrm{H}) ; 7,88-7,82(\mathrm{~m}, 2 \mathrm{H}) ; 7,80(\mathrm{~d}, J=15,8 \mathrm{~Hz}, 1 \mathrm{H}) ; 7,78(\mathrm{~s}, 1 \mathrm{H}) ; 7,66-7,62$ (m, 2H); 7,54 (d, $J=15,8 \mathrm{~Hz}, 1 \mathrm{H}) ; 7,49-7,39(\mathrm{~m}, 3 \mathrm{H}) ; 7,12(\mathrm{~d}, J=8,8 \mathrm{~Hz}, 2 \mathrm{H}) ; 5,40$ $(\mathrm{s}, 2 \mathrm{H})$.

(E.17.2) $\mathrm{RMN}{ }^{13} \mathrm{C}\left(150 \mathrm{MHz} ; \mathrm{CDCl}_{3}\right): \delta 188,7 ; 183,7 ; 179,2 ; 161,8 ; 144,5 ; 144,2 ;$ 139,$1 ; 135,1 ; 135,0 ; 134,4 ; 131,8 ; 131,5 ; 131,0 ; 130,9 ; 130,4 ; 128,9 ; 128,4 ; 127,3$; 126,$8 ; 126,6 ; 125,4 ; 121,8 ; 114,7 ; 61,7$

\subsection{Procedimento para a síntese do composto híbrido 76b}

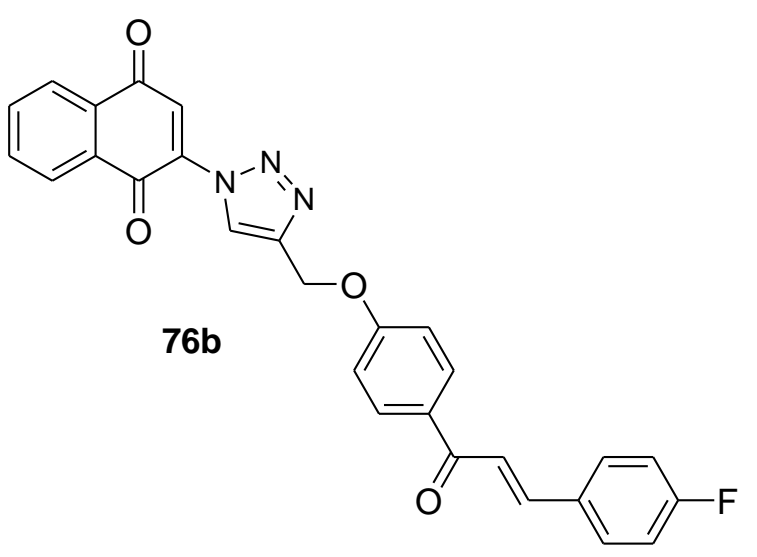

Preparado seguindo o método A do procedimento geral para síntese de compostos híbridos através de reações click. Após 5 horas de reação, obteve-se o composto $\mathbf{7 6 b}$ $(0,47 \mathrm{mmol}, 0,22 \mathrm{~g})$. 
Sólido marrom

Rendimento: $93 \%$

Ponto de Fusão: $173-175{ }^{\circ} \mathrm{C}$

(E.18.1) $\mathrm{RMN}{ }^{1} \mathrm{H}\left(600 \mathrm{MHz} ; \mathrm{CDCl}_{3}\right): \delta 8,79(\mathrm{~s}, 1 \mathrm{H}) ; 8,25-8,14(\mathrm{~m}, 2 \mathrm{H}) ; 8,05(\mathrm{~d}, J=$ $8,8 \mathrm{~Hz}, 2 \mathrm{H}) ; 7,90-7,82(\mathrm{~m}, 2 \mathrm{H}) ; 7,79$ (s, 1H); 7,76 (d, $J=15,8 \mathrm{~Hz} \mathrm{1H}) ; 7,66-7,60$ $(\mathrm{m}, 2 \mathrm{H}) ; 7,46(\mathrm{~d}, J=15,8 \mathrm{~Hz}, 1 \mathrm{H}) ; 7,16-7,07(\mathrm{~m}, 4 \mathrm{H}) ; 7,12(\mathrm{~d}, J=8,8 \mathrm{~Hz}, 2 \mathrm{H}) ; 5,40$ $(\mathrm{s}, 2 \mathrm{H})$.

(E.18.2) $\mathrm{RMN}{ }^{13} \mathrm{C}\left(150 \mathrm{MHz} ; \mathrm{CDCl}_{3}\right): \delta 188,5 ; 183,6 ; 179,2 ; 164,0(\mathrm{~d}, J=250,5 \mathrm{~Hz})$; $161,8 ; 144,5 ; 142,9 ; 139,1 ; 135,1 ; 135,0 ; 131,6 ; 131,5 ; 131,2$ (d, $J=3,0 \mathrm{~Hz}) ; 131,0$; $130,9 ; 130,2$ (d, $J=9,0 \mathrm{~Hz}) ; 127,3 ; 126,8 ; 126,6 ; 125,4 ; 121,4$ (d, $J=3,0 \mathrm{~Hz}) ; 116,1$ (d, $J=19,5 \mathrm{~Hz}) ; 114,7 ; 61,7$.

\subsection{Procedimento para a síntese do composto híbrido 76c}

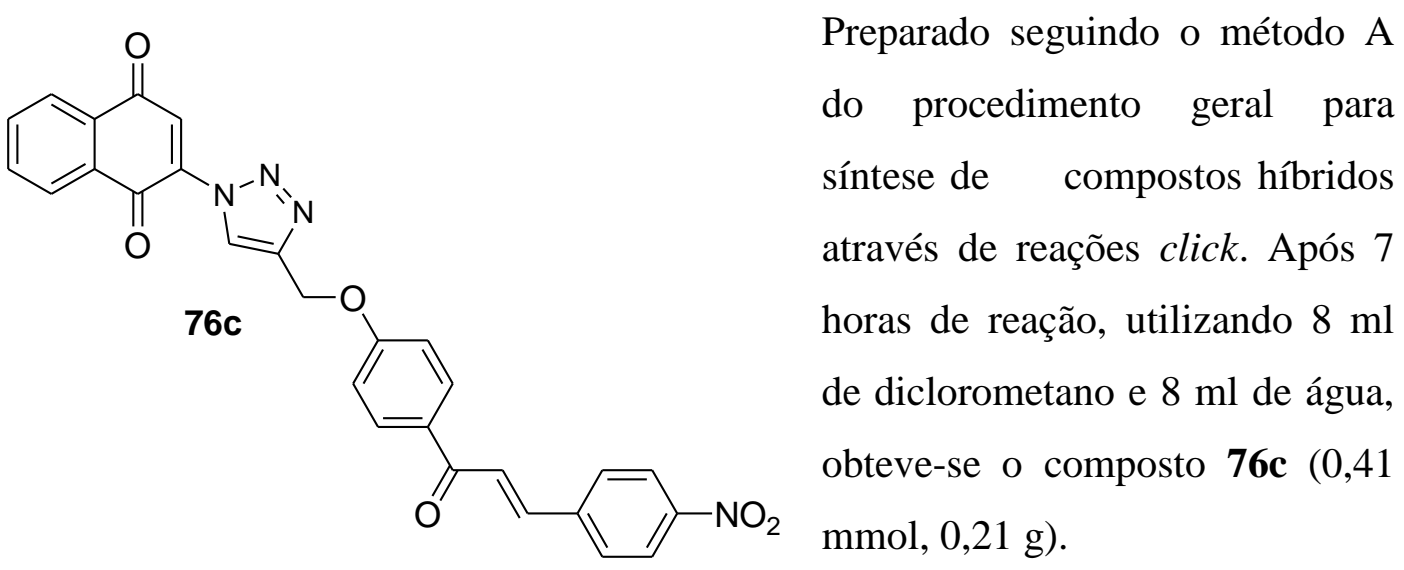

Sólido marrom

Rendimento: $82 \%$

Ponto de Fusão: $219-222{ }^{\circ} \mathrm{C}$

(E.19.1) $\mathrm{RMN}{ }^{1} \mathrm{H}\left(600 \mathrm{MHz}\right.$; DMSO- $\left.d_{6}\right): \delta 8,85(\mathrm{~s}, 1 \mathrm{H}) ; 8,29(\mathrm{~d}, J=8,8 \mathrm{~Hz}, 2 \mathrm{H}) ; 8,24$ $(\mathrm{d}, J=9,2 \mathrm{~Hz}, 2 \mathrm{H}) ; 8,18-8,15(\mathrm{~m}, 4 \mathrm{H}) ; 8,09-8,08(\mathrm{~m}, 1 \mathrm{H}) ; 7,97-7,96(\mathrm{~m}, 1 \mathrm{H}) ; 7,79$ $(\mathrm{d}, J=15,8 \mathrm{~Hz}, 1 \mathrm{H}) ; 7,53(\mathrm{~s}, 1 \mathrm{H}) ; 7,29(\mathrm{~d}, J=9,2 \mathrm{~Hz}, 2 \mathrm{H}) ; 5,47(\mathrm{~s}, 2 \mathrm{H})$. 
(E.19.2) $\mathrm{RMN}{ }^{13} \mathrm{C}\left(150 \mathrm{MHz}\right.$; DMSO- $\left.d_{6}\right): \delta 187,2 ; 184,0 ; 178,7 ; 162,1 ; 148,0 ; 143,1$; 141,$3 ; 140,4 ; 140,2 ; 134,8 ; 134,6 ; 131,3 ; 131,2 ; 130,5 ; 130,0 ; 129,8 ; 127,1 ; 126,7$; 126,$6 ; 126,1 ; 125,8 ; 123,9 ; 114,9 ; 60,9$.

\subsection{Procedimento para a síntese do composto híbrido 76d}

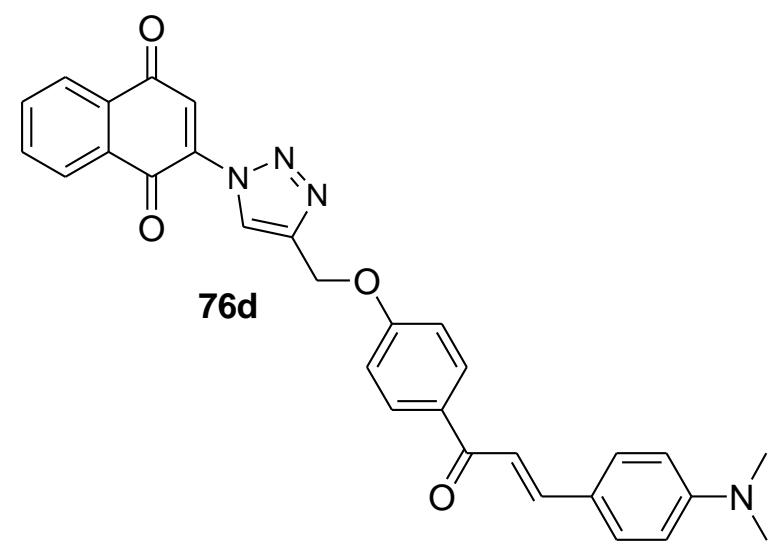

Preparado seguindo o método A do procedimento geral para síntese de compostos híbridos através de reações click. Após 5 horas de reação, obteve-se o composto $\mathbf{7 6 d}$ $(0,43 \mathrm{mmol}, 0,21 \mathrm{~g})$.

Sólido verde

Rendimento: $85 \%$

Ponto de Fusão: $163-164{ }^{\circ} \mathrm{C}$

(E.20.1) $\mathrm{RMN}{ }^{1} \mathrm{H}\left(600 \mathrm{MHz} ; \mathrm{CDCl}_{3}\right): \delta 8,78(\mathrm{~s}, 1 \mathrm{H}) ; 8,24-8,15(\mathrm{~m}, 2 \mathrm{H}) ; 8,04(\mathrm{~d}, J=$ $8,8 \mathrm{~Hz}, 2 \mathrm{H}) ; 7,87-7,83(\mathrm{~m}, 2 \mathrm{H}) ; 7,78(\mathrm{~s}, 1 \mathrm{H}) ; 7,77$ (d, $J=15,4 \mathrm{~Hz}, 1 \mathrm{H}) ; 7,57$ (d, $J=$ $8,4 \mathrm{~Hz}, 2 \mathrm{H}) ; 7,11(\mathrm{~d}, J=8,8 \mathrm{~Hz}) ; 6,93-6,83(\mathrm{~m}, 2 \mathrm{H}) ; 5,39$ (s, 2H).

(E.20.2) $\mathrm{RMN}{ }^{13} \mathrm{C}\left(150 \mathrm{MHz} ; \mathrm{CDCl}_{3}\right): \delta 188,7 ; 183,7 ; 179,3 ; 161,5 ; 144,7 ; 139,2$; 135,$1 ; 134,5 ; 132,4 ; 131,5 ; 131,1 ; 130,7 ; 130,3 ; 127,3 ; 126,8 ; 126,6 ; 125,4 ; 114,6 ; 61,7$; 41,0 .

\subsection{Procedimento para a síntese do composto híbrido 76e}

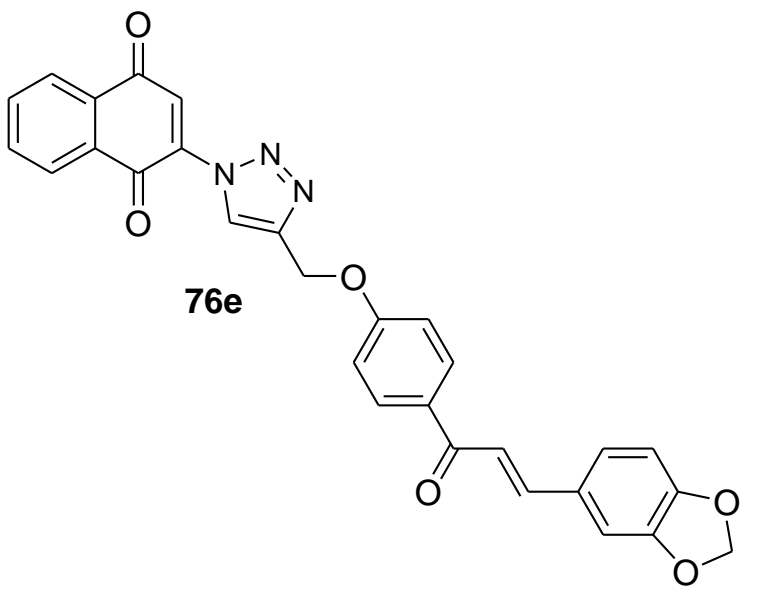

Preparado seguindo o método A do procedimento geral para síntese de compostos híbridos através de reações click. Após 5 horas de reação, obteve-se o composto $\mathbf{7 6 e} \quad(0,42$ mmol, 0,21 g). 
Sólido marrom escuro

Rendimento: $84 \%$

Ponto de Fusão: $202-205{ }^{\circ} \mathrm{C}$

(E.21.1) $\mathrm{RMN}^{1} \mathrm{H}\left(600 \mathrm{MHz}\right.$; DMSO- $\left.d_{6}\right): \delta 8,79(\mathrm{~s}, 1 \mathrm{H}) ; 8,14(\mathrm{~d}, J=9,2 \mathrm{~Hz}, 2 \mathrm{H}), 8,12$ - 8,10 (m, 1H), 8,04 - 8,02 (m, 1H); 7,92 - 7,91 (m, 2H); 7,78 (d, J = 15,4 Hz, 1H); 7,61 (d, $J=1,5 \mathrm{~Hz}, 1 \mathrm{H}) ; 7,60(\mathrm{~d}, J=15,4 \mathrm{~Hz}) ; 7,48$ (s, 1H); 7,27 (dd, $J=8,1 \mathrm{e} \mathrm{1,5} \mathrm{Hz,}$ $1 \mathrm{H}) ; 7,20(\mathrm{~d}, J=9,2 \mathrm{~Hz}, 2 \mathrm{H}) ; 6,94(\mathrm{~d}, J=8,1 \mathrm{~Hz}, 1 \mathrm{H}) ; 6,05(\mathrm{~s}, 2 \mathrm{H}) ; 5,40(\mathrm{~s}, 2 \mathrm{H})$.

(E.21.2) $\mathrm{RMN}{ }^{13} \mathrm{C}\left(150 \mathrm{MHz}\right.$; DMSO- $\left.d_{6}\right): \delta 187,2 ; 184,0 ; 178,6 ; 161,7 ; 149,4 ; 148,1$; 143,$3 ; 143,2 ; 140,2 ; 134,8 ; 134,6 ; 131,3 ; 131,0 ; 130,8 ; 129,3 ; 121,7 ; 126,7 ; 126,6$; 125,$8 ; 125,7 ; 119,9 ; 114,7 ; 108,5 ; 106,9 ; 101,6 ; 60,9$.

\subsection{Procedimento para a síntese do composto híbrido 76f}

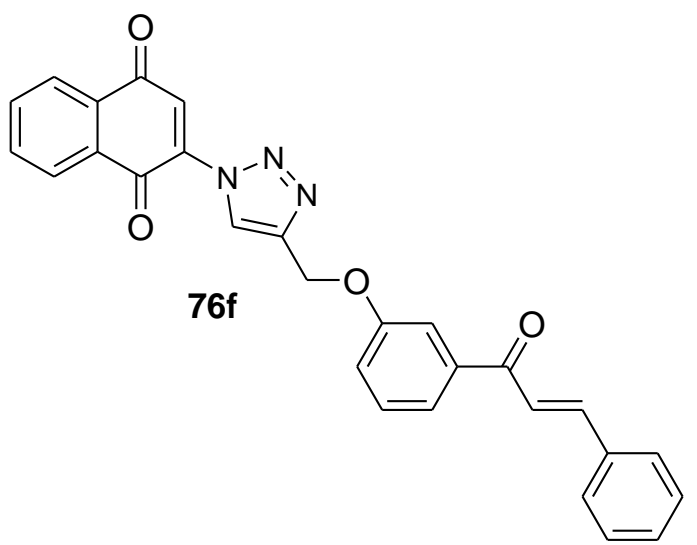

Preparado seguindo o método A do procedimento geral para síntese de compostos híbridos através de reações click. Após 2 horas de reação, obteve-se o composto $7 \mathbf{6 f}(0,48 \mathrm{mmol}, 0,22 \mathrm{~g})$.

Sólido marrom claro

Rendimento: $95 \%$

Ponto de Fusão: $152-155^{\circ} \mathrm{C}$

(E.22.1) $\mathrm{RMN}{ }^{1} \mathrm{H}\left(600 \mathrm{MHz} ; \mathrm{CDCl}_{3}\right): \delta 8,79(\mathrm{~s}, 1 \mathrm{H}) ; 8,21-8,15(\mathrm{~m}, 2 \mathrm{H}), 7,87-7,82(\mathrm{~m}$, 2H); 7,81 (d, $J=15,8 \mathrm{~Hz}, 1 \mathrm{H}) ;$ 7,77 (s, 1H); 7,69-7,68 (m, 1H); 7,67-7,64 (m, 3H); 7,52 $(\mathrm{d}, J=15,8 \mathrm{~Hz}, 1 \mathrm{H}) ; 7,45(\mathrm{t}, J=8,1 \mathrm{~Hz}, 1 \mathrm{H}) ; 7,43-7,40(\mathrm{~m}, 3 \mathrm{H}) ; 7,25(\mathrm{dd}, J=6,2 \mathrm{~Hz} \mathrm{e}$ $2,2 \mathrm{~Hz}, 1 \mathrm{H}) ; 5,38(\mathrm{~s}, 2 \mathrm{H})$. 
(E.22.2) RMN ${ }^{13} \mathrm{C}\left(150 \mathrm{MHz} ; \mathrm{CDCl}_{3}\right): \delta 190,0 ; 183,7 ; 179,3 ; 158,4 ; 145,1 ; 144,8$; 139,$8 ; 139,2 ; 135,1 ; 134,9 ; 134,5 ; 131,5 ; 131,1 ; 130,6 ; 129,9 ; 129,0 ; 128,5 ; 127,3$; 126,$8 ; 126,6 ; 125,4 ; 122,0 ; 121,8 ; 119,8 ; 114,3 ; 61,8$.

\subsection{Procedimento para a síntese do composto híbrido 81a}

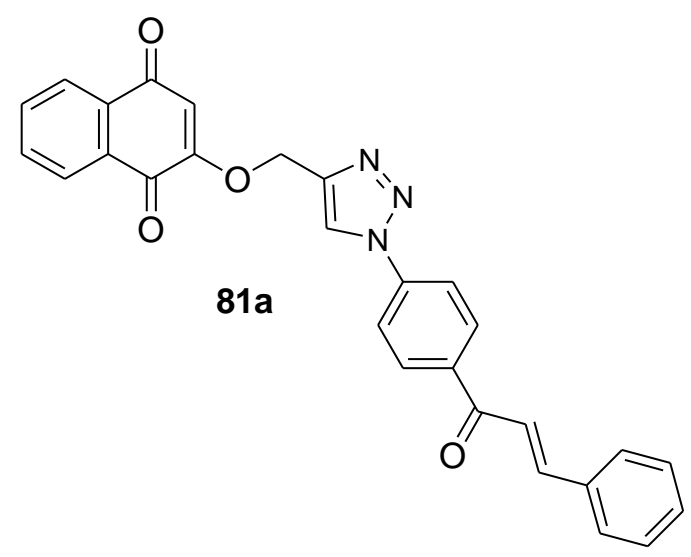

Preparado seguindo o método B do procedimento geral para síntese de compostos híbridos através de reações click. Após 3 horas de reação, obteve-se o composto 81a $(0,45 \mathrm{mmol}, 0,21 \mathrm{~g})$.

Sólido amarelo-claro

Rendimento: $90 \%$

Ponto de Fusão: $217-219{ }^{\circ} \mathrm{C}$

(E.23.1) RMN ${ }^{1} \mathrm{H}\left(600 \mathrm{MHz}\right.$; DMSO- $\left.d_{6}\right): \delta 9,20$ (s, $\left.1 \mathrm{H}\right) ; 8,40(\mathrm{~d}, J=8,8 \mathrm{~Hz}, 2 \mathrm{H}) ; 8,16$ (d, $J=8,8 \mathrm{~Hz}, 2 \mathrm{H}) ; 8,03-7,99$ (m, 2H); 8,02 (d, $J=15,8 \mathrm{~Hz}, 1 \mathrm{H}) ; 7,99-7,92$ (m, 2H); 7,89 - 7,83 (m, 2H); 7,81 (d, $J=15,8 \mathrm{~Hz}, 1 \mathrm{H}) ; 7,49-7,48(\mathrm{~m}, 3 \mathrm{H}) ; 6,68(\mathrm{~s}, 1 \mathrm{H}) ; 5,40$ $(\mathrm{s}, 2 \mathrm{H})$.

(E.23.2) $\mathrm{RMN}{ }^{13} \mathrm{C}\left(150 \mathrm{MHz}\right.$; DMSO- $\left.d_{6}\right): \delta 188,0 ; 184,5 ; 179,4 ; 158,8 ; 144,6 ; 142,3$; 139,$4 ; 137,3 ; 134,6 ; 134,5 ; 133,7 ; 131,5 ; 130,82 ; 130,76 ; 130,4 ; 129,0 ; 128,9 ; 126,1$; 125,$6 ; 123,9 ; 121,8 ; 120,1 ; 111,0 ; 62,1$. 


\subsection{Procedimento para a síntese do composto híbrido 81b}

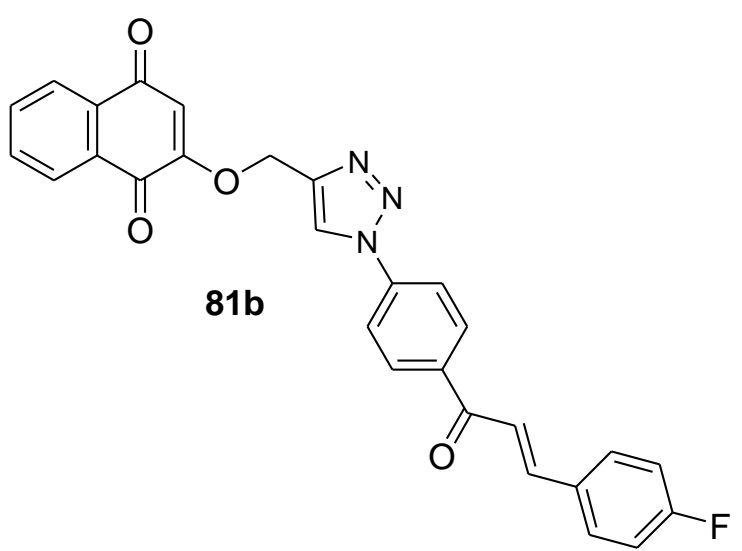

Preparado seguindo o método B do procedimento geral para síntese de compostos híbridos através de reações click. Após 3,5 horas de reação, obteve-se o composto $\mathbf{8 1 b} \quad(0,43$ mmol, 0,21 g).

Sólido rosa-claro

Rendimento: $86 \%$

Ponto de Fusão: $213-214{ }^{\circ} \mathrm{C}$

(E.24.1) $\mathrm{RMN}{ }^{1} \mathrm{H}\left(600 \mathrm{MHz}\right.$; DMSO- $\left.d_{6}\right): \delta 9,19$ (s, $\left.1 \mathrm{H}\right) ; 8,39$ (d, $\left.J=8,8 \mathrm{~Hz}, 2 \mathrm{H}\right), 8,16$ $(\mathrm{d}, J=8,8 \mathrm{~Hz}, 2 \mathrm{H}) ; 8,03-7,99(\mathrm{~m}, 4 \mathrm{H}) ; 7,98(\mathrm{~d}, J=15,8 \mathrm{~Hz}, 1 \mathrm{H}) ; 7,89-7,83(\mathrm{~m}, 2 \mathrm{H})$; 7,80 (d, 1H); 7,32 (t, $J=8,4 \mathrm{~Hz}, 2 \mathrm{H}) ; 6,68(\mathrm{~s}, 1 \mathrm{H}) ; 5,40(\mathrm{~s}, 2 \mathrm{H})$.

(E.24.2) $\mathrm{RMN}{ }^{13} \mathrm{C}\left(150 \mathrm{MHz} ; \mathrm{DMSO}-d_{6}\right): \delta 188,0 ; 184,6 ; 179,5 ; 163,6(\mathrm{~d}, J=247,5$ $\mathrm{Hz}) ; 158,9 ; 143,4 ; 142,4 ; 139,4 ; 137,3 ; 134,6 ; 133,7 ; 131,5 ; 131,4$ (d, $J=9 \mathrm{~Hz}) ; 131,3$ $(\mathrm{d}, J=3 \mathrm{~Hz}) ; 130,8 ; 130,5 ; 126,1 ; 125,6 ; 123,9 ; 121,7 ; 120,1 ; 116,0$ (d, $J=21 \mathrm{~Hz})$; 111,$1 ; 62,2$.

\subsection{Procedimento para a síntese do composto híbrido 81c}

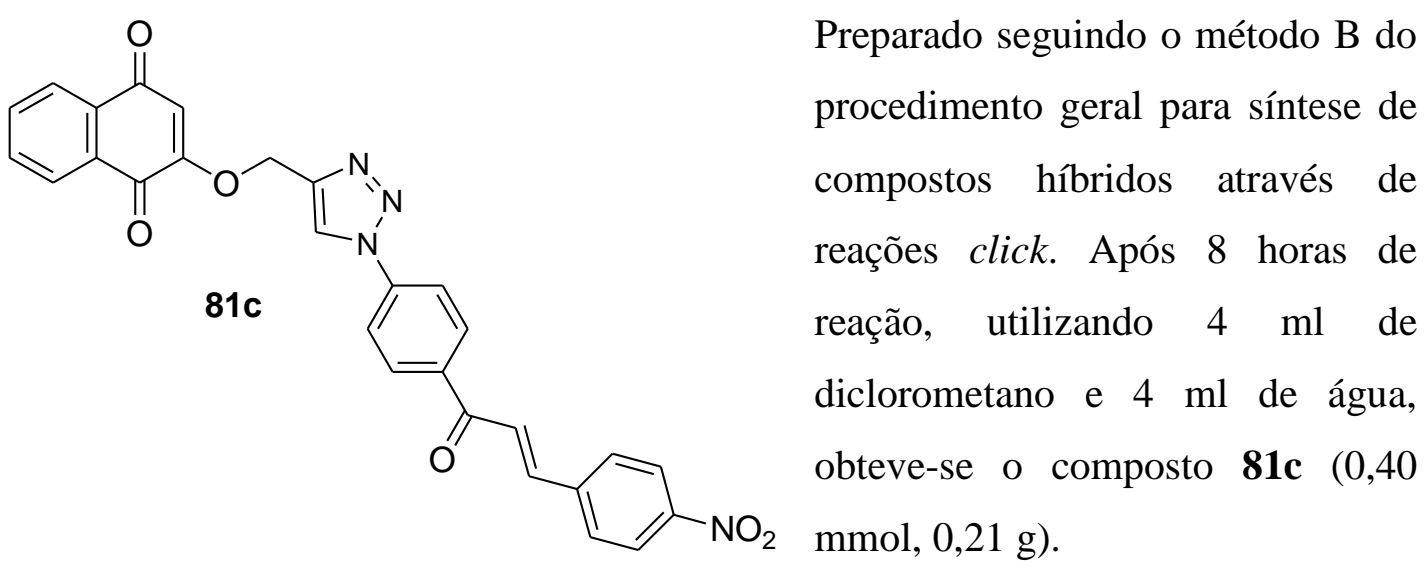


Sólido marrom claro

Rendimento: $80 \%$

Ponto de Fusão: $221-224{ }^{\circ} \mathrm{C}$

(E.25.1) RMN ${ }^{1} \mathrm{H}\left(600 \mathrm{MHz}\right.$; DMSO- $\left.d_{6}\right): \delta 9,21(\mathrm{~s}, 1 \mathrm{H}) ; 8,43(\mathrm{~d}, J=8,4 \mathrm{~Hz}, 2 \mathrm{H}), 8,30$ $(\mathrm{d}, J=8,5 \mathrm{~Hz}, 2 \mathrm{H}) ; 8,22-8,17(\mathrm{~m}, 5 \mathrm{H}) ; 8,03-7,99(\mathrm{~m}, 2 \mathrm{H}) ; 7,89-7,83$ (m, 3H); 6,68 $(\mathrm{s}, 1 \mathrm{H}) ; 5,39(\mathrm{~s}, 2 \mathrm{H})$.

(E.25.2) $\mathrm{RMN}{ }^{13} \mathrm{C}\left(150 \mathrm{MHz}\right.$; DMSO- $\left.d_{6}\right): \delta 187,8 ; 184,5 ; 179,4 ; 158,8 ; 148,1 ; 142,3$; 141,$6 ; 141,0 ; 139,6 ; 136,8 ; 134,5 ; 133,6 ; 131,4 ; 130,8 ; 130,6 ; 129,9 ; 126,1 ; 125,7$; 125,$5 ; 123,9 ; 120,1 ; 111,0 ; 62,1$.

\subsection{Procedimento para a síntese do composto híbrido 81d}

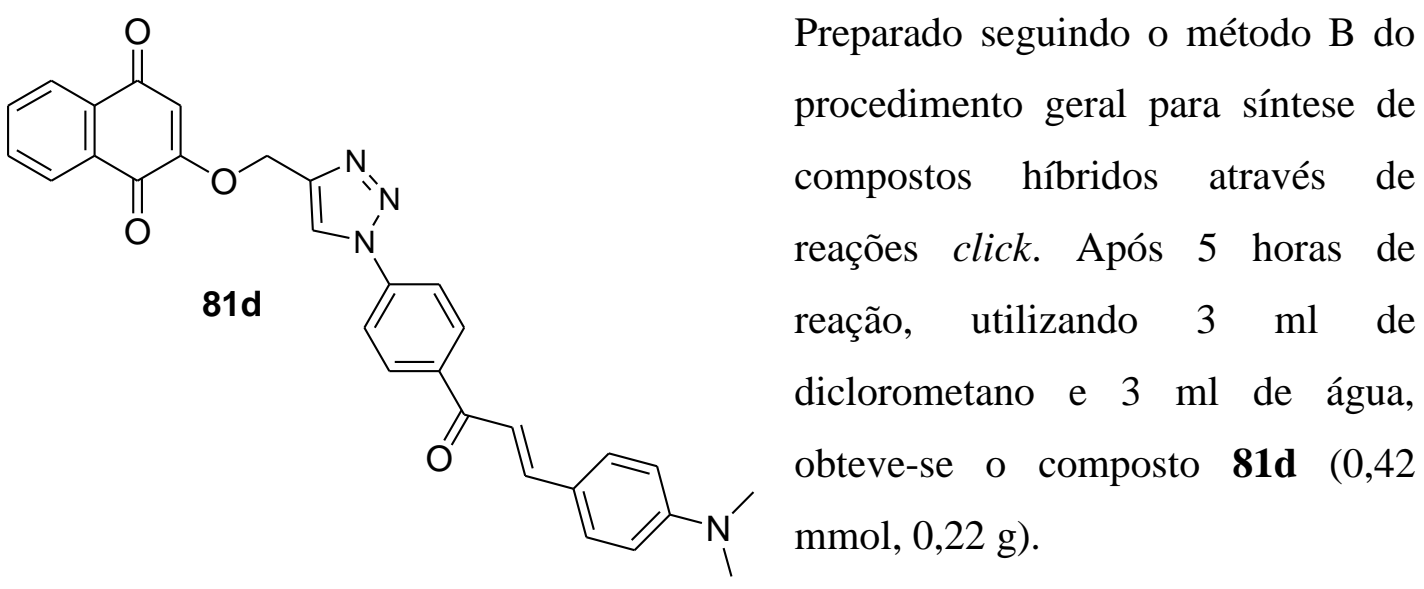

Sólido marrom escuro

Rendimento: $84 \%$

Ponto de Fusão: $251-253{ }^{\circ} \mathrm{C}$

(E.26.1) $\mathrm{RMN}^{1} \mathrm{H}\left(600 \mathrm{MHz}\right.$; DMSO- $\left.d_{6}\right): \delta 9,17(\mathrm{~s}, 1 \mathrm{H}) ; 8,34(\mathrm{~d}, J=8,8 \mathrm{~Hz}, 2 \mathrm{H}), 8,12$ (d, $J=8,8 \mathrm{~Hz}, 2 \mathrm{H}) ; 8,03-7,99$ (m, 2H); 7,89 - 7,83 (m, 2H); 7,76-7,73 (m, 3H); 7,70 $(\mathrm{d}, J=15,4 \mathrm{~Hz}, 1 \mathrm{H}) ; 6,76(\mathrm{~d}, J=8,8 \mathrm{~Hz}, 2 \mathrm{H}) ; 6,68(\mathrm{~s}, 1 \mathrm{H}) ; 5,39(\mathrm{~s}, 2 \mathrm{H})$. 
(E.26.2) RMN ${ }^{13} \mathrm{C}\left(150 \mathrm{MHz}\right.$; DMSO- $\left.d_{6}\right): \delta 187,4 ; 184,5 ; 179,4 ; 158,9 ; 152,1 ; 145,8$; 142,$3 ; 139,0 ; 134,5 ; 133,7 ; 131,5 ; 131,0 ; 130,8 ; 130,0 ; 126,1 ; 125,6 ; 123,9 ; 121,9$; 120,$0 ; 115,7 ; 115,4 ; 111,7 ; 111,1 ; 62,2$.

\subsection{Procedimento para a síntese do composto híbrido 81e}

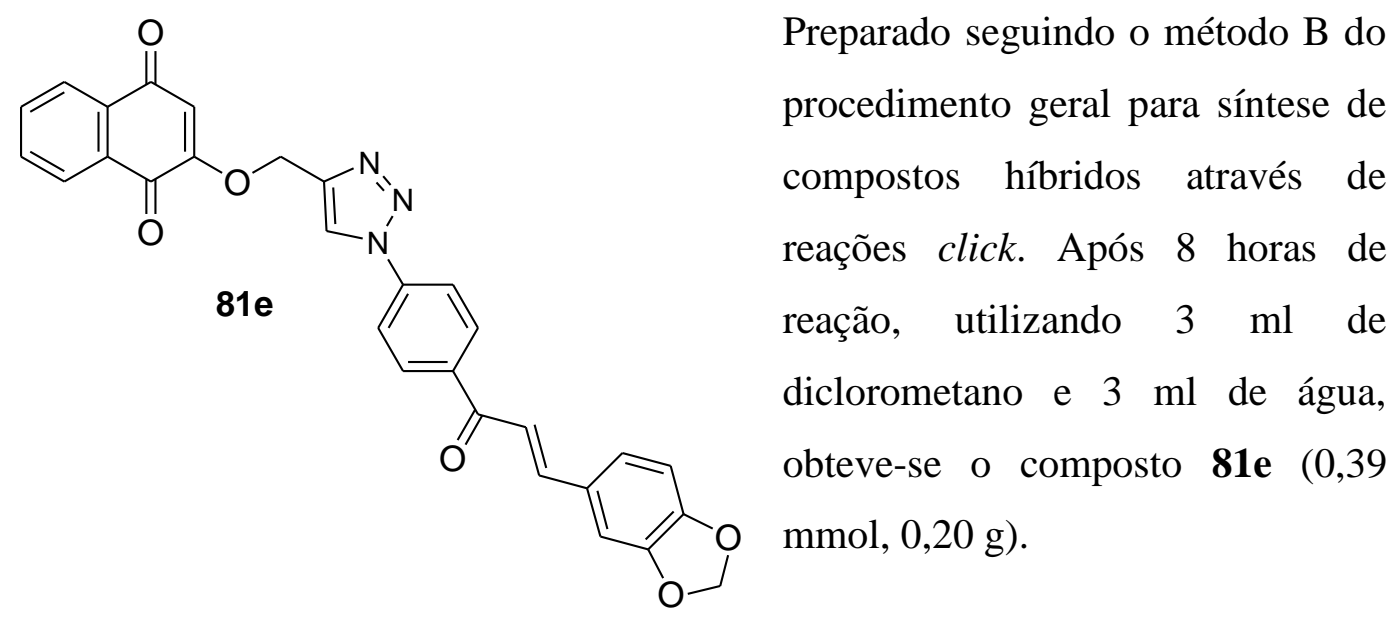

Sólido amarelo

Rendimento: $78 \%$

Ponto de Fusão: $242-244{ }^{\circ} \mathrm{C}$

(E.27.1) RMN ${ }^{1} \mathrm{H}\left(600 \mathrm{MHz}\right.$; DMSO- $\left.d_{6}\right): \delta 9,19$ (s, $\left.1 \mathrm{H}\right) ; 8,39$ (d, $\left.J=8,8 \mathrm{~Hz}, 2 \mathrm{H}\right), 8,15$ (d, $J=8,8 \mathrm{~Hz}, 2 \mathrm{H}) ; 8,03-7,99(\mathrm{~m}, 2 \mathrm{H}) ; 7,90-7,83(\mathrm{~m}, 3 \mathrm{H}) ; 7,74(\mathrm{~d}, J=15,4 \mathrm{~Hz}, 1 \mathrm{H})$; $7,69(\mathrm{~d}, J=1,8 \mathrm{~Hz}, 1 \mathrm{H}) ; 7,37(\mathrm{dd}, J=8,1$ e $1,8 \mathrm{~Hz}, 1 \mathrm{H}) ; 7,01(\mathrm{~d}, J=8,1 \mathrm{~Hz}, 1 \mathrm{H}) ; 6,68$ (s, 1H); 6,12 (s, 2H); 5,39 (s, 2H).

(E.27.2) RMN ${ }^{13} \mathrm{C}\left(150 \mathrm{MHz}\right.$; DMSO- $\left.d_{6}\right): \delta 187,7 ; 185,5 ; 179,4 ; 158,9 ; 149,8 ; 148,1$; 144,$7 ; 142,3 ; 139,3 ; 137,3 ; 134,5 ; 133,7 ; 130,8 ; 130,3 ; 129,1 ; 126,3 ; 126,1 ; 125,6$; 123,$9 ; 120,1 ; 119,7 ; 111,1 ; 108,6 ; 107,0 ; 101,7 ; 62,2$. 


\section{Referências Bibliográficas}

1. Lumb, J. P. G. Progress in the Chemistry of Quinoidal Natural Products. ProQuest, 2008, p. 1-12.

2. Gleicher, G. J.; Church, D. F.; Arnold, J. C. J. Amer. Chem. Soc. 1974, 96, 2403.

3. a) Hannan, R. L.; Barber, R. B.; Rapoport, H. J. Org. Chem. 1979, 44, 2153; b) Jacob III, P.; Callery, P. S.; Shulgin, A. T.; Castagnoli Jr, N. J. Org. Chem. 1976, 41, 3627; c) Nair, V.; Deepthi, A. Chem. Rev. 2007, 107, 1862.

4. Willis, J. P; Gogins, K. A. Z.; Miller, L. J. Org. Chem. 1981, 46, 3215.

5. a) Heinzman, S. W.; Grunwell, J. R. Tetrahedron Lett. 1980, 21, 4305; b) Brimble, M. A.; Bachu, P.; Sperry, J. Synthesis 2007, 2887.

6. Errazuriz, B.; Tapia, R.; Valderrama, J. A. Tetrahedron Lett. 1985, $26,819$.

7. Monks, T. J.; Hanzlik, R. P.; Cohen, G. M.; Ross, D.; Graham, D. G. Toxico. Appl. Pharmacol. 1992, 112, 2.

8. Wellington, K. W. RSC Adv. 2015, 5, 20309.

9. Nelson, D. L.; Lehninger, A. L.; Cox, M. M. Lehninger Principles of Biochemistry. W. H. Freeman; 5 ${ }^{\text {a }}$ d, 2008, p. 719.

10. Stryer, L. Biochemistry. $4^{\text {a }}$ Ed., Standford University, New York, 1995, p. 501.

11. Kurosu, M.; Begari, E. Molecules 2010, 15, 1531.

12. Shearer, M. J. The Lancet 1995, 345, 229.

13. Meganathan, R. Vitam. Horm., 2001, 61, 173.

14. Jin, S.; Sato, N. Phytochem. 2003, 62, 101.

15. Valderrama, J. A.; Zamorano, C.; González, M. F.; Prina, E.; Fournet, A. Bioorg.Med. Chem. 2005, 13, 4153.

16. Brimble, M. A.; Bachu, P.; Sperry, J. Synthesis 2007, 2887.

17. Zhang, Q.; Raheem, K. S.; Botting, N. P.; Slawin, A. M.; Kay, C. D.; O'Hagan, D. Tetrahedron 2012, 68, 4194.

18. Glossário de nomes e reatividades de intermediários de classes de compostos orgânicos baseados em suas estruturas. IUPAC. 1995, 67, 1307

19. Silva, W. A.; Andrade, C. K. Z.; Napolitano, H. B.; Vencato, I.; Lariucci, C.; Castro, M.; Camargo, A. J. J. Braz. Chem. Soc. 2013, 24, 133.

20. Clayden, J.; Warren, W.; Greeves, N.; Wothers, P. Organic Chemistry. Oxford, $2^{\mathrm{a}} \mathrm{Ed}, \mathbf{2 0 1 2}$, p.521-542. 
21. Iwata, S.; Nishino, T.; Inoue, H.; Nagata, N.; Satomi, Y.; Nishino, H.; Shibata, S. Biol. Pharm. Bull. 1997, 20, 1266.

22. Sabzevari, O.; Galati, G.; Moridani, M. Y.; Siraki, A.; O’Brien, P. J. Chem. Biol. Interact. 2004, 148, 57.

23. Wu, J.; Li, J.; Cai, Y.; Pan, Y.; Ye, F.; Zhang, Y.; Liang, G. J. Med. Chem. 2011, 54, 8110 .

24. Lahtchev, K. L.; Batovska, D. I.; St P, P.; Ubiyvovk, V. M.; Sibirny, A. A. Eur. J. Med. Chem. 2008, 43, 2220.

25. a) Tadigoppula, N.; Korthikunta, V.; Gupta, S.; Kancharla, P.; Khaliq, T.; Soni, A.; Mohammad, I. S. J. Med. Chem. 2012, 56, 31.; b) Kumar, D.; Kumar, M.; Kumar, A.; Singh, S. M. Mini-Ver. Med. Chem. 2013, 13, 2116.

26. a) Mello, T. F.; Bitencourt, H. R.; Pedroso, R. B.; Aristides, S. M.; Lonardoni, M. V.; Silveira, T. G. Exp. Parasit. 2014, 136, 27.; b) Pacheco, D.; Trilleras, J.; Quiroga, J.; Gutiérrez, J.; Prent, L.; Coavas, T.; Marín, J; C.; Delgado, G. J. Braz. Chem. Soc. 2013, 24, 1685.

27. Qian, Y. P.; Shang, Y. J.; Teng, Q. F.; Chang, J.; Fan, G. J.; Wei, X.; Zhou, B. Food Chem. 2011,126, 241.

28. Liu, X. L.; Xu, Y. J.; Go, M. L. Eur. J. Med. Chem. 2008, 43, 1681.

29. Trivedi, J. C.; Bariwal, J. B.; Upadhyay, K. D.; Naliapara, Y. T.; Joshi, S. K.; Pannecouque, C. C.; Shah, A. K. Tetrahedron 2007, 48, 8472.

30. Organização Mundial de Saúde, 2010. Relatório Técnico série 949 - Controle da Leichmaniose.

http://apps.who.int/iris/bitstream/10665/44412/1/WHO_TRS_949_eng.pdf?ua=1 Acessado em 21 de abril de 2016

31. Kolb, H. C.; Finn, M. G.; Sharpless, K. B. Angew. Chem. Int. Ed. 2001, 40, 2004.

32. Melo, J. O. F.; Donnici, C. L.; Augusti, R.; Ferreira, V. F.; Souza, M. C. B. V.; Ferreira, M. L. G.; Cunha, A. C. Quim. Nova 2006, 29, 569.

33. Michael, A. J. Prakt. Chem. 1893, 46, 94.

34. Huisgen, R. Pure Appl. Chem. 1989, 61, 613.

35. a) Rostovtsev, V. V.; Green, L. G.; Fokin, V. V.; Sharpless, K. B. Angew. Chem. Int. Ed. 2002, 41, 2596; b) Himo, F.; Lovell, T.; Hilgraf, R.; Rostovtsev, V. V.; Noodleman, L. Sharpless, K. B.; Fokin, V. V. J. Am. Chem. Soc. 2005, 127, 210. 36. Tornfe, C. W.; Christensen, C.; Meldal, M. J. Org. Chem. 2002, 67, 3057. 
37. de Oliveira Freitas, L. B.; Ruela, F. A.; Pereira, G. R.; Alves, R. B.; de Freitas, R. P.; dos Santos, L. J. Quim. Nova 2011, 34, 1791.

38. Berg, R.; Straub, B. F Beilstein J. Org. Chem. 2013, 9, 2715

39. Meldal, M.; Tornoe, C. W. Chem. Rev. 2008, 108, 2952.

40. Worrel, B. T.; Malik, J. A.; Fokin, V. V. Science 2013, 340, 457.

41. Hein, C. D.; Liu, X. M.; Wang, D. Pharm. Res. 2008, 25, 2216.

42. Melo, J. O. F.; Donnici, C. L.; Augusti, R.; Ferreira, V. F.; de Souza, M. C. B. V.; Ferreira, M. L. G.; Cunha, A. C.; Quim. Nova 2006, 29, 569.

43. Mudd, W. H.; Stevens, E. P; Tetrahedron Lett. 2010, 51, 3229

44. Reddy, D. M.; Srinivas, J.; Chashoo, G.; Saxena, A. K.; Kumar, H. S. Eur. J. Med. Chem. 2011, 46, 1983.

45. Barreiro, E. J.; Fraga, C. A. M. Química Medicinal: As bases moleculares da ação dos fármacos. Artmed Editora, 2014.

46. Junior, C. V.; Danuello, A.; Bolzani, V. S.; Barreiro, E. J.; Fraga, C. A. M. Curr. Med. Chem. 2007, 14, 1829.

47. Van Minh, N.; Le Anh, N.; Thi Thao, D.; Khac Vu, T. Lett. Drug Des. Discov. 2014,11, 297.

48. Bala, B. D.; Muthusaravanan, S.; Choon, T. S.; Ali, M. A.; Perumal, S. Eur. J. Med. Chem. 2014, 85, 737.

49. Chinthala, Y.; Thakur, S.; Tirunagari, S.; Chinde, S.; Domatti, A. K.; Arigari, N. K.; Srinivas, K. V. N. S.; Alam, S.; Jonnala, K. K.; Khan, F.; Tiwari, A.; Grover, P. Euro. J. Med. Chem. 2015, 93, 564.

50. a) Guantai, E. M.; Ncokazi, K.; Egan, T. J.; Gut, J.; Rosenthal, P. J.; Smith, P. J.; Chibale, K. Bioorg. Med. Chem. 2014,18, 8243.; b) Khanage, S. G.; Raju, A. S. J. Curr. Res. Sci. 2013, 1, 521.; c) Guimarães, T. T.; do Carmo, F. R. M.; Lanza, J. S.; Melo, M. N.; Rubens, L.; de Melo, I. M.; Diogo, E. B. T.; Ferreira, V. F.; Camara, C. A.; Valença, W. O.; de Oliveira, R. N.; Frézard, F.; da Silva Júnior, E. N. Eur. J. Med. Chem. 2013, 63, 523.

51. Radaeva, N. Y.; Dolgushina, L. V.; Sakilidi, V. T.; Gornostaev, L. M. Russ. J, Org. Chem. 2005, 41, 9267.

52. Molina, P.; Pastor, A.; Vilaplana, M. J. Tetrahedron 1995, 51, 1265

53. Rajakumar, P.; Raja, S. Synth. Commun. 2009, 39, 3888.

54. Hans, R. H.; Guantai, E. M.; Lategan, C.; Smith, P. J.; Wan, B.; Franzblau, S. G.; Gut, J.; Rosenthal, P. J.; Chibale, K. Bioorg. Med. Chem. Lett. 2010, $20,942$. 
55. Zhao, L.; Mao, L.; Hong, G.; Yang, X.; Liu, T. Bioorg. Med. Chem. Lett. 2015, 25,2540 .

56. Kumar, Y.; Bahadur, V.; Singh, A. K.; Parmar, V. S.; Van der Eycken, E. V.; Singh, B. K. Beilstein. J. Org. Chem. 2014, 10, 1413.

57. Barreto, A. F. S.; Vercillo, O. E.; Birkett, M. A.; Caulfied, J. C.; Wessjohann, L. A.; Andrade, C. K. Z. Org. Biom. Chem. 2011, 9, 5024.

58. da Cruz, E. H. G.; Hussene, C. M. B.; Dias, G. G.; Diogo, E. B. T.; de Melo, I. M. M.; Rodrigues, B. L.; Silva, M. G.; Valença, W. O.; Camara, C. A.; Oliveira, R. N.; Paiva, Y. G.; Goulart, M. O. F.; Cavalcanti, B. C.; Pessoa, C.; Júnior, E. N. S. Bioorg. Med. Chem. 2014, 22, 1608.

59. Bian, J.; Xu, L.; Deng, B.; Qian, X.; Fan, J.; Yang, X.; Liu, F.; Xu, X.; Guo, X.; Li, X.; Sun, H.; You, Q.; Zhang, X. Bioorg. Med. Chem. Lett. 2015, 25, 1244.

60. Balamurugan, S.; Nithyanandan, S.; Selvarasu, C.; Yeap, G. Y.; Kannan, P. Polymer 2012, 53, 4104.

61. Tian, H.; Qian, J.; Sun, Q.; Jiang, C.; Zhang, R.; Zhang, W. R. Soc. Chem. 2014, $139,3373$.

62. Kimatura, M.; Kato, S.; Yano, M.; Tashiro, N.; Shiratake, Y.; Sando, M.; Okauchi, T. Org. Biomol. Chem. 2014, 12, 4397.

63. a) Zarghi, A.; Zebardast, T.; Hakimion, F.; Shirazi, F. H.; Rao, P. N. P.; Knaus, E. E. Bioorg. Med. Chem. 2006, 14, 7044.; b) Iqbal, H.; Prabhakar, V.; Sangith, A.; Chandrika, B.; Balasubramanian, R. Med. Chem. Res. 2014, 23, 4383.

64. Perrin, D. D.; Armarego, W. L. F. Purification of Laboratory Chemicals, $3^{\mathrm{a}}$ Ed. Pergamon Press, New York, 1998.

65. Pokhodylo, N. T.; Savka, R. D.; Matiichuk, V. S.; Obushak, N. D. Russ. J. Gen. Chem. 2009, 79, 309.

66. Karki, R.; Thapa, P.; Kang M. J.; Jeong, T. C.; Nam. J. M.; Kim, H. L.; Na, Y.; Cho, W. J.; Kwon, Y.; Lee, E. S. Bioorg. Med Chem. 2010, 18, 3066. 


\section{Anexos}

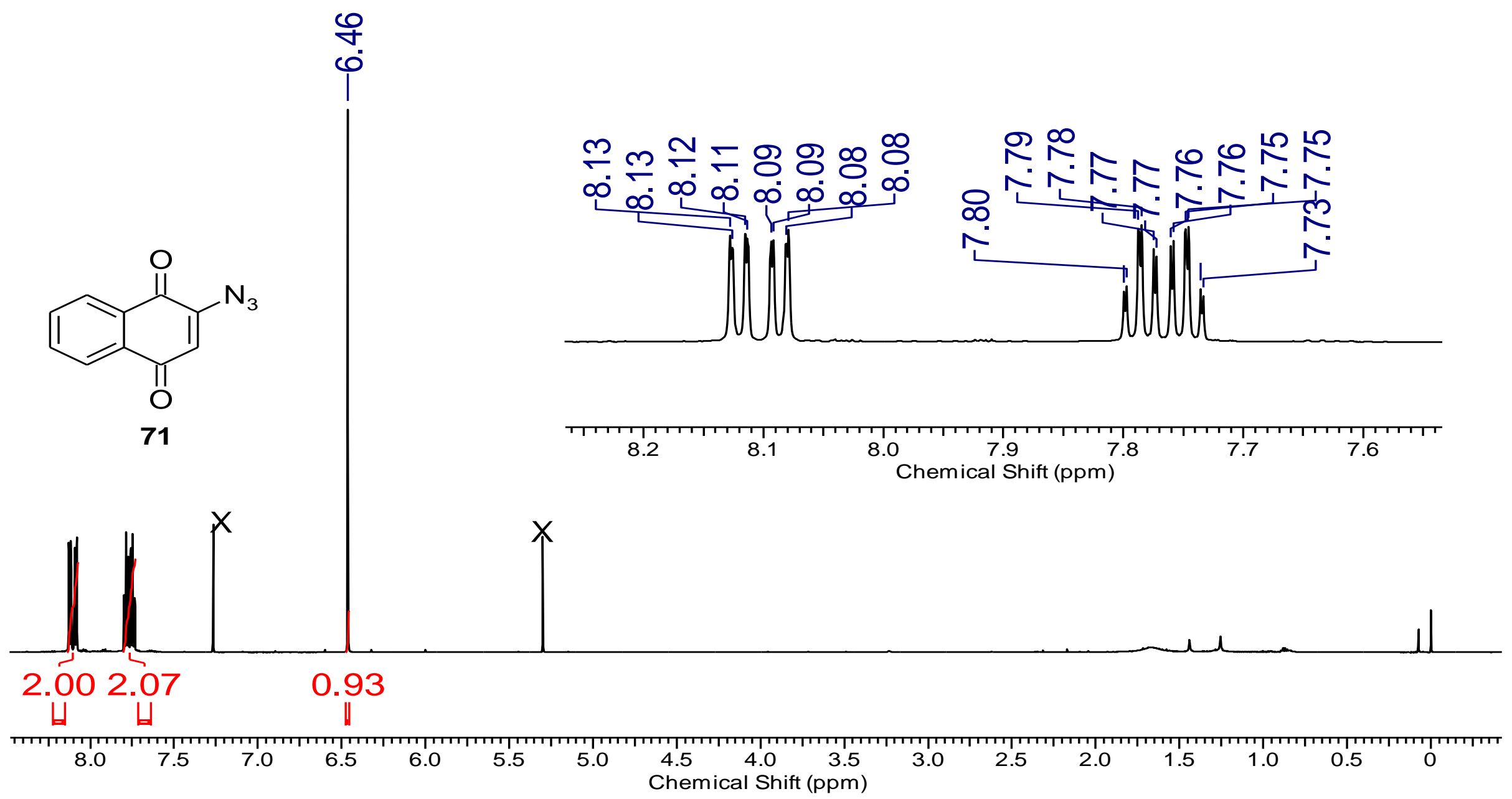

Espectro 1.1 - Espectro de $\mathrm{RMN}$ de ${ }^{1} \mathrm{H}\left(600 \mathrm{MHz}, \mathrm{CDCl}_{3}\right)$ da 2-azido-1,4-naftoquinona 71. 


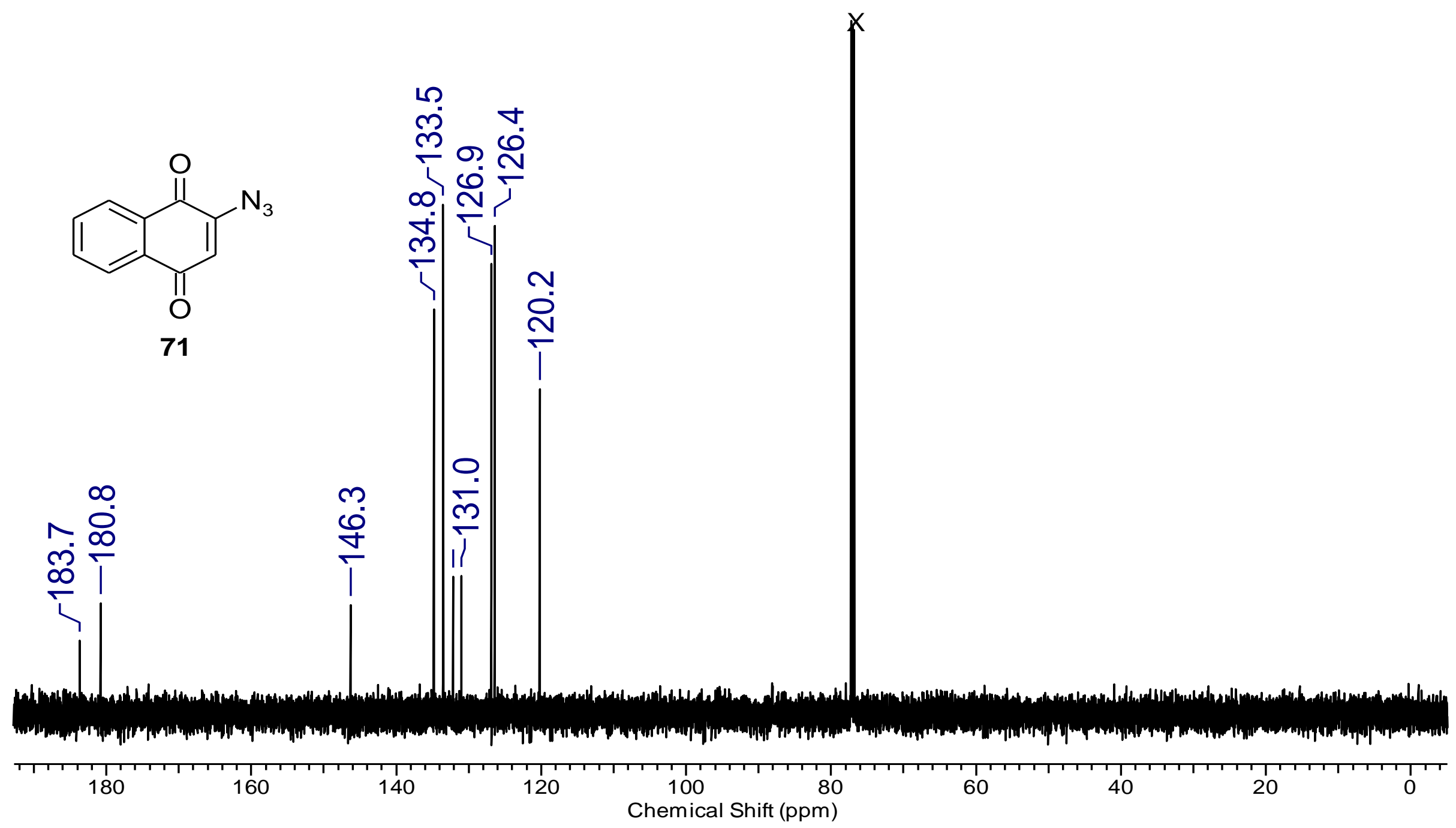

Espectro 1.2 - Espectro de RMN de ${ }^{13} \mathrm{C}\left(150 \mathrm{MHz}, \mathrm{CDCl}_{3}\right)$ da 2-azido-1,4-naftoquinona 71. 


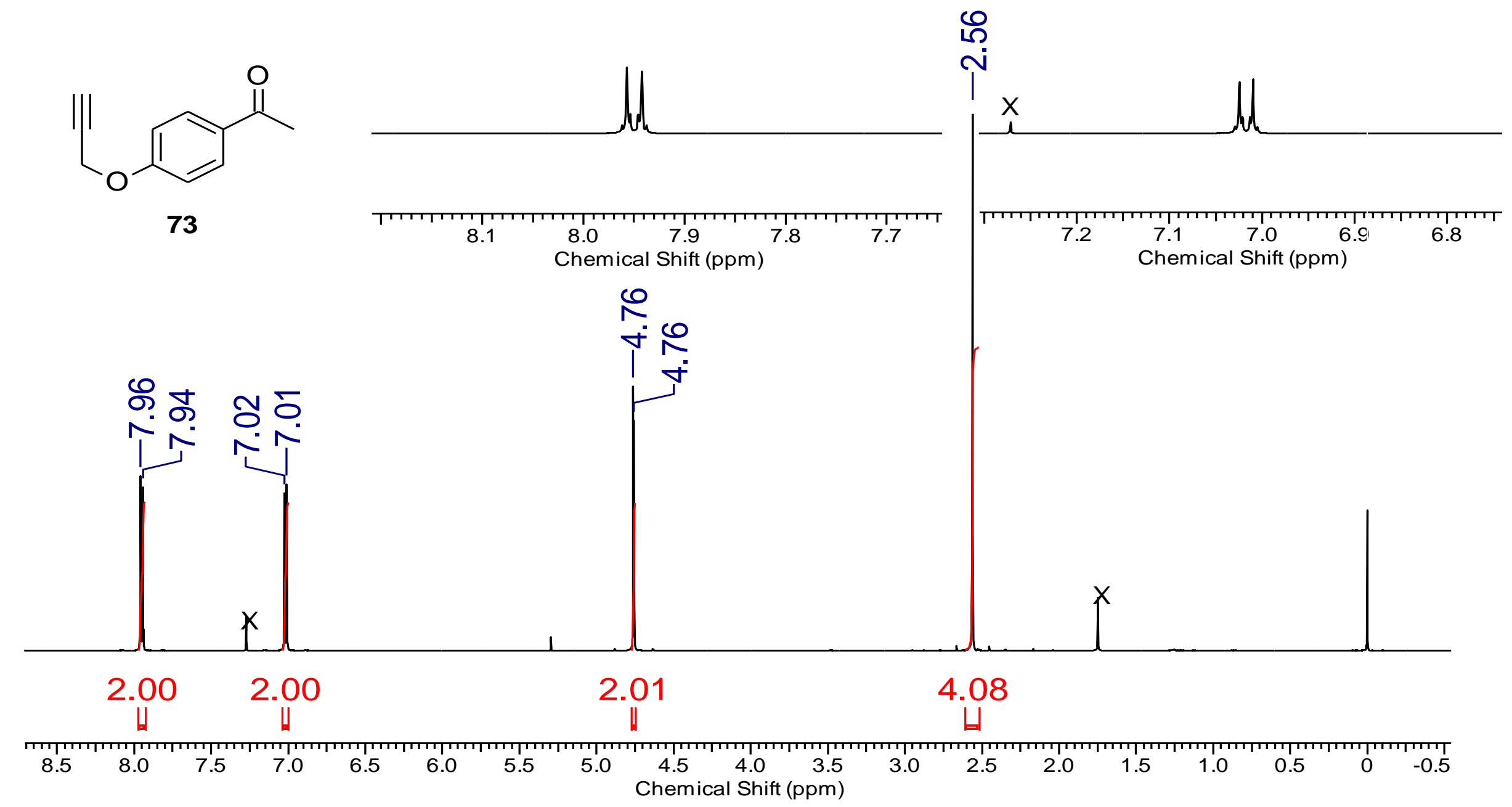

Espectro 2.1 - Espectro de $\mathrm{RMN} \mathrm{de}{ }^{1} \mathrm{H}\left(600 \mathrm{MHz}, \mathrm{CDCl}_{3}\right)$ da 4-propargiloxi-acetofenona 73. 


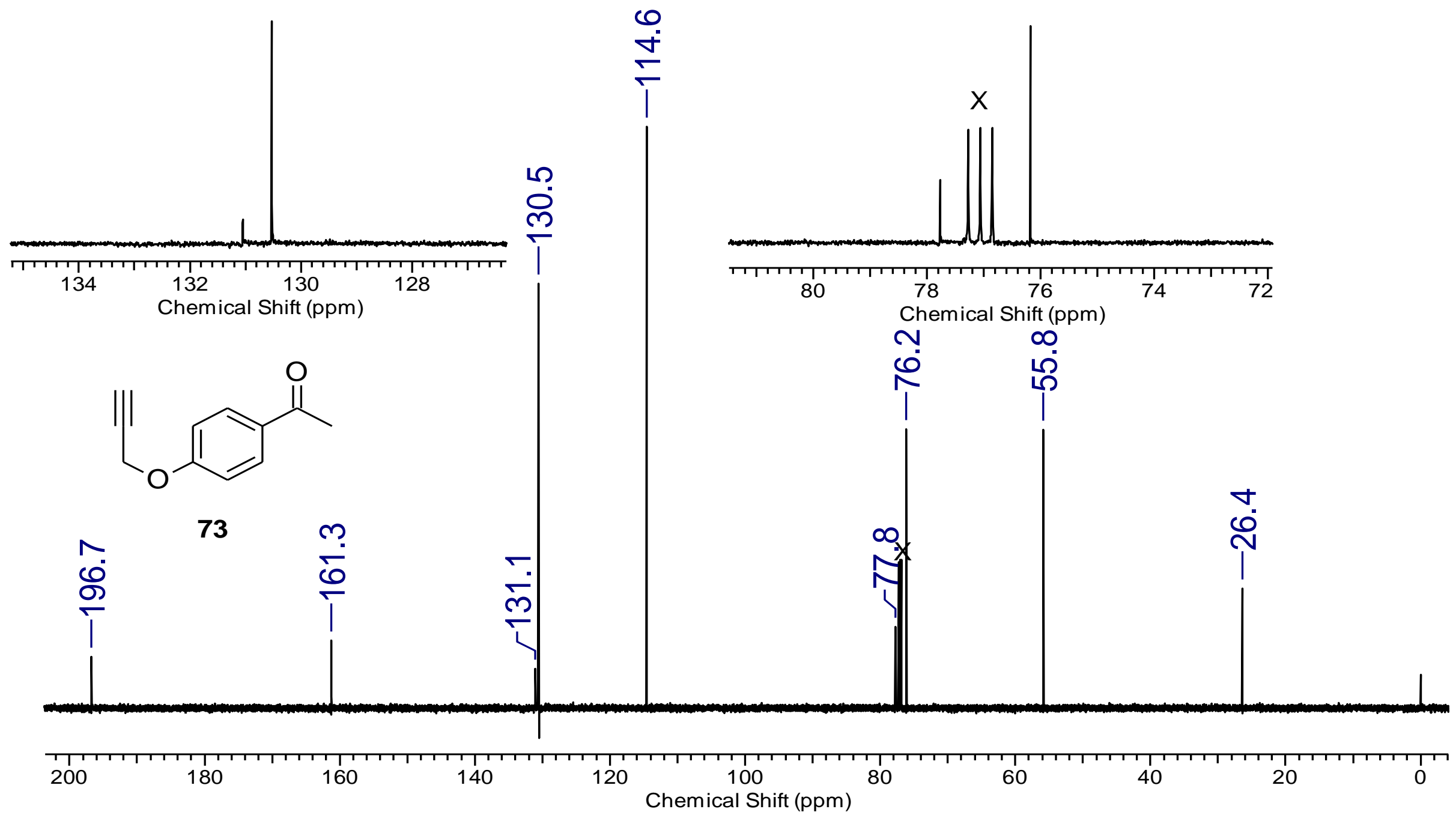

Espectro 2.2 - Espectro de RMN de ${ }^{13} \mathrm{C}\left(150 \mathrm{MHz}, \mathrm{CDCl}_{3}\right)$ da 4-propargiloxi-acetofenona 73 . 


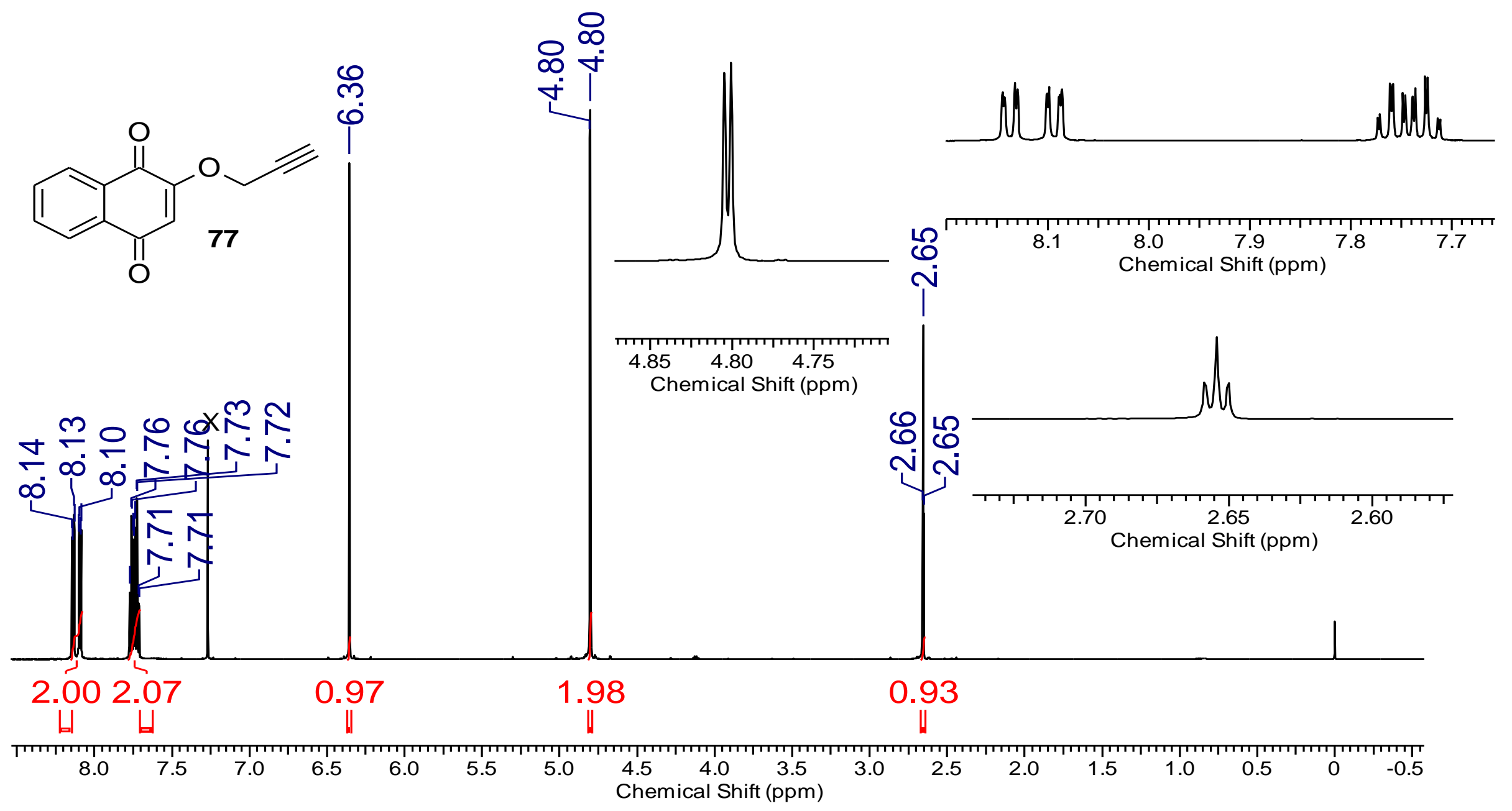

Espectro 3.1 - Espectro de RMN de ${ }^{1} \mathrm{H}\left(600 \mathrm{MHz}, \mathrm{CDCl}_{3}\right)$ da 2-propargiloxi-1,4-naftoquinona 77. 

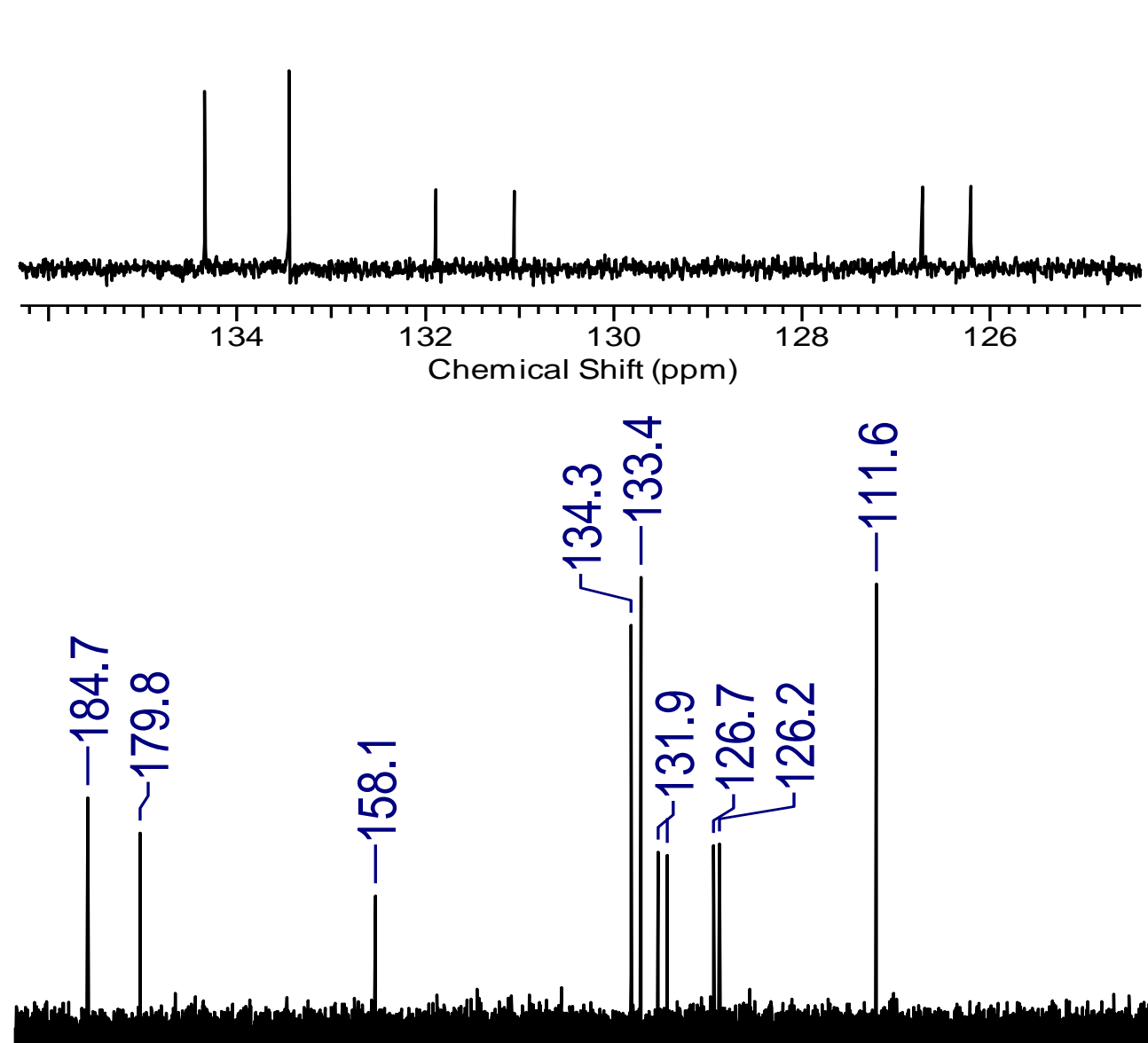

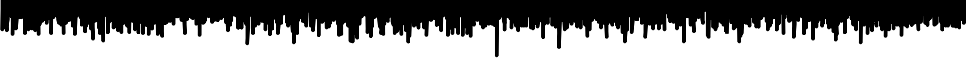

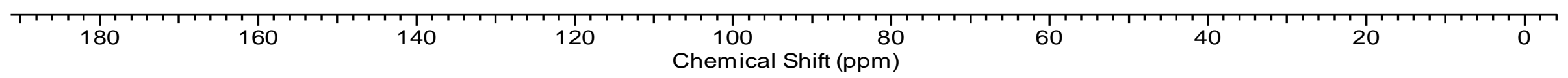

Espectro 3.2 - Espectro de $\mathrm{RMN}$ de ${ }^{13} \mathrm{C}\left(150 \mathrm{MHz}, \mathrm{CDCl}_{3}\right)$ da 2-propargiloxi-1,4-naftoquinona 77 .

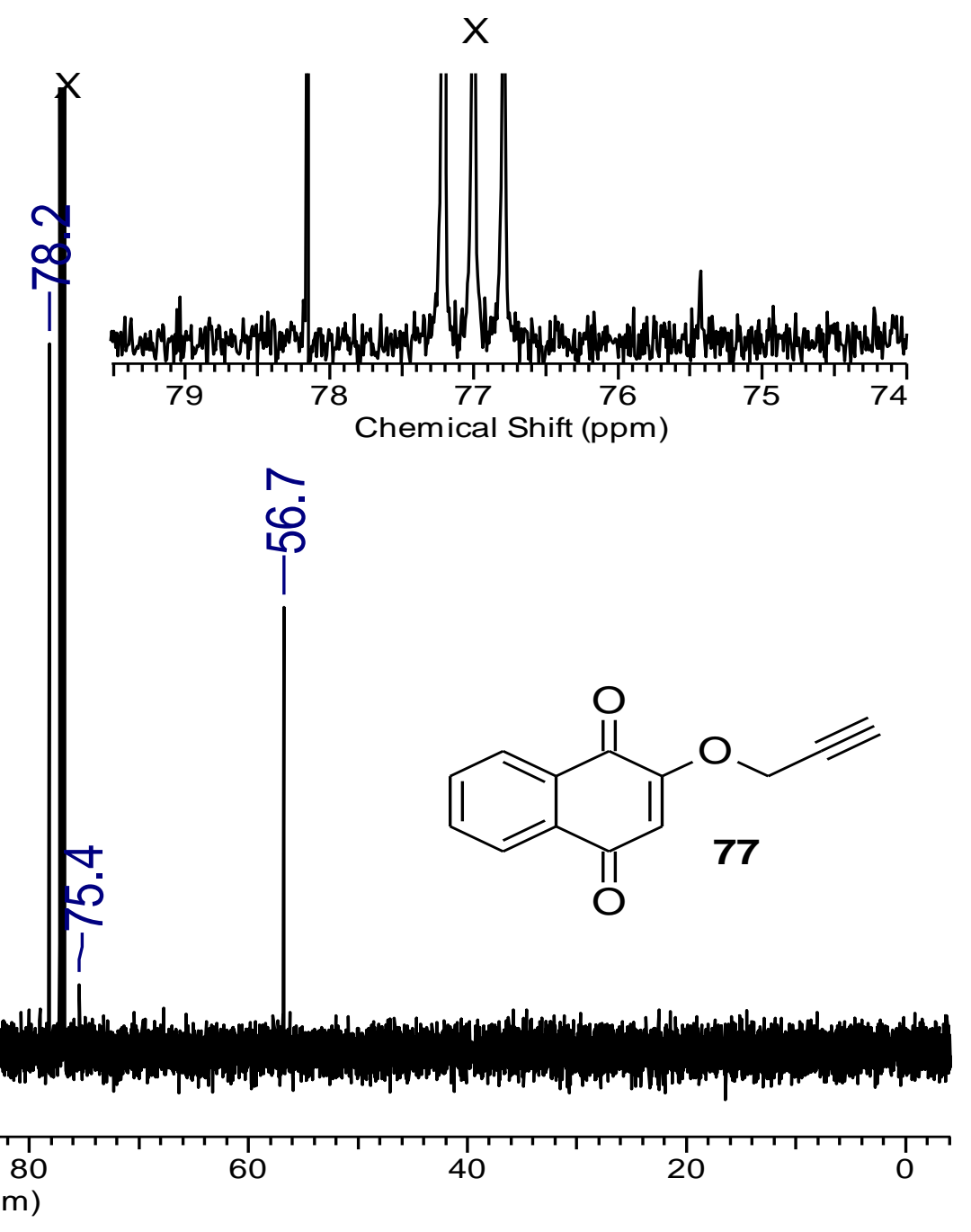




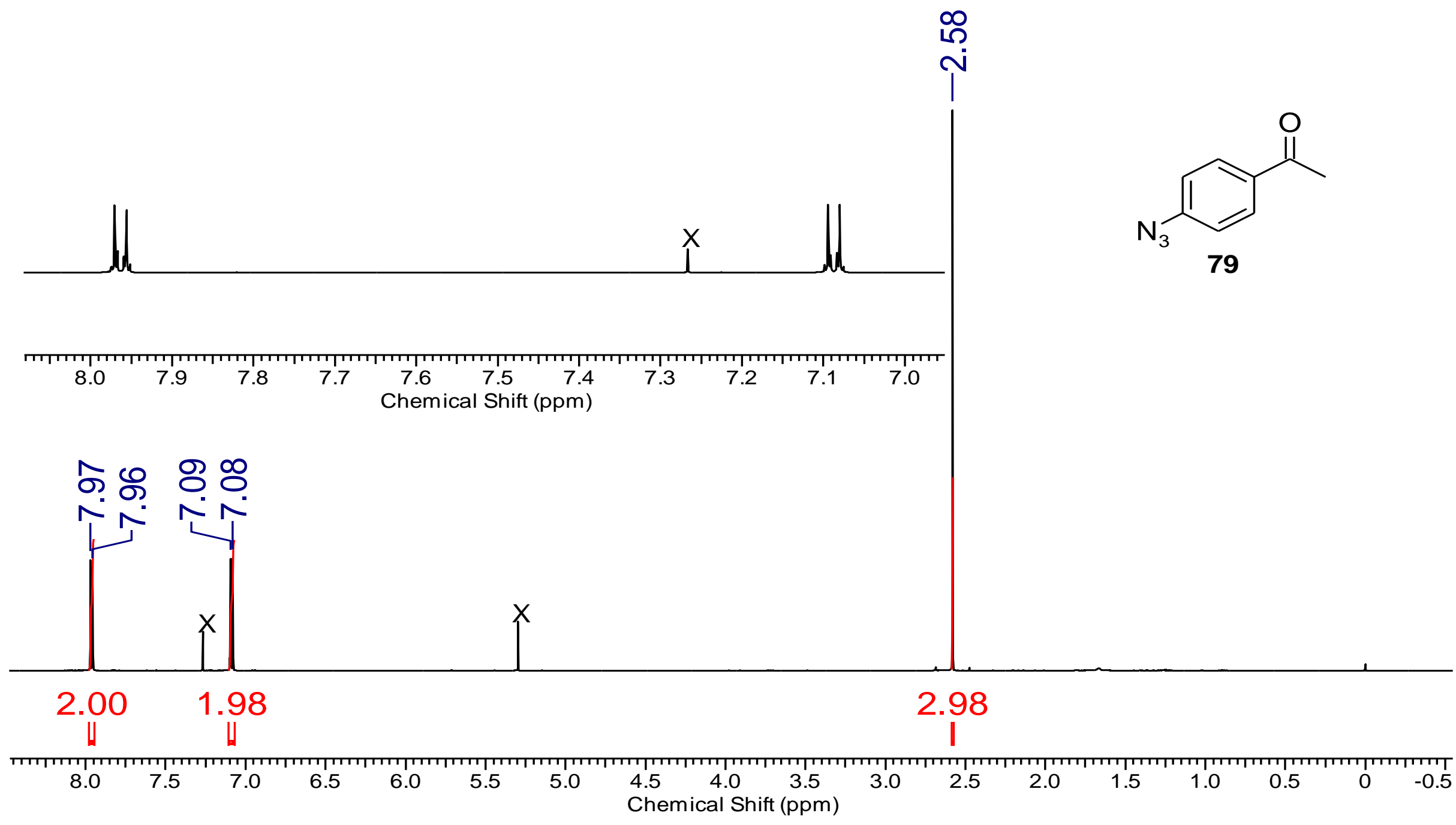

Espectro 4.1 - Espectro de RMN de ${ }^{1} \mathrm{H}\left(600 \mathrm{MHz}, \mathrm{CDCl}_{3}\right)$ da 4-azido-acetofenona 79. 


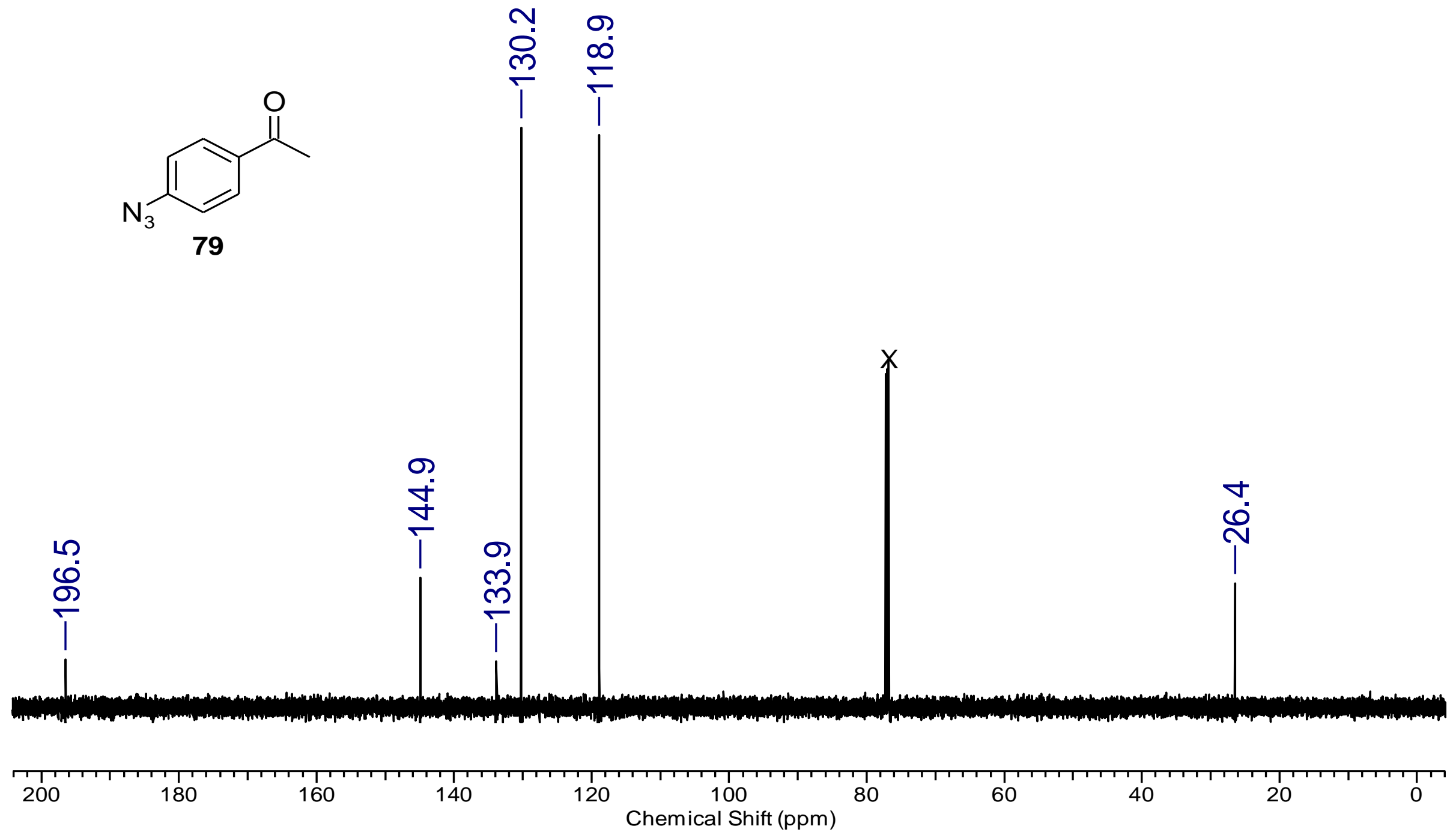

Espectro 4.2 - Espectro de RMN de ${ }^{13} \mathrm{C}\left(150 \mathrm{MHz}, \mathrm{CDCl}_{3}\right)$ da 4-azido-acetofenona 79. 


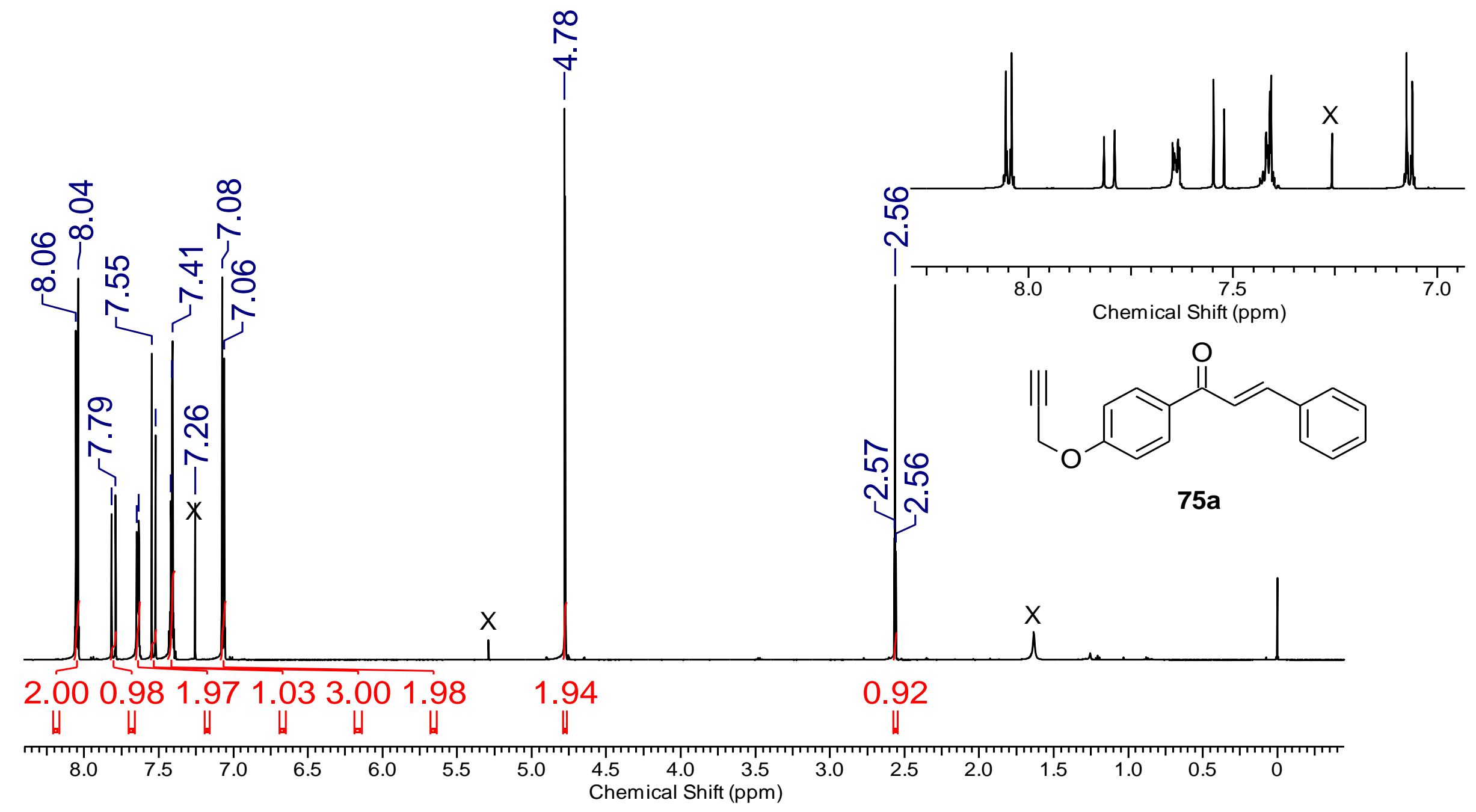

Espectro 6.1 - Espectro de $\mathrm{RMN} \mathrm{de}{ }^{1} \mathrm{H}\left(600 \mathrm{MHz}, \mathrm{CDCl}_{3}\right)$ da chalcona 75a. 

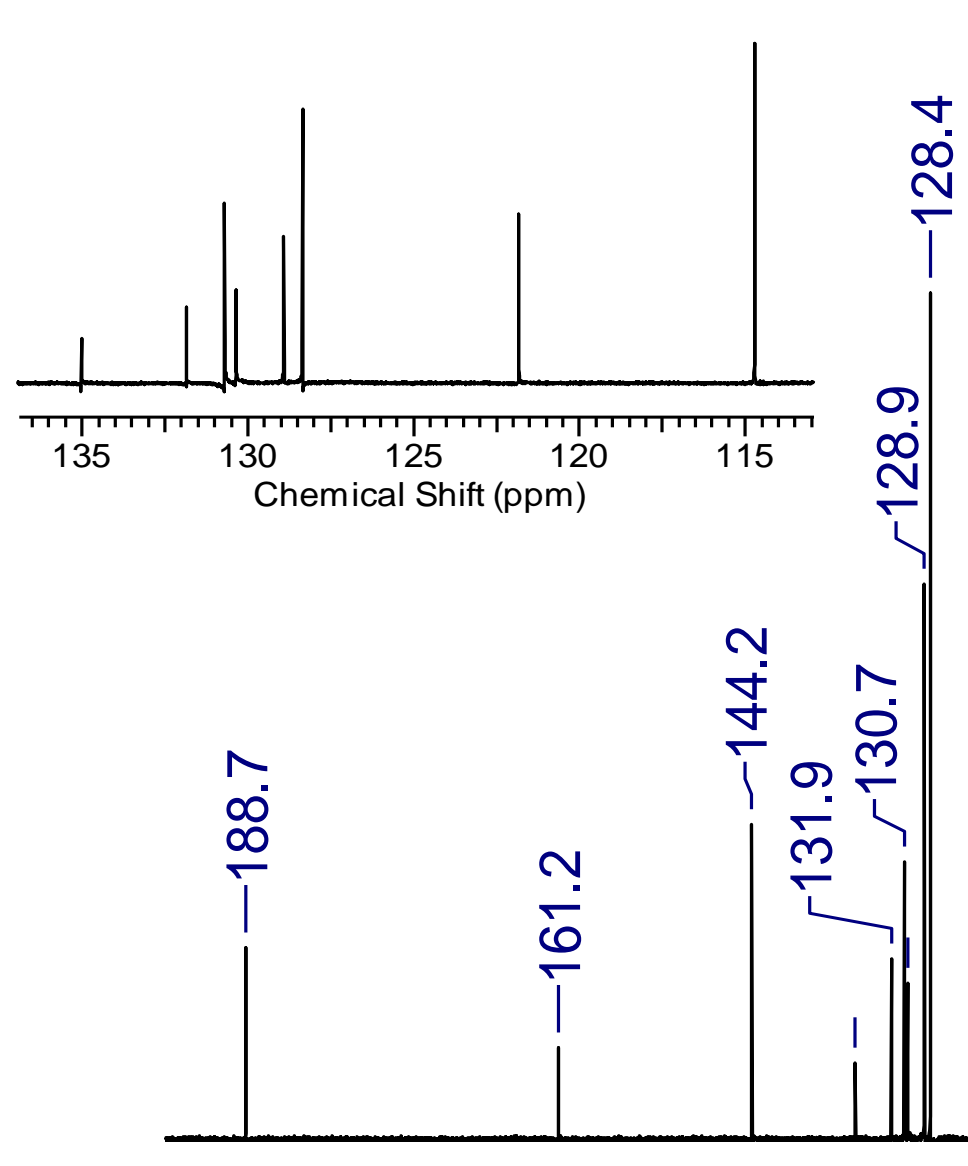

Tा 180

180

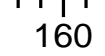

160

$\stackrel{1}{\searrow}$ a ल m. n
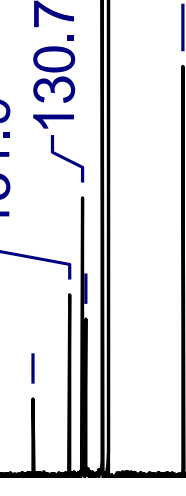

$\frac{\infty}{\pi}$

$\frac{\infty}{\stackrel{亠}{\square}}$

ป

$\stackrel{+}{\stackrel{\square}{\sim}}$

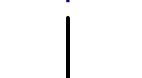

Espectro 6.2 - Espectro de $\mathrm{RMN}$ de ${ }^{13} \mathrm{C}\left(150 \mathrm{MHz}, \mathrm{CDCl}_{3}\right)$ da chalcona 75a. 


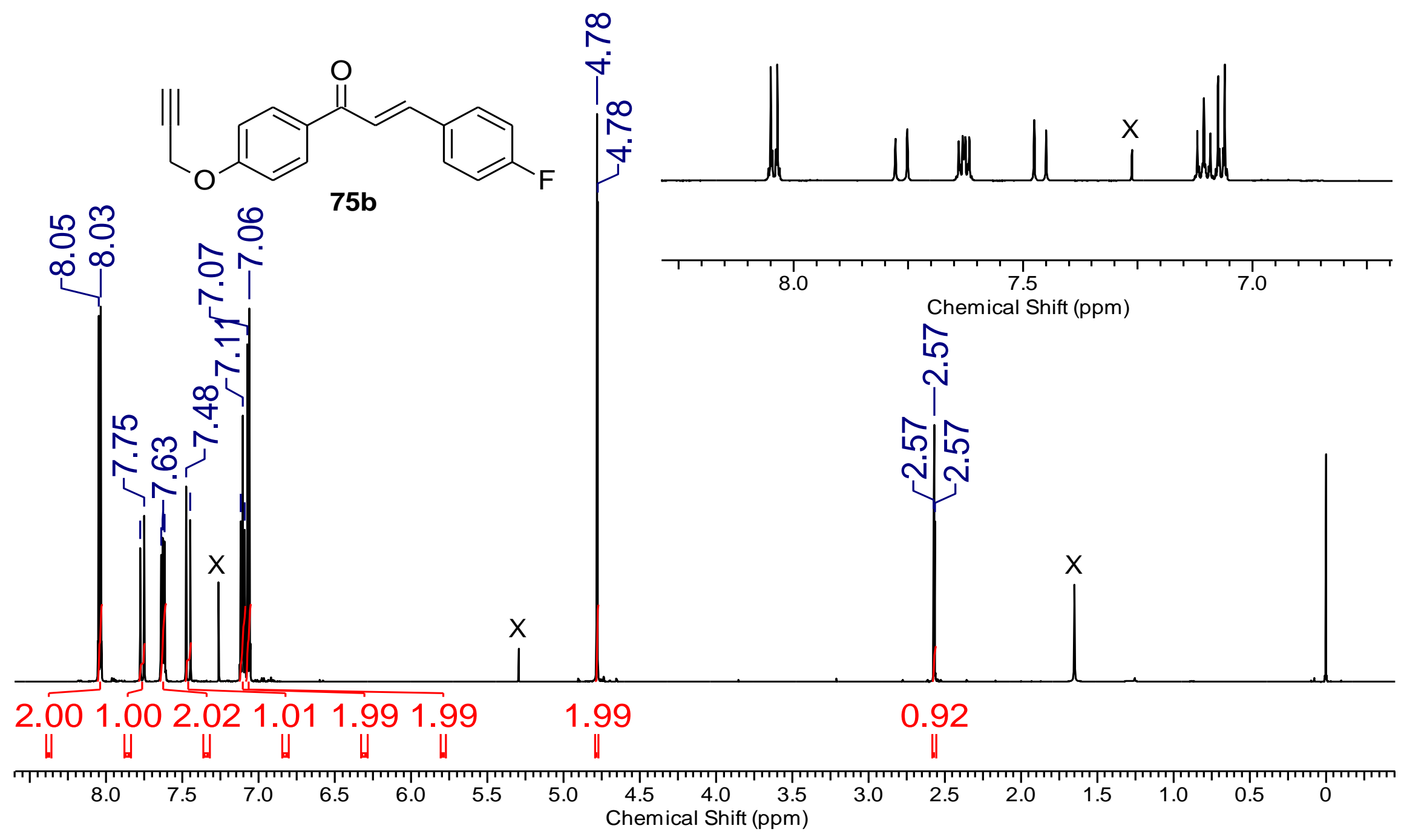

Espectro 7.1 - Espectro de $\mathrm{RMN} \mathrm{de}{ }^{1} \mathrm{H}\left(600 \mathrm{MHz}, \mathrm{CDCl}_{3}\right)$ da chalcona 75b. 


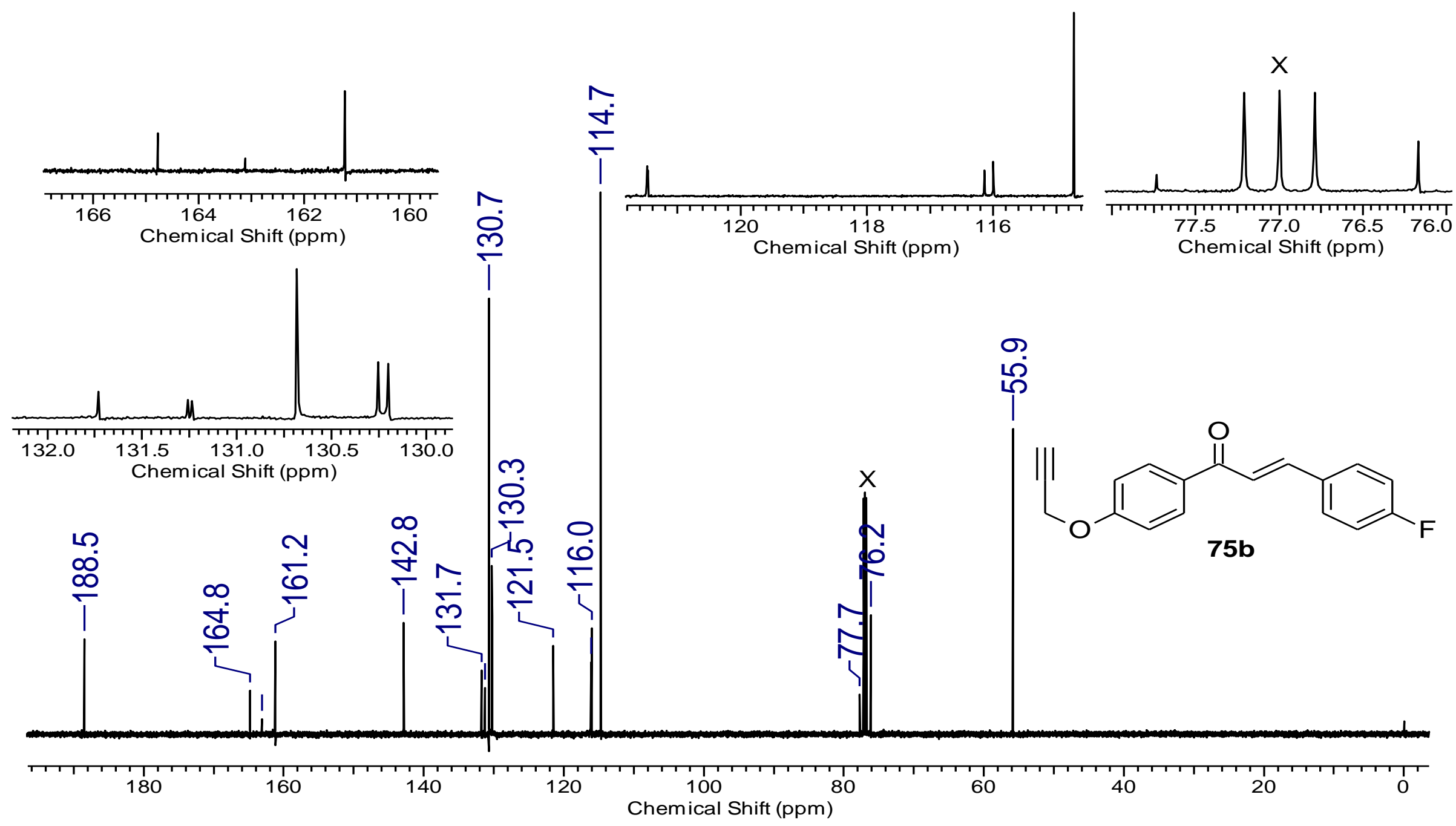

Espectro 7.2 - Espectro de $\mathrm{RMN} \mathrm{de}{ }^{13} \mathrm{C}\left(150 \mathrm{MHz}, \mathrm{CDCl}_{3}\right)$ da chalcona $\mathbf{7 5 b}$. 


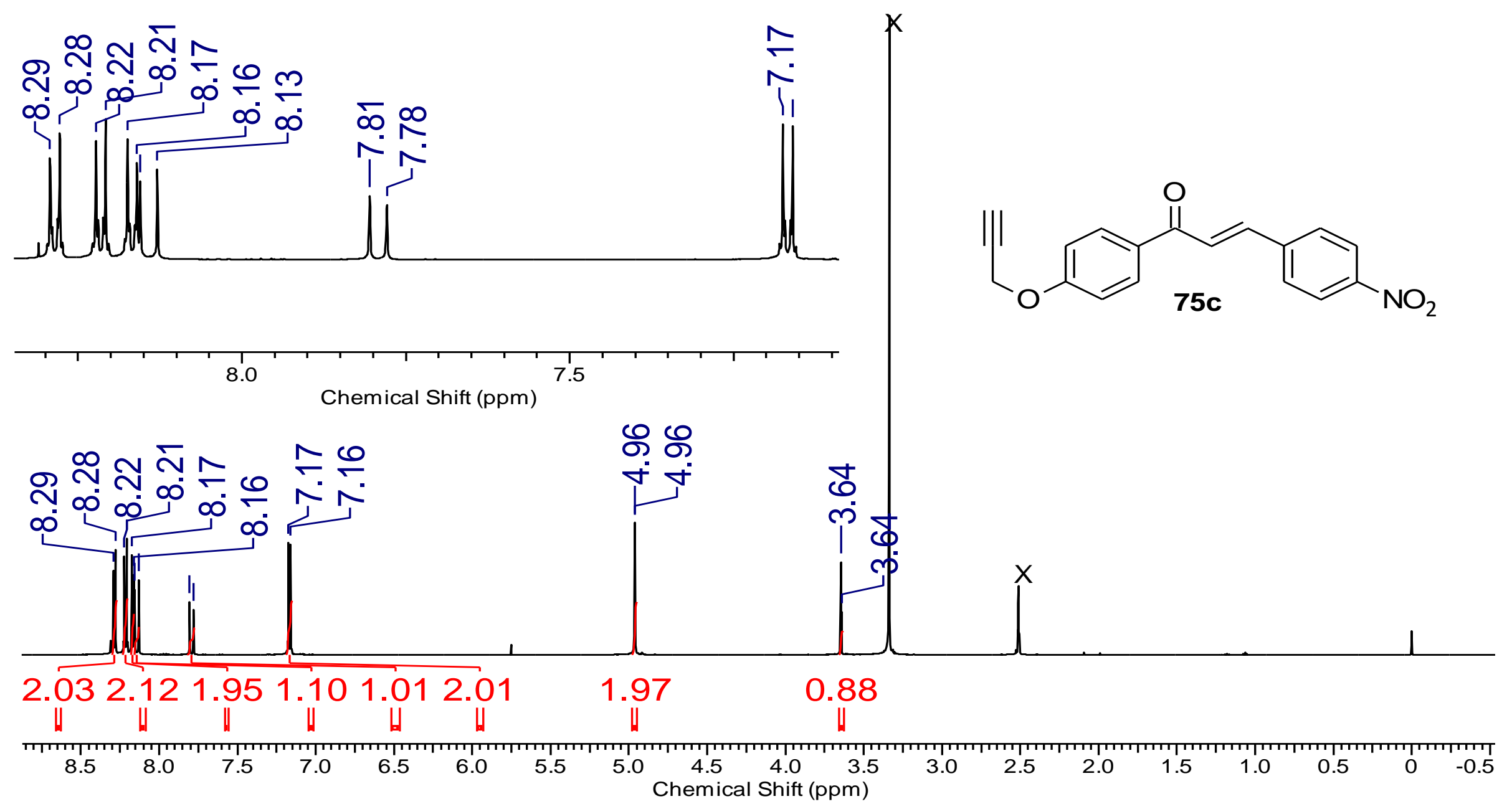

Espectro 8.1 - Espectro de RMN de ${ }^{1} \mathrm{H}\left(600 \mathrm{MHz}\right.$, DMSO- $\left.d_{6}\right)$ da chalcona 75c. 


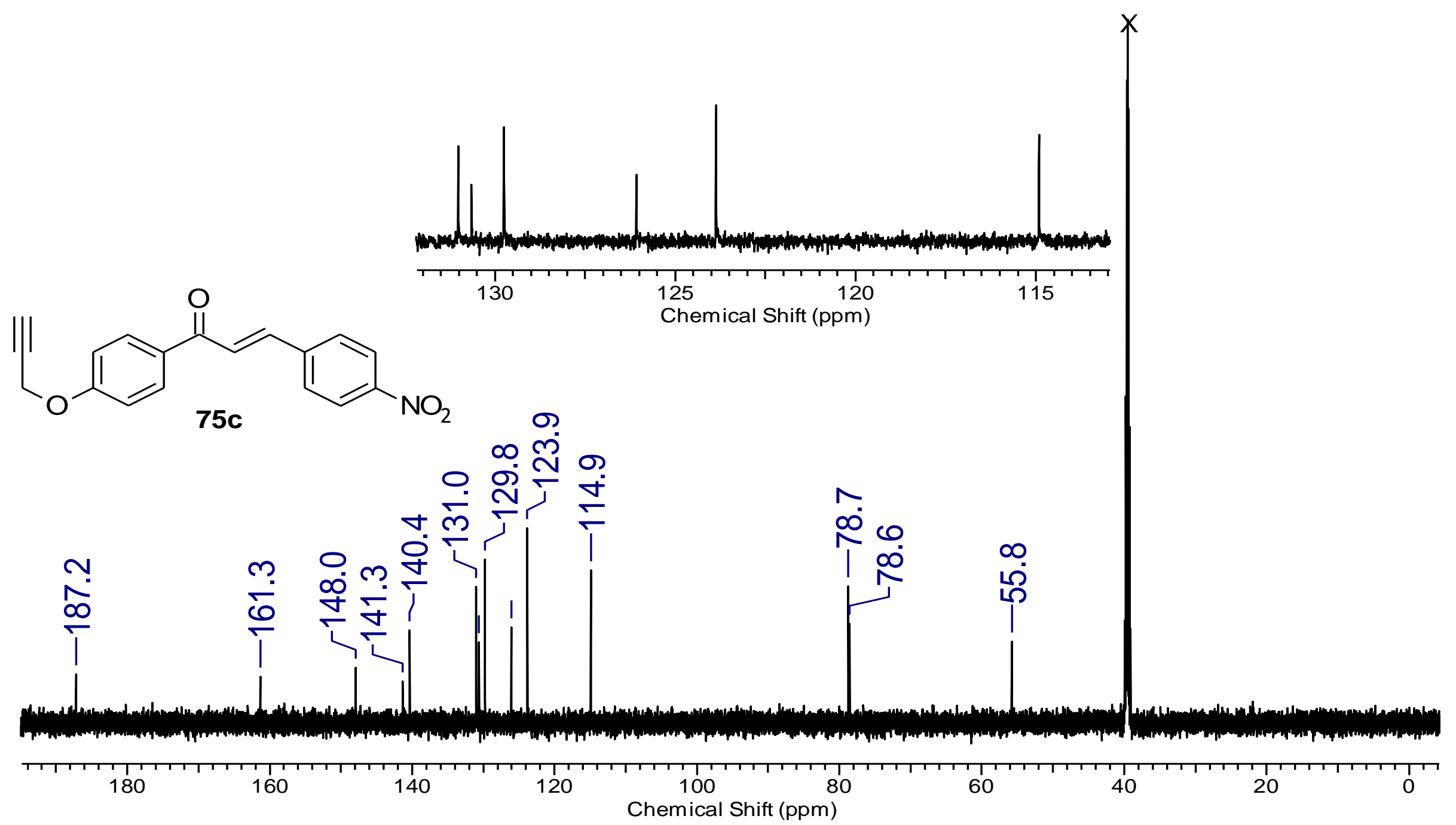

Espectro 8.2 - Espectro de RMN de ${ }^{13} \mathrm{C}\left(150 \mathrm{MHz}\right.$, DMSO- $\left.d_{6}\right)$ da chalcona 75c. 


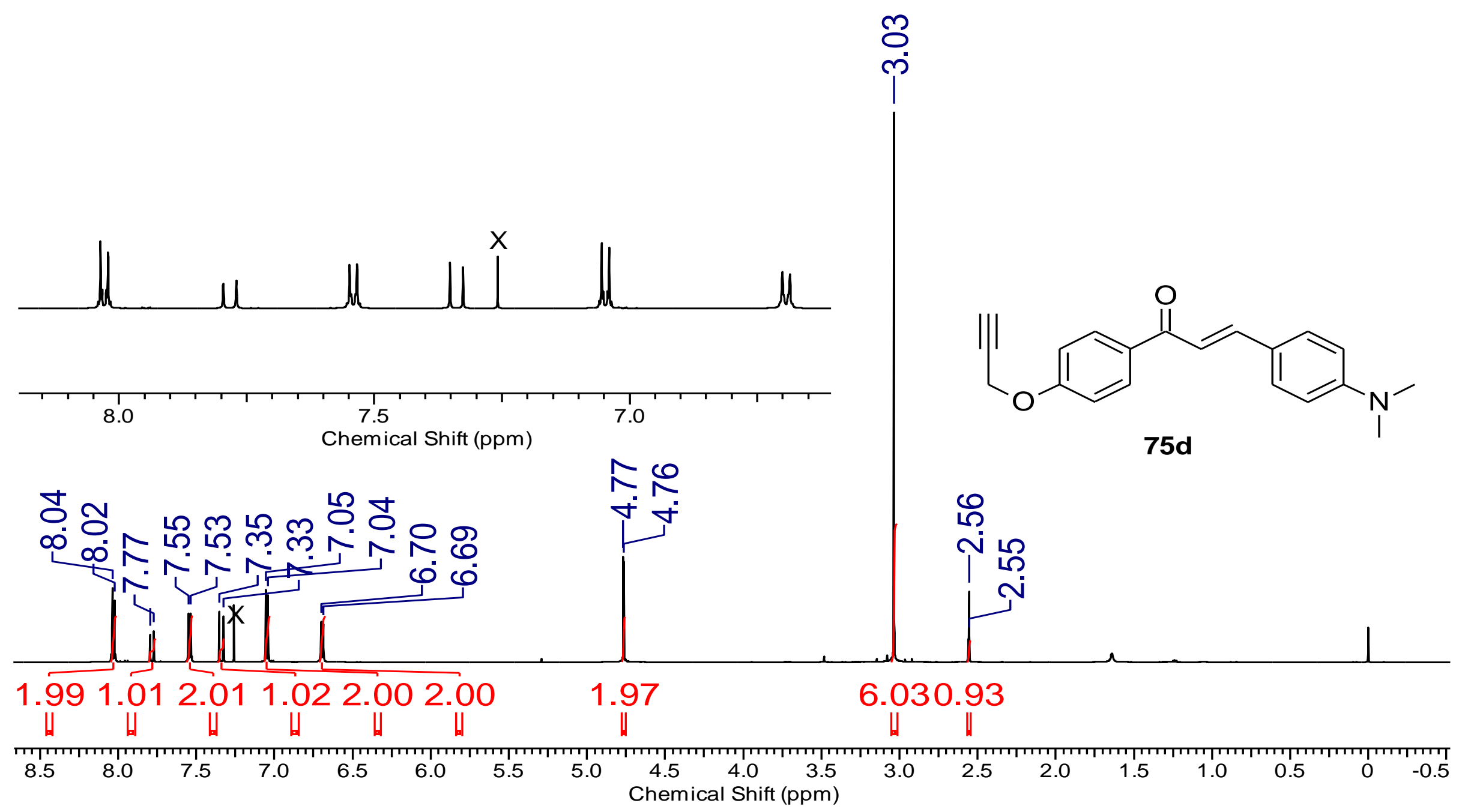

Espectro 9.1 - Espectro de RMN de ${ }^{1} \mathrm{H}\left(600 \mathrm{MHz}, \mathrm{CDCl}_{3}\right)$ da chalcona 75d. 


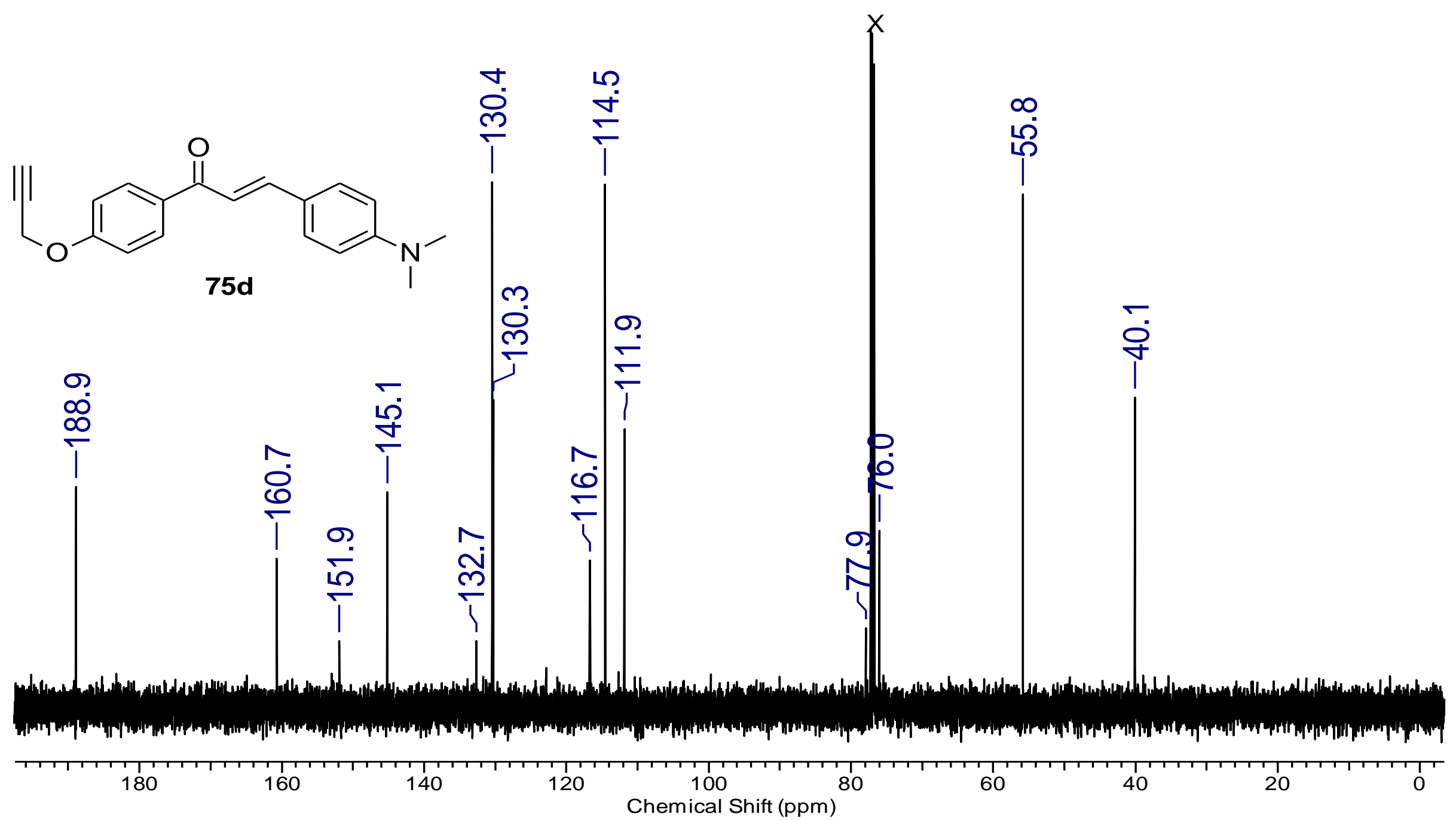

Espectro 9.2 - Espectro de $\mathrm{RMN} \mathrm{de}{ }^{13} \mathrm{C}\left(150 \mathrm{MHz}, \mathrm{CDCl}_{3}\right)$ da chalcona $\mathbf{7 5 d}$. 


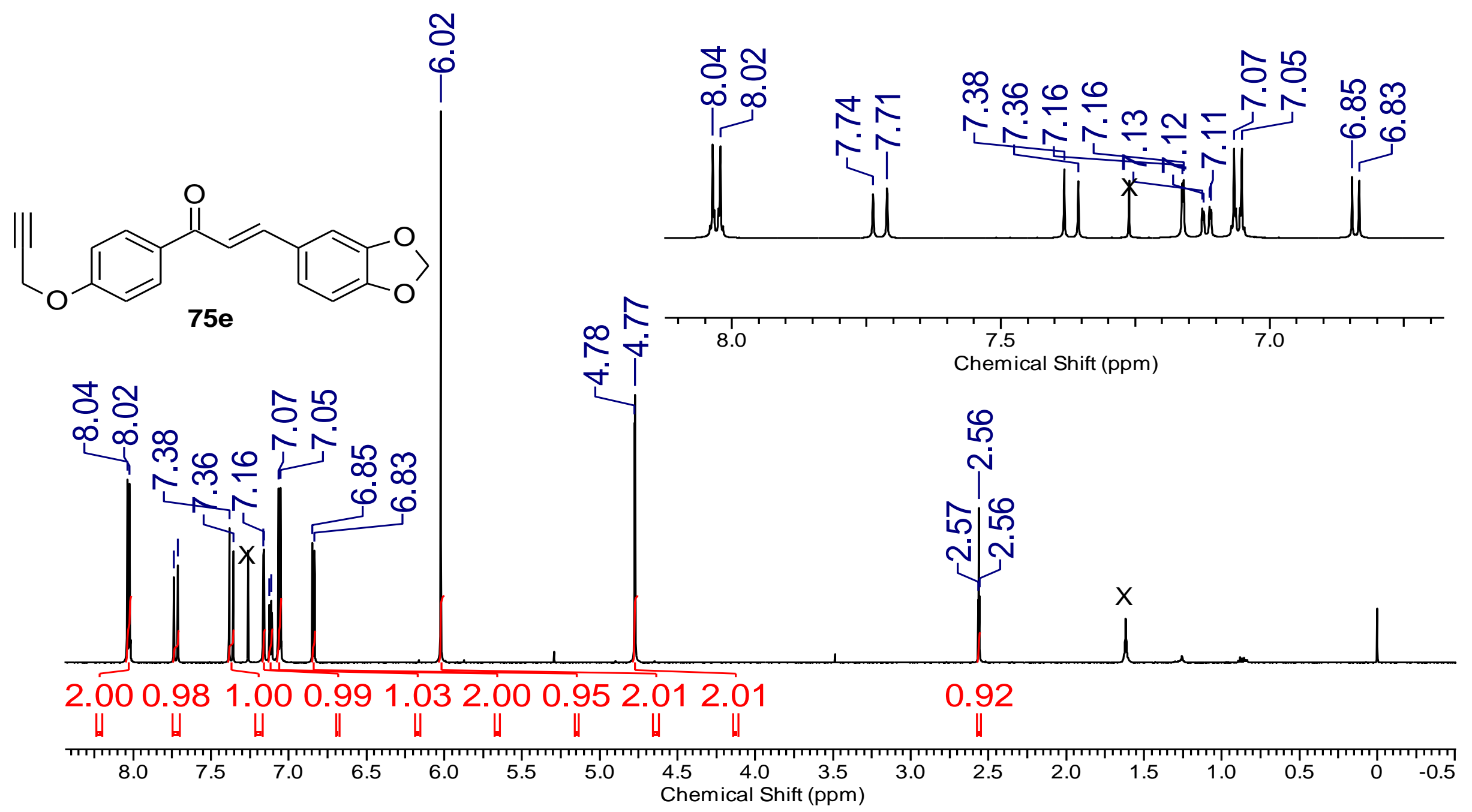

Espectro 10.1 - Espectro de $\mathrm{RMN} \mathrm{de}{ }^{1} \mathrm{H}\left(600 \mathrm{MHz}, \mathrm{CDCl}_{3}\right)$ da chalcona $75 \mathbf{e}$. 


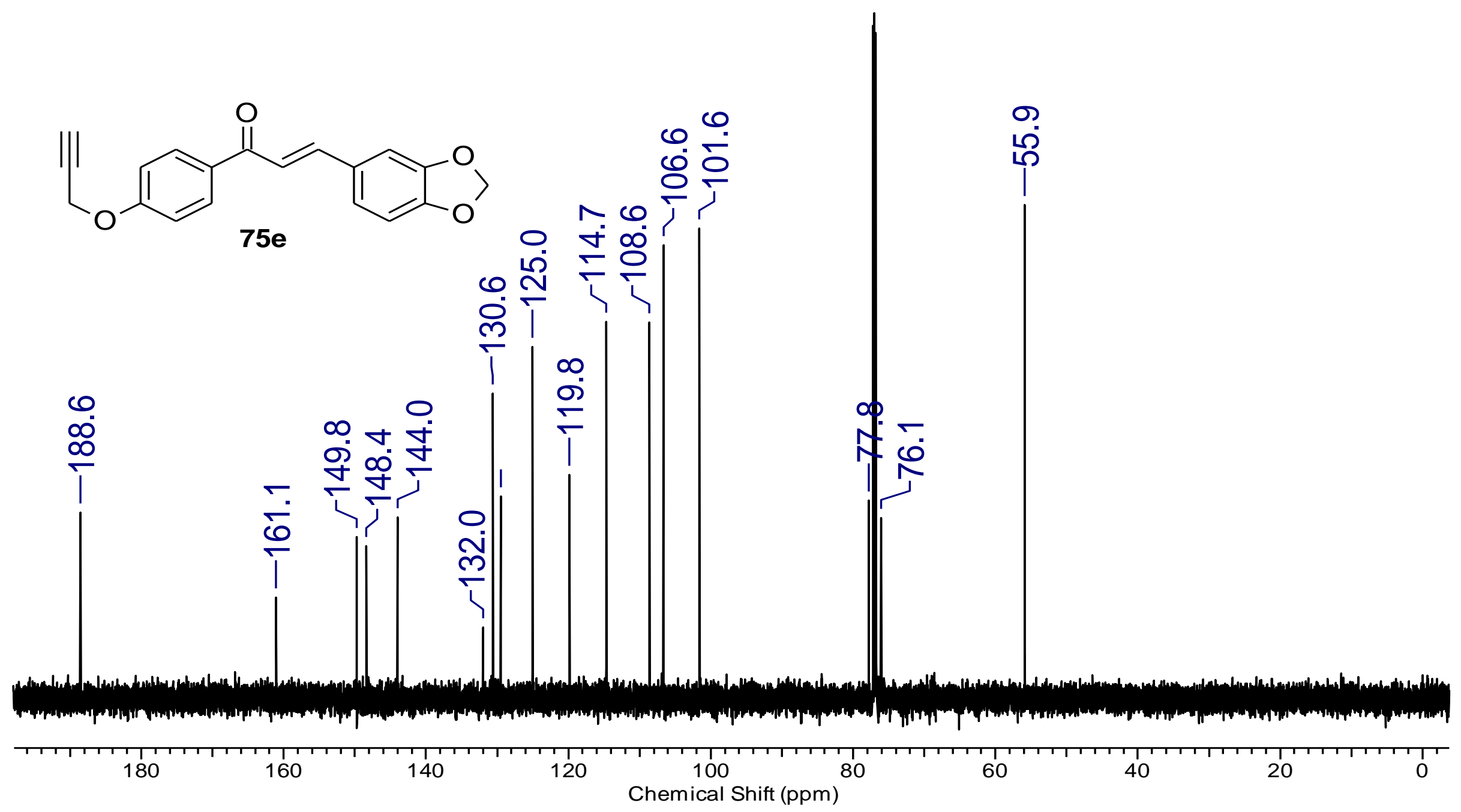

Espectro 10.2 - Espectro de $\mathrm{RMN} \mathrm{de}{ }^{13} \mathrm{C}\left(150 \mathrm{MHz}, \mathrm{CDCl}_{3}\right)$ da chalcona $75 \mathbf{e}$. 


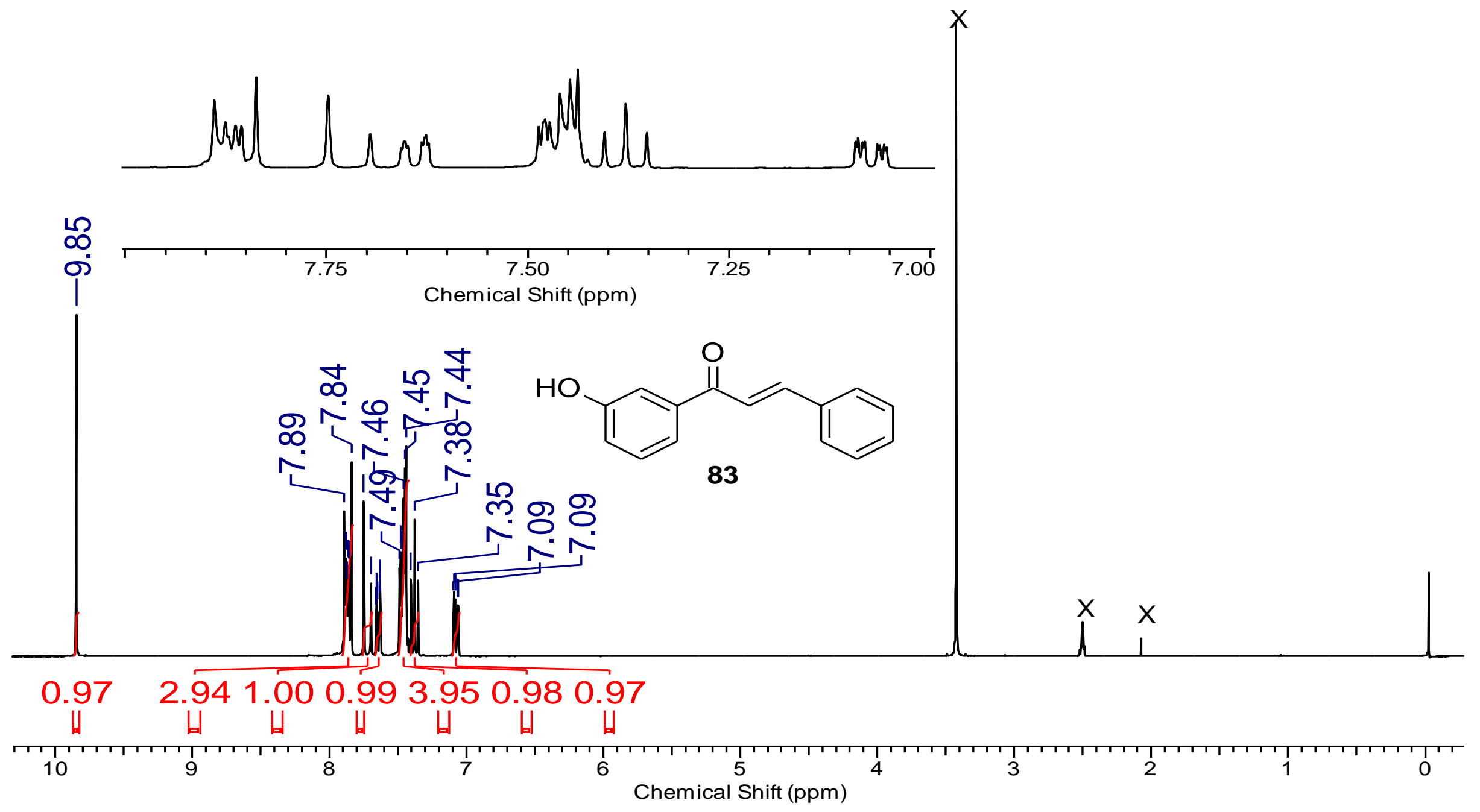

Espectro 11.1 - Espectro de RMN de ${ }^{1} \mathrm{H}\left(300 \mathrm{MHz}, \mathrm{DMSO}-d_{6}\right)$ da chalcona 83. 

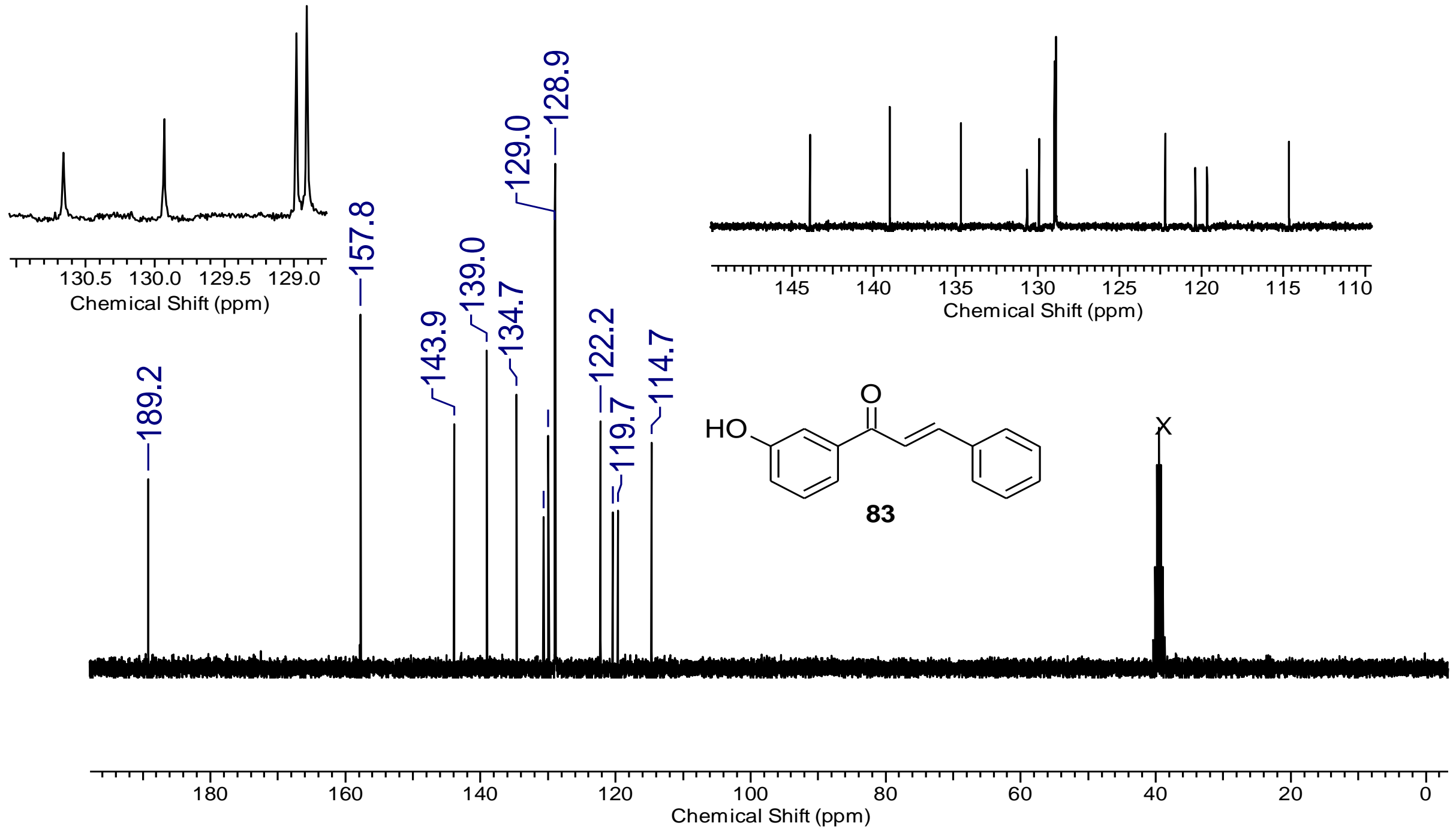

Espectro 11.2 - Espectro de RMN de ${ }^{13} \mathrm{C}\left(75 \mathrm{MHz}\right.$, DMSO- $\left.d_{6}\right)$ da chalcona 83. 


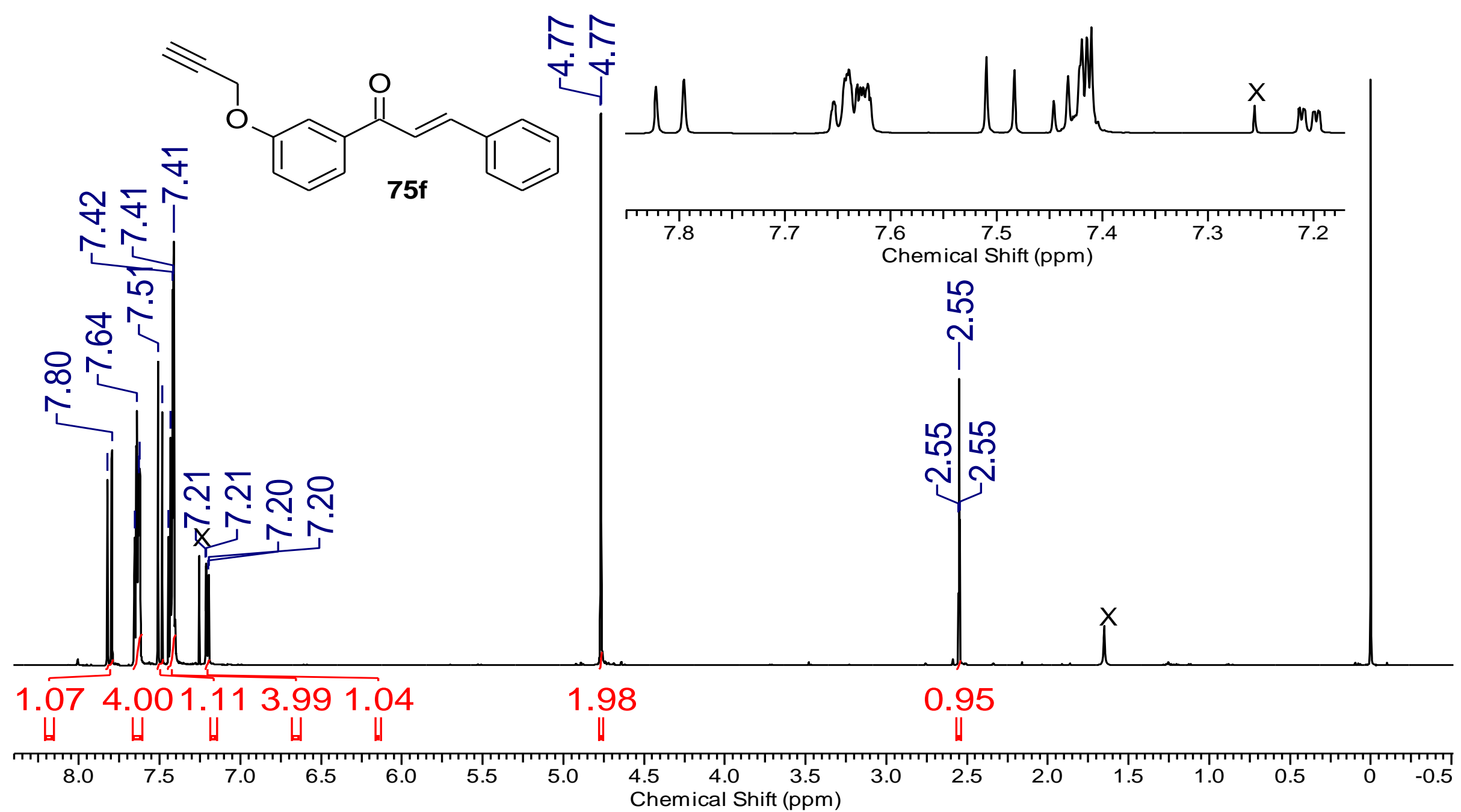

Espectro 12.1 - Espectro de $\mathrm{RMN} \mathrm{de}{ }^{1} \mathrm{H}\left(600 \mathrm{MHz}, \mathrm{CDCl}_{3}\right)$ da chalcona $75 \mathbf{f}$. 


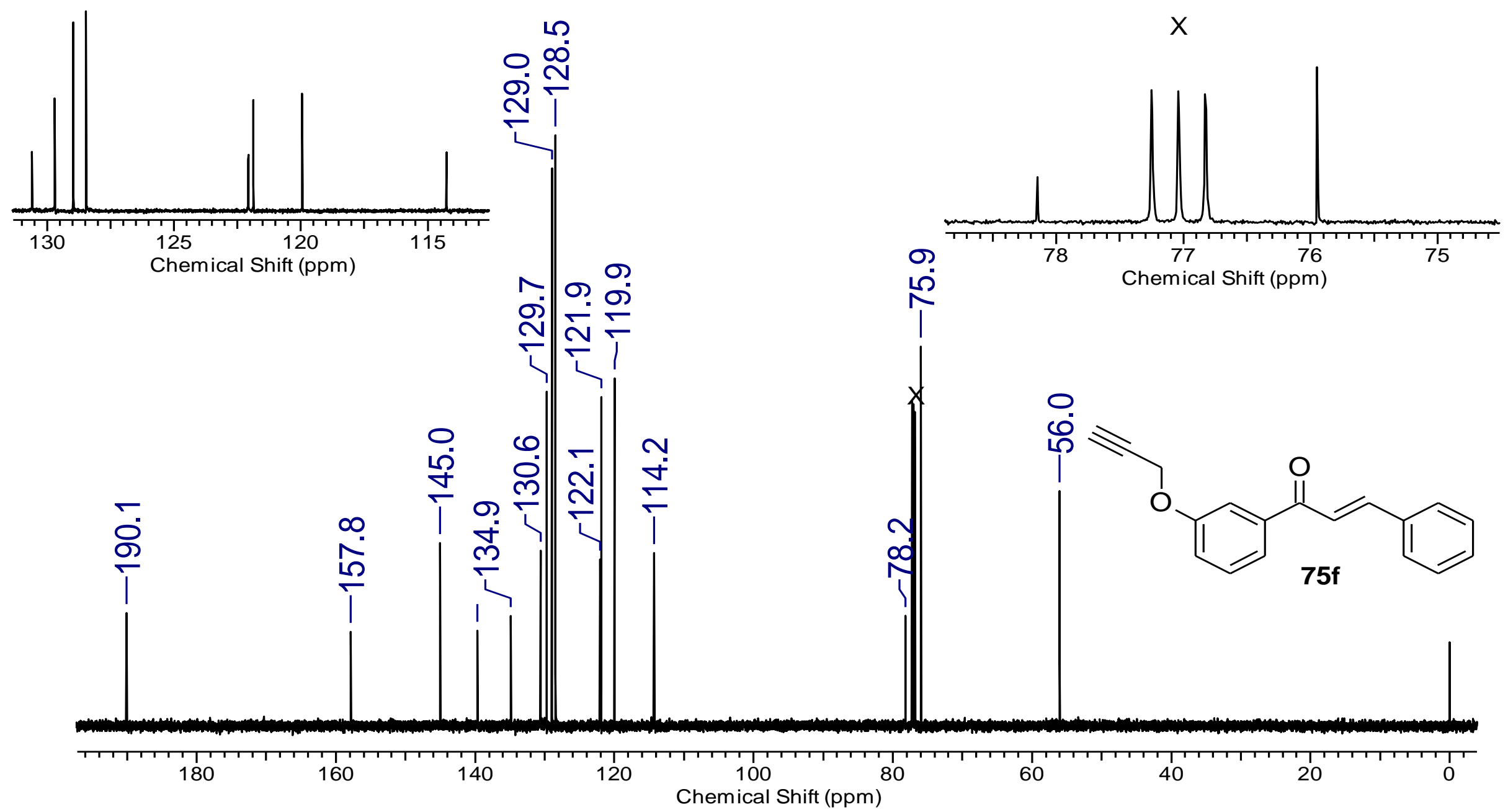

Espectro 12.2 - Espectro de $\mathrm{RMN} \mathrm{de}{ }^{13} \mathrm{C}\left(150 \mathrm{MHz}, \mathrm{CDCl}_{3}\right)$ da chalcona $75 f$. 


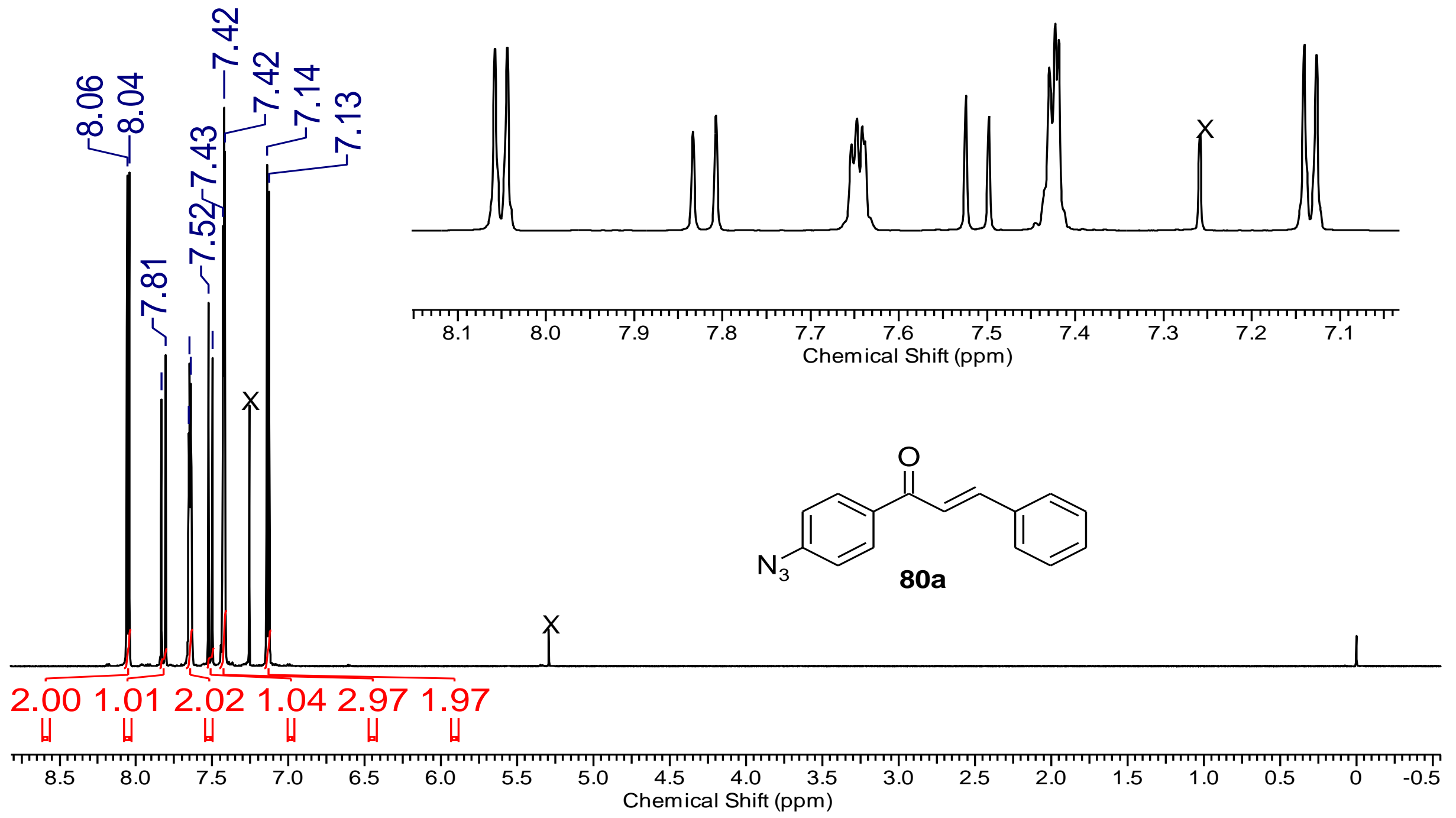

Espectro 13.1 - Espectro de RMN de ${ }^{1} \mathrm{H}\left(600 \mathrm{MHz}, \mathrm{CDCl}_{3}\right)$ da chalcona 80a. 


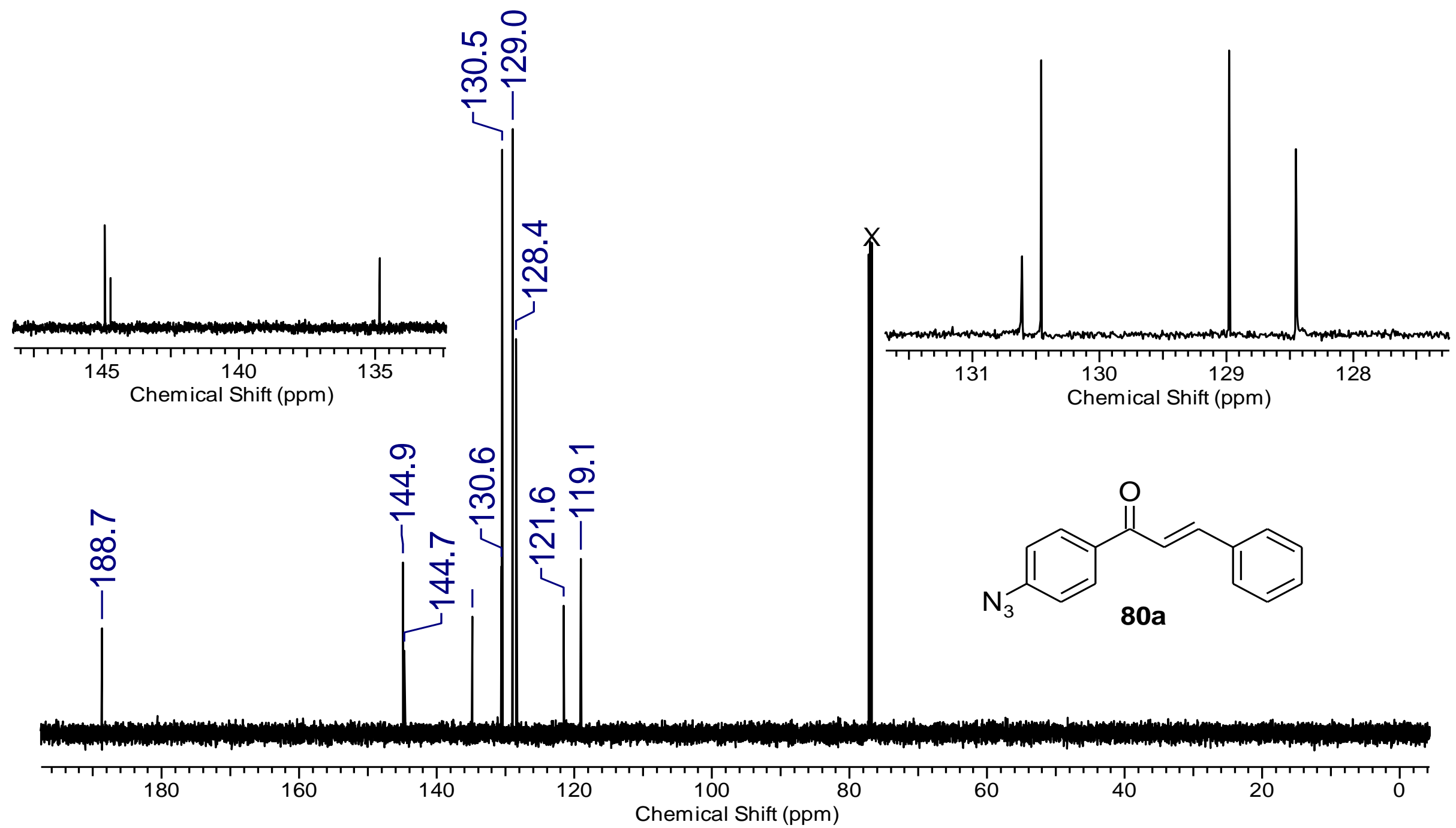

Espectro 13.2 - Espectro de $\mathrm{RMN} \mathrm{de}{ }^{13} \mathrm{C}\left(150 \mathrm{MHz}, \mathrm{CDCl}_{3}\right)$ da chalcona 80a. 


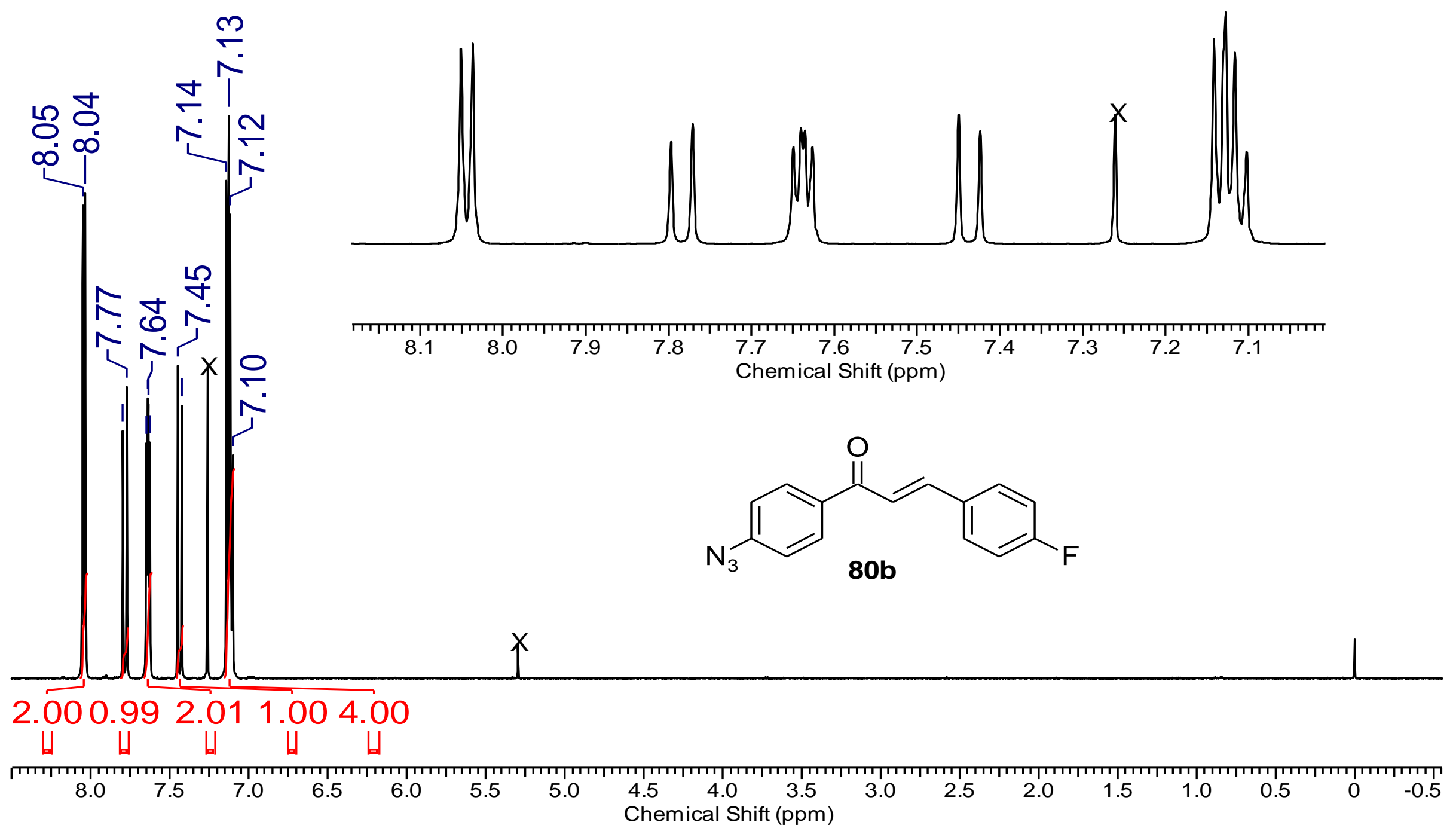

Espectro 14.1 - Espectro de RMN de ${ }^{1} \mathrm{H}\left(600 \mathrm{MHz}, \mathrm{CDCl}_{3}\right)$ da chalcona 80b. 


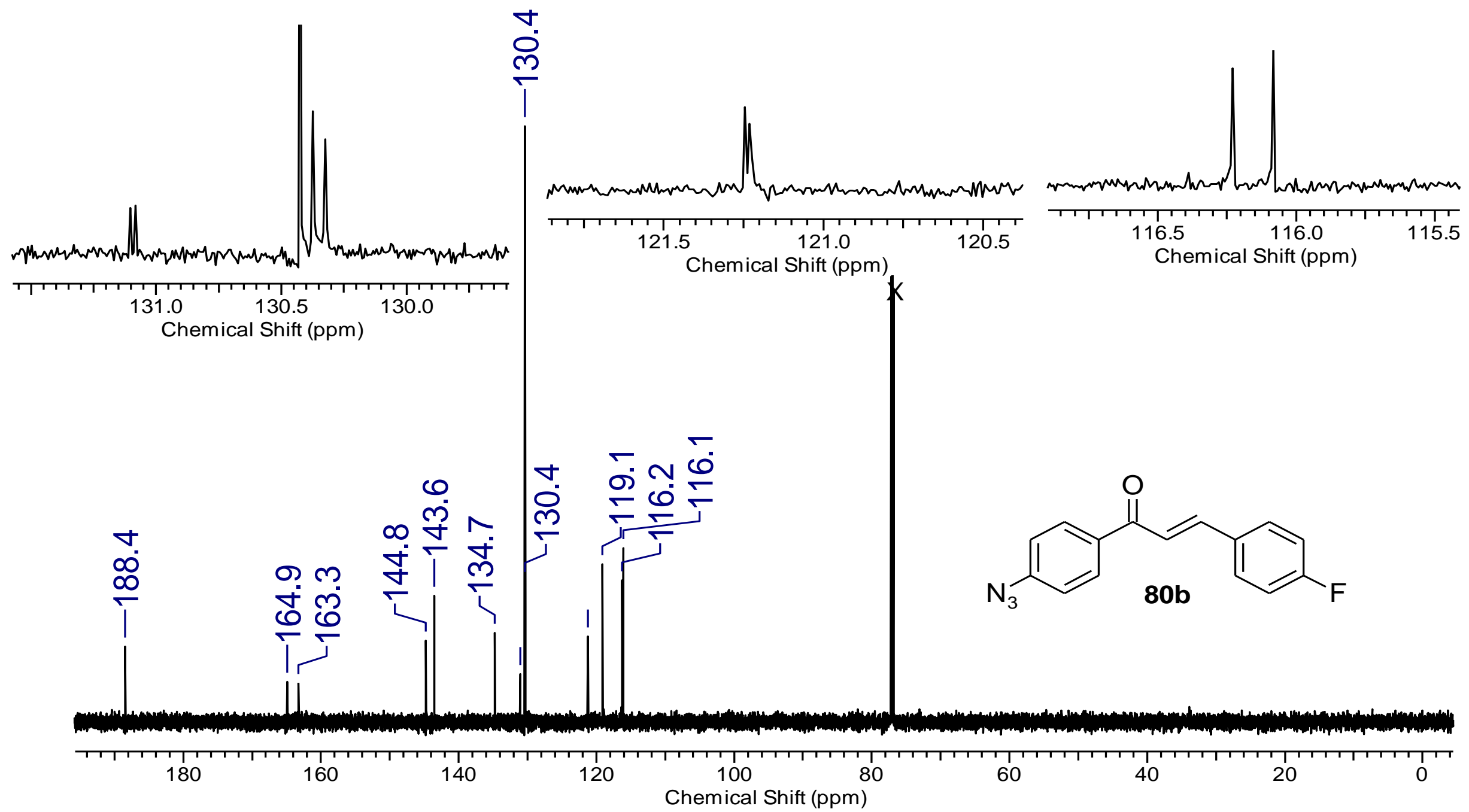

Espectro 14.2 - Espectro de RMN de ${ }^{13} \mathrm{C}\left(150 \mathrm{MHz}, \mathrm{CDCl}_{3}\right)$ da chalcona 80b. 


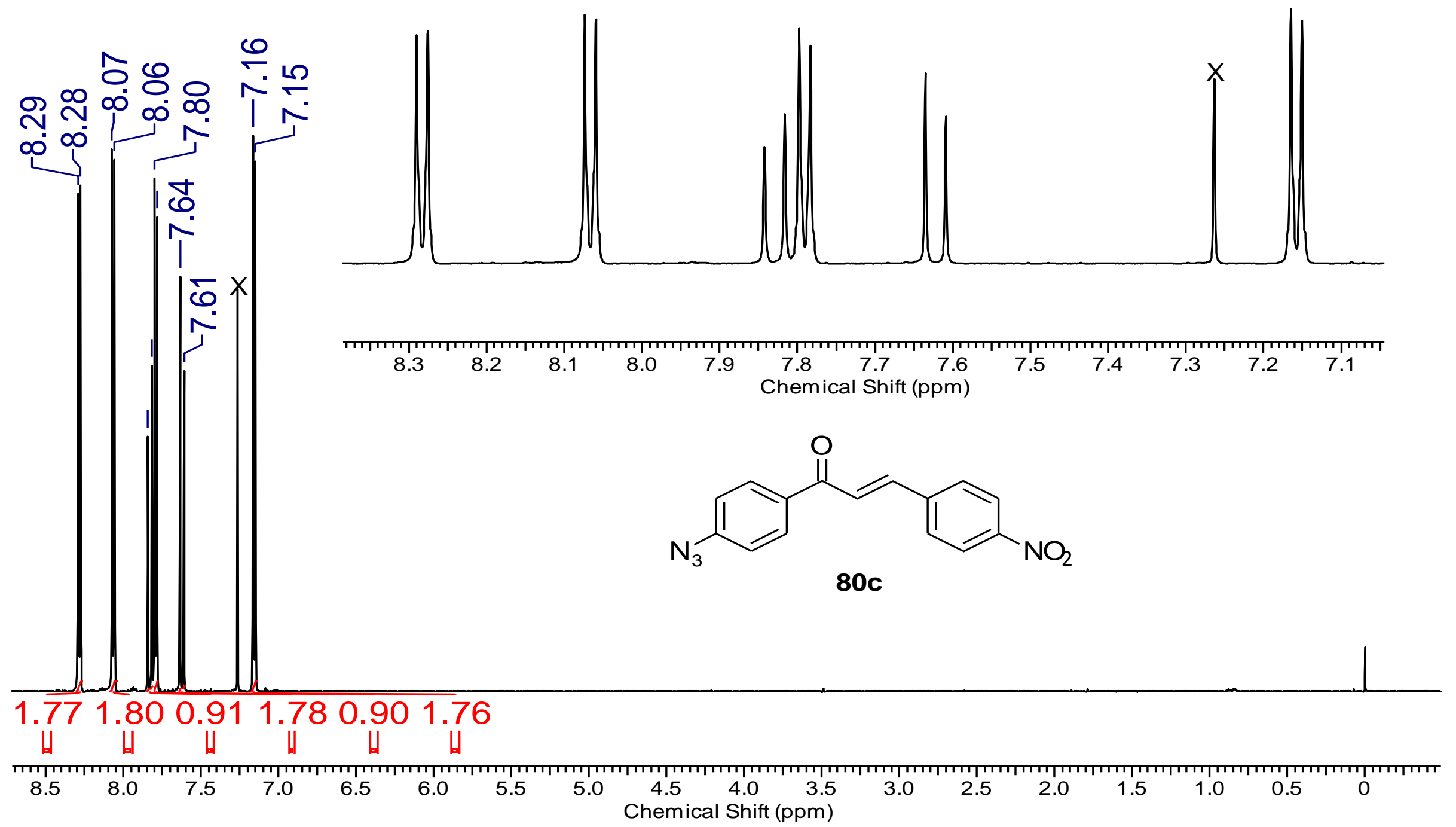

Espectro 15.1 - Espectro de RMN de ${ }^{1} \mathrm{H}\left(600 \mathrm{MHz}, \mathrm{CDCl}_{3}\right)$ da chalcona 80c. 


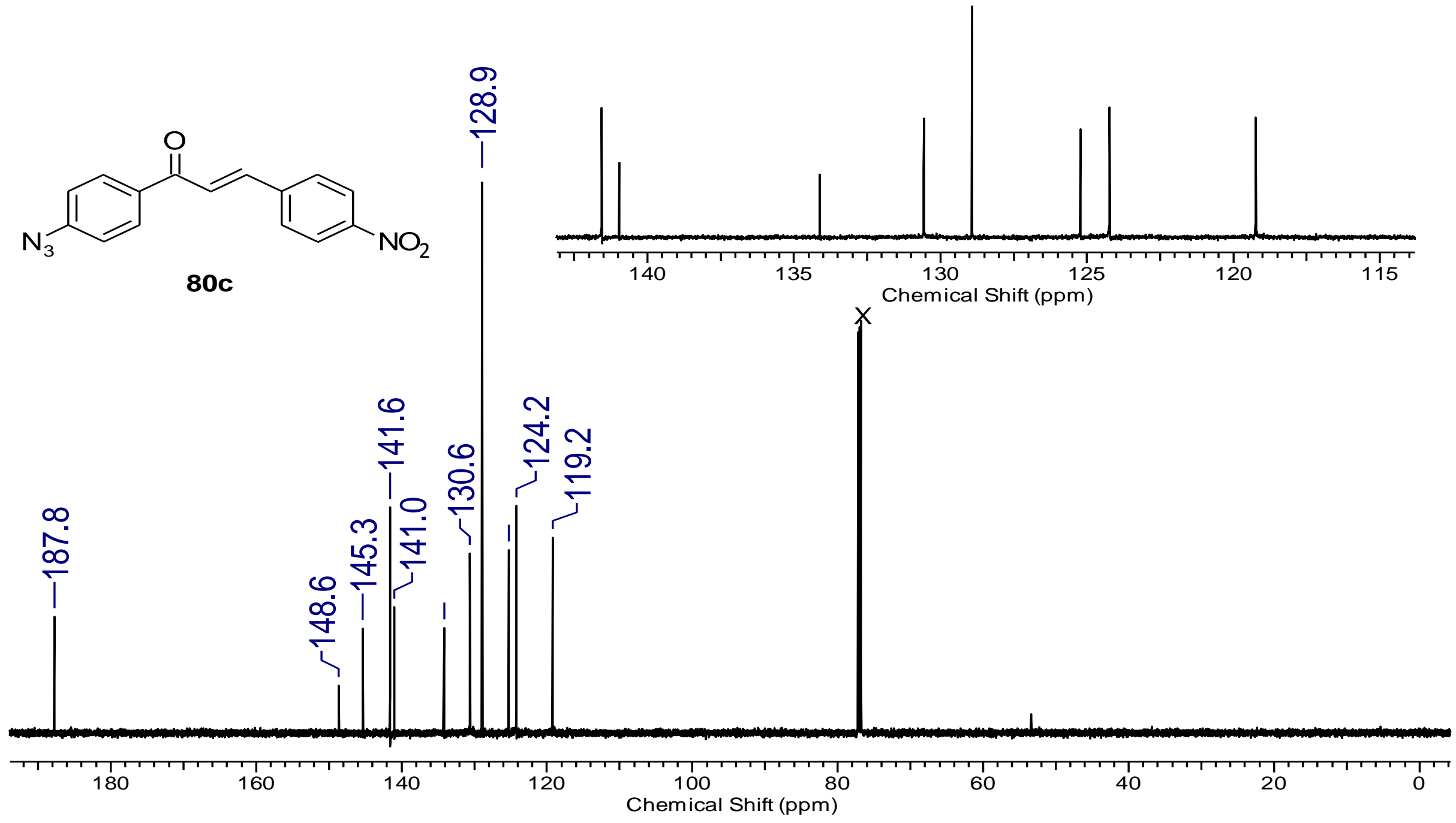

Espectro 15.2 - Espectro de $\mathrm{RMN} \mathrm{de}{ }^{13} \mathrm{C}\left(150 \mathrm{MHz}, \mathrm{CDCl}_{3}\right)$ da chalcona 80c. 


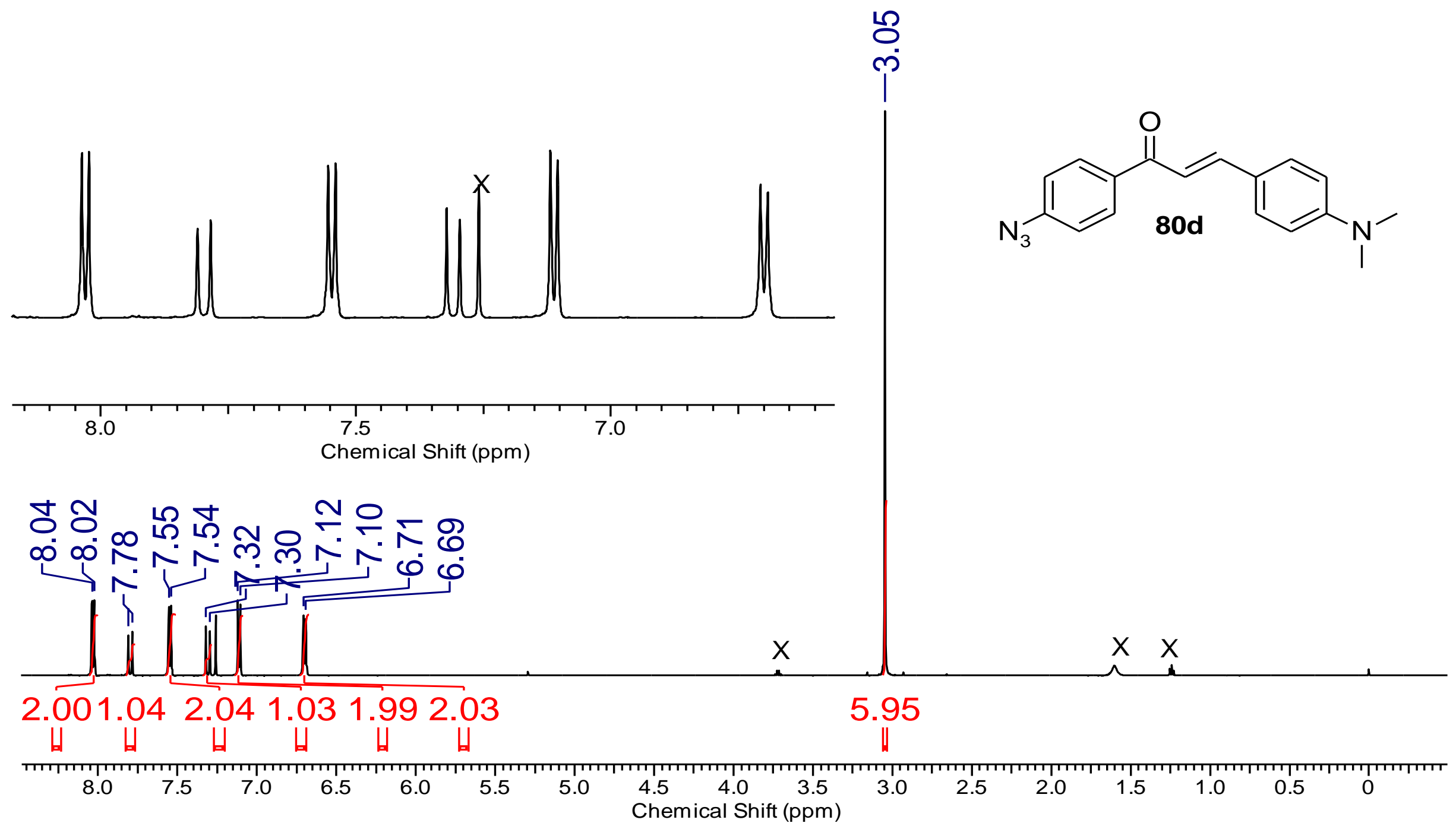

Espectro 16.1 - Espectro de $\mathrm{RMN} \mathrm{de}{ }^{1} \mathrm{H}\left(600 \mathrm{MHz}, \mathrm{CDCl}_{3}\right)$ da chalcona 80d. 


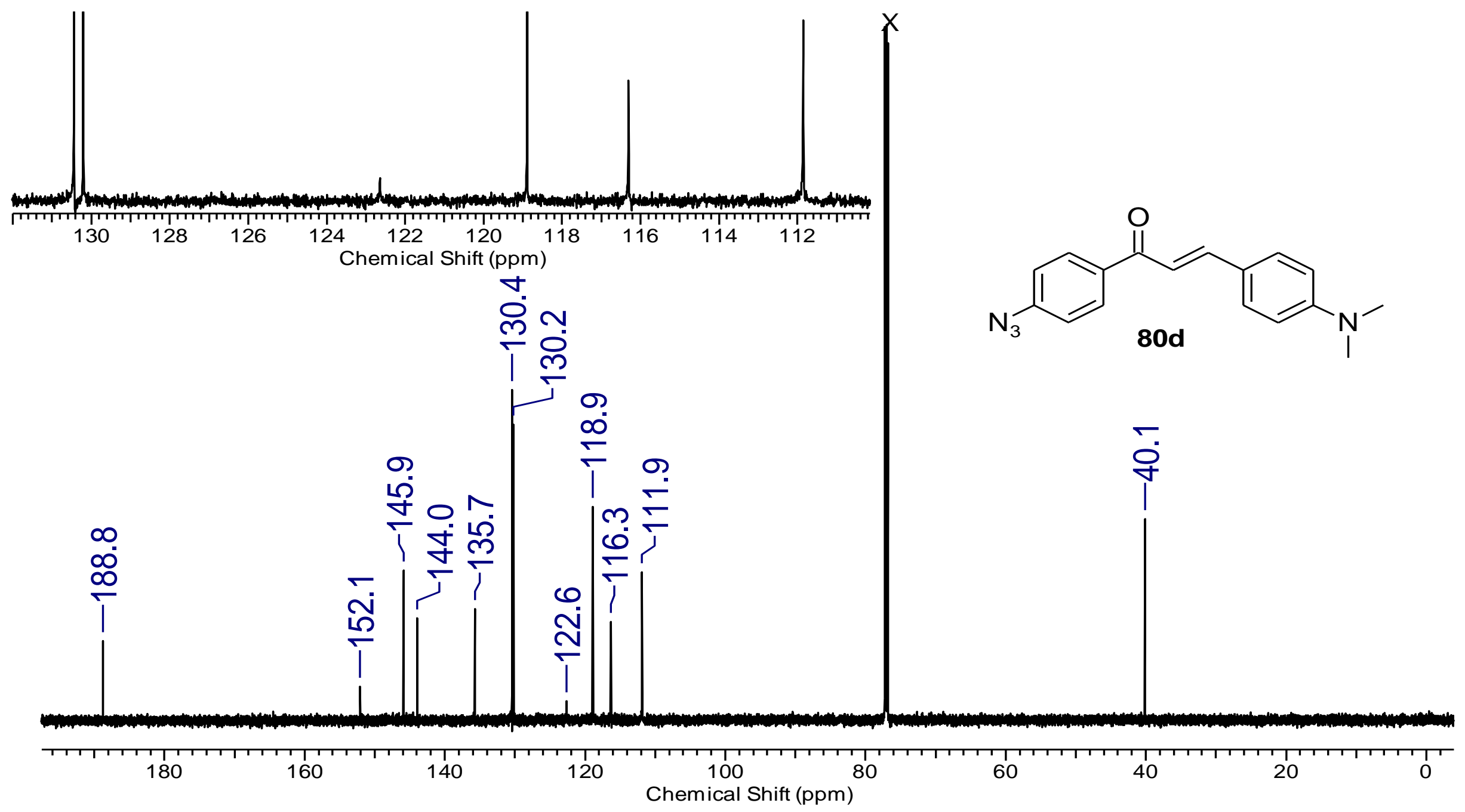

Espectro 16.2 - Espectro de RMN de ${ }^{13} \mathrm{C}\left(150 \mathrm{MHz}, \mathrm{CDCl}_{3}\right)$ da chalcona 80d. 


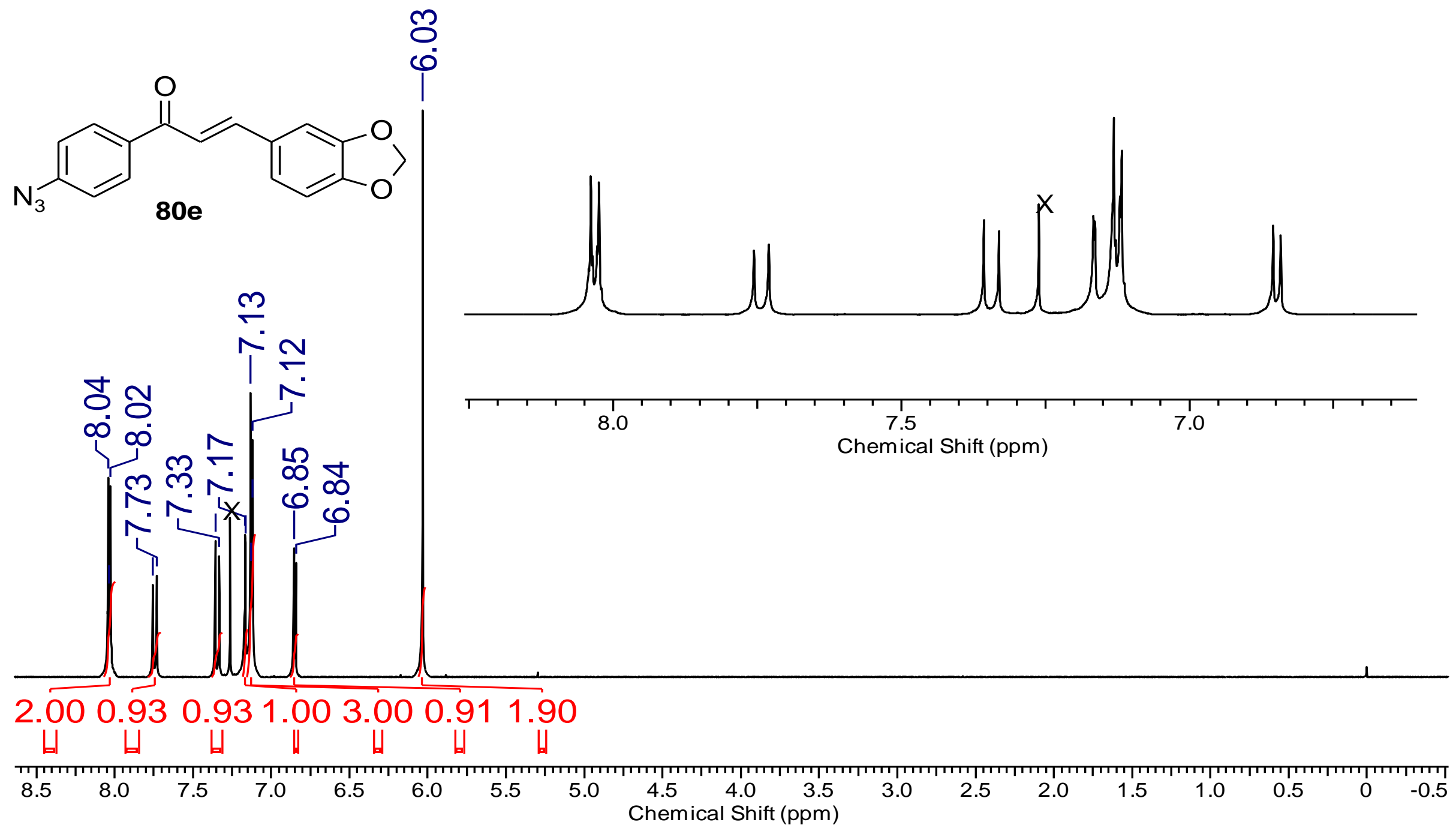

Espectro 17.1 - Espectro de RMN de ${ }^{1} \mathrm{H}\left(600 \mathrm{MHz}, \mathrm{CDCl}_{3}\right)$ da chalcona 80e. 


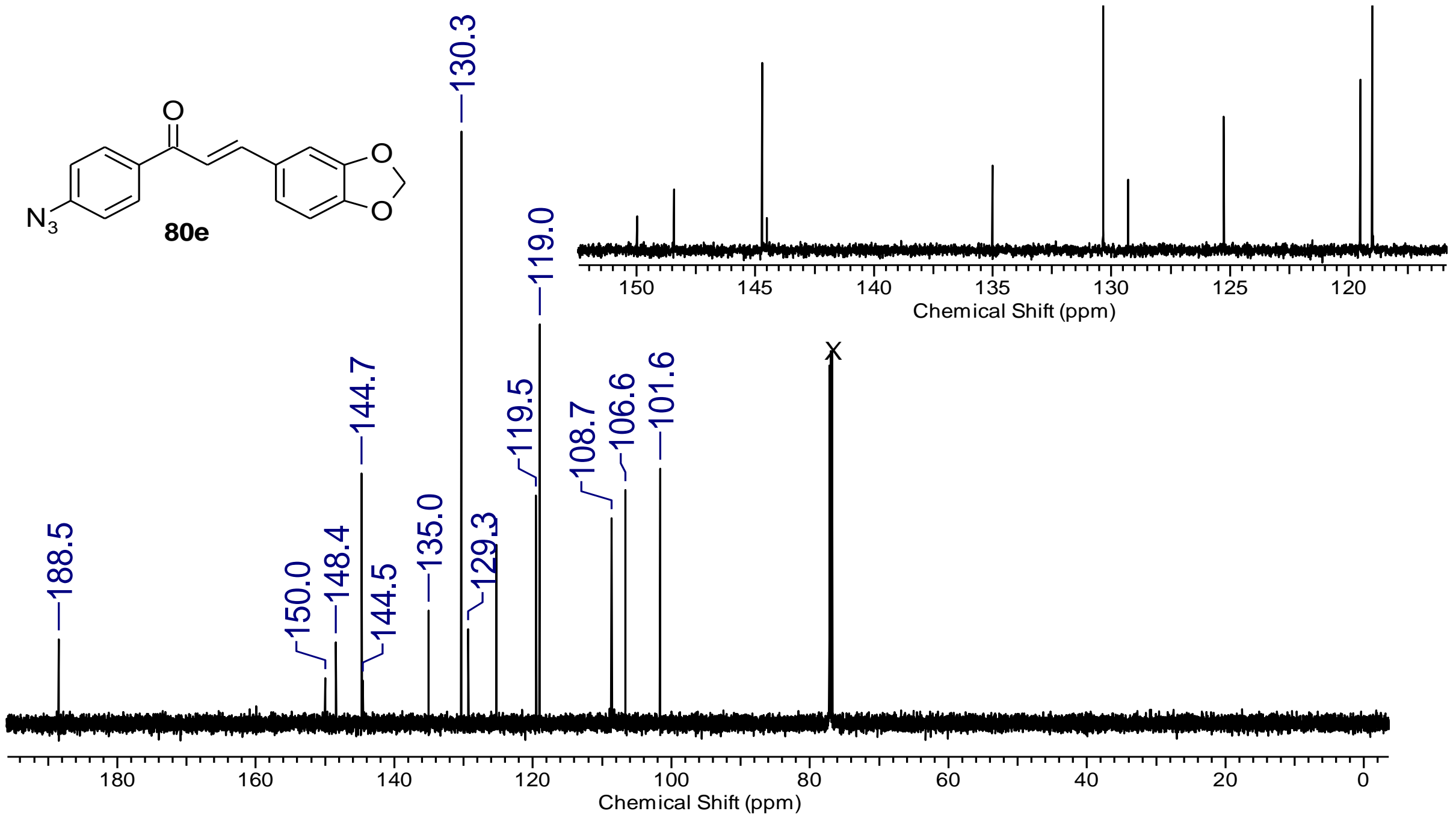

Espectro 17.2 - Espectro de $\mathrm{RMN} \mathrm{de}{ }^{13} \mathrm{C}\left(150 \mathrm{MHz}, \mathrm{CDCl}_{3}\right)$ da chalcona 80e. 


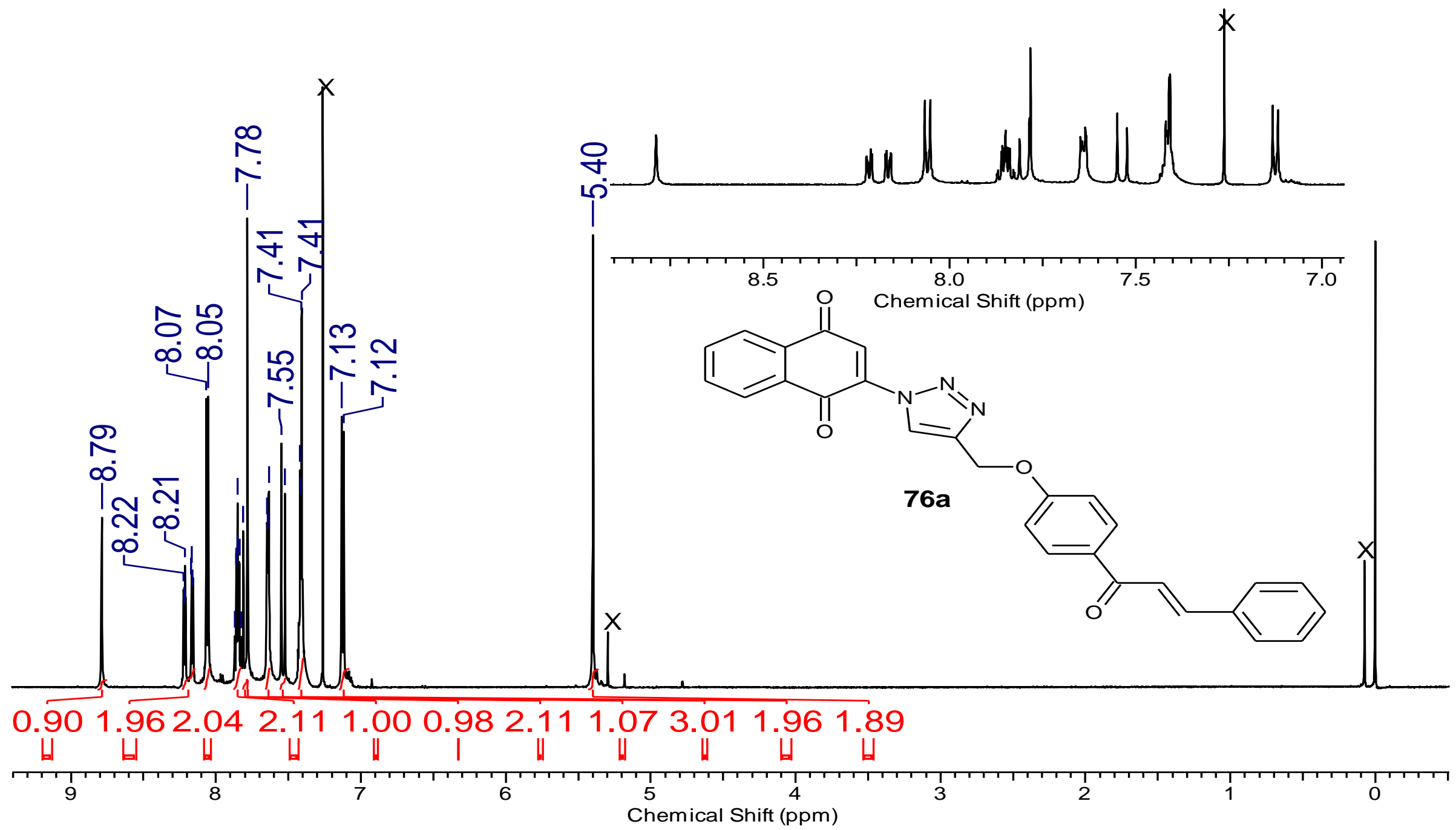

Espectro 18.1 - Espectro de $\mathrm{RMN}$ de ${ }^{1} \mathrm{H}\left(600 \mathrm{MHz}, \mathrm{CDCl}_{3}\right)$ do composto 76a. 


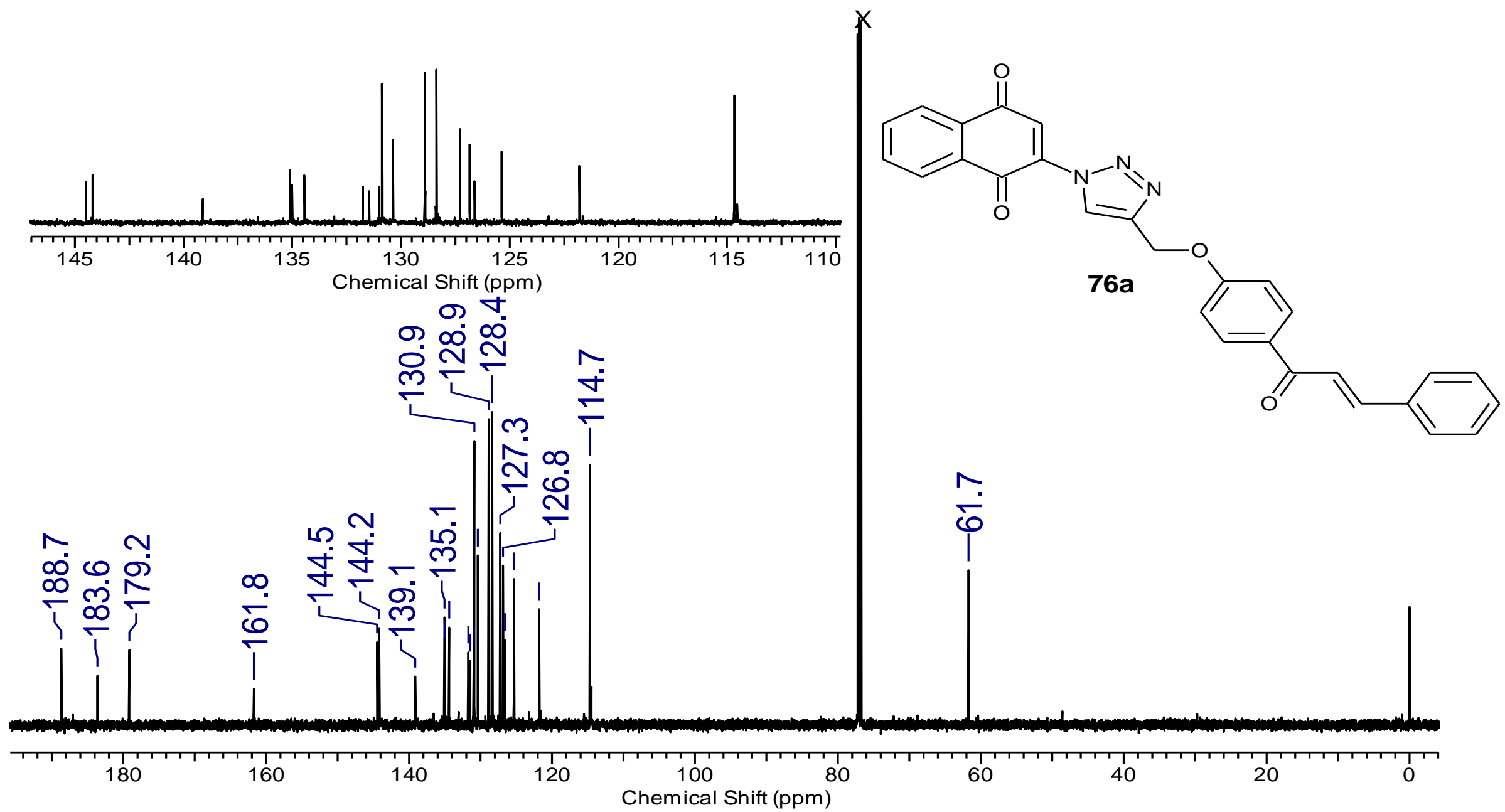

Espectro 18.2 - Espectro de $\mathrm{RMN} \mathrm{de}{ }^{13} \mathrm{C}\left(150 \mathrm{MHz}, \mathrm{CDCl}_{3}\right)$ do composto 76a. 


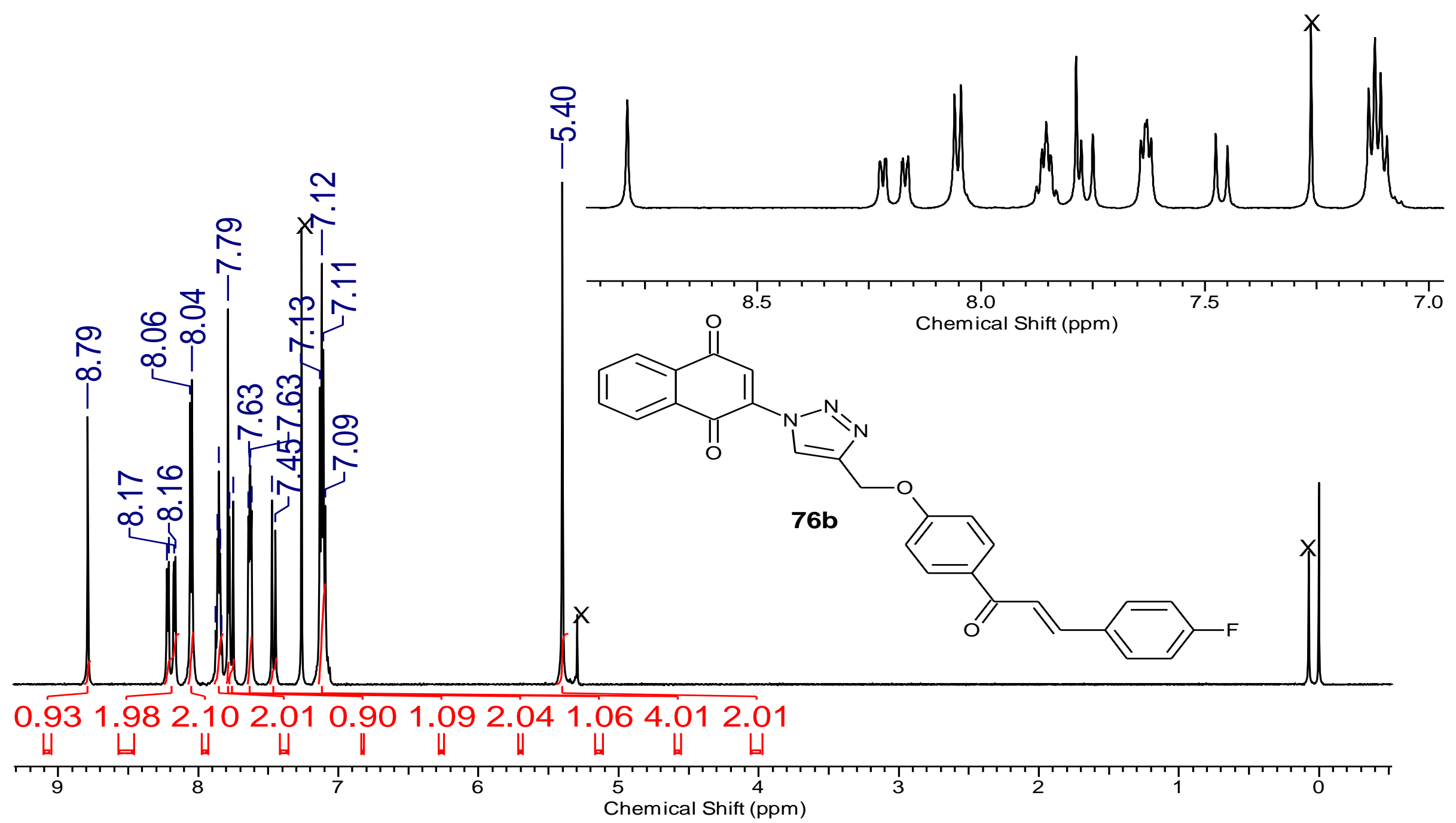

Espectro 19.1 - Espectro de RMN de ${ }^{1} \mathrm{H}\left(600 \mathrm{MHz}, \mathrm{CDCl}_{3}\right)$ do composto 76b. 

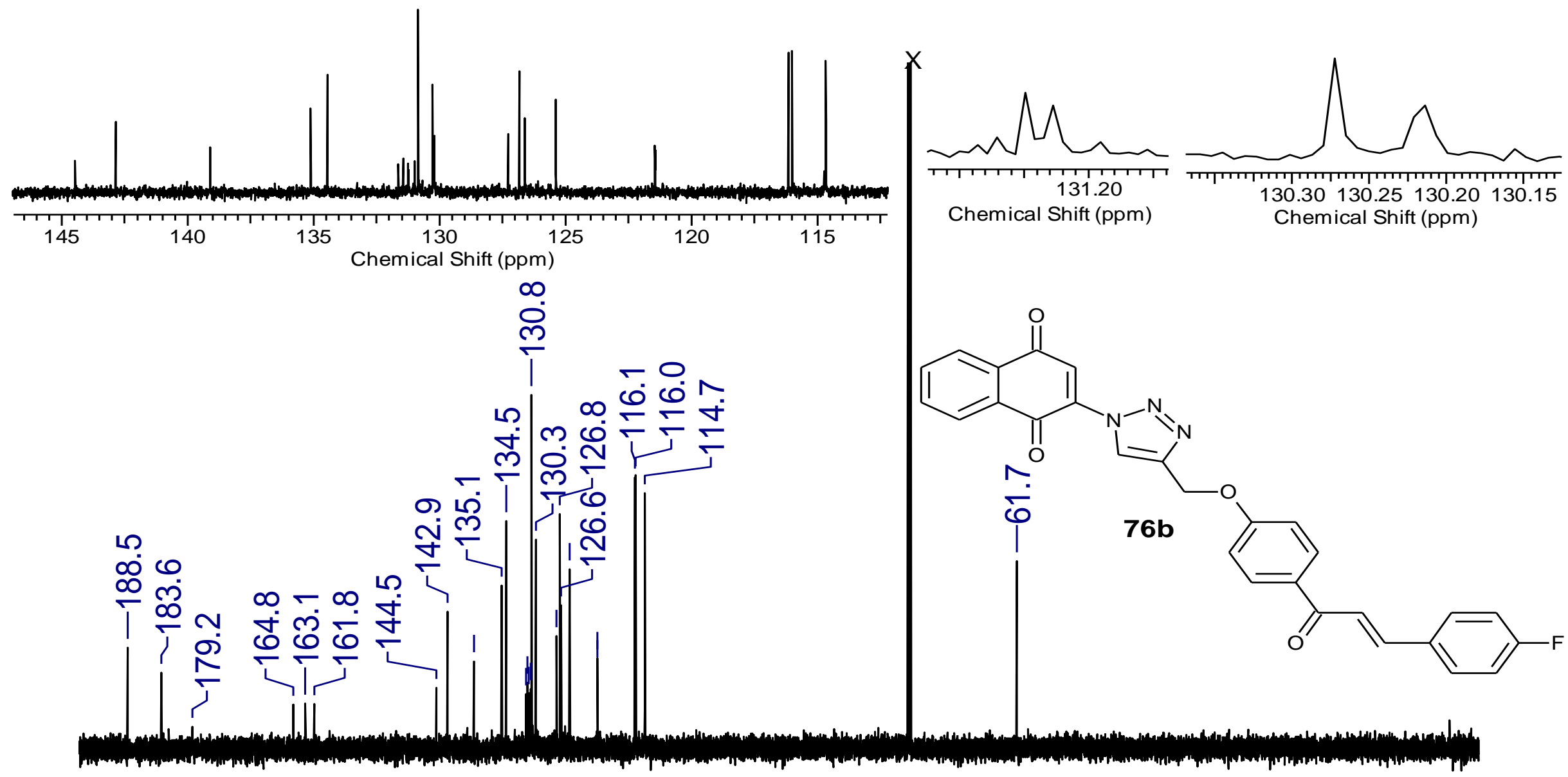

160

140

120

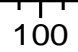

Chemical Shift (ppm)

60

40

20

0

Espectro 19.2 - Espectro de $\mathrm{RMN} \mathrm{de}{ }^{13} \mathrm{C}\left(150 \mathrm{MHz}, \mathrm{CDCl}_{3}\right)$ do composto $\mathbf{7 6}$. 


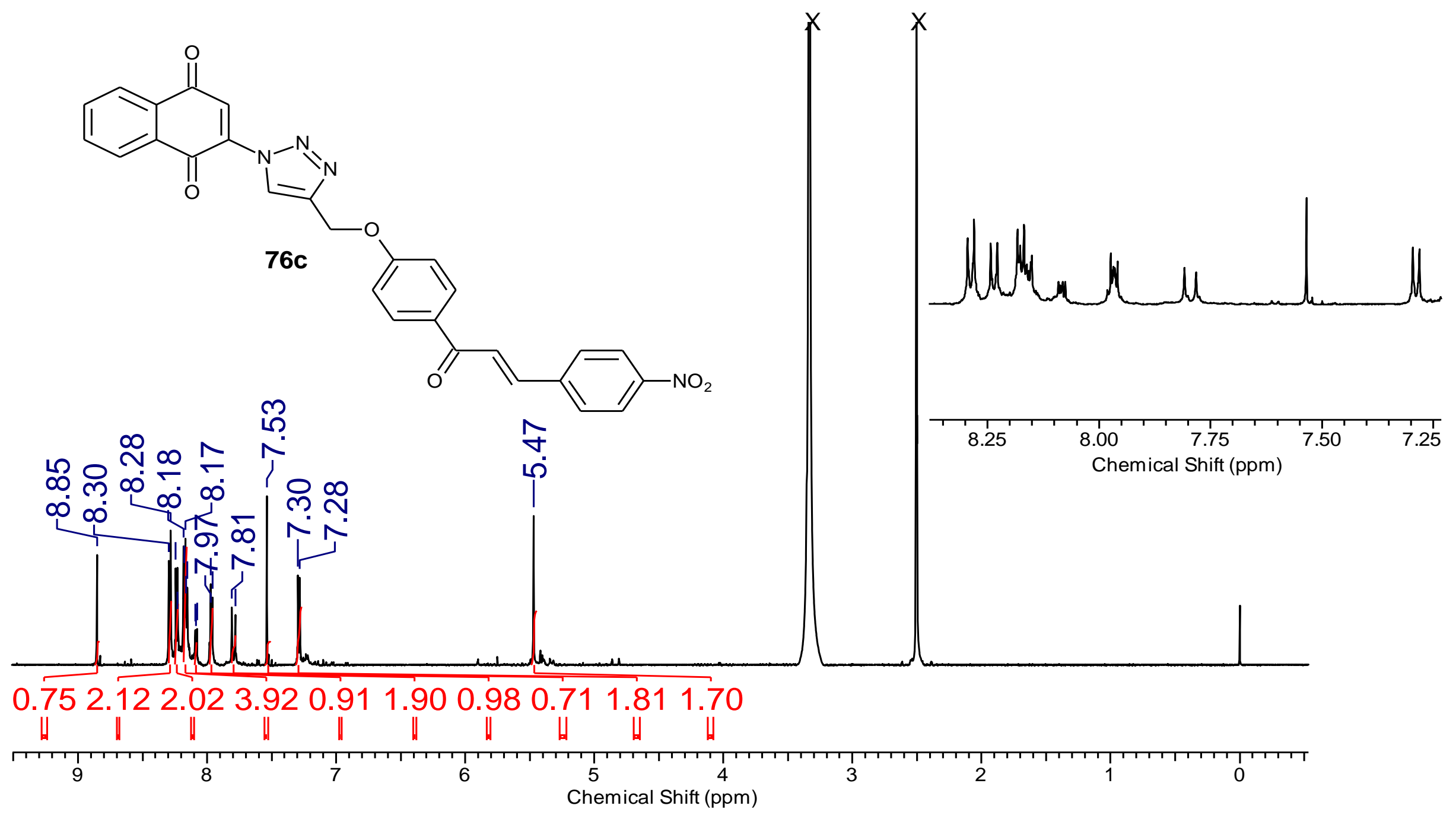

Espectro 20.1 - Espectro de RMN de ${ }^{1} \mathrm{H}\left(600 \mathrm{MHz}, \mathrm{DMSO}-d_{6}\right)$ do composto 76c. 


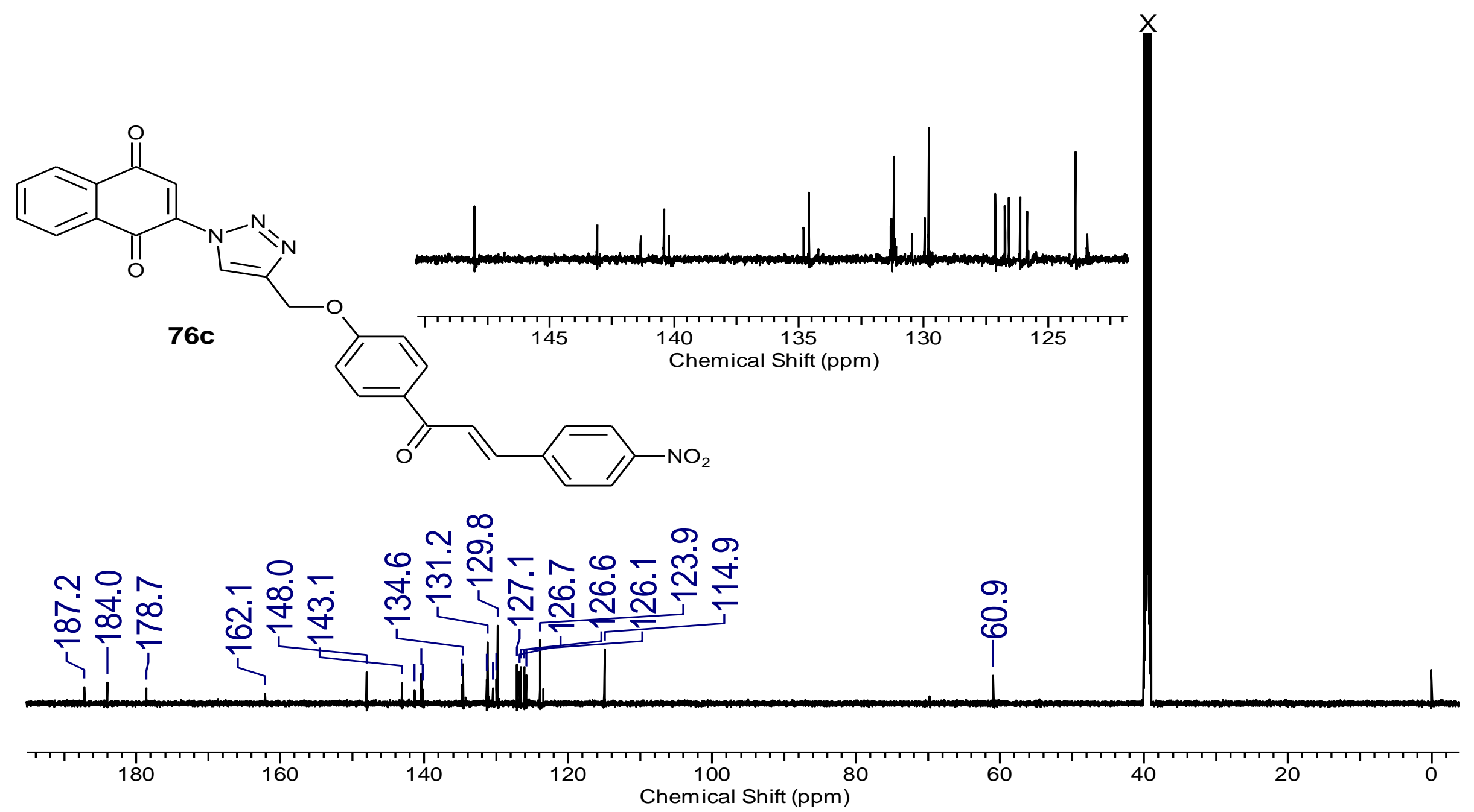

Espectro 20.2 - Espectro de RMN de ${ }^{13} \mathrm{C}\left(150 \mathrm{MHz}, \mathrm{DMSO}-d_{6}\right)$ do composto 76c. 


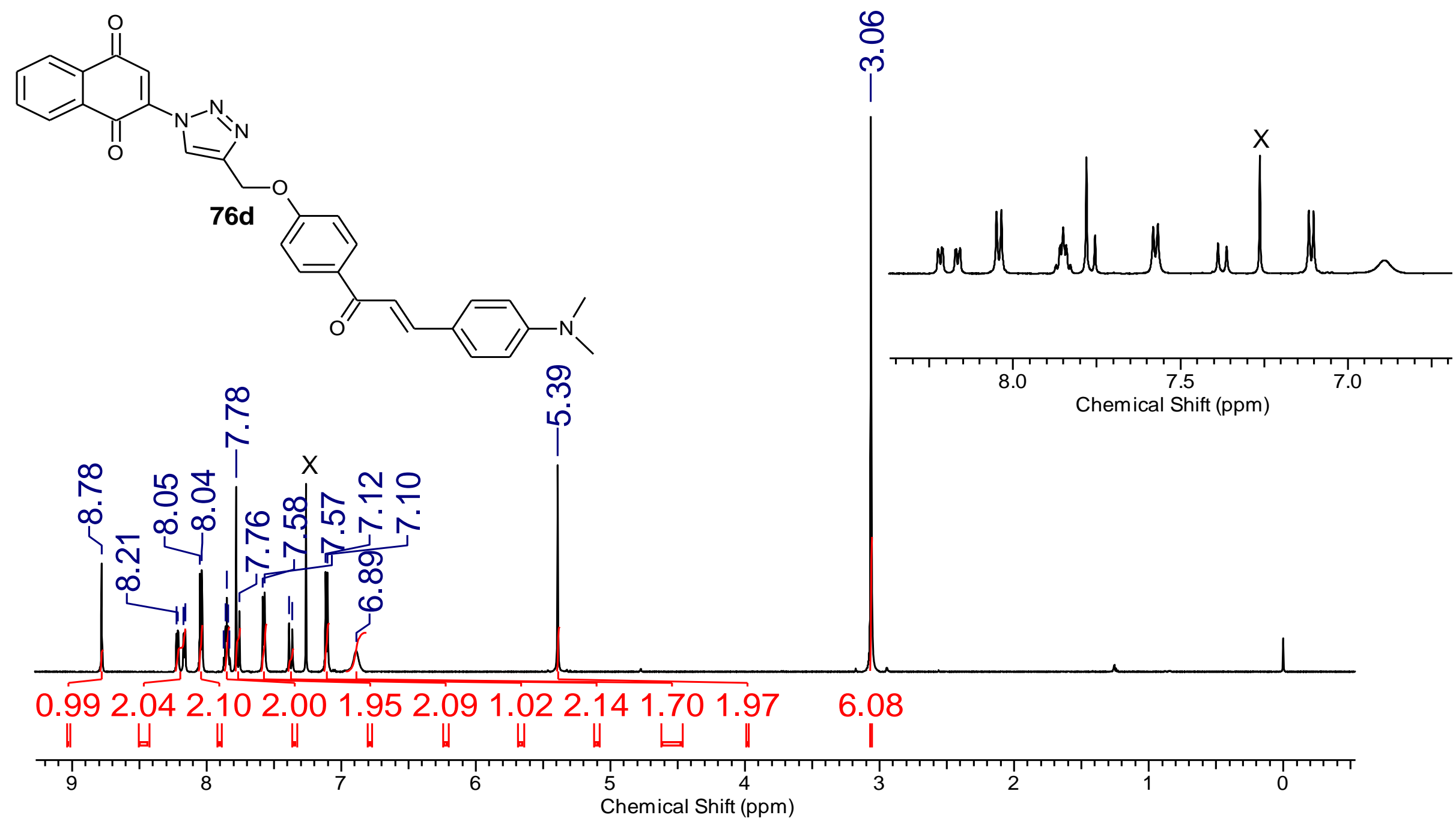

Espectro 21.1 - Espectro de $\mathrm{RMN}$ de ${ }^{1} \mathrm{H}\left(600 \mathrm{MHz}, \mathrm{CDCl}_{3}\right)$ do composto 76d. 


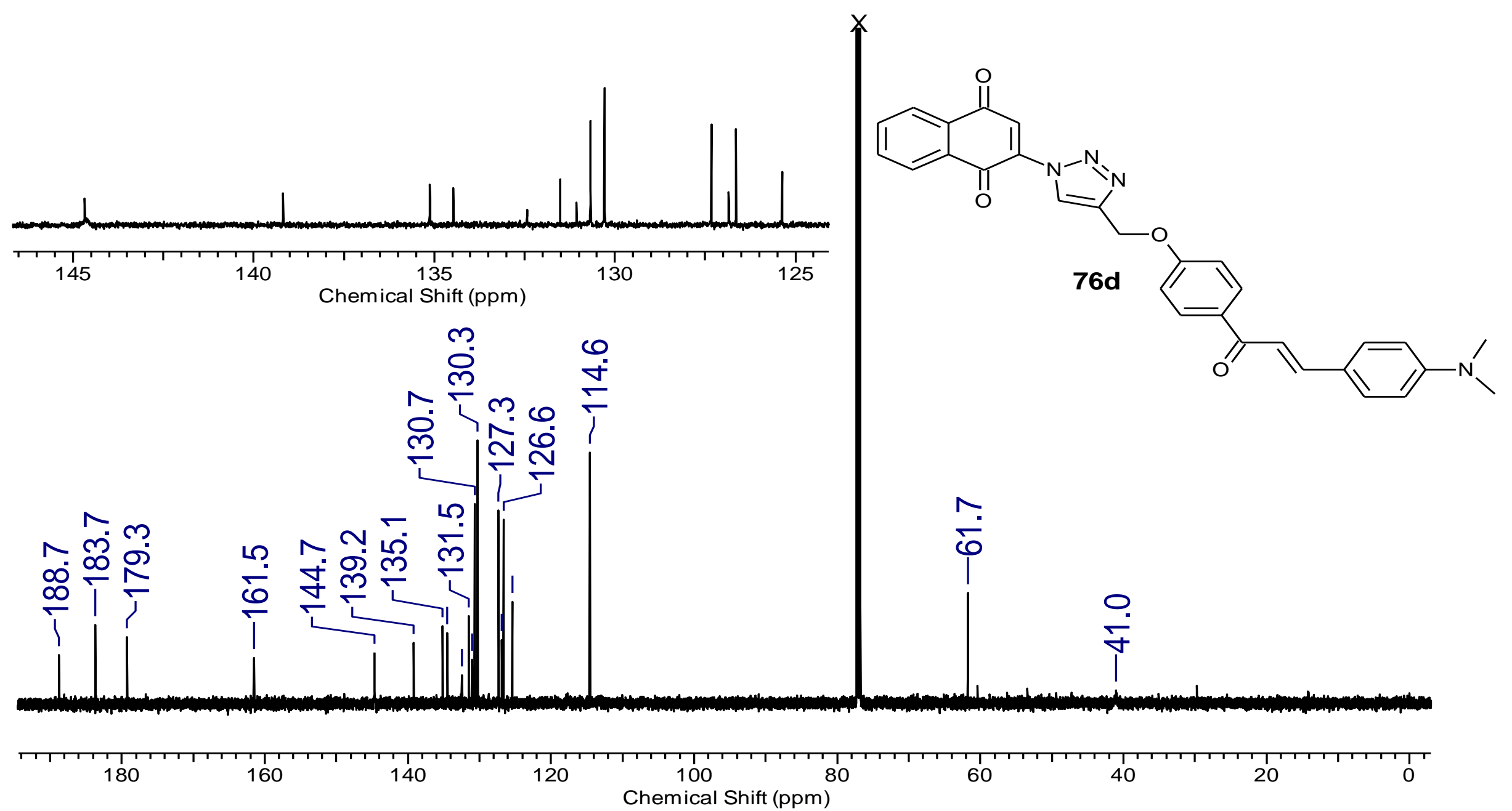

Espectro 21.2 - Espectro de $\mathrm{RMN} \mathrm{de}{ }^{13} \mathrm{C}\left(150 \mathrm{MHz}, \mathrm{CDCl}_{3}\right)$ do composto 76d. 

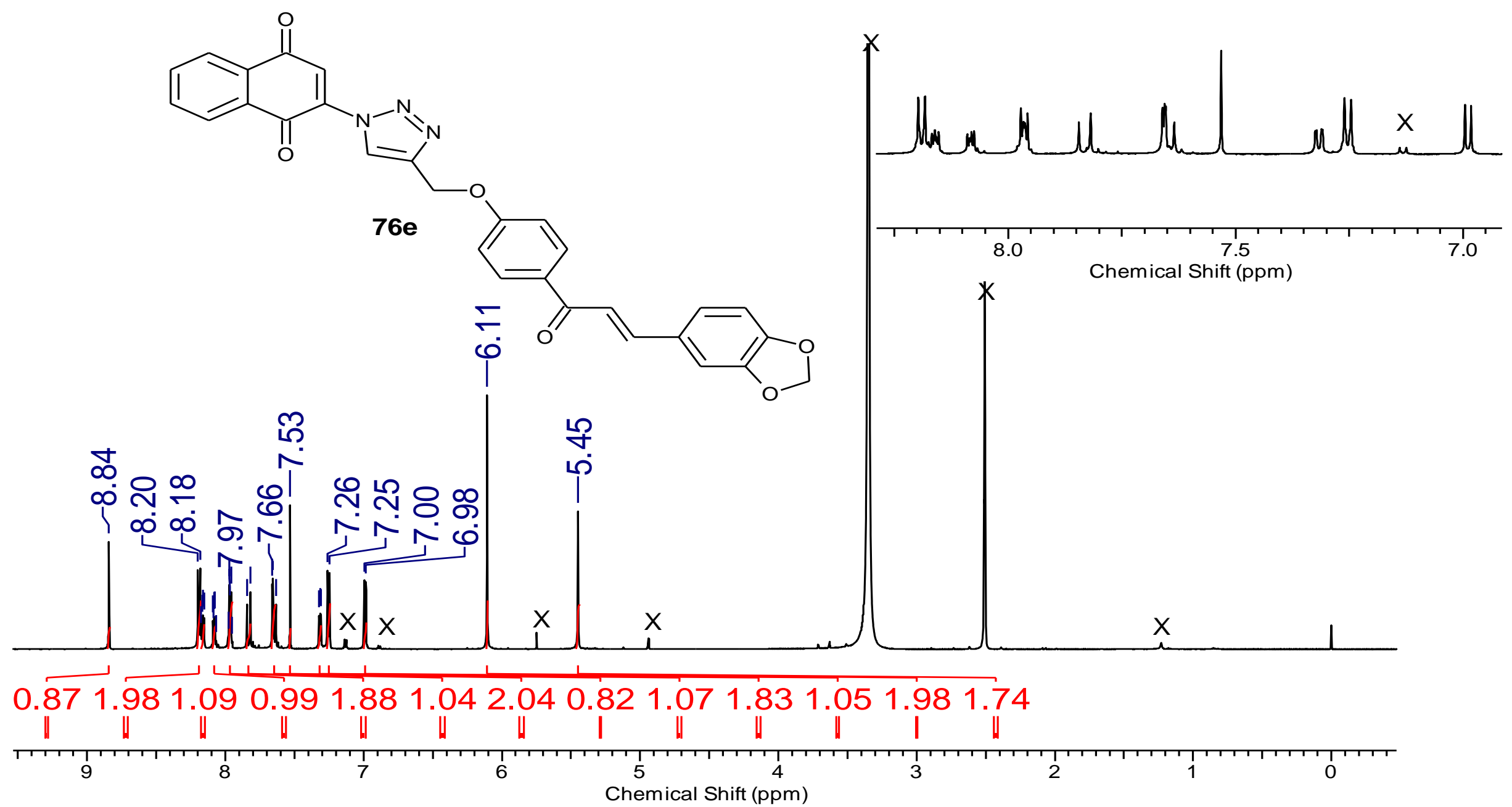

Espectro 22.1 - Espectro de RMN de ${ }^{1} \mathrm{H}\left(600 \mathrm{MHz}, \mathrm{DMSO}-d_{6}\right)$ do composto 76e. 

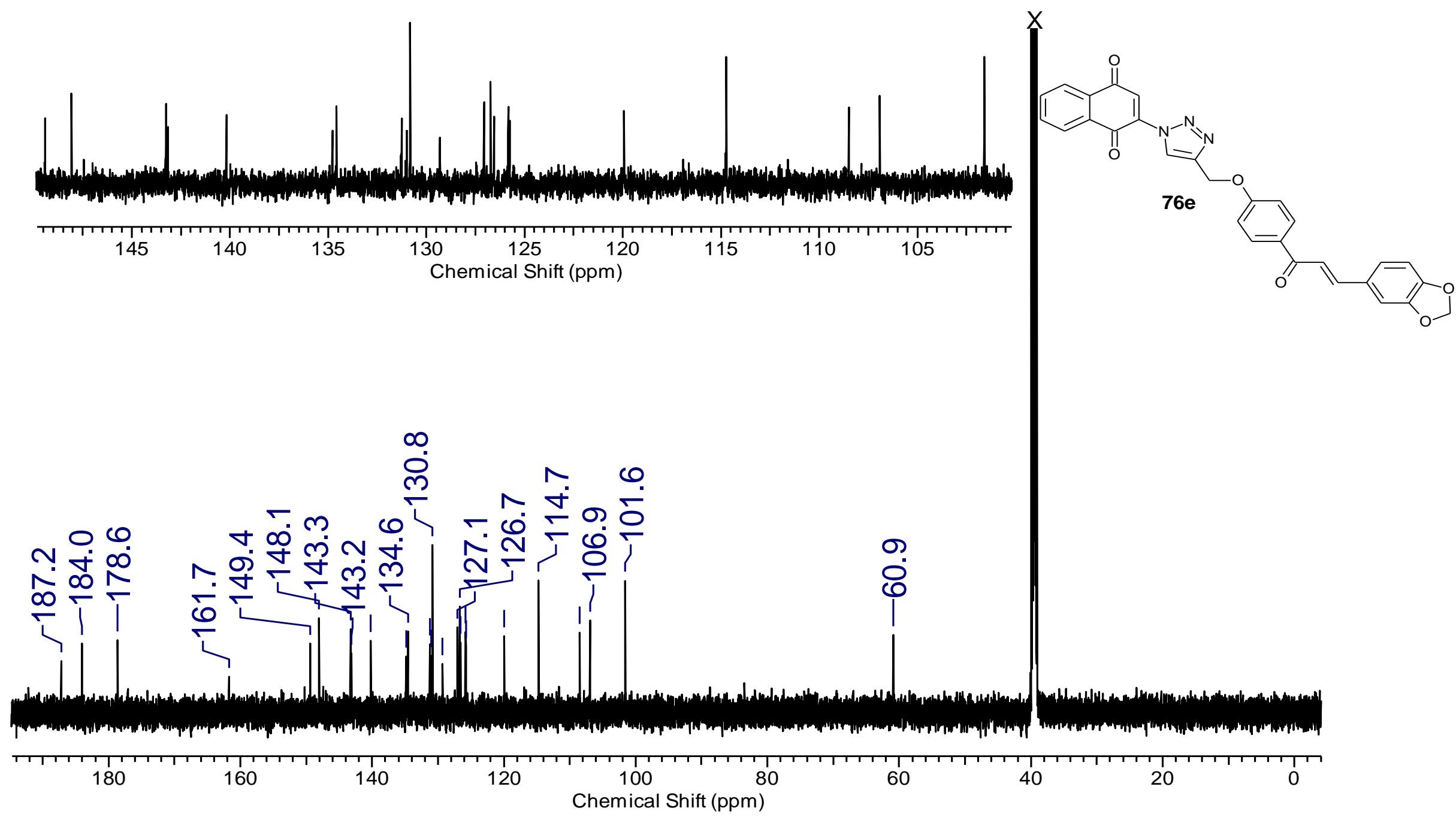

Espectro 22.2 - Espectro de RMN de ${ }^{13} \mathrm{C}\left(150 \mathrm{MHz}, \mathrm{DMSO}-d_{6}\right)$ do composto $76 \mathbf{e}$. 


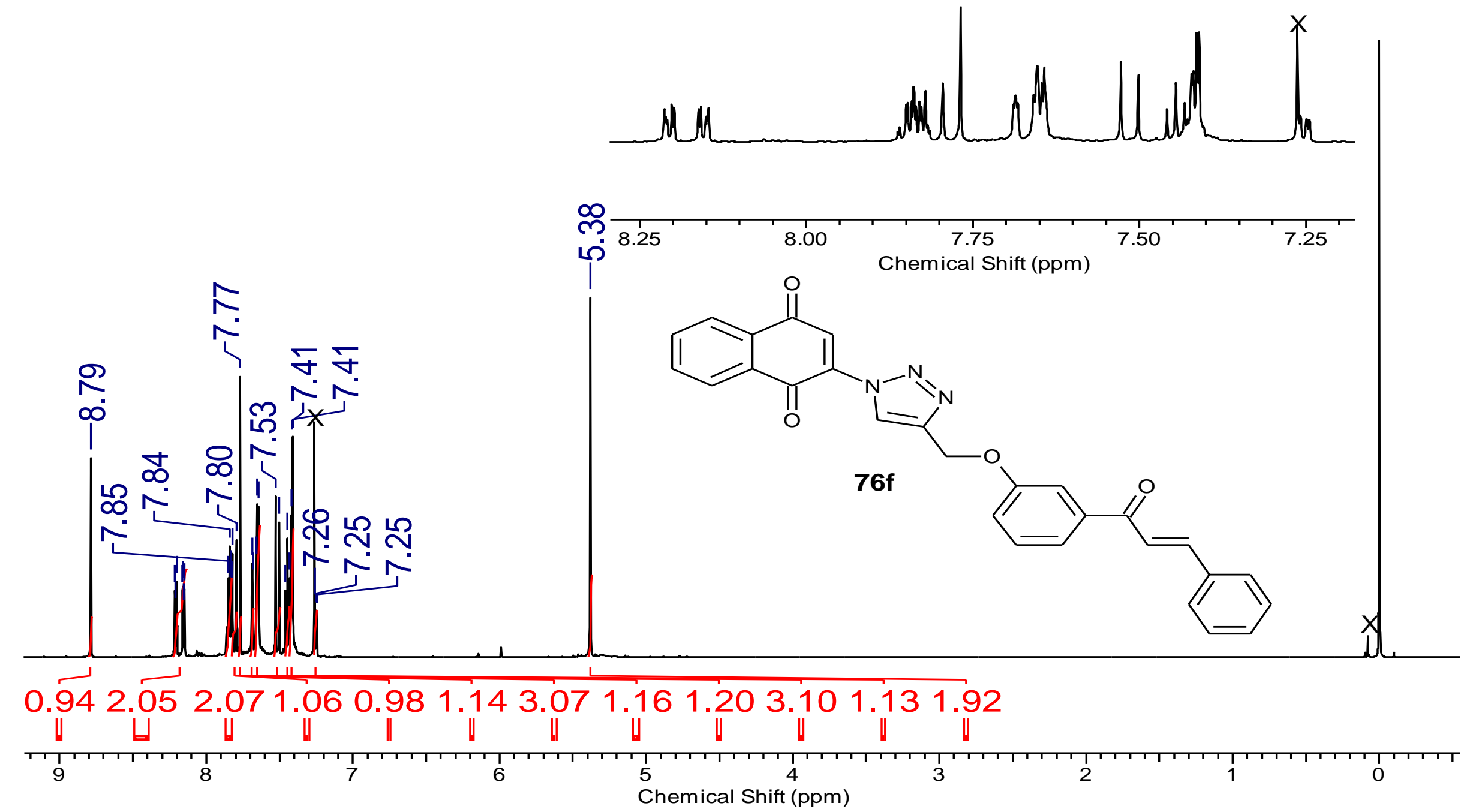

Espectro 23.1 - Espectro de $\mathrm{RMN}$ de ${ }^{1} \mathrm{H}\left(600 \mathrm{MHz}, \mathrm{CDCl}_{3}\right)$ do composto $76 \mathbf{f}$. 


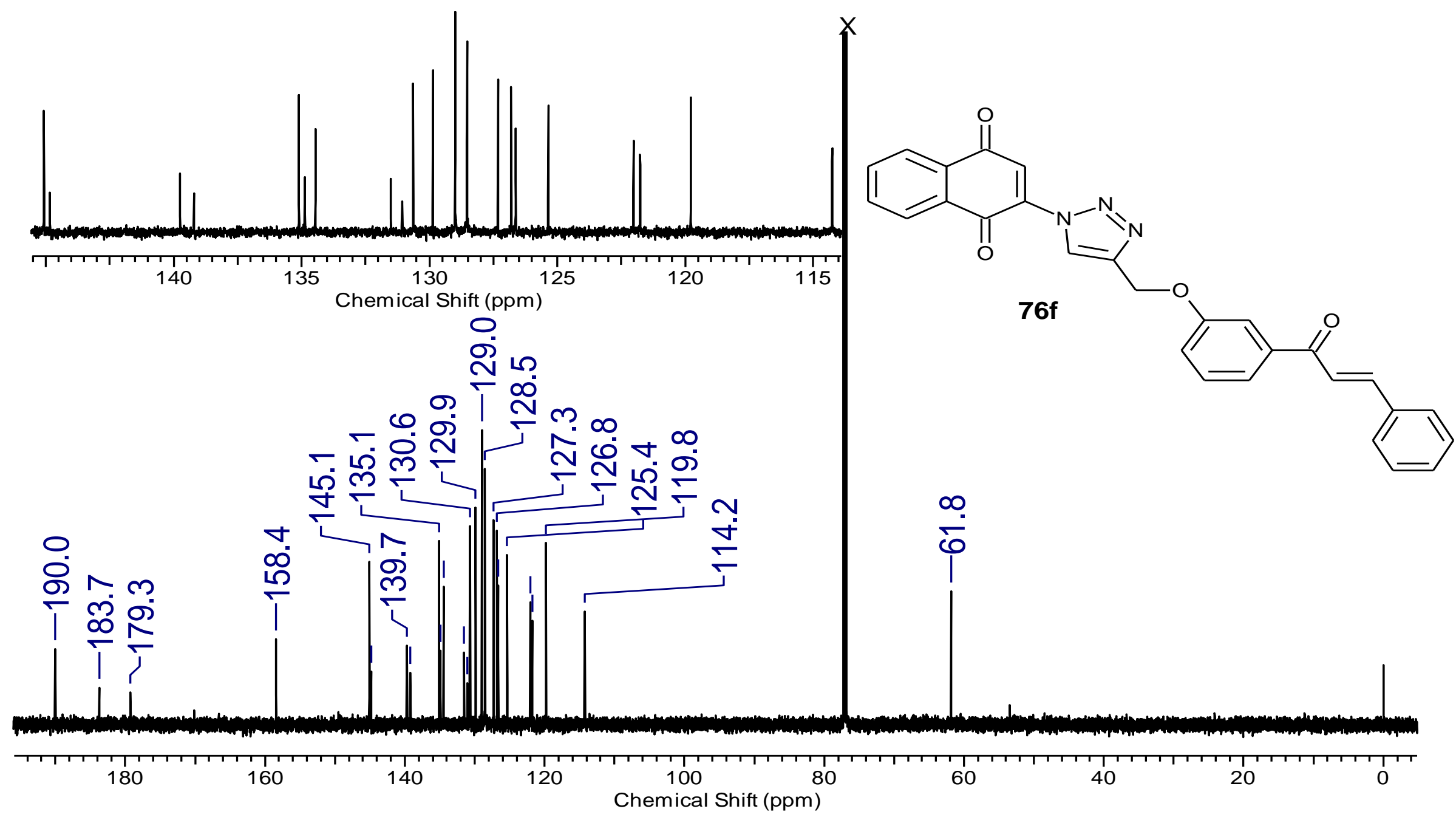

Espectro 23.2 - Espectro de $\mathrm{RMN} \mathrm{de}{ }^{13} \mathrm{C}\left(150 \mathrm{MHz}, \mathrm{CDCl}_{3}\right)$ do composto $76 \mathbf{f}$. 


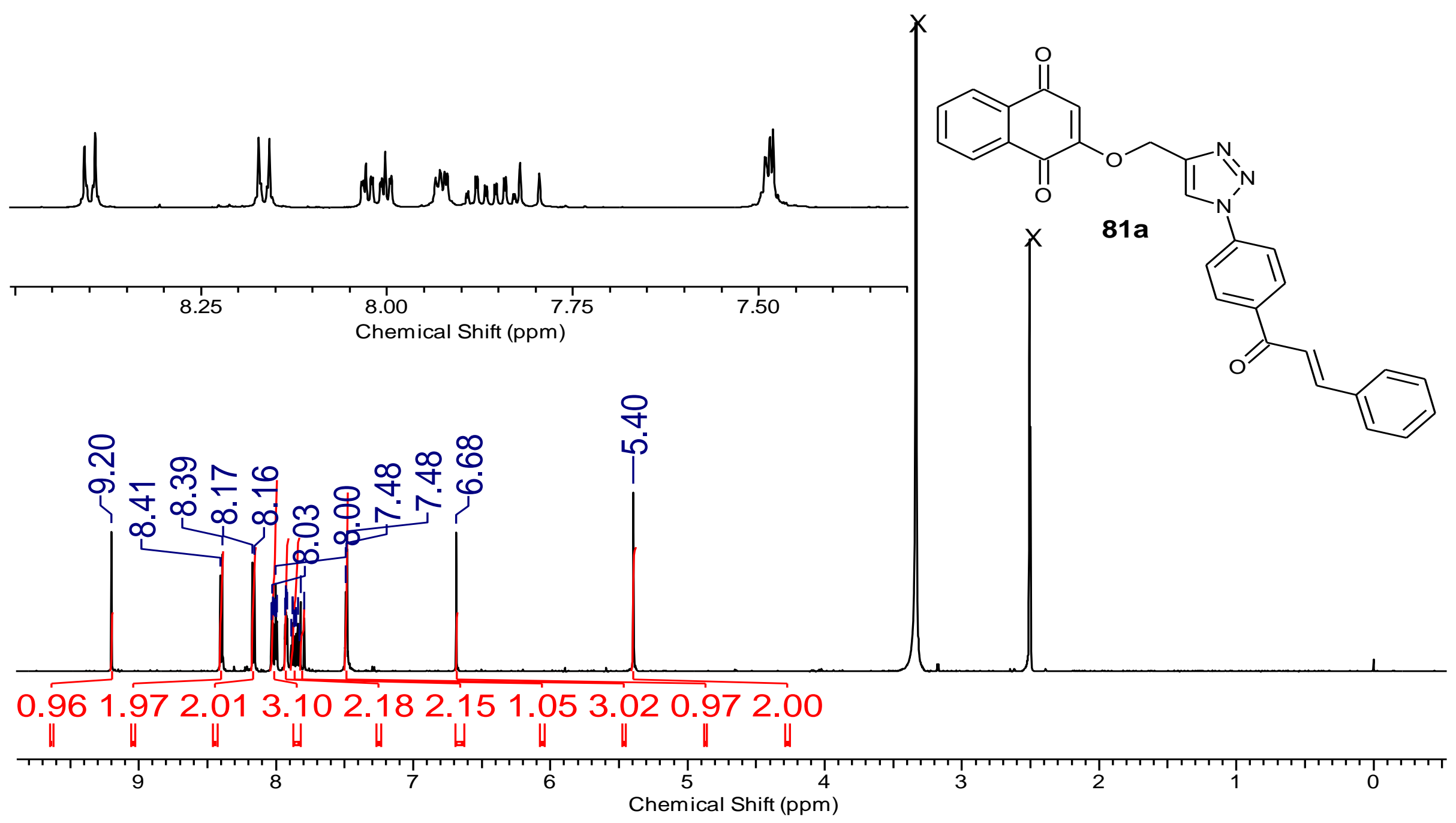

Espectro 24.1 - Espectro de RMN de ${ }^{1} \mathrm{H}\left(600 \mathrm{MHz}, \mathrm{DMSO}-d_{6}\right)$ do composto 81a. 


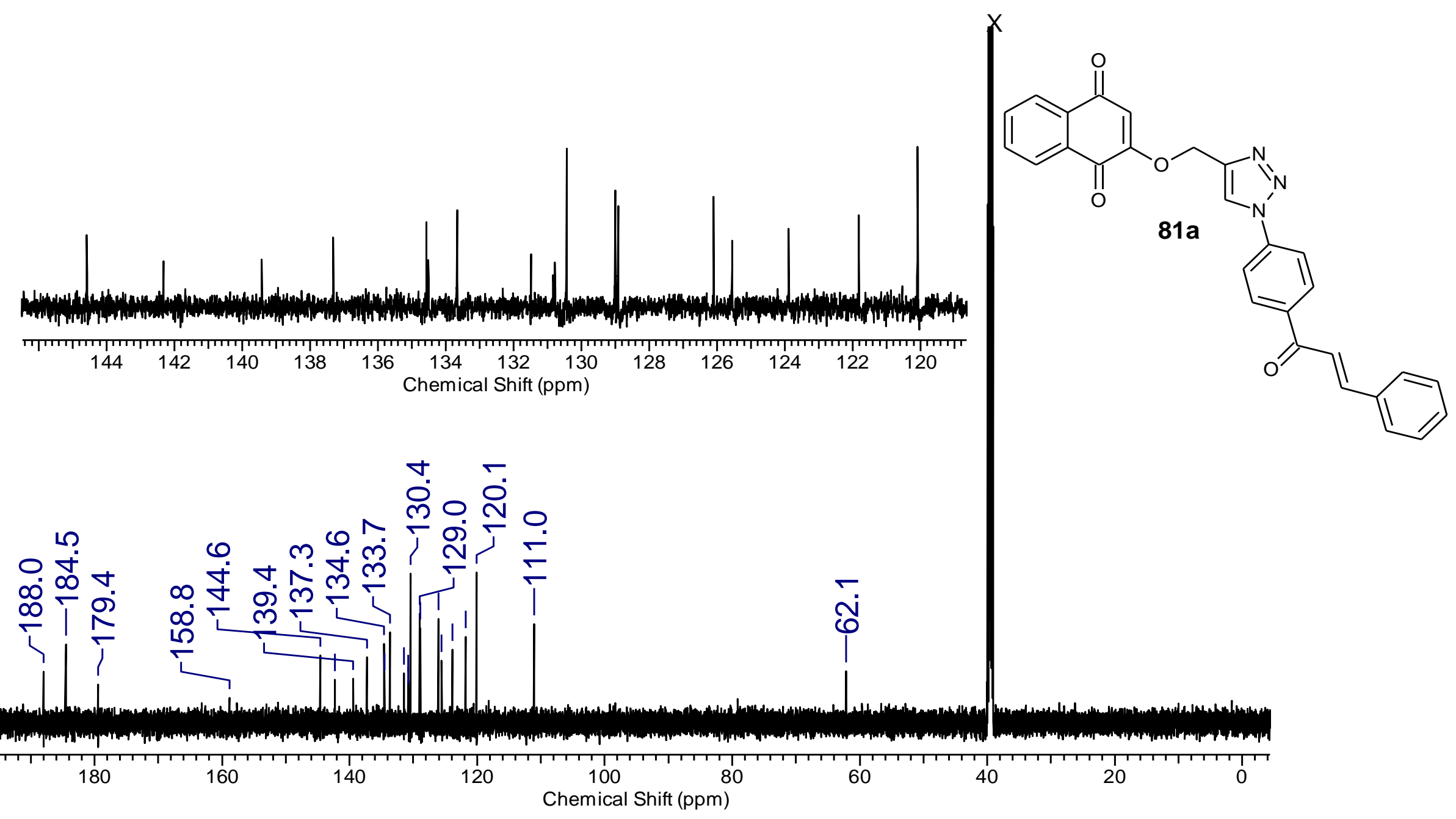

Espectro 24.2 - Espectro de RMN de ${ }^{13} \mathrm{C}$ (150 MHz, DMSO- $d_{6}$ ) do composto 81a. 


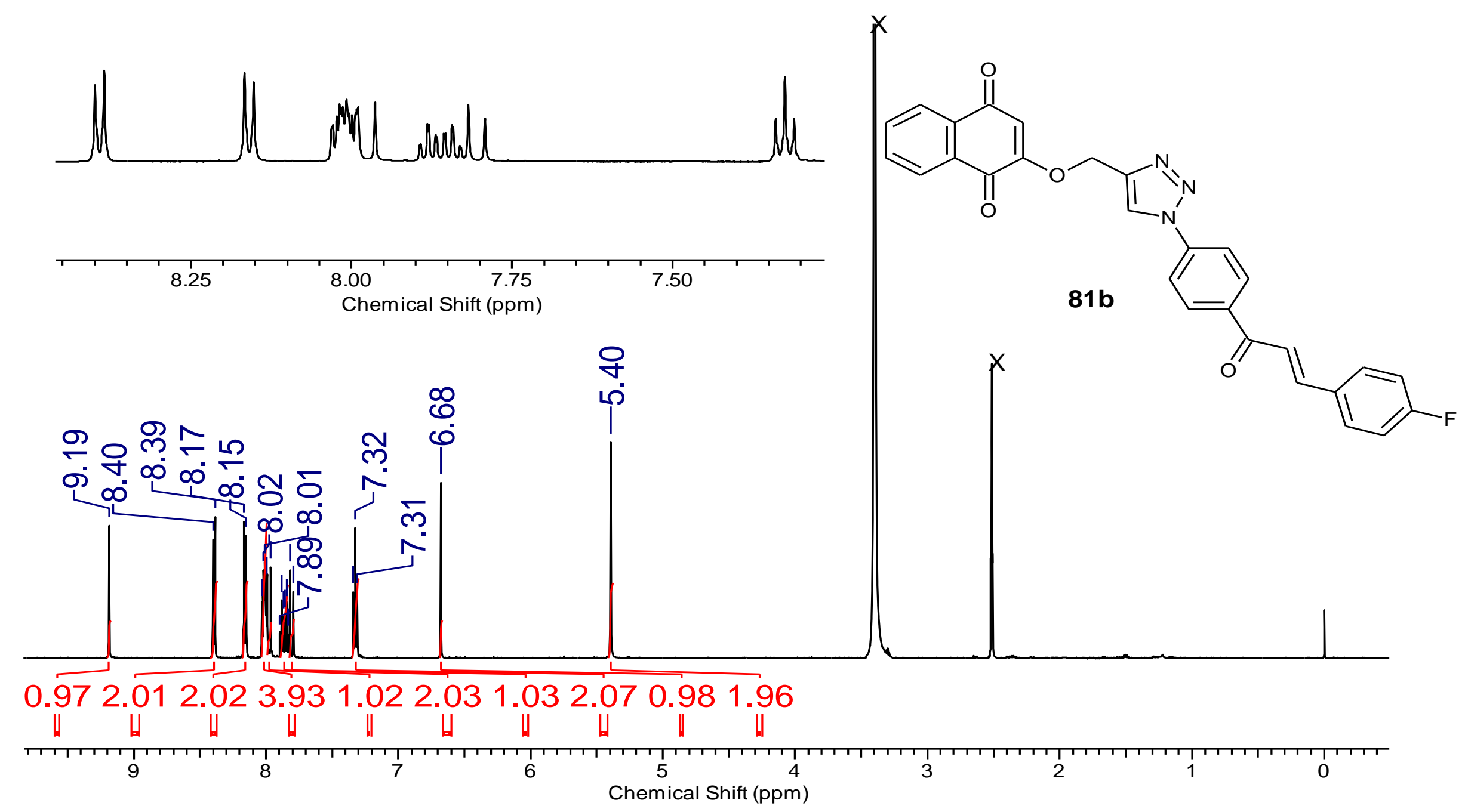

Espectro 25.1 - Espectro de RMN de ${ }^{1} \mathrm{H}\left(600 \mathrm{MHz}, \mathrm{DMSO}-d_{6}\right)$ do composto 81b. 


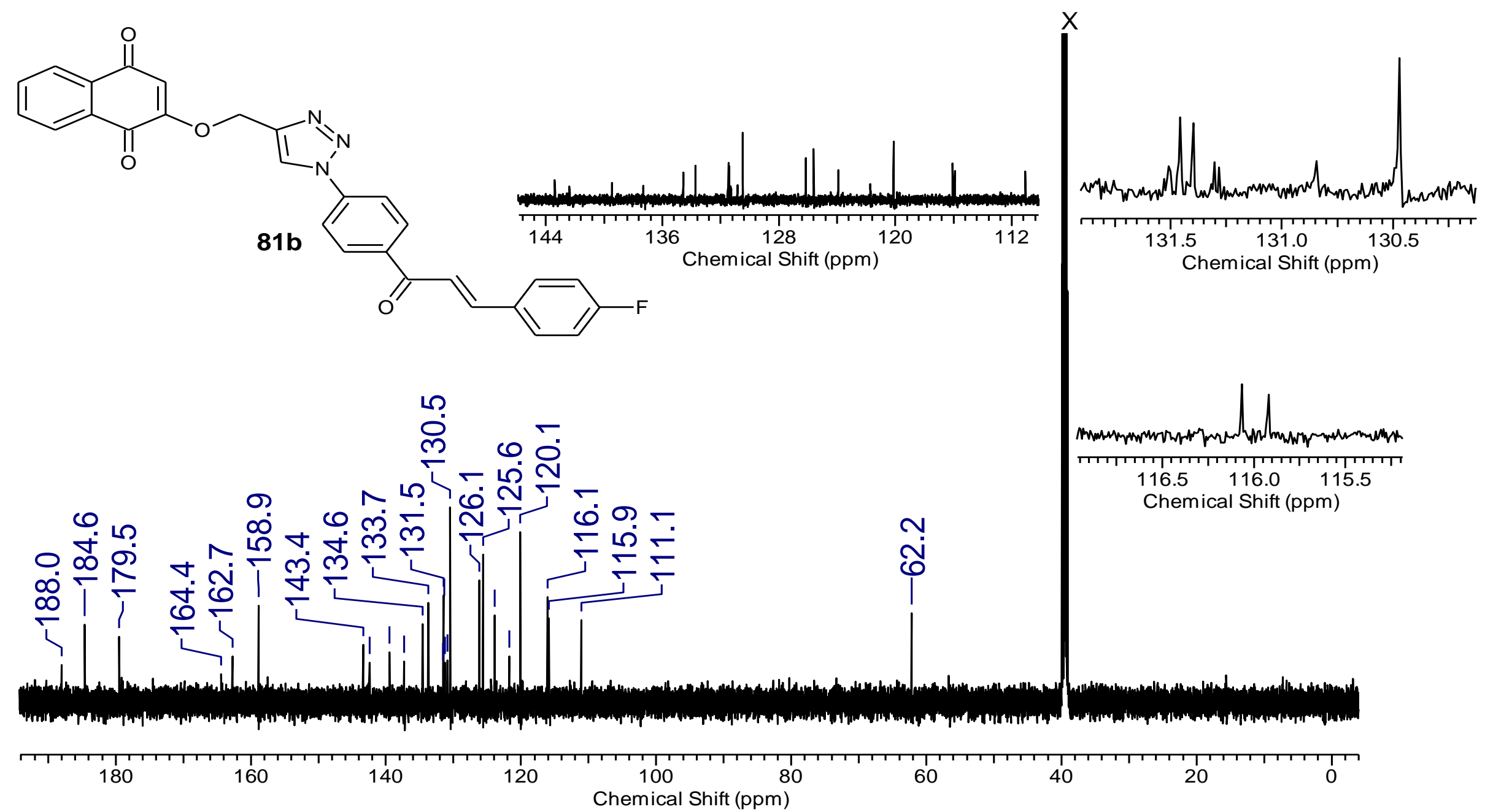

Espectro 25.2 - Espectro de RMN de ${ }^{13} \mathrm{C}$ (150 MHz, DMSO-d 6 ) do composto 81b. 


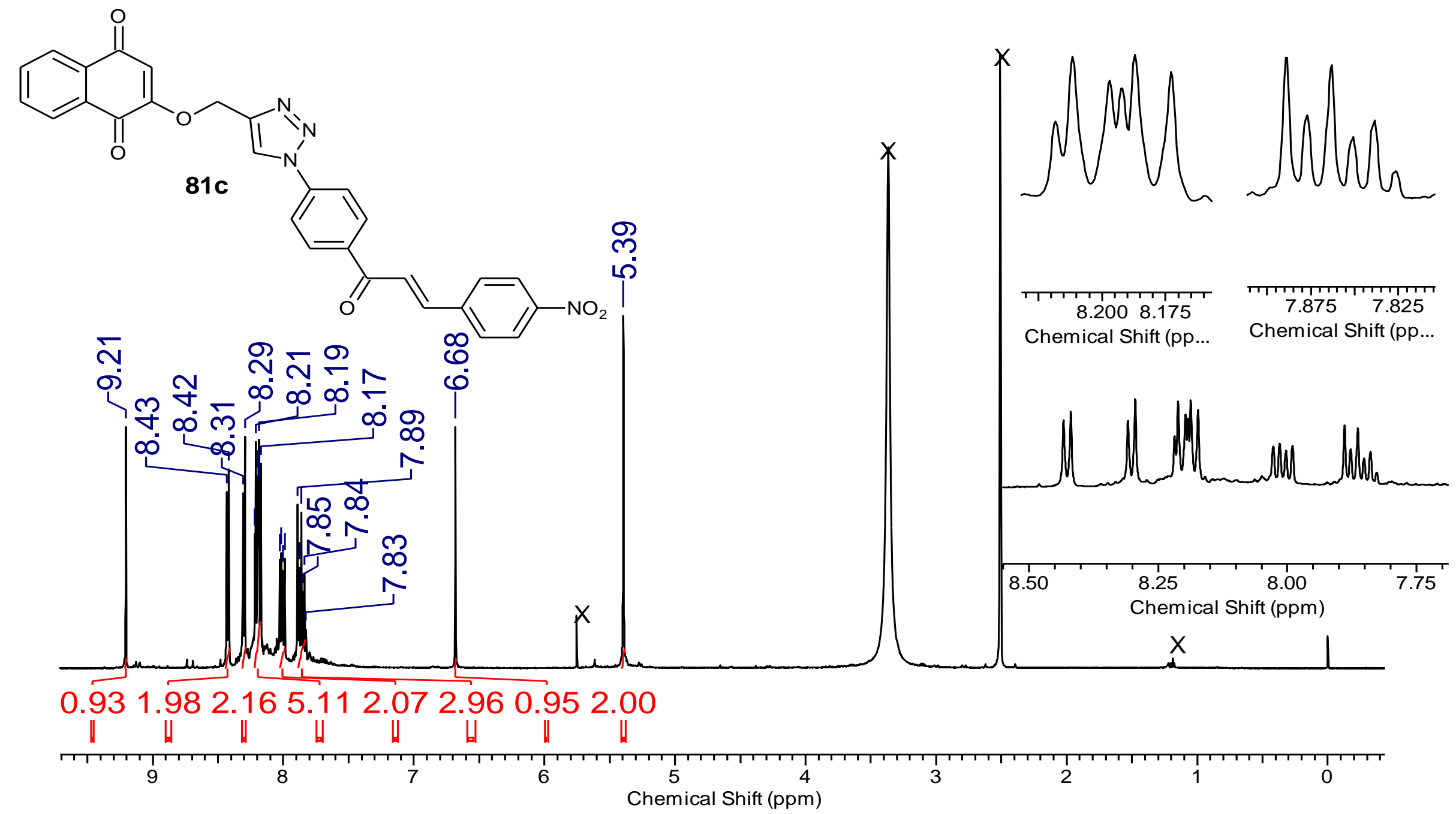

Espectro 26.1 - Espectro de RMN de ${ }^{1} \mathrm{H}\left(600 \mathrm{MHz}\right.$, DMSO- $\left.d_{6}\right)$ do composto 81c. 


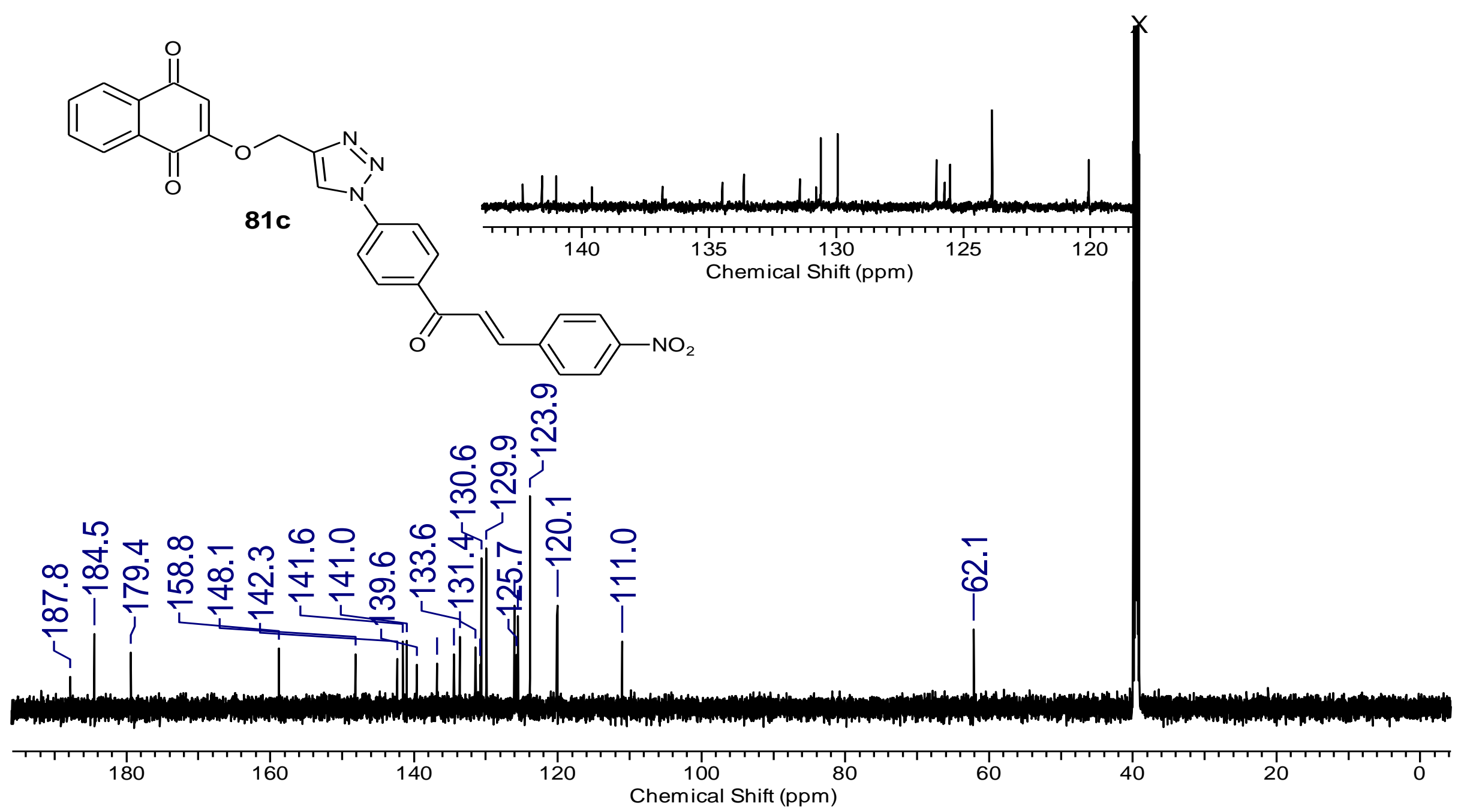

Espectro 26.2 - Espectro de RMN de ${ }^{13} \mathrm{C}$ (150 MHz, DMSO- $\left.d_{6}\right)$ do composto 81c. 


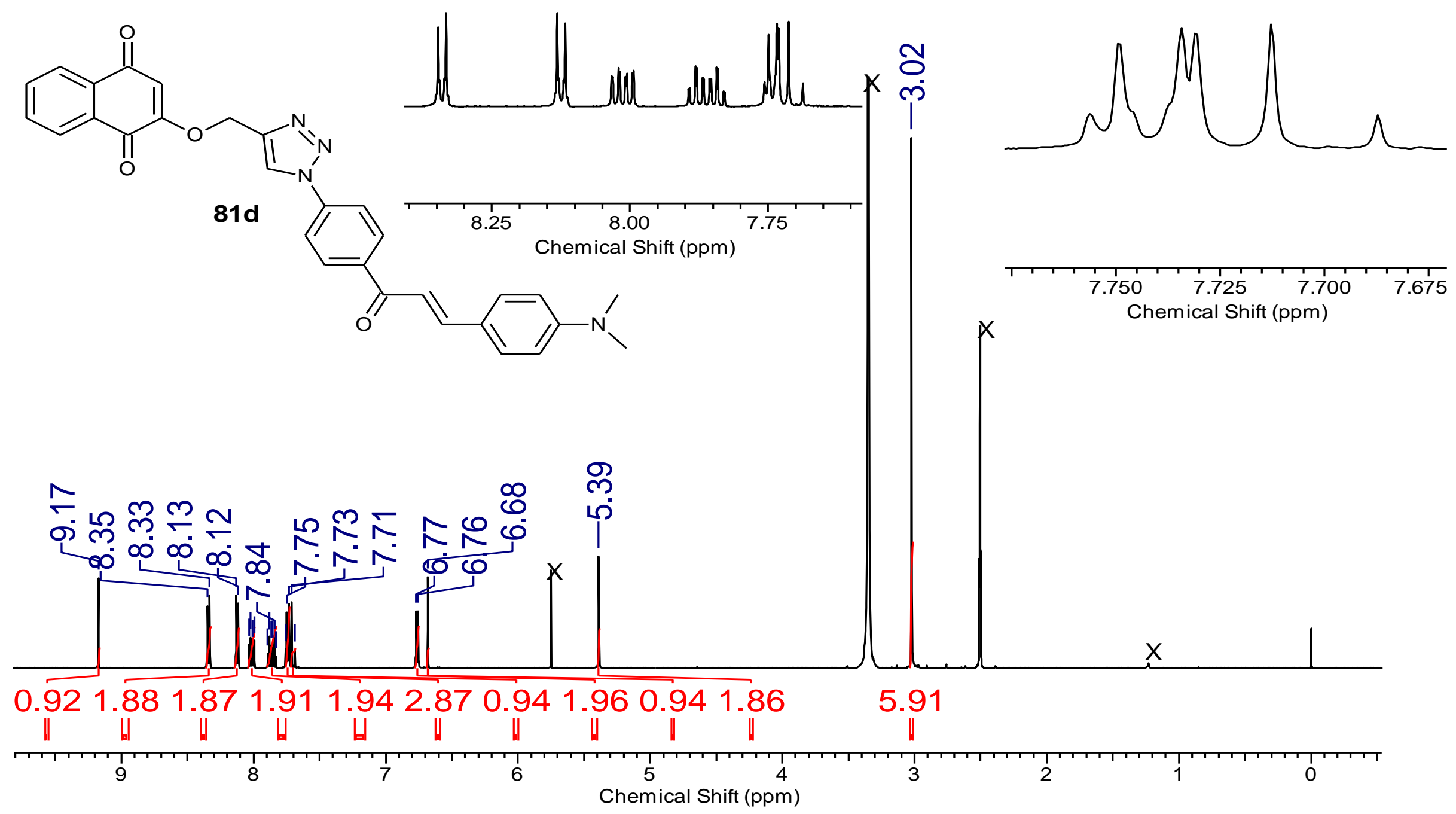

Espectro 27.1 - Espectro de RMN de ${ }^{1} \mathrm{H}\left(600 \mathrm{MHz}\right.$, DMSO- $\left.d_{6}\right)$ do composto 81d. 

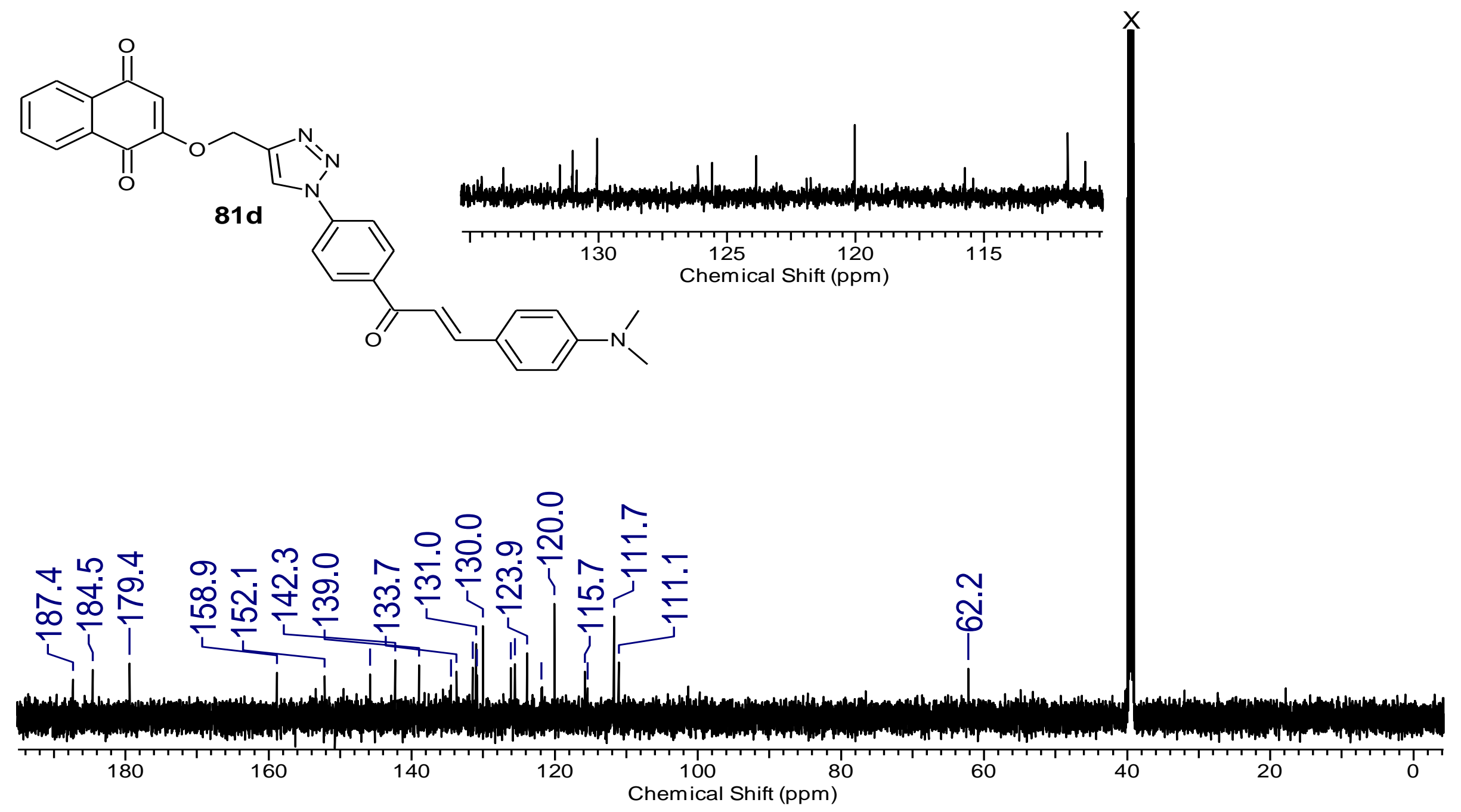

Espectro 27.2 - Espectro de RMN de ${ }^{13} \mathrm{C}$ (150 MHz, DMSO- $d_{6}$ ) do composto 81d. 


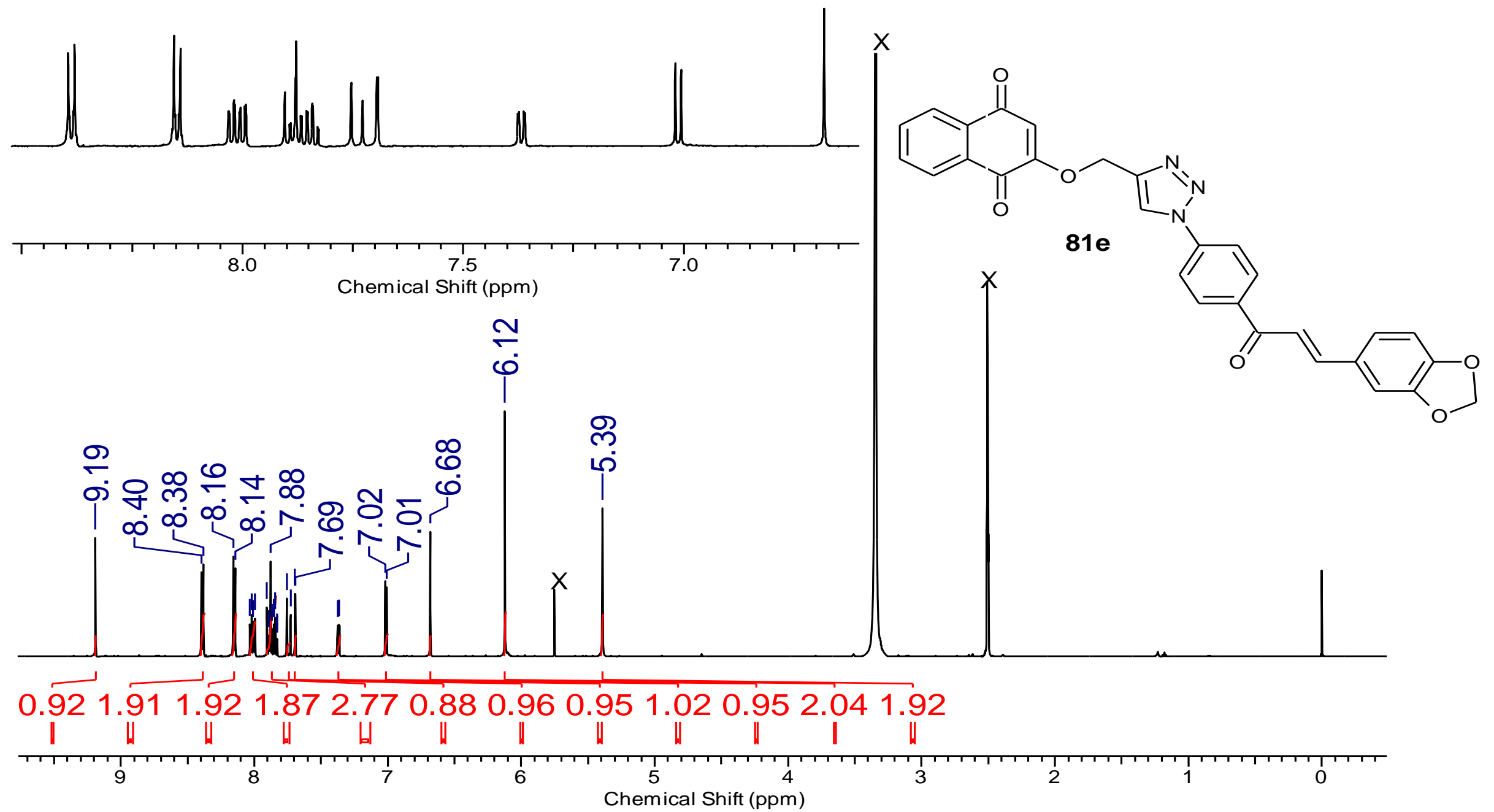

Espectro 28.1 - Espectro de RMN de ${ }^{1} \mathrm{H}\left(600 \mathrm{MHz}\right.$, DMSO- $\left.d_{6}\right)$ do composto 81e. 


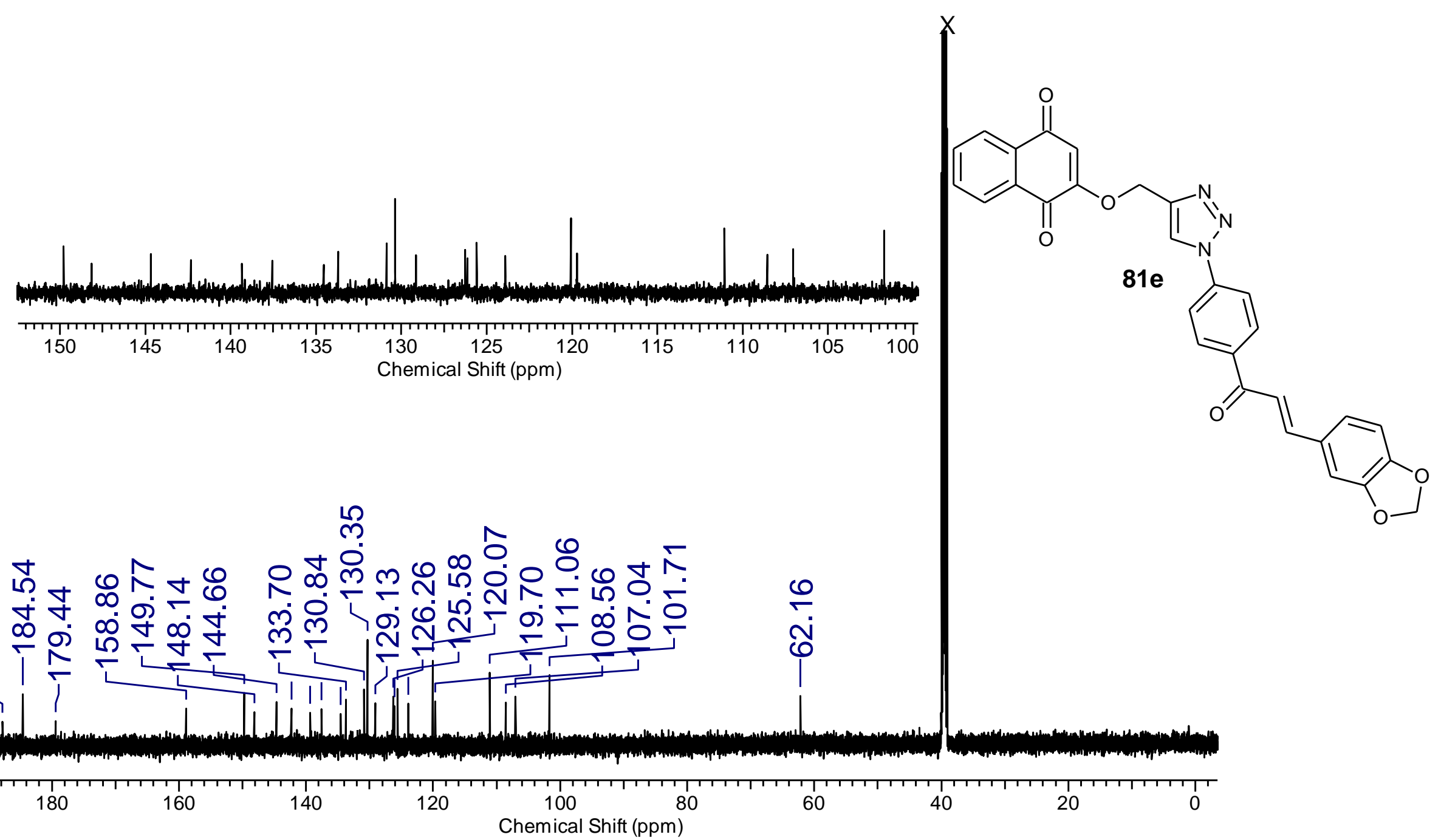

Espectro 28.2 - Espectro de RMN de ${ }^{13} \mathrm{C}$ (150 MHz, DMSO- $d_{6}$ ) do composto 81e. 